\title{
Concealed diversity
}

Taxonomical, phytogeographical and phytosociological notes on brambles

(Rubus L. subgen. Rubus) in north-west Europe

Rense Haveman 



\section{CONCEALED DIVERSITY}

Taxonomical, phytogeographical and phytosociological notes on brambles (Rubus L. subgen. Rubus) in north-west Europe 


\section{Thesis committee}

\section{Promotor}

Prof. Dr J.H.J. Schaminée

Special professor Community Ecology

Wageningen University \& Research

\section{Co-promotor}

Dr R.J. Bijlsma

Senior researcher, Vegetation, Forest and Landscape Ecology

Wageningen University \& Research

\section{Other members}

Prof. Dr E. Bergmeier, Georg-August-Universität, Göttingen, Germany

Dr H. Duistermaat, Naturalis Biodiversity Centre, Leiden

Prof. Dr J.M. van Groenendael, Radboud University, Nijmegen

Prof. Dr M.F. Wallis de Vries, Wageningen University \& Research

This research was conducted under the auspices of the Graduate School for Production Ecology and Resource Conservation 


\title{
CONCEALED DIVERSITY
}

\section{Taxonomical, phytogeographical and phytosociological notes on brambles (Rubus L. subgen. Rubus) in north-west Europe}

\author{
Rense Haveman
}

Thesis

submitted in fulfilment of the requirements for the degree of doctor at Wageningen University

by the authority of the Rector Magnificus, Prof. Dr A.P.J. Mol, in the presence of the

Thesis Committee appointed by the Academic Board to be defended in public on Tuesday 4 April 2017 at 4 p.m. in the Aula. 
Rense Haveman

Concealed Diversity. Taxonomical, phytogeographical and phytosociological notes on brambles (Rubus L. subgen. Rubus) in north-west Europe,

200 pages.

PhD thesis, Wageningen University, Wageningen, the Netherlands (2017)

With references, with summaries in Dutch and English

ISBN 978-94-6343-101-9

DOI http://dx.doi.org/ 10.18174/406096 
Dedicated to Piet Bakker, who encouraged me to study brambles almost 30 years ago 



\section{Table of contents}

1 General introduction 9

2 Freakish patterns - species and species concepts in apomicts 23

3 The role of the Weberian Reform in European Rubus research and the 45 taxonomy of locally distributed species - which species should we describe?

4 Checklist and distribution data of Dutch brambles

(Rubus L. subgenus Rubus)

5 Capricious, or tied to history's apron strings? Floristic regions in north-west European brambles (Rubus subgenus Rubus, Rosaceae)

6 Systematic randomised sampling along three landscape transects

in the Netherlands reveals the geographically structured variation in Rubus scrubs

7 The Rubetum taxandriae ass. nov. (Lonicero-Rubion silvatici, Lonicero-Rubetea plicati), a new bramble association from the Belgian and Dutch Campine

8 General discussion, with some additional notes on nature conservation

References

List of photos

Summary

Samenvatting 
CHAPTER 1

General introduction 


\section{Worldwide plant diversity and the flora of temperate Europe}

Over the centuries, generations of biologists have considered among their major tasks to catalogue, interpret, and explain the diversity of life on Earth. Knowing how many species inhabit Earth's ecosystems is considered one of the megascience questions (Cracraft 2002), and this translates in systematic botany as the questions how many plant species do exist worldwide, and where these species are found. Plants, together with mammals and birds, are the three best known species groups, but even in these groups taxonomic knowledge is still very incomplete (Pimm et al. 2014; Pimm \& Joppa 2015). Recent estimates of the number of extant seed plant species are between 400,000 and 450,000 (Govaerts 2001; Pimm et al. 2014; Pimm \& Joppa 2015), many more than were assumed to exist conventionally. This $400,000+$ number is an estimate indeed: currently, The Plant List (2013) enumerates 304,419 accepted names in the Angiosperms (32.0 \%), 430,346 synonyms (45.2\%), and 216,132 unassessed (22.7 \%) names, and the numbers for Conifers, Cycads and allies are 1,104 (23.7\%), 3,356 (72.2\%), and 191 (4.1\%) respectively. Besides, it is estimated that a further $10-15 \%$ of extant plant species is still unknown, awaiting discovery.

Seen from the perspective of worldwide plant diversity, temperate Europe is poor in plant species. In Barthlott's map (Barthlott et al. 2007), this region is classified as diversity zone 3-5, which corresponds with 200-1,500 plant species per 10,000 $\mathrm{km}^{2}$. For the Atlantic Mixed Forest eco-region, the broad coastal region reaching from northwestern Denmark to southern France, Kier et al. (2005) used a min-max species number of 1,700-2,200 and for the Western European Broadleaf Forest eco-region, bordering the former one in the east, they used a number of 2,500-3,300 species. A remarkable feature of the north- and north-west European flora seems to be the high proportion of apomicts (Gregor 2013). One of the groups in north-west Europe with a predominantly apomictic reproduction is Rubus L. subgenus Rubus (bramble). Rubus is one of the largest genera worldwide: on The Plant List (accessed February 2016) 1494 accepted species names are mentioned. However, a major part of these names apply to apomict lineages from subgenus Rubus, and there is much debate whether such apomict lineages deserve species status. In comparison with the other two large apomict genera in northwest Europe, Hieracium and Taraxacum, Rubus is relatively well known and is therefore chosen as study object in this thesis. The taxonomy of the genus is cleared to a large extent (Weber 2002a; Kurtto et al. 2010), the distribution of many apomict lineages is mapped over larger areas (Kurtto et al. 2010), and phytosociological and ecological studies give a first indication how the taxonomical results can be used in more applied research (Weber 1998a; Haveman et al. 1999a; Haveman et al. 1999b; Weber 1999b; Bijlsma 2002; Royer \& Ferrez 2012). Therefore, the genus seems to be an appropriate case to study fundamental and more applied aspects of apomicts. 
In the following a short introduction on apomixis is given, followed by an introduction on taxonomical, biogeographical and ecological questions regarding Rubus subgen. Rubus. After these introductory words, the objectives and research questions of this thesis are given, followed by the outline of the subsequent chapters.

\section{Apomixis}

Apomixis (derived from the Greek $\alpha \pi o^{\prime}=$ away from, and $\mu 1 \xi \eta=$ mixing) is a mode of generative reproduction in which seeds are formed without fertilisation of the female gamete (Stebbins 1941; Asker \& Jerlings 1992; Mogie et al. 2007). In older literature, also vegetative reproduction was included in the term, but this is usually excluded in more recent literature (see also Van Dijk 2007 for some arguments). Used in this sense, excluding vegetative reproduction, apomixis is synonym with agamospermy, asexual seed formation. The opposite of apomixis is amphimixis (from the Greek $\alpha \mu \varphi \underline{i}=$ both sides, and $\mu \xi \eta \eta=$ mixing). Asker \& Jerlings (1992) classified the different modes of apomixis, and they discerned two basically different forms of apomixis, i.e. gametophytic apomixis and adventitious embryony, or sporophytic apomixis. In the latter, the embryos arise from somatic cells of the nucellus or integument, whereas in gametophytic apomixis the embryo arises from unreduced embryo sacs. Sporophytic apomixis is found in the economically important genus Citrus, amongst others. Gametophytic apomixis can further be divided in two different forms: diplospory (embryos arise from unreduced megaspore mother cells), and apospory (embryos are formed from somatic cells of the ovule), and diplospory can be subdivided in meiotic diplospory, in which the normal reductional meiosis is replaced by a non-reductional first division restitution, and mitotic diplospory, in which the replacing non-reductional division is mitotic-like (Van Dijk 2007). Examples of genera with diplospory are Taraxacum and Antennaria, whereas in Hieracium apospory is found. In several Rosaceae, the division between diplospory and apospory is vague: in Potentilla and Rubus, embryo sacs can be formed from almost all cells of the archesporium, even in the same species (Gustafsson 1946a; Weber 1995). In several genera (e.g. Poa, Taraxacum, Hieracium), embryo development doesn't need pollination (autonomous apomixis), and starts before anthesis. In other genera with gametophytic apomixis (e.g. Rubus, Hypericum, Ranunculus, Hierochloe, Panicum), pollination is necessary for the development of the endosperm though (pseudogamous apomixis), and the embryo only develops after the initiation of the endosperm (Asker $\&$ Jerlings 1992). In both adventitious embryony and both forms of gametophytic apomixis, the unreduced egg cell develops through parthenogenesis into an embryo, which is genetically identical to the mother plant.

Gametophytic apomixis is tightly associated with hybridisation and polyploidy (Gustafsson 1946b; Bierzychudek 1985; Asker \& Jerlings 1992 and the substantial cited references therein; Van Dijk 2007). In fact most known apomictic groups are polyploid 
complexes in which the diploids are sexuals and the apomicts are mostly allopolyploids, partly even polyploids with an odd chromosome number (tri-, penta-, and heptaploids) which normally would be infertile because of meiotic disturbance. Apomixis is therefore sometimes referred to as 'an escape from sterility', a term already used by Darlington (1939).

Van Dijk \& Vijverberg (2005) mapped the occurrence of gametophytic apomixis onto the (now somewhat outdated) phylogeny of the angiosperms according to Soltis et al. (1999). They found that at the family level, almost $70 \%$ of all genera with gametophytic apomixis are found in only three families: the Asteraceae (27 genera with apospory; 15 with diplospory), the Poaceae (31 genera with apospory; 9 with diplospory) and the Rosaceae (12 genera with apospory; 5 with diplospory). According to the authors, apomixis is restricted to isolated species-complexes in other families. At the suprageneric level, more specific the (sub-)tribal level, the authors found a clustering of types of gametophytic apomixis, which was attributed to pre-adaptation (more specific the absence of endosperm obstacles in the Asteraceae) and common origin.

Well-known examples of apomict genera from temperate Eurasia and North-America are found in the Asteraceae (Hieracium, Taraxacum, Crepis, Antennaria), Rosaceae (Rubus, Sorbus, Alchemilla), Ranunculaceae (the Ranunculus auricomus aggregate) and Poaceae (the Poa pratensis aggregate). Apomixis is found in other families too, although this generally is less realised, for instance in the Hypericaceae (Hypericum perforatum), and Polypodiaceae (the Dryopteris affinis complex as well as Phegopteris connectilis) (Asker \& Jerlings 1992; Gregor \& Matzke-Hajek 2002; Haveman et al. 2002).

\section{Taxonomical debate: are apomict lineages species?}

Maternal inheritance, as is the case in apomixis, leads to the stabilisation and dissemination of single genotypes (Hörandl et al. 2009a). These stabilised genotypes, are considered as species ${ }^{1}$ by many European authors (e.g. Dandy 1958; Kent 1992; Oberdorfer 1994; Wisskirchen \& Haeupler 1998; Stace 2001; Jäger \& Werner 2002; 2006, 2014). Especially in the genera Alchemilla (Fröhner 1995), Rubus (Beijerinck 1956; Van de Beek 1974; Matzke-Hajek 1993; Weber 1995), Hieracium and Pilosella (Von Naegeli \& Peter 1885-1889; Arvet-Touvet 1888; Zahn 1921-1923; Van Soest 1926, 1927, 1928, 1929; Zahn 1930-1935, 1936-1938; Sell \& West 1976; Gottschlich \& Raabe 1991; Gottschlich et al. 1998; Schou 2001; Juxip 2002; Tyler 2006; Tyler

1 Sometimes referred to as 'microspecies', as is done hereafter in appropriate cases in order to avoid unnecessary elaborate digression; this should not be understood as a formal denial of the species status of apomict lineages or a formal acceptance of a taxonomical category apart from the species category. It is merely used as informal taxonomical subunit of a cryptic species group or a species aggregate. 
\& Jönsson 2013), Taraxacum (Van Soest 1939, 1957; Hagendijk et al. 1975, 1982; De Kovel \& De Jong 2000; Sell \& Murrell 2006), and the Ranunculus auricomus aggregate (Marklund 1961, 1965; Ericsson 1992; Hörandl 1998) up to hundreds or even thousands of microspecies are distinguished. However, there is much controversy over the taxonomical status of these apomict lineages and the question whether they can be regarded as species. Wiens (2007) stated: “... how should asexual species be delimited? Should we even call them species?" Ghiselin (1987), and Löve (1962) argued that species do not exist in asexual groups by definition, which can be attributed to their adherence to the Biological Species Concept which requires interbreeding (Mayr 1942, 1957, 1996). Stebbins (1941: 535) even set aside apomict complexes as "...anomalous or "freakish" from the systematic point of view".

Although the debate on the status of apomicts appears to be an academic one at first sight, it has impact on very practical questions of biodiversity research and nature conservation. The abundance of apomicts and the wide distribution of apomictic groups raise the need for practicable taxonomic concepts for biodiversity research and flora writing (Hörandl et al. 2009a). Since species are the central units of biodiversity and conservation (Stebbins 1987; Cracraft 2002), the opinion on the taxonomical status of apomict lineages significantly influences the estimation of species numbers, as well as conservation efforts (Claridge et al. 1997). Haveman et al. (2002) and Gregor \& Matzke-Hajek (2002) argued that neglecting apomict species in floras and species check-lists leads to an underestimation of threatened species in Red Lists, thus diluting species conservation efforts. Similar arguments are brought forward in the discussion on the status of autopolyploids and other cryptic and sibling species (Bickford et al. 2007; Soltis et al. 2007).

To illustrate this, the numbers of microspecies in Rubus, Taraxacum and Hieracium are given in Figure 1.1 as fraction of the total flora of Great-Britain and Ireland (Preston $e t$ al. 2002; Sell \& Murrell 2006, 2014), Germany (Wisskirchen \& Haeupler 1998), and the Netherlands (Haveman et al. 2002; Van der Meijden 2005). Numbers for apomict lineages in Hieracium in Germany are not available, so this number is an estimated 500, which might be rather conservative. From this figure it shows that about 30 to $35 \%$ of the total vascular plant flora in these countries consists of microspecies of the mentioned genera.

\section{Rubus L subgen. Rubus}

\section{Diversity, taxonomy and systematics}

Rubus L 1753 has a worldwide distribution and is lacking only in Antarctica, the far North, and extreme arid areas. In the tropics and subtropics it is almost completely confined to the mountains. The highest diversity is found in south-east Asia, the Andes- 


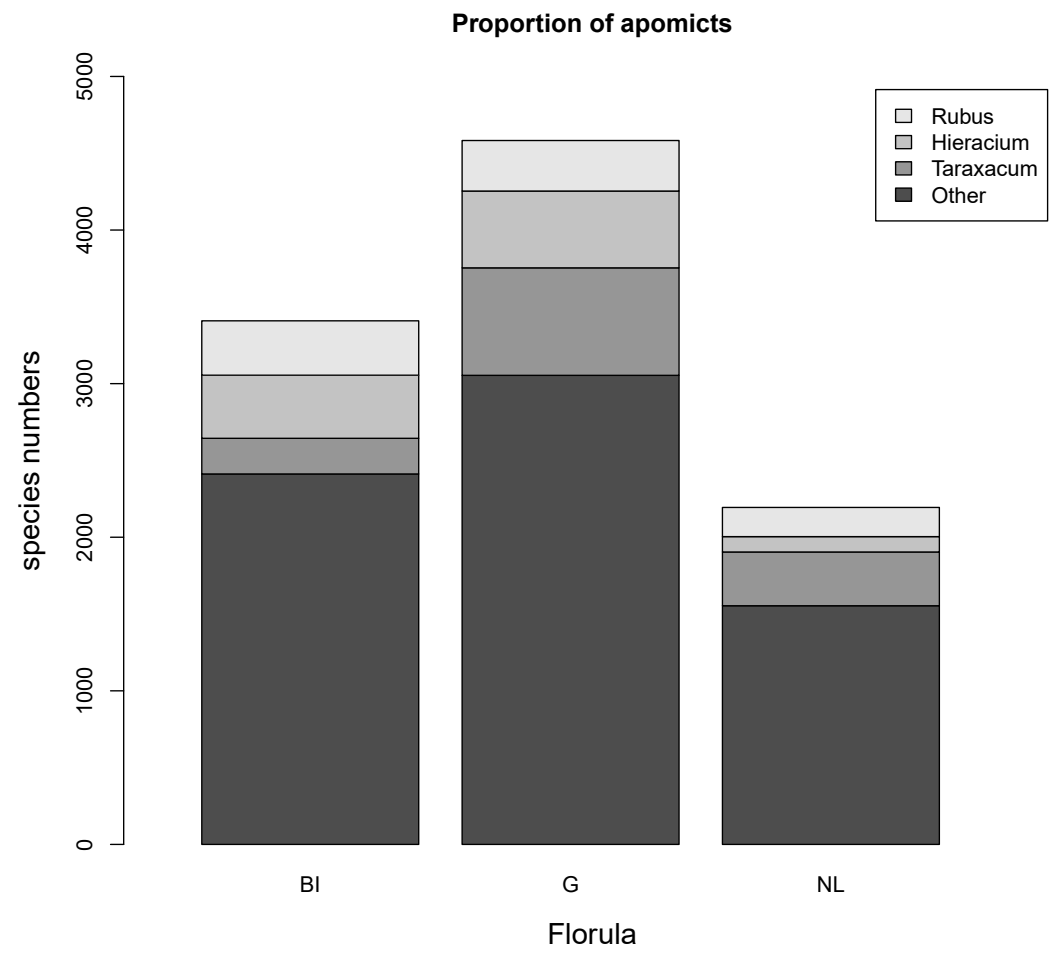

Figure 1.1. The proportion of apomicts in the flora of Great-Britain and Ireland (BI), Germany (G), and the Netherlands (NL), illustrated by the numbers of apomict lineages in the three largest apomict genera. See text for the used references.

region in South-America, the coastal region in eastern North-America, and Atlantic to sub-Atlantic regions of temperate Europe. The genus is very species rich, with an estimate of 300-400 sexual species worldwide (Weber 1995). Focke (1910-1914) distinguished 12 subgenera, of which four are native to Europe: subgenus Idaeobatus (Focke) Focke 1910, subgen. Rubus, subgen. Cyclatus (Rafinesque) Focke 1910, and subgen. Chamaerubus O. Kuntze 1867. In Europe, the subgenera Idaeobatus, Cyclatus, and Chamaerubus consist only of one or a few species, but subgen. Rubus comprises hundreds of taxa, forming a polyploid series with a base number of $7: 2 \mathrm{n}=14,21$, 28, 35, and 42. In Europe, only a few extant sexual diploids are known, i.e. Rubus ulmifolius Schott 1818, Rubus sanctus Schreb. 1766, Rubus canescens DC 1813, and Rubus incanescens (DC) Bertol. 1842. Apart from these diploids, only the tetraploid Rubus caesius L 1753 is propagating sexually. All other European taxa in the subgenus are considered allopolyploid facultative apomict derivates of only a few parental species. In a recent study, Sochor et al. (2015) could detect six parental gene-pools in their study of the evolution of Rubus subgen. Rubus. They concluded that the current diversity of the subgenus is a result of the hybridisation and subsequent polyploidisation of $R$. ulmifolius, $R$. canescens, $R$. caesius, Rubus idaeus L. 1753, and two unknown and extinct 
sexual species, one of which belonged to series Glandulosi (Wimmer \& Grabowski) Focke 1877, the other to series Rubus.

Sochor et al. (2015) sketched a highly complex reproduction system in subgen. Rubus. Most members are tetraploid pseudogamous apomict lineages, but other ploidylevels (triploids, pentaploids and hexaploids) are not uncommon (Gustafsson 1943; Krahulcová et al. 2013). The mode of reproduction is highly variable, ranging from obligate sexual reproduction to obligate apomixis, both at the species level as well as at the individual or even floral level (Pratt \& Einset 1955; Šarhanová et al. 2012). Apomictic reproduction combines both diplospory and apospory, and this mode of reproduction can be influenced by environmental factors (Šarhanová et al. 2012). Especially in tetraploids, retained sexuality can be considerable (Antonius \& Nybom 1995; Nybom 1995), but triploid and pentaploid taxa are almost obligate apomicts (Šarhanová et al. 2012). Artificial hybrids are rather easily obtained, not only when a sexual partner is involved, but also between apomict lineages. According to Lidforss (1907: 35) hybrid formation is enhanced if the vitality of the $P$-plant was somehow weakened, e.g. when growing in shade.

Modern attempts to classify the diversity of forms resulting from this complex propagation system can be traced back to Focke (1877), who included pollen fertility and distribution area characteristics in his classification scheme. It was enhanced by Van de Beek (1974) and notably Weber (1972, 1981b, 1986b, 1995). All modern authors agree that not every single occurring form is worth describing, but instead only stabilised biotypes should be described as species. To assure this, only lineages with a distribution area $>50 \mathrm{~km}$ are described as species, and biotypes with smaller distribution areas are ignored as taxonomically unimportant 'local biotypes' (Weber 1995, 1996; Holub 1997; see e.g. Bijlsma \& Haveman 2007; Kurtto et al. 2010; Király et al. 2013b, a). This resulted in a vast but accessible number of accepted species at the European level and a cleansing of the batological literature, which historically was burdened with innumerable synonyms and names for primary hybrids and local forms (Holub 1997).

\section{Morphology and life history traits}

Rubus subgen. Rubus consists of perennial, deciduous (subsect. Rubus) and wintergreen (subsect. Apendiculati) hemi-phanerophytes with a long-living subterranean root-system and bi-annual, semi-lignified, hollow and pith-filled shoots (Weber 1995). In the first year, these shoots are bearing leafs and are called primocanes or long-shoots. In the second year, after shedding the leafs, inflorescences are formed, and after fructification the above-ground shoot dies. The fruit is a compound berry. Vegetative propagation is possible by underground stolons (subsect. Rubus) or rooting tips of the primocanes (subsect. Apendiculati), which makes the first less susceptible to grazing and mowing 
(Bijlsma 2004). In general, Rubus seeds are dormant after dispersal, thus forming a soil seed bank (Grime et al. 2007). Suzuki (1997) demonstrated that individual species in sect. Idaeobatus can vary considerably in germination characteristics, but seed bank data for individual microspecies in sect. Rubus are lacking.

\section{Phytogeographical aspects}

Rubus subgen. Rubus is found almost in all temperate and Mediterranean Europe. Its northern boundary is formed by the $60^{\text {th }}$ parallel north, except along the Atlantic coast in Norway, where the distribution area stretches to about a latitude of $64^{\circ}$ and it is absent from large parts north of the Black Sea and Caspian Sea. The highest diversity is found in Atlantic and sub-Atlantic Europe (Ireland, Britain, the northern parts of the Iberian Peninsula, France, the Benelux, Denmark, Germany, the Czech Republic, the southern parts of Poland, Slovakia, and, to a lesser extent, Switzerland an Austria: Kurtto et al. 2010: 42).

In contrast to the two other large apomict groups in central and north-west Europe, Taraxacum and Hieracium, the Rubus flora is well known, although there still remain rather large areas for which data is very scarce. In several publications, Weber (1999a, 2002a) and Kurtto et al. (2010: 28-31) evaluated the state of taxonomy and mapping of Rubus species over Europe, and from these it can be concluded that especially in France the diversity of brambles is known insufficiently. Other regions without modern batological research, and subsequently insufficient knowledge of the genus, include Italy, the south-eastern part of central Europe, as well as south-east Europe (especially Bulgaria and Romania), but this is of lesser importance for this thesis, which focuses on the Netherlands and central and north-west Europe.

Rubus subgen. Rubus is an example of what is known as 'geographical parthenogenesis' (Vandel 1928; Lynch 1984; Bierzychudek 1985; Haag \& Ebert 2004; Verduijn et al. 2004; Kearney 2005; Hörandl 2006; Thompson \& Whitton 2006; Hörandl et al. 2009b; Mráz et al. 2009): apomicts 1) have larger distribution areas than their sexual relatives, 2) tend to range to higher altitudes and latitudes than their sexual relatives, and 3) tend to occupy previously glaciated areas. As a note: it is important to realise that this concept relates to apomixis as phenomenon, and not on the individual apomict microspecies. The prevalence for areas influenced by Pleistocene ice sheets has most likely the same background as their hybrid origin, viz. the expansion of species in these areas which gave rise to large hybrid swarms and polyploid offspring (Stebbins' secondary contacthypothesis (Stebbins 1986)), followed by the stabilisation of morphologically distinct biotypes by apomixis. Already Gustafsson (1943) and Richards (1973) hypothesised this origin in apomict Rubus and Taraxacum species respectively, and recent molecular studies of the evolutionary background of species in Rubus subgen. Rubus largely confirmed 
this hypothesis (Sochor et al. 2015). As was reviewed by Hörandl (2006), geographical parthenogenesis has a more complex background though, and also includes advantages of polyploidy and/or hybrid origin, better colonisation abilities because of uniparental reproduction, introgression of apomixis into sexuals, niche differentiation of clones, and biotic interactions.

Another phytogeographical aspect of Rubus subgen. Rubus (and other highly polymorph apomict groups) is the very restricted distribution range of many apomict lineages, resulting in different species assemblages even in neighbouring regions. This was elaborated by Newton (1980) and Newton \& Randall (2004) in an intuitive regionalisation of the Rubus flora of the British Isles. They were able to distinguish several 'florulas' (= small floras), and regional species complexes and microflorulas within these florulas. Newton \& Randall (2004) discuss the cause of the found patterns in terms of evolutionary ancestry and isolation/accessibility, although these factors are not studied in concreto. Matzke-Hajek (1997) argued that the regionally distributed Rubus microspecies are very young $(<6,000 \mathrm{yr})$, having unsaturated distribution ranges (i.e. ranges unconstrained by climatic factors) being in the phase of range expansion (neospecies sensu Levin 2000). A rather rare clear example of such an expanding apomict is Rubus wittigianus: it was considered a local species in the 1980's and not included in Weber's Rubi Westfalici (Weber 1986b), but in the 1990's the number of occurrences increased, thus satisfying the condition to be described as regional species (Weber 2002b). Considering this, it is clear that the patterns which were found by Newton \& Randall (2004) are strongly influenced by evolutionary processes, like the in situ origin and climatologically unconstrained range expansion of apomict neospecies.

\section{Ecology and phytosociology}

Although Rubus subgen. Rubus consists of a large group of expanding neospecies, not all patterns are necessarily to be explained by (evolutionary) history only. Generally, the subgenus is characteristic for intermediate site conditions: moist but not flooded, mesotrophic, not too acidic or purely calcareous sands and loams, preferably in halfshadowed conditions. The highest diversity in apomict microspecies within the subgenus is found on loams and sandy loams in Atlantic and sub-Atlantic Europe (Matzke-Hajek 1997). To the south and south-east, the distribution is more and more limited by summer drought, to the east and north by winter cold (Weber 1995). This explains the scarcity of wintergreen species of subsection Apendiculati Genevier 1869 and the relative abundance of leaf-shedding species of subsection Rubus and section Corylifolii Lindley 1835 in the northern parts of the distribution of the subgenus. To the south, species with xeromorphic adaptations (felted leaves, stems with waxy cuticulas) belonging to the series Discolores (P.J. Müller) Focke 1914 and several series in the section Corylifolii, have their optimum. Whereas brambles are a typical element of scrubs and more open 
landscapes in the Atlantic and sub-Atlantic parts of Europe they avoid openness in less humid areas, and tend to grow in the sheltered conditions in wooded areas, or in higher altitudes.

Already Beijerinck $(1953,1956)$ noticed the differences in preference for wooded or open areas across Rubus species in the Netherlands. He distinguished three groups, viz. 1) species which preferably grow along roads or forest edges and in scrubs in the agricultural landscape, 2) species with a prevailing in wooded areas, and 3) species with a strong preference for old woodland remnants (ancient woodland species). In a somewhat similar way, Weber (1986b, 1995) differentiates between thamnophilous (= preferentially growing in open areas) and nemophilous (= preferentially in microclimatically sheltered areas in woodlands) Rubus species. Bijlsma (2004) classified the subgenus into five groups, in an attempt to make an ecological interpretation of the series, ranging from leaf-shedding, non shadow-tolerant and grazing tolerant species to wintergreen, very shadow-tolerant and grazing intolerant species.

The different ecological amplitudes and preferences of the Rubus microspecies are reflected in the species composition of the vegetation. Phytosociological research in Germany (Weber 1967, 1974; Wittig 1976, 1977; Wittig \& Burrichter 1979; Reif 1983, 1985; Weber 1990, 1998a; Rosskamp 1999; Weber 1999b; Huwer \& Wittig 2012), the Netherlands (Haveman 1997; Haveman et al. 1999a; Haveman et al. 1999b) and France (Royer \& Ferrez 2012; Royer 2013; de Foucault \& Royer 2014) proved that bramble microspecies can be used to distinguish between and characterise different shrub types, which are claimed to be ecologically distinctive. The combined occurrence of regionally distributed species could theoretically promote the description of numerous scrub types, differing in species composition, but growing in similar environments (Haveman 1997). In such cases though, it is not always clear whether the found patterns are the result of differences in site conditions or of historical factors (e.g. the recent origin of regionally distributed species, or random colonisation events). An example is the Rubetum sciocharitis Weber in Pott 1995, which is considered to be a vicariant association of the Rubetum silvatici Weber in Pott 1995 of more Atlantic regions of north-west Germany (Weber 1998a, 2003b). Rubus sciocharis tends to dominate the vegetation, even in regions where it was introduced unintentionally (De Ronde \& Haveman 2016), thus forming scrubs indistinguishable from the Rubetum sciocharitis even in climatically different regions than Sleswig-Holstein, the locus classicus of the association.

This leads to the question whether the found phytosociological patterns could be caused by a limited data set, collected through preferential sampling in a limited number of regions. Bramble scrubs belong to the least known and understood vegetation types in 
Europe, and the bramble scrubs in large regions with substantial numbers of bramble species remain uninvestigated (Weber 1997, 2003b). Even in Germany, in many respects the front runner in batological research, large areas can be considered blank areas when it comes to batosociological knowledge (Weber 1997, 1998b, 1999b). Better knowledge from a wider area should eventually lead to a better understanding of the role of ecological versus historical processes in the realisation of the species composition of bramble scrubs.

\section{Nature conservation and policy}

Historically, Rubus subgen. Rubus has played hardly any role in nature conservation, despite the obvious presence in large parts of the north-west European landscape. Although they represent a substantial part of the phytodiversity, they are often considered a nuisance by foresters and nature managers, since they are often considered an indicator for deteriorating environmental conditions (see Bijlsma 2004), despite the variety of ecological requirements across species and the occurrence of regional endemics and ancient woodland indicators (Gregor \& Matzke-Hajek 2002; Haveman et al. 2002; Bijlsma \& Haveman 2007). Because Rubus, like other apomictic groups, are usually not included in general floras, their status is known to a small group of experts at best, and conservation agencies and managers remain unaware of their uniqueness. Gregor \& Matzke-Hajek (2002) and Haveman et al. (2002) have pleaded for the inclusion of apomict microspecies in red lists and other nature policy instruments. In Britain, dedicated conservation plans are made for rare (often local) Rubus species (Randall \& Rich 2000, 2001), as well as other apomict microspecies (e.g. Rich \& Houston 2000; Rich 2002, 2003; Rich et al. 2008). Several German Bundesländer included apomicts in their red lists, like Bayern (Bayerisches Staatsministerium für Umwelt 2005) and Sachsen-Anhalt (Frank et al. 2004). A detailed example of a red list of Rubus species is given by Weber (1986a).

The phytosociological classification of bramble scrubs gives the possibility to address them in nature conservation plans, but the recognition of the bramble species still is a bottleneck for an adequate management. Surveys of bramble species on the level of nature conservation areas (like the survey of the brambles in the Mantingerbos, Bijlsma 2006) are rare, although they can be essential in the planning of conservation measurements. Furthermore, it remains unknown how the Rubus diversity in communities facilitates the occurrence of other species, like nectar feeding or in the stem hibernating insects.

\section{Objective and outline of this thesis}

In this thesis, a rather wide range of aspects of Rubus diversity is studied, serving a twofold objective: 1) an increase of the understanding of the taxonomical and ecological aspects of Rubus subgen. Rubus, and 2) to provide a basis for the inclusion of apomict 
species in general and Rubus in particular in conservation management and policy. To reach this objective, different scales of bramble diversity in the Netherlands are studied by the following questions:

I. What are the arguments to distinguish apomict lineages in Rubus as species, and how many species can be distinguished (especially in the Netherlands) based on this?

II. What are the main factors in the realisation of large scale spatial patterns in Rubus subgen. Rubus, and are these patterns primarily ecological or historical confounded?

III. Which factors determine the spatial distribution and species assemblage of bramble scrubs and what is the importance of ecology and history herein?

IV. What is the nature conservation value of brambles and bramble scrubs, considering the gained insights in the taxonomy, phytogeography and phytosociology?

The following of this thesis consists of six published papers and a synthesising general discussion. The first three papers are dealing with the species question (I). The first is a philosophical paper on the species concept in apomict groups, amongst which Rubus subgen. Rubus. The second paper gives an historical account of modern Rubus taxonomy and an evaluation of the so-called 'pragmatic species concept' in modern batology. The third paper is a first annotated check-list of Dutch bramble species, which was originally published in Dutch (Van de Beek et al. 2014) but translated and modified to be included in this thesis.

The fourth paper is a study of large scale phytogeographical patterns, based on the distribution areas of all Rubus species in Ireland, Britain, the Netherlands, Denmark and Germany. The evaluation of floristic bramble regions in this paper contributes not only to question II, on large scale patterns, but gives also a basis for answering question III, on the historical versus ecological factors underlying the variation in scrub types. This will be elaborated in the general synthesis.

Both paper five and six are dealing with phytosociological questions (III). In the fifth paper, $\beta$-diversity in Rubus scrubs along three landscape transects is studied, using classical phytosociological classification methods. In this paper, the variation in species composition in bramble scrubs is investigated, and the results are compared to published classification schemes. Arising from this paper, and based on additional data, in paper six a new scrub type is described from the Campine area in south Netherlands and west Flanders. 
In the general discussion, the results of all papers are resumed and combined to answer question I-III. Furthermore, in this section, ideas for the representation of apomicts and Rubus especially - in nature conservation and policy will be presented (IV). The end of this general discussion is formed by an overall conclusion. 


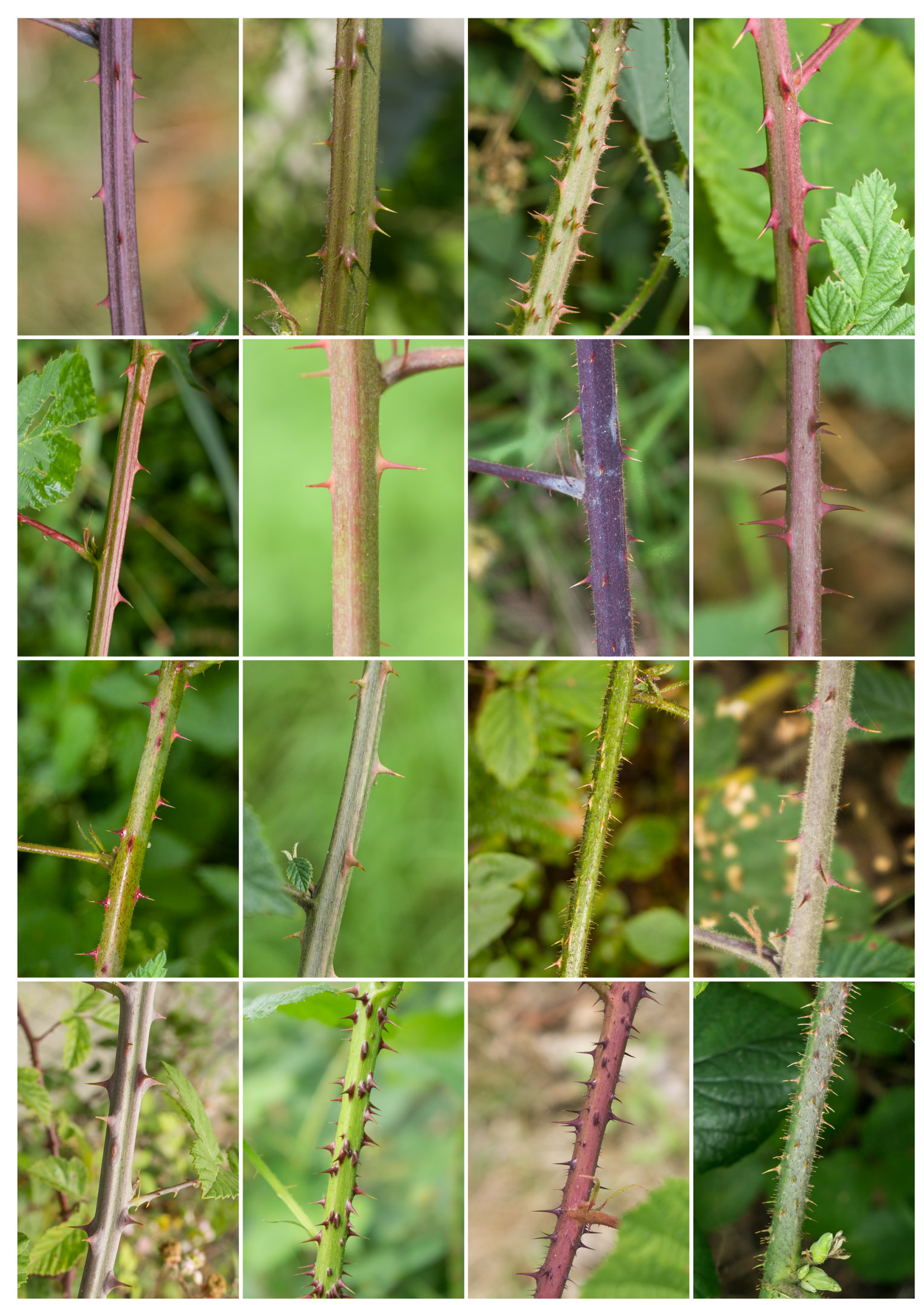


CHAPTER 2

Freakish patterns - species and species concepts in apomicts

Reprinted with permission from:

Haveman, R. 2013. Freakish patterns - species and species concepts in apomicts - Nord. J. Bot. 31: 257-269. 


\begin{abstract}
Apomict groups keep challenging taxonomists, in classifications as well as in the more fundamental question about the nature of apomict species. The latter question is not just an academic one, since the outcome influences practical questions of biodiversity and conservation. A historical overview over the species problem shows that a period of confusion and proliferation of species concepts between 1940 and 1990 was followed by an increasing consensus at the end of the $20^{\text {th }}$ century that the species category is heterogeneous. Species come in kinds, which is understandable in the light of their different evolutional histories. Recently, Wilkins stated that we don't need a generally applicable species concept, because species are not an a priori category into which all biological organisms must fit, but salient phenomena that are to be explained. Not only biparental, but also asexual organisms often form such species-as-phenomena, explained as some combination of adaptation to an ecological niche and reproductive compatibility. The above is illustrated by historical and current studies in three well-studied apomict groups, viz. Ranunculus cassubicus agg., Rubus subgen. Rubus, and Hieracium (subgen. Hieracium and Pilosella). Species in the Ranunculus cassubicus aggregate are the few existing sexuals, which are surrounded by a hybrid swarm of only partial apomictic forms, whereas in Rubus subgen. Rubus and Hieracium s.str. sexuals as well as numerous apomicts form well defined species. How species should be circumscribed in Pilosella is yet to be clarified. Largely, the differences between these groups can be contributed to the different modes of apomixis and the associated retained sexuality. From this review it is clear that the question is not so much "What is a species?", but "What is a species in this particular group?" To answer this question a thorough knowledge and understanding of the biology of the genus in question is required.
\end{abstract}




\section{Introduction}

The answer to the question "What is a species?" is considered one of the central issues of biology as well as one of its most vexing problems, as was stated literally by de Queiroz (1998). This so-called "species debate" resulted in an overwhelming amount of literature on the conceptualisation and delimitation of species. It was circumscribed by Hey (2001) as "the long-standing failure of biologists to agree on how we should identify species and how we should define the word "species"”. This astounding proliferation of species concepts was not only caused by the awareness that species are the fundamental biological unit (Löve 1962; Ghiselin 1974; Mayr 1996; Ghiselin 1997; Mayden 1999, 2002; Sites Jr \& Jonathon 2004; de Queiroz 2005b), but also by the rapid developments in modern evolutionary biology. In an attempt to review the most important species concepts, de Queiroz (1998) discusses 13 of such, and Mayden (1997) even lists 22 species concepts. A substantial number of these concepts was published in the 10 years preceding the publication of Mayden's and de Queiroz's papers, and after publishing these overviews several new ones have arisen (e.g. de Pinna 1999; Levin 2000; Hausdorf 2011).

A special problem in the species debate is formed by polyploid apomictic complexes. Their classification is a challenge for evolutionary research and systematics alike. Apomixis, a mode of asexual reproduction via seeds which are formed without recombination (Asker \& Jerlings 1992), leads to the stabilization and dissemination of single genotypes (Hörandl et al. 2009a). There is much controversy over the taxonomical status of these apomict lineages and the question whether they can be regarded as species. Or, as Wiens (2007) stated it: "... how should asexual species be delimited? Should we even call them species?"

How apomict lineages are treated taxonomically depends largely on the adopted species concept. Just before the boom of species concepts, Stebbins (1941, p. 535) set aside apomict complexes as "...anomalous or "freakish" from the systematic point of view". As was argued before by various authors (e.g. Mishler \& Budd 1990; Asker \& Jerlings 1992; Hörandl 1998; Haveman et al. 2002), asexually propagating organisms cannot be classified as species under what is probably the best known, most widely used, and most influential species concept, Mayr's Biological Species Concept (BSC, see for the abbreviations of species concepts also Table 2.1): species are groups of (actually or potentially) interbreeding natural populations which are reproductively isolated from other such groups (Mayr 1940, 1957, 1996; de Queiroz 2005b). Ghiselin (1987), an influential advocate of the BSC, and Löve (1962) even argued that species do not exist in asexual groups by definition. In other species concepts, asexual organisms are explicitly excluded, like in Patterson's Recognition Species Concept: species are the most inclusive population of individual biparental organisms which share a common fertilization system (Paterson 1985). By contrast, the Agamospecies Species Concept (Turesson 1929) 
Table 2.1. Species concepts as reviewed in Mayden 1997, with the standardised abbreviations therein, as well as their ability to recognise apomict lineages as species. $+=$ apomicts recognised as species; - = apomicts not recognised as species; +/- recognition of apomicts dependent on the used characters.

\begin{tabular}{|c|c|c|c|}
\hline Abbreviation & Concept & $\begin{array}{l}\text { Apomict } \\
\text { recognition }\end{array}$ & Reference \\
\hline ASC & Agamospecies & + & Turesson 1929 \\
\hline BSC & Biological & - & Mayr 1942 \\
\hline ClSC & Cladistic & + & Ridley 1989 \\
\hline CSC & Cohesion & + & Templeton 1989 \\
\hline CpSC & Composite & - & $\begin{array}{l}\text { Kornet \& McAllister 2005, } \\
\text { Kornet \& McAllister } 1993\end{array}$ \\
\hline EcSC & Ecological & + & Van Valen 1976 \\
\hline ESC & Evolutionary & + & Simpson 1951, Wiley 1978 \\
\hline ESU & Evolutionary Significant Unit & - & Waples 1996 \\
\hline GCC & Genealogical Concordance & + & Avise \& Ball 1990 \\
\hline GSC & Genetic & $+1-$ & Simpson 1943 \\
\hline GCD & Genotypic Cluster Definition & + & Mallet 1995 \\
\hline HSC & Hennigian & - & Hennig 1950 \\
\hline ISC & Internodal & + & Kornet 1993 \\
\hline MSC & Morphological & + & Du Rietz 1930, Shull 1923 \\
\hline NDSC & Non-dimensional & $+/-$ & Paterson 1993 \\
\hline PhSC & Phenetic & + & Sneath 1976 \\
\hline PSC & Phylogenetic & + & $\begin{array}{l}\text { Eldredge \& Cracraft 1980, } \\
\text { McKitrick \& Zink 1988, Rosen } \\
1978\end{array}$ \\
\hline $\mathrm{PtSC}$ & Polythetic & + & -- \\
\hline RSC & Recognition & - & Paterson 1985 \\
\hline RCC & Reproductive Competition & - & Ghiselin 1974 \\
\hline SSC & Successional Chrono- & $\begin{array}{l}\text { not } \\
\text { applicable }\end{array}$ & George 1956 \\
\hline TSC & Taxonomical & + & Blackwelder 1967 \\
\hline
\end{tabular}

was invented solely for apomictic groups (see Mayden 1997). Recently, several authors argued that the exclusion of asexual groups, amongst which bacteria, bdelloid rotifers as well as (facultative) apomictic plants, is a serious drawback of some species concepts (Hausdorf 2011; Chambers 2012). It seems preferable to search for a definition which covers both sexual and agamic groups.

A consistent recognition of apomict lineages as species, as is practiced by some mainly highly specialised taxonomists (see for instance Erben 1993 for Limonium; Fröhner 1995 for Alchemilla; Weber 1995 for Rubus; Sell \& Murrell 2006 for Hieracium and Taraxacum) would increase species diversity of many regions significantly, perhaps beyond practicality (Stebbins 1941; Schuhwerk 2002). According to Haveman et al. (2002), the number of plant species in the Netherlands would increase from about 1450 
to about 1900 if all known apomict lineages of Hieracium, Taraxacum, and Rubus were accepted as species. The flora of the British Isles would even double if apomict lineages were recognised as species consistently (Richards 2003).

This abundance of apomicts and the wide distribution of apomictic groups raise the need for practicable taxonomic concepts for biodiversity research and flora writing, as was stated by Hörandl et al. (2009a). Since species are normally considered the central units of biodiversity and conservation (Stebbins 1987; Cracraft 2002; Wilson 2010), the opinion on apomict lineages as species significantly influences the estimation of species numbers, as well as conservation efforts (Claridge et al. 1997). Haveman et al. (2002) and Gregor \& Matzke-Hajek (2002) argued that neglecting apomict species in floras and species check-lists leads to an underestimation of threatened species in Red Lists, thus diluting species conservation efforts. This is in concordance with the view of Soltis et al. (2007) and Bickford et al. (2007) on autopolyploids and other cryptic and sibling species. Therefore, although the species debate appears to be an academic one at first sight and only significant for a few initiated scientists, it has a crucial impact on very practical questions.

In this paper, I will review the philosophical and taxonomical literature concerning apomict species groups. The main question to be answered in this paper will be: what are species within agamic complexes? I will stroll along several pathways to get a bit closer to the answer of this question. In the first part of this paper, I will give a short overview over the history of literature on species concepts, concentrating on the period from the Modern Synthesis (Huxley 1942) until now, and I will identify some key moments in the development of species concepts. In the second part of this paper, I will discuss some arguments against the apomicts-as-species idea, as well as some alternatives for the classification as species. In the last section, I will review the existing taxonomical (in a broad sense) and plant systematics literature on apomicts in order to get a clearer picture how the conclusions from the first two sections of this paper have effect on the species concepts in apomict groups. Hereby I will concentrate on a few well-studied groups: Ranunculus auricomus agg., Rubus sect. Rubus, Hieracium and Pilosella, although the conclusions will be applicable in other groups too.

\section{A short history of the species problem}

As was elucidated by Richards (2010), the species problem as experienced today has both its philosophical and biological roots in the understanding of Aristotelian philosophy, and the interpretation of the species ideas of early naturalists like John Ray and Carolus Linnaeus. The traditional view, which was developed by Cain, Mayr and Hull in the mid-twentieth century, claims that until the "Origin of Species" by Charles Darwin both philosophy and biology considered species as invariable natural kinds with essential 
features. This "Essentialism Story" was adopted by many authors, but questioned from the beginning by a minority (see Richards 2010 chapters 3 and 4 for an overview). Recently also Richards (2010) and Wilkins (2009b, 2010) gave good arguments for the contrary: when Aristotle and the early naturalists wrote of essences of species, they meant essential functions, not essential properties. Richards pointed out that Linnaeus saw species as eternally fixed only in his very first publication in 1735, but only a few years later he discovered hybridization as a modus for speciation. In a letter to Albrecht von Haller in 1744, he wrote (Larson 1968, referred to by Richards 2010): "I beg of you not to suppose it [the Peloria] anything else than the offspring of (Anthirrhinum) Linaria, which plant I know well. This new plant propagates itself by its own seed, and is therefore a new species, not existing from the beginning of the world; it is a new genus, never in being until now." Therefore the "Essentialism Story" has to be qualified as 'bad history', or, as Wilkins (2009b, p. 233) has put it: "the standard stories and assumptions from the architects of the modern synthesis are often simply incorrect". What is clear from the historical overviews by Wilkins (2009b) and Richards (2010) is that the investigators in the pre-Darwinian period had ideas on what species are, namely "the generation of similar form" (Wilkins 2009b, p. 232), or, as John Ray (the father of natural history in Britain) has put in 1686, "progeny resembling their parents" (Ray 1686). This was named the Generative Notion (or Conception) of Species by Wilkins (2009b, p. 195; 2010, 2011), and I will return to this later.

The common view that Charles Darwin regarded species arbitrary constructions of taxonomists, rather than real and objective entities in nature, has been derived primarily from a number of pages in the Origin, as was stated by Kottler (1978). A comprehensive description of the ideas of Darwin where it comes to the nature of species has recently been given by Wilkins (2009b, p. 129-164), Richards (2010, p. 78-112), and Mallet (2013). All these authors state that Darwin was fully aware of well-defined species. However, he was more interested in 'borderline cases' (Kottler 1978), because these provided evidence for continuous evolution between species (Mallet 2013). The most important thing Darwin added to the above idea of species as those groups of organisms that resemble their parents was the theory of how species came into existence: through natural selection. Richards paraphrases Darwin's species concept as follows: "Species are those lineages that have passed through sufficient divergent change to become distinct and permanent" (Richards 2010, p. 208).

The most important thing for our sake - the understanding of the different species concepts - is that Darwin's evolutionary theory affected thinking of species, and the discovery of the gene and the subsequent development of population genetics in combination with the rediscovery of Mendelian laws formed a powerful basis for evolutionary biology in the Modern Synthesis (Huxley 1942). It was Dobzhansky in his 
classical 1935 paper who brought intersterility in species concept definition: "a species is a group of individuals fully fertile inter se, but barred from interbreeding with other similar groups by its physiological properties (producing either incompatibility of parents, or sterility of the hybrids, or both)" (Dobzhansky 1935). Better known is Mayr's version of this species concept, taught in most biology classes and textbooks, which is called the Biological Species Concept by himself (Mayr 1942): "Species are groups of actually or potentially interbreeding natural populations, which are reproductively isolated from other such groups". In the decennia following the articulation of the BSC, a confusing plethora of species concepts was published: Mayden (1997) counted 22 of them, Wilkins (2009b, 2011) 26 , or even 27. According to Wilkins, these species concepts can be clustered into seven "basic" species concepts: agamospecies, biospecies, ecospecies, evolutionary species, genetic species, morphospecies, and taxonomic species (Wilkins 2009b, 2011). Since these concepts have been reviewed extensively by others (Cracraft 1992; Mayden 1997; Wilkins 2009b; Richards 2010), I will not discuss them in detail again.

The long standing debate on species concepts might give the idea that the 27 published species concepts are mutually exclusive, but I think that the discussion, although as heated as the decennia before, moved towards a unification of ideas in the years around the start of the new millennium. The first step in this process was the rediscovery of the difference between primary and secondary species concepts by Mayden $(1997,1999)$. Already Mayr (1957) distinguished between theoretical (primary or non-operational) and operational (secondary) properties of species concepts, but this difference was ignored in later decennia (notably by Mayr himself, see Cotterill 2003). Much of the controversy between biologists in the species debate finds its origin in the lack of understanding between these two levels of species concepts. Primary species concepts are those answering the question: "What are species?", whereas secondary species concepts are giving answer to the question: "How do we recognise species?" The first question is an ontological one, searching for the nature of species. The second one, however, is an epistemological question, since it searches for the properties of species by which species can be known. The first are species concepts, the second are species criteria (Mayden 1997; de Queiroz 1998, 1999; Cotterill 2003; Richards 2010).

Of the 22 species concepts mentioned by Mayden (1997), there is only one candidate that could serve as primary concept as was concluded by several independent reviewers: Simpson's Evolutionary Species Concept (ESC) amended by Wiley (Frost \& Kluge 1994; Mayden 1997; de Queiroz 1998, 1999; Mayden 1999; Cotterill 2003). According to Wiley (1978), "a species is a single lineage of ancestral-descendant populations which maintains its identity from other such lineages and which has its own evolutionary tendencies and historical fate”. De Queiroz (2005a) rephrased Simpson's ESC to his General Lineage Concept (GLC) in which "a species is a separately evolving (segment of a) metapopulation 
lineage". A lineage is specified as a population extended through time or an ancestraldescendant series of time-limited populations (de Queiroz 2005a). Although Hausdorf (2011) argued that the ESC as well as the GLC are circular in their reasoning since they introduce the notion of population in the concept, in Wiley's definition it can easily be replaced by group of individuals without change of meaning, just as was done by Richards (2010, p. 158).

The question remains how to detect separate lineages, and this is where the secondary species concepts or operational rules come in. Discussing this topic, Mayden (1997), and in his footsteps Cotterill (2003), fall back on the notion of consilience, or the unification of (disparately derived) knowledge. Much of what is called 'species' in contemporary floras can be considered hypotheses of the lineages existing in nature. According to Mayden and Cotterill, the secondary species concepts can indicate whether to accept these hypotheses: intrinsic reproductive isolation (BSC), shared specific mate recognition or fertilization systems (RSC), phenetic differences (PSC), ecological distinctiveness (EcSC), monophyly (PhSC), morphology (MSC) to name some examples (see de Queiroz 2005a for more examples). Every single of these characters can (but not necessarily does) add evidence that our hypotheses are real entities in nature (Sites Jr \& Jonathon 2004; de Queiroz 2005a).

In the last decades, many authors stated that the species category is heterogeneous: it consists of various types of lineages bound by different processes that display different structures (Mishler \& Brandon 1987; Stebbins 1987; Hörandl 1998; Stace 1998; Cotterill 2003; Pigliucci 2003; Wilkins 2003; de Queiroz 2005a; Ereshefsky 2010, 2011; Hausdorf 2011; 2011; Chambers 2012). An interesting view on this was published by Chambers (2012), who claims that the process of speciation is a multidimensional phenomenon, since it has a time dimension. Although speciation can be instant (e.g. by polyploidisation, see Soltis \& Soltis 1999; Soltis et al. 2007), in most cases a new species 'develops' from an ancestral species, until it is 'forever different' and 'reproductively isolated'. According to Chambers (2012) the different secondary species concepts point towards different developmental stages in the evolution of species. He proposed a twostep decision matrix for species diagnosis to account for these different stages or levels. Quite a different view on species concepts was published by Wilkins (2009b, 2011), who seems to consider Simpsons ESC on the same level as all other species concepts. He claims, based on a thorough analysis of the history of biology and the conceptualisation of species through time, that "species has always been thought to mean the generation of similar form. That is, a living kind or sort [species, RH] is that which has a generative power to make more instances of itself' (Wilkins 2009b, p. 232). In a noteworthy, yet unpublished paper which can be found in the internet, Wilkins (2009a) rephrased it in "A species is any lineage of organisms that is distinct from other lineages because of differences 
in some shared biological property". This is called the Generative Conception of Species by Wilkins himself. A somewhat similar species conception was proposed by Hörandl (1998), who circumscribed species as "all organisms of an ancestral-descendent lineage which are products of the same evolutionary process, which have a constancy of progeny (upheld by a certain reproductive system) and consequently a similarity of phenotype and of ecogeographical unity." An important notion, derived from the mentioned unpublished paper by Wilkins, which might influence future discussions, is that species are no explanations in some theory, but they are to be explained salient phenomena (explicanda more philosophically spoken): "If species were theoretical objects, we ought to find them as a consequence of theory, not as a "unit" that we feed into theoretical or operational processes. ... Theory does not define species. ... We do not define species, we see them" (Wilkins 2009a). In this paper he makes the important account: "Of course, not all lineages are species gene, haplotype and population lineages, for example - so the point at which lineages coalesce into different kinds of species is not something that we can define abstractly. Instead, it is a phenomenon that we observe, and seek to explain with one of the 26 or so conceptions in each case" (see also Wilkins 2011). His final point is that we don't need a singular definition of species, because species-as-phenomena are real things to be explained, not an a priori category or rank into which every biological organism must be fitted (Wilkins 2009a in the last sentence).

Probably the most striking and staggering conclusion from the historical analysis of species concepts is the insight that taxonomists kept describing species and kept making their classifications within their realms of specialisation, in spite of the prevailing species concept or concepts: batologists kept on describing new Rubus species, as hieraciologists did with new Hieracium species, and bacteriologists with new bacteria species, although most of them - probably all - were brought up with Mayr's BSC in biology classes. In my opinion, this pleads in favour of Wilkins' ideas on species: taxonomists describe the phenomena they encounter in nature, irrespective of theoretical objections. We cannot escape the conclusion that any of the proposed species concepts have failed to account for all types of diversity we are inclined to call "species". This seems logical when one realises that there are many ways how these species come into being (Hörandl 1998; Wilkins 2003, 2007).

\section{Species recognition in apomict groups: possible objections}

If the species category is an evolutionary heterogeneous amalgam of phenomena, is there any ground for the recognition of species within apomict groups? Before entering this question, I first have to discuss some of the objections that are made against such recognition: 1.) apomict species are impossible by definition, 2.) apomict species do not resemble amphimictic outbreeders, and 3.) apomict species show a lack of coherence. 


\section{Apomict species are impossible by definition}

The idea that apomict species (or asexual species more general) are impossible by definition is expressed most explicitly by the defenders of the BSC, for instance Mayr himself (Mayr 1987, 1992). One of most dedicated proponents of this species concept, Ghiselin, states in the appendix of his excellent Metaphysics and the Origin of Species: "An asexual biological species is a contradiction in terms" (Ghiselin 1997, p. 305). As it is clear in a glance, apomict species are not compatible with the BSC, because they lack interbreeding.

The question remains how apomicts are dealt with (or better: how they could be dealt with) under the premise of the other species concepts. Table 1 gives an overview over the species concepts reviewed by Mayden (1997) and the conception of apomict species therein (see also Asker \& Jerlings 1992; and Dickinson 1998a for a discussion). The Successional Species Concept (SSC) was developed for fossil species only, and is therefore not applicable to extant organisms at all. All other species concepts in Table 1 are applicable to apomicts, but several will reject apomicts as species. The species concepts under which apomict lineages are (or can be) regarded as species, are marked with a '+', otherwise a '-' is given. To be recognised as species, the BSC, CpSC, ESU, HSC, RCC and RSC demand biparental reproduction. Clearly, apomict lineages are rejected by default under these species concepts, but it might be less obvious that also the entire agamic complexes are to be rejected as species because biparental reproduction is lacking. Thus, common flora entries like Rubus fruticosus, Hieracium murorum, or Taraxacum officinale fail to be recognised as species when these concepts are applied strictly. Concerning the GSC, it depends largely on the author how apomictics are treated. In the original circumscription by Simpson (1943), no reference was made to the reproduction mode, but Dobzhansky (1950) added the notion of "most inclusive reproductive community of sexual and cross-fertilizing individuals". The NDSC is more of an umbrella term for several species concepts, amongst which for instance the BSC (rejecting apomicts as species) as well as the MSC (accepting apomicts as species). All other listed species concepts, over $50 \%$, are able to accommodate apomict lineages as species.

Mayden (1997) argues that a useful species concept should give account for all biodiversity (p. 382), and that the recognition of hybrids and apomicts are the prerequisite for any monistic (i.e. universally valid) species concept (p. 415-416). The denial of apomictic species seems problematic indeed, "given that sex is a relatively rare property in the universal tree of life, which would mean that most biological taxa do not come in species" (Wilkins 2011). This notion is understood by other authors too (Ereshefsky 2010; Van Regenmortel 2010). 


\section{Apomict species do not resemble amphimictic outbreeders}

Sometimes it is stated in one or another way that agamosperm species should include multiple genotypes to be equivalent to sexually reproducing species, and that the lineages or microspecies recognised by many highly specialised taxonomists do not fulfil this requirement (Turesson 1929; Stebbins 1941; Dickinson 1998b, a). As was stressed by Stace (1998), this argument is not very convincing, since sexual outbreeders are not mutually equivalent by any means themselves. Furthermore, studies on population genetics have shown that apomictic complexes can harbour considerable genetic diversity within and among populations, as a result of the history of descent of apomictic complexes, the influence of backcrossing with sexual relatives, hybridization between apomictic lineages and facultative sexuality, and mutations (review in Hörandl \& Paun 2007). Also from a more philosophical viewpoint, this objection doesn't keep up: the demand of one or more necessary properties (like the amount of genetic variation) is the kind of essentialism that is widely rejected when discussing the nature of species (Ghiselin 1997; e.g. de Queiroz 2005a; Richards 2010; Wilkins 2010).

\section{Apomict species are not coherent}

Sex is an important feature by which species maintain their coherence. The major processes that bind the members of a sexual species together and make them evolve as populations and not as mere individuals are recombination and intraspecific gene flow (Rieseberg \& Burke 2001). Such strong internal cohesive processes are lacking in strictly asexual lineages and this invited Chambers (2012) to heave the sigh: "each individual must simply be considered as a species of some sort or we must stop thinking about them in this way at all' (a similar notion has allready been expressed by Fisher 1958, p. 135).

However, asexual organisms seem actually to be organised in units that resemble species of biparental organisms both in morphological and functional respect (Mishler \& Brandon 1987; Goodfellow et al. 1997; Cohan 2002; Hillis 2007; Hausdorf 2011), whereas one would expect that asexual organisms would form a smear or continuum of variation (Wilkins 2006; Hillis 2007). Templeton (1989) has argued that not only internal cohesive processes can hold a group of organisms together as species, but that ecological pressure or selection can play a similar role. This idea was worked out in more detail by Wilkins (2006) in a paper on the concept and causes of microbial species. According to Wilkins, species (as phenomena, both uni- and biparental) are genetic clusters in genome space, to be explained as some combination of adaptation to an ecological niche and reproductive compatibility (cf. Van Valen 1976).

\section{Case studies on apomict groups}

The question remains how to deal with apomict lineages. Although much effort has been made to find a universally applicable species definition in the last six decennia by both biologists and philosophers, rather recently there seems to grow some consensus 
that the species category is heterogeneous, and that the search for one universal species concept might be idle. This is not very surprising, considering the diversity of the living world around us and the different modes of speciation (cf. Wilkins 2003; Wilkins 2007). However, we don't experience the organismal world as a complete chaos of variation: the fact that organisms are organised in lineages of similar organisms that we call species is evident to both specialists and laypersons (Hillis 2007). Wilkins (2009a) has put forward that species are no theoretical objects, but phenomenal objects: they push themselves upon the attentive observer, both in sexual and asexual groups, and they ask for an explanation. This idea has received little attention until now, although it seems a valuable notion.

How does this affect the way we treat apomict lineages in our taxonomies? Stace (1998) advocated a utilitarian pragmatic approach in apomict taxonomy. This was based on the assumption that the precise biological meaning has disappeared that once could be inferred from the term "species" (Stace 1998, p. 325), but I am not sure this is really the case. More than before we understand what species are, although the awareness that species come in different kinds has grown simultaneously. I am opposing to the view of Stace, who stated that species are reduced to a utilitarian role in taxonomy, as if they were not real (see also Rieseberg et al. 2006; Haveman \& De Ronde 2013). Hörandl et al. (2009a, p. 1211) interpreted Stace's pragmatic apomict taxonomy as a case-wise approach, resulting in a rejection of apomict species in the "cassubicus" group within the Ranunculus auricomus aggregate. As was already pointed out by Davis (1958), there is no overall solution for the species recognition and taxonomy of all apomict groups, because each apomictic genus presents problems a little different from the others (Gustafsson 1947). The idea that an overall prescriptive solution to the taxonomic problems posed by apomictic groups is impossible (Richards et al. 1996; Chrtek \& Marhold 1998) and that a case-wise approach is necessary, concurs with the notion of a heterogeneous species category, and that species are phenomena to be explained. It is even true for "ideal" outbreeding species. Every taxonomy must rely on gained expert knowledge on traits and features that are of importance in that particular group, and all traits in the above mentioned secondary species concepts and even more can be used as such.

In the following sections, I will exemplify the case-wise approach for three large and more or less well studied apomict groups, viz. the Ranunculus auricomus aggregate, Rubus subgen. Rubus, and Hieracium (incl. Pilosella). However, before doing so I have to make some remarks about the classification of apomict lineages on other than the species level, which are valid for all discussed groups, viz. the classification 1.) as some taxon at the infraspecific level, or 2.) as nothospecies. Although the classification at the infraspecific level might be convenient for getting a quick overview, as was argued by Schuhwerk (2002), at least in most cases it doesn't reflect the phylogenetic structure of most genera, 
which seem to be highly reticulate (e.g. Ericsson 1992; Wittzell 1999; Hörandl et al. 2009a). This taxonomical practice thus leads to the grouping of lineages with different evolutionary histories under one species (Tyler 2006), which becomes polyphyletic (Ericsson 1992) and artificial consequently. Since systematics is not only aiming at naming the diversity of life, but also at clarifying their relationships and building the tree of life (Cracraft 2002; Cracraft \& Donoghue 2004), classifying apomict lineages at the infraspecific level is hindering broader systematics goals.

Most apomicts are considered to be of hybrid origin (Gustafsson 1943, 1947; Grant 1971; Richards 1973; Stace 1989, p. 154; Matzke-Hajek 1997; Richards 2003; Paun et al. 2006b; Hörandl \& Paun 2007; Fehrer et al. 2009; Mráz et al. 2011), and classification of the apomicts lineages as nothospecies would therefore be a considerable option. Since most (but not all, see e.g. Robertson et al. 2004) apomict lineages are thought to be ancient hybrids though, from which the parental species are unknown, and most probably extinct (e.g. Weber 1995; Mráz et al. 2011), a formal treatment as nothospecies is impossible (art. H.3.2, Vienna Code, McNeill et al. 2007). More fundamentally, a hybrid origin is not exceptional in the plant kingdom, and it is argued by several authors that hybridisation is an important driving force in the evolution of angiosperms. The topic was placed on the scientific agenda by Stebbins (1959) and extensively reviewed in Grant's seminal Plant Speciation (Grant 1971), and Arnold's Natural Hybridization and Evolution (Arnold 1997). More recently, Soltis \& Soltis (2009) even argued that most angiosperms have a hybrid background. Considering this claim, the ancient hybrid origin of apomicts might be no exception at all, and seems no profound argument to treat them differently from other angiosperms.

\section{Ranunculus auricomus agg.}

The Ranunculus auricomus complex (Goldilocks) is distributed across Europe, western Siberia and Greenland, and can be found from the Arctic to the Mediterranean zone (Jalas \& Suominen 1989). It forms a polyploid complex in which the (few) diploids show sexual propagation (Hörandl \& Greilhuber 2002), whereas polyploids are usually aposporous apomicts (Hörandl et al. 2001; Hörandl \& Greilhuber 2002; Hörandl et al. 2009a).

Linnaeus (1753) described two species, Ranunculus auricomus and $R$. cassubicus, which represent two morphological nuclei within the complex (Hörandl 1998). Marklund (1961, 1965) classified the complex in four morphologically distinct 'main species' $(R$. cassubicus, $R$. monophyllus, $R$. fallax, and $R$. auricomus), and distinguished the agamic lineages as subspecies under these main species. Hörandl \& Gutermann (1998) treated the main species as informal 'collective groups', each of them including groups of morphologically similar apomictic lineages; the latter were distinguished as species. 
Within the aggregate, approximately 800 apomictic lineages have been described as species by central and northern European taxonomists (Ericsson 1992; Hörandl 1998), mainly on the basis of morphology.

In the treatment of the complex for Flora Nordica, Ericsson (1992) argued in favour of the treatment as species, and not as subspecies as was done by Marklund. His arguments are the polyphyletic 'main species' with ill-defined limits, while the apomictic lineages are sympatric, very constant, and lack intermediate forms. Hörandl (1998) discussed the alternatives to the agamospecies concept in the Ranunculus auricomus aggregate, and reached the same conclusion as Ericsson. For the whole complex, she questioned monophyly, and therefore, treating the whole complex as a single species was rejected. The same holds, mutatis mutando, for the collective groups. Because the parental species were unknown at that time, a classification as hybrids was impossible as well. Consequently, the $R$. auricomus complex could not be classified at all (except the few sexual species) if the species level was to be rejected.

However, more recently, a detailed study of the "cassubicus" group on the basis of morphological, karyological, and molecular data (Hörandl et al. 2009a) revealed the instability of the apomictic species due to frequent sexuality of apomicts, increasing genetic diversity by continuous formation of new cytotypes, local hybridization and introgression. Similar morphotypes may have multiple origins, which seriously undermines the assumption that phenetically similar populations in an area also possess an historical evolutionary coherence. To reflect the evolutionary processes involved, the authors propose a separate classification of the sexual species, $R$. notabilis, and the closely related species pair $R$. cassubicifolius and $R$. carpaticola. Based on these well-defined species, the apomictic biotypes of the "cassubicus" group can best be classified as broad nothotaxa $(R$. carpaticola $\times R$. cassubicifolius, and $R . \times$ hungaricus $)$.

This example shows how the understanding of multiple features leads to a better understanding of the complex evolutionary relationships within the aggregate, and how taxonomy can benefit from such understanding. In the case of the Ranunculus auricomus agg., multiple data lead to the conclusion that an agamospecies concept (for at least the studied group) must be rejected, although formerly it was thought to be the only possible solution for the aggregate.

\section{Rubus subgen. Rubus}

Rubus subgen. Rubus (Blackberry) is a polyploid complex which has its main centres of diversity across Europe, North America and the mountainous areas of South America. Furthermore it is native in Africa, western Asia, the northern part of India, in Japan and New Zealand (Weber 1995, p. 318). It is a polyploid complex in which only six 
extant sexual species are known in Europe: the (sub-)Mediterranean $R$. ulmifolius and $R$. canescens, the West-Mediterranean $R$. incanescens, $R$. caesius (with a wide distribution across Europe) and the Canarian R. bollei, and the Caucasian R. moschus (Weber 1995, p. 302). All other European species of the subgenus are (allo-)polyploids and (mostly facultative) apomicts; obligate apomixis was detected in the triploid members of the series Discolores (Šarhanová et al. 2012). In the recent chorological overview over the genus in the Atlas Flora Europaeae (Kurtto et al. 2010), about 700 apomicts are included. Historically there have been various attempts to classify the numerous apomicts (Weber 1996, 1999a; Kurtto et al. 2010, p. 28): 1.) the description of each different bramble as a separate species (e.g. Müller 1859; Boulay 1864-1869; Genevier 1869), 2.) as infraspecific taxa (e.g. Syme 1864), 3.) as hybrid formulae (Kuntze 1867; Schipper 1925), 4.) arranging an naming of each unknown plant as infraspecific taxon in an artificial system (Sudre 1908-1913), and 5.) as species with different values with respect to their fertility and distribution (Focke 1877; Gustafsson 1943). From the 1970's onward, Rubus systematics started with a whole new approach, which was called the 'Weberian Reform' by Holub (1997). This reform consists of four major pillars: 1.) mapping projects over larger areas, 2.) evaluation of type material, 3.) visits to loci classici, and 4.) the evaluation of the status of species by means of their distribution areas (Haveman $\&$ De Ronde 2013). Species are distinguished almost only on the basis of morphology, so a morphologically based agamospecies concept is used. To prevent the overflow of the systematic system, the convention among European Rubus taxonomists is to describe only species with a distribution area over $50 \mathrm{~km}$ (the fourth pillar under the 'Weberian Reform'). The basis for a phenetic agamospecies concept in Rubus is defendable, since DNA fingerprinting showed that the agamic lineages which are regarded as species proved to consist mainly of one clone with very limited genetic variation (Kraft \& Nybom 1995; Kraft et al. 1996; Nybom 1998; Kollmann et al. 2000), contrary to many other agamic genera (reviewed in Hörandl \& Paun 2007). Thorough knowledge of the phenotypic variation of the apomictic lineages will therefore lead to the distinguishing of these lineages properly (e.g. Ryde 2011), even in the case of biotypes with a very limited distribution. Therefore, Ryde (2011), and in his footsteps Haveman \& De Ronde (2013) declined the categorical rejection of Rubus species with a distribution area $<50 \mathrm{~km}$, as was done before by Loos (2008). However, this phenetic approach will fail in those cases where a raised percentage of sexuality is apparent, especially in the series Hystrix and Glandulosi (Haveman \& De Ronde 2013). In the mountainous areas of Europe, these series form swarms of only partly stabilised apomicts from which stabilised biotypes with large enough distribution areas are actually recognised as species, like $R$. guentheri and $R$. nigricatus (Kurtto et al. 2010). However, it is unclear which percentage of these groups (classified as 'Rubus hirtus agg.', see Weber 1995) consist of stabilised apomicts with only a local distribution, and what is the percentage of sexual forms and primary hybrids. Recently Šarhanová et al. (2012) showed preferential sexual propagation in the 
western Carpathians, and preferential apomictic propagation in the southern Bohemian Massive in the series Glandulosi using flow cytometric seed screen (FCSS). An approach similar to the work of Hörandl et al. (2009a) in cassubicus group of the Ranunculus auricomus aggregate could give insight in the structure of these hybridogenic swarms, which seems prerequisite for an adequate taxonomic treatment. Such a genetical analysis of the $R$. hirtus aggregate was advocated before by Holub (1997) and Haveman \& De Ronde (2013).

\section{Hieracium s.l.}

Within Hieracium s.l. (Hawkweed), originally four subgenera were recognised: the American subgenus Chionoracium (formerly Stenotheca, see Garland 1990), the Eurasian subgenera Hieracium and Pilosella, and the African-European subgenus Tolpis (Zahn 1921-1923; Fehrer et al. 2005). These subgenera, nowadays often considered as genera, differ in their mode of reproduction: Tolpis and Chionoracium species are all outcrossing sexual diploids (as far as known), Hieracium s.str. species are thought to be either polyploid obligate (diplosporous) apomicts or diploid sexuals, and subgenus Pilosella is characterised by a mixture of sexual and facultatively aposporous apomicts (Koltunow et al. 1995; Krahulcová et al. 2000; Chrtek et al. 2009; Crawford et al. 2010). Contemporary taxonomies exclude Tolpis from Hieracium, which is supported by molecular phylogenetic analysis (Park et al. 2001). During the last decades, generic recognition of Pilosella has gained increased support. When excluding "Hieracium" intybaceum, Hieracium as well as Pilosella form monophyletic groups (Chrtek et al. 2009), morphologically differing in achene features mainly (Bräutigam \& Greuter 2007). I will concentrate on the (apomictic) Eurasian (sub)genera here.

Over 10,000 names have been published in Hieracium and Pilosella (Beaman 1990), making Hieracium s.l. one of the largest genera worldwide. Hieracium taxonomy is much hindered by different regional traditions, which has led to two major, fundamentally differing taxonomical schools (cf. Schuhwerk 2002). The 'Nordic' school, in which the apomict lineages are described as species, which are grouped in 'circle species', 'series', 'sections' and other informal groupings, followed the work of Fries (1862), Almquist (1881), and others in the Nordic countries, Jordan (in Boreau 1857), Boreau (1857), and Arvet-Touvet $(1888,1913)$ in continental western Europe, and Backhouse (1856) in Britain. The 'Central-European school' of hieraciology is based on the work of Von Nägeli \& Peter (1885), who grouped the supposed apomict lineages in Pilosella as subspecies and varieties under major aggregate species. This was extended to Hieracium s.str. by Zahn (1921-1923, 1931, 1936-1938), who used a hierarchical system of principal species ('Hauptarten') and intermediate species ('Zwischenarten', displaying characters intermediate between two or more principal species), grex, subgrex, subspecies, varieties, subvarieties, formae, and subformae to give account of all variation. His system is highly 
artificial though, like the treatment of Sudre for Rubus (Sudre 1908-1913): the grouping of the apomict lineages under principal and intermediate species doesn't necessarily reflect natural relationships, and, as shown before, the grouping of apomict lineages as subspecies under one (collective) species makes the latter one polyphyletic most likely. Besides, like Sudre in his Rubus monograph, Zahn often aggregated (sometimes only superficially) similar forms from over Europe together in one taxon, irrespective the large gaps in distribution areas (see for examples Chrtek \& Mráz 2007).

A part of the problems with the classification of Hawkweeds has had its origin in the historical lack of awareness of the fundamental differences in reproduction systems between the subgenera Hieracium s.str. and Pilosella. Recent attempts to classify both (sub)genera try to give account of this difference (Sell \& West 1976; Schou 2001; see also Tyler 2001; 2005; Sell \& Murrell 2006).

\section{Hieracium s.str}

Most of the analysed taxa of Hieracium s.str. are tri- or tetraploid apomicts, while sexual diploids are rare and mostly confined to southern latitudes (Schuhwerk 2002; Chrtek et al. 2007a; Tyler \& Jönsson 2009). There are several arguments to accept a narrow (micro)-species concept in Hieracium. To a large extent, apomixis in Hieracium is obligate; although the variation in Hieracium s.str., like in all apomict taxa, is thought to be partly due to hybridisation events, recent hybridisation is very rare (Mráz et al. 2005; Mráz et al. 2011). Ancient hybridisation events must have occurred rather frequently (Fehrer et al. 2009). Other causes of the immense variation within the genus might be 'pseudo-sexual' recombination among the different copies of the same chromosomes within the seed-forming individual, structural mutations, or series of point-mutations affecting single genes influencing morphological characters. The relative importance of these various processes is still largely unknown though (Tyler 2006). Most apomictic lineages are morphologically rather well defined, due to the very low genotypic variation: as was shown in several studies, most consist of only one or very few genotypes (Shi $e t$ al. 1996; Mráz et al. 2001; Štorchová et al. 2002; Chrtek et al. 2007b; Ronikier \& Szeląg 2008). Morphologically distinguished (micro)-species from the Nordic countries appeared to be homogeneous with respect to ploidy level too (Tyler \& Jönsson 2009). Like in the Ranunculus auricomus aggregate and Rubus sect. Glandulosi, genetic as well as morphological variation is higher especially in regions and groups where sexual diploids occur (Mráz et al. 2001). Considerable genotypic variation can be found in species with a wider distribution, especially when they harbour diploid as well as polyploid populations, as was shown for the arctic-alpine H. alpina s.str. (Shi et al. 1996; Štorchová et al. 2002). However, widespread Hieracium species may consist of only one clone too (Shi et al. 1996; Ronikier \& Szeląg 2008). Similarly, Sell and Murrell (2006, p. 221) report only little variation in some apomicts, whereas others appear to be distinct species when only 
the extremes are taken into account. Probably such species are of polytopic origin (Shi et al. 1996; Mráz et al. 2001; Mráz et al. 2009). How to deal with this variation will be dependent on the situation. In some cases, morphological variation can provoke the recognition of a new species, for instance when morphological variation coincides with genetic variation and chorological evidence (cf. Mráz et al. 2001; Ronikier \& Szeląg 2008). In cases where the variation is clinal, like in $H$. alpina s.str., the recognition of subspecies is suggested (Shi et al. 1996), but to do so, phylogenetic relationships must be clear and allow for this.

Considering all evidence, the lack of recent hybridisation and the low genetic variation, resulting in distinct lineages with only little morphological variation are arguments to accept a narrow (micro)-species concept in Hieracium s.str. To define these narrow species, Tyler $(2006,2011)$ applied a statistically based morphometric approach with convincing results.

\section{Pilosella}

The taxonomic situation in Pilosella is far more complex, due to a combination of sexuality, facultative apomixis, polyploidy, and frequent hybridizations (Ostenfeld 1912; Krahulcová et al. 2000; Fehrer et al. 2007). Many field populations are heterogeneous in respect to ploidy level and/or reproductive system (Krahulcová et al. 2000; Krahulcová et al. 2009a; Šingliarová et al. 2011), and hybrids are formed often, although uneven in different mixed populations (Krahulec et al. 2008). The combination of hybridization, apomixis and clonal growth leads to the maintenance of various hybrids, having originated from backcrossing and hybridization between more than two species (Krahulcová et al. 2000), and making the classification very cumbersome. Gene-flow is considerable among all morphotypes, including the principal species (Tyler 2005; Krahulcová et al. 2009a). As a consequence, classification in Pilosella cannot follow the criteria applied in Hieracium s.str., where hybridisation and gene-flow are very rare.

Bräutigam \& Greuter (2007) sketched a brief history of the classification in Pilosella, starting with the revision by Fries (1862), who recognised 42 species. Von Nägeli \& Peter (1885) and Zahn (1921-1923) multiplied this number, by recognizing 164 and 182 species respectively. To give account of the many micro-species that were described already, Zahn included a mind-boggling number of subspecies (624 in Hieracium pilosella L. alone!).

Several suggestions are given to deal with this complicated situation. In the Flora Europaea, Sell \& West (1976) recognised species as normal sexual species in other genera, and these agreed with the narrowly circumscribed main species of Zahn (1921-1923). The Zahnian intermediate species are considered as hybrids. A very similar approach 
was published by Sell \& Murrell (2006, p. 209), who additionally distinguished the infraspecific groups of Zahn ("grex") as subspecies. However, this system ignores welldefined taxa as meaningless hybrids (Schuhwerk 2002), and the discrimination between good and hybrid species is hypothetical at its best. Tyler $(2001,2005)$ argued against this approach that most of the morphotypes encountered in nature are classified as hybrids. He proposed a new classification scheme in which very broadly circumscribed species are recognised, and only the recent hybrids are treated as hybrids (Schou 2001; Tyler 2001). The species recognised by him include many morphotypes treated as hybrids or intermediate taxa by Central European authors. Although allozyme variation in Nordic members of Pilosella did not reflect the proposed classification adequately (Tyler 2005), it underlined the gene flow between virtually all morphotypes to such an extent that he wrote: "... it may even be argued that the whole genus Pilosella should be regarded as a single biological species". The main used argument to reject Tyler's solution is the loss of information, caused by the lumping of easily recognised types (Schuhwerk 2002; Bräutigam \& Greuter 2007).

Whereas the putative hybrids in the treatment in the Flora Europaea (Sell \& West 1976) are omitted, they are included in the Euro+Med Checklist with binomials as if they were good species (Bräutigam \& Greuter 2007). The hybridogenous taxa or taxon swarms are thus not treated as nothospecies, but they are termed "collective species", which are of very unequal nature and value: they may comprise newly formed, primary hybrids only, or correspond to stable hybridogenous species, or they often include both (Bräutigam $\&$ Greuter 2007, p. 125). In a recent paper on population structure of mixed Pilosella populations, Krahulcová et al. (2009a) argued that both hybrid categories should be distinguished, because "Evidently, the recent hybrids are repeatedly formed, even at the same locality. Because of a low production of identical progeny by (facultative) apomixis, they usually do not spread outside the place of their origin. The stabilized hybridogenous taxa, however, behave like species at least at the landscape level." Conceptually, the approaches by Krahulcová et al. (2009a) and Tyler $(2001,2005)$ are congruent to a high extent. Although the treatment by Krahulcová et al. (2009a) was hardly tested for its usability (see however Krahulcová et al. 2009b), of all proposed systems it seems to reflect the structure of the genus best. Future taxonomical treatments of Pilosella have to prove its tenability.

\section{Concluding remarks}

Considering their different evolutionary histories, it cannot come as surprise that species come in kinds. Even asexuals are no homogenous group in this respect, but come in all sorts (Bengtsson 2009). If one thing is clear from the species debate, it is that there are numerous ways to define species, that they all have their own merit, but that no single one seems to capture the real essence of all groups of organisms we tend to name species 
(Ereshefsky 2011). It was only in approximately the last two decades that more and more philosophers and biologists alike came to the conclusion that the species category is heterogeneous, after several decades of intense, not yet closed debate. From the examples in this paper it might be clear that it is not so much the question what species are in general, but what species are in a particular group. Species in the cassubicus group in Ranunculus auricomus are a few sexuals, which gave rise to an only partly apomictic hybrid swarm. Species in Rubus subgenus Rubus are numerous facultative apomictic lineages differing in morphology, distribution area, and ecology, besides a very few sexual 'biological species'. Species in Hieracium s.str. are mostly ancient hybrids, stabilised by almost obligate apomixis; only in some regions sexual species are found. At what species may be discerned in Pilosella, is not yet very clear: there are sexuals, 'ancient' hybrids stabilised by apomixis, as well as large quantities of recent hybrids, and to what extent these groups form species has still to be discovered for some part. Such an approach is not some kind of new pragmatism, let alone only a way to order the chaos in a utilitarian way, but it has to do with a thorough biological understanding of the patterns in nature that reveal themselves after hard scientific labour. 
CHAPTER 3

\section{The role of the Weberian Reform in European Rubus research and the taxonomy of locally distributed species - which species should we describe?}

Reprinted with permission from:

Haveman, R. \& I. de Ronde 2013. The role of the Weberian Reform in European Rubus research and the taxonomy of locally distributed species - which species should we describe? Nord. J. Bot. 31: 145-150. 


\begin{abstract}
After Sudre published his treatment of European Rubi in the early 20th Century, Rubus taxonomy in Europe suffered from a scholastic phase and a longer period of stagnation. The so-called 'Weberian Reform' shaped the necessary revival of European batology. It rests on four major pillars: 1.) mapping projects over larger areas, 2.) evaluation of type material, 3.) visits to loci classici, and 4.) the evaluation of the status of species by means of their distribution areas. It is widely accepted in European batology that only species with a distribution area over $50 \mathrm{~km}$ should be described. Although this pragmatic species concept has been useful in making a continent-wide overview of brambles, we argue that it is lacking any scientific basis, and that it thus should be rejected. There are at least four distinctive problems when speaking of locally distributed brambles: 1.) primary hybrids, 2.) locally distributed stabilised apomicts, 3.) intraspecific variation in species with a larger distribution range, and 4.) unstabilised swarms of hybridogenic biotypes and the derivates thereof (mainly in the montane regions). When facing the problems in Rubus systematics, we argue that all independently evolving lineages should be described as species, including apomictic lineages with very small distribution ranges, both from the mountain-dwelling glandular series, as well as such lineages from the lowlands. Neither primary hybrids (which are not stabilised by apomixis), nor biotypes without an independent and coherent distribution area are independently evolving lineages, and should thus not be described as species. We advocate a restrained attitude when describing new species with limited distribution areas.
\end{abstract}

\title{
Nomenclature
}

Weber (1995) for Rubus 


\section{Introduction}

In a recent paper in this journal, Ryde (2011) challenged the pragmatic species concept which is in use in European Rubus taxonomy over the last decades. This species concept goes back to ideas by Weber (1977b, 1986b, 1999a), who stated that alongside morphological characteristics, distribution area characteristics also play an important role in the delimitation and recognition of apomict bramble species. The practice of recognising only species with a sufficient large enough distribution range is often seen as a intrinsic part of the 'Weberian Reform' (Holub 1997) of European batology (the science of brambles, from Greek $\beta \alpha$ á $\varsigma$ = bramble), and until recent there was remarkably little debate about the scientific value of the species concept in the Weberian school. What is called the PrSC (pragmatic species concept) in this paper was never introduced or meant as a formal species concept, and we will use the abbreviation only for the sake of convenience.

The taxonomy of polyploidy agamic complexes, like Rubus subgen. Rubus, Hieracium, Taraxacum, and the Ranunculus auricomus complex, is not self-evident and rather problematic at least. The plentitude of morphologically only slightly differing units, the omnipresent existence of biotypes with only very limited distribution areas, and not least the historically-founded and bewildering synonymy in many groups make it almost impossible to classify the diversity in scientifically sound units. Considering this, together with the different apomict modi of agamic complexes (Asker \& Jerlings 1992; Richards et al. 1996), it may come as no surprise that not one single taxonomical scheme or species concept is at hand for the classification of all apomict groups (Hörandl 1998). Recent genetic studies have shown that apomict lineages can harbour a considerable amount of genetic diversity and that at least some lineages (here: historically defined progenitor-descendant groups) are not 'closed boxes' indifferent to gene flow as thought before (see several contributions in Hörandl et al. 2007). Highly-variable DNA markers have revealed even unique genotypes for each individual as in sexual plants (Paun et al. 2006a). The main focus of such studies is almost without exception developmental and evolutionary, but the taxonomical implications of these studies are hardly ever substantiated. This leaves us with different taxonomical treatments in different apomictic groups, not reflecting the biological realm, but merely an historically and geographically constrained tradition (Richards et al. 1996). Stace (1998) advocated pragmatic species concepts in all apomictic groups, but he did so under the assumption that species are no real entities, and that they only have an utilitarian role in taxonomy. However, species are not just merely constructs of our minds, but real entities, playing their role in evolution, and taxonomy should reflect this biological reality (Kluge 1990; Mayr 1996; Ghiselin 1997; Cracraft 2002; Mayden 2002; Cotterill 2003; Rieseberg et al. 2006; de Queiroz 2007). Species are historical individuals (Ghiselin 1997), forming separately evolving lineages (or lineage segments), as pointed out by de Queiroz (2005c). In 
taxonomy, species descriptions act as hypotheses of these natural entities, and research has to reveal the tenability of these hypotheses (Hey et al. 2003; de Queiroz 2005a). As was pointed out by de Queiroz (2007), evidence on the existence of a species can be gained in several ways, depending on the organisms one is dealing with. Morphology, exclusive interbreeding, ecological characteristics, genetic differences, distribution area characteristics, and more: all can help to get a clue which species really exist.

In this essay we will evaluate the value of the pragmatic species concept in use in modern Rubus taxonomy. We will do so by reviewing some historical attempts to classify apomict brambles and by showing the role of the 'Weberian Reform' in the clarification of Rubus systematics and the role of the pragmatic species concept herein. After an overview of some recent modifications and critiques of the PrSC, we will evaluate the influence of it, as well as its prospects. We will identify and differentiate the main problems in Rubus taxonomy related to the PrSC and we will offer some solutions to these problems as an outlook.

\section{Historical taxonomical treatments, the Weberian Reform, and the PrSC}

The historical attempts to classify brambles have been discussed in some detail elsewhere (Van de Beek 1974; Weber 1999a; Kurtto et al. 2010). They can be grouped into two large classes: natural classifications, reflecting the structure of the genus, and largely artificial classifications. Unfortunately, especially the latter had major impact on Rubus taxonomy far into the $20^{\text {th }}$ century. The first artificial method to mention here is the usage of hybrid formulae: a few bramble species were declared progenitors of all other ones, and the latter ones were arranged as hybrids of the former. This method was founded by Kuntze (1867), who found a supporter in the Netherlands in Schipper, who described many of such supposed Rubus hybrids (e.g. Schipper 1925). Amongst Dutch botanists it is still regularly heard that Rubus taxonomy is a Gordian Knot because of the innumerable hybrids, and this can probably be traced back to the papers by Schipper in the 20's and 30's of last century.

A second artificial system which had a major impact on $20^{\text {th }}$ century batology was the treatment of the genus by Sudre (1908-1913). He arranged all known species as subspecies, 'microgenes', varieties or formae of species well known to him, mainly from France. His monograph gives the false impression that all European brambles have finally been treated. As was described by Van de Beek (1988), Sudre's monograph made the recognition of brambles ultimately cumbersome: every new bush had to be identified separately by keying it out, and bushes clearly belonging to the same species were often identified as separate species because of minor differences. The wide adaptation of Sudre's 'batological bible' brought batology in a blind alley and caused a longer period of stagnation. Rubus taxonomy was in need of a complete reform. 
What Holub (1997) called the 'Weberian Reform' of European batology has its start with the publication of the famous overview of the Rubus species of north-western Europe (Weber 1972), and the dissertation of the Dutch batologist Van de Beek (1974). It rests on four major pillars:

- extensive mapping projects over larger areas,

- evaluation of type material and herbarium collections of early batologists,

- collecting material from the loci classici, and

- evaluation of the status of species by means of their distribution areas.

The first pillar, the mapping projects, gave a clear insight in the variability of forms over larger areas, necessary for the much-needed cleaning of nomenclature with countless synonyms, which hindered taxonomy a great deal. By comparing regional Rubus floras it was possible to weed out most of these synonyms and it revealed the similarity of species compositions of floras over larger areas. The second and third pillars, comparing original herbarium material, in combination with visits to regions from which the species were described, made it possible to couple names and forms. This was done consistently for the first time by Van de Beek in his dissertation (1974), and later it was also adopted by Weber. We consider this as the heart of the Weberian Reform, since it is indeed the end of the scholastic assignment of taxa from a certain region to already described taxa from a more or less remote region, as was introduced by Sudre (1908-1913). The rigid application of the type method is a first attempt to describe natural species, instead of artificial ones.

The last pillar, the evaluation of the status of species by their distribution areas, is in fact Weber's PrSC, which developed over time from some preliminary notes in the 1972 overview (Weber 1972, p. 9). It is based on the classification of distribution areas of apomict Rubus species by Focke (1877) and Gustafsson (1943), which was followed by Van de Beek (1974). Weber (1977b) discerns 4 distribution categories, which varied a little in upper and lower distribution limits over time. In the recent volume of the Atlas Florae Europaeae on Rubus, the categories are defined as follows:

(A) Widely distributed biotypes: diameter of the distribution area $500 \mathrm{~km}$ to more than $1000 \mathrm{~km}$.

(B) Regionally distributed biotypes: diameter of the distribution area $50-250 \mathrm{~km}$.

(C) Locally distributed biotypes: diameter of the distribution area less than $20 \mathrm{~km}$ (but not belonging to category D).

(D) Individual biotypes: a single bush or a small to large shrubbery formed by vegetative expansion.

The author claims "It is generally adopted that only regionally and widely distributed apomicts (categories A and B), not local or individual ones, should be treated as species" 
(Kurtto et al. 2010), and in an earlier work: "Von taxonomischem Interesse sind nur die Sippen der Kategorien A und B. Dagegen muß eine Beschreibung und Benennung aller Individuen und Lokalbildungen als irrelevant betrachtet werden..." (Weber 1986b). This is the PrSC, adopted by current European batology on a wide scale.

The Weberian Reform, as sketched above has reshaped European batology and has contributed more than anything else to a better understanding of the Rubus flora of the continent. Taxonomy and nomenclature are cleared to a large extent, although there are regions in Europe where batological research is still in its infancy (Kurtto et al. 2010, p. 30-31). The PrSC played an important role in this process, albeit not the only, and in our opinion not even the most important one. But before we pass judgement on the $\mathrm{PrSC}$ we have to examine the critiques on the PrSC as given by other authors first.

\section{Recent modifications and critiques}

There are two types of critiques on the PrSC, from which the first only results in modifications of the concepts without rejecting it. The second type of critique is more fundamental and leads to a rejection of the PrSC. Examples of modifications are the papers by Holub (1997), and Bijlsma \& Haveman (2007). On the basis of field work in the Czech Republic, Holub suggests a modification of the lower limit of the distribution areas of regionally distributed species to $20 \mathrm{~km}$. In practice this will result in an increase of the number of species to be described, but it retains the distribution area as a classification criterion. Bijlsma and Haveman propose a further subdivision of the distribution classes as given by Weber, to take account of differences in range structure for the benefit of phytogeographical analyses. Again this is not a fundamental change or rejection of the PrSC, as they hold the four classes as given by Weber as a first entry.

More pronounced are the objections given by Loos (2008) and Hörandl (1998), leading to a rejection of the PrSC as a valid species concept for the classification of Rubus and other agamic complexes. Loos's main objection and the vanguard of his elucidation is the lack of scientific grounds for the use of distribution area as a part of species concepts, be it amphi- or apomictic. It leads to an underestimation of real species numbers because of the structural rejection of species which differ from other species only in the extent of their distribution area. Apart from the principal objection of the unscientific character of the PrSC, this seems indeed to be the major practical drawback of the PrSC, in a time where biodiversity is under high pressure and the major effort of taxonomists ought to be focussed on the description of the whole 'encyclopaedia of life' (Cotterill 1999). Hörandl's main objection against the PrSC is its weak theoretical background: it doesn't reflect the process of speciation. Besides, she concluded that it is not generally applicable even in apomictic groups (Hörandl 1998). 
Also the previously mentioned recent paper by Ryde (2011) practically and inevitably leads to an abandonment of the PrSC. The author shows the marginal added value of the PrSC in local to regional studies, at least in particular regions of Sweden. In a combined classic morphological-cytological study of Rubus sect. Corylifolii in Halland, the author was able to distinguish between primary Rubus hybrids and stabilised taxa which all occupied rather clear distribution ranges. This lead to the recognition of only 6 extra locally distributed taxa in addition to the taxa already described regionally and from wider distributions. It remains unclear what the number of such locally distributed Rubus taxa is in other regions; Weber (in Kurtto et al. 2010, p. 29) estimates the number for Europe at 'tens of thousands', but this remains uncertain, and in the light of the study of Ryde probably an overestimation. This might be the effect of an insufficient analysis of the problems which Rubus taxonomy is facing; see below.

Edees has put the PrSC in perspective in the first paragraph of the preface of Brambles of the British Isles (Edees \& Newton 1988): "There are valid reasons for describing new local species, e.g. writers of regional and county Floras may justifiably hope to present a full account of the brambles of their area. The batologist's first duty, however, is to prepare accounts of those species known to be widespread or showing marked geographical distributions." This is how the PrSC has worked in a positive way: it made it possible to sort agamic Rubus species to provide a continent-wide overview over the most important widespread species. This goal has been reached however, and in this light there seems no reasonable and sound scientific ground for the maintenance of the PrSC. On the contrary, it hampers real insight in the actual diversity within the genus.

\section{Classifying locally distributed brambles: what are the real problems?}

In various publications, Weber is quite clear why in his opinion batology needs the pragmatic species concept (Weber 1972, 1986b, 1995, 1999a, 2002a; Kurtto et al. 2010). In the Atlas Flora Europaeae (Kurtto et al. 2010, p. 29) it is stated: “... single biotypes of Rubus, which are usually hybrids of unknown origin or derivatives thereof, are no longer the subject of taxonomic treatment and naming. Otherwise, millions of descriptions and names for this many different biotypes would be necessary, resulting taxonomy and nomenclature ad absurdum", and in a treatment of the north European species of the section (Weber 1981b): "Würde man auch alle Lokalsippen zu "Arten" erheben, müßten Tausende davon beschrieben werden. Die Rubus-Systematik wäre damit ad absurdum geführt, weil niemand mehr einen Überblick darüber gewinnen könnte." From these quotes it is clear that the $\mathrm{PrSC}$ is aiming at a reduction of the number of species descriptions and names in use. In fact, it is not a real species concept, in an ontological sense, but merely an epistemological rule about which brambles to treat taxonomically. 
An obvious weakness of the classification of distribution ranges by Weber is the absence of an analysis of taxonomical problems in Rubus systematics, as if all biotypes with (very) limited distribution areas represent similar entities (and thus similar problems for taxonomy). However, there are at least four distinctive problems (already partly addressed by Loos (2008)) when speaking of locally distributed brambles which systematics has to account for.

1. Primary hybrids. Primary hybrids are mainly found in landscapes where sexual Rubus species (like $R$. caesius, $R$. ulmifolius, and $R$. canescens) are common. Ryde (2011) described such primary hybrids with $R$. caesius and $R$. idaeus from Sweden. In the Netherlands certain habitats, e.g. dried-out Alnus-woodlands, can be inhibited by numerous $R$. caesius hybrids in manifold forms. Often these hybrids are at least partly sterile, and their distribution areas are only developed by vegetative propagation. Most often it is not clear which second parent contributed to the hybrid. Sometimes these primary Rubus hybrids are formally described, like in the case of R. xpseudoidaeus (Weber 1995), but most often they are left aside. Hybridisation between apomictic lineages of Rubus subgen. Rubus is possible as a result of re-sexualisation followed by pollination, as was proved in DNA research (Nybom 1995; Werlemark \& Nybom 2003). Lidforss (1905, 1907) showed that primary hybrids between apomictic species seem to be largely sexual. However, surprisingly, such hybrids are very rarely encountered in nature.

2. Locally distributed stabilised biotypes. These biotypes don't differ fundamentally from the regionally and widely distributed biotypes usually described as species, apart from the extent of their distribution area (probably due to their recent origin, see MatzkeHajek 1997). They can originate from hybridisation followed by fixation by apomixis, or as mutations from established species. A priori exclusion from taxonomical treatment of these taxa leads to an underestimation of species numbers (Loos 2008) and is pseudoscientific.

3. Variation in species with a larger distribution range. As opposed to Rubus species with a small distribution area, which most often are morphologically rather uniform, widely distributed species often show a fair amount of morphological variation. The background of this variation can be diverse. The two variants of $R$. vestitus with white resp. pink flowers are genetically fixed, and the difference is reflected also in their habitat preferences (Weber 1999b). Though the cause of the variation is often not clear, yet the pattern of variation gives rise to the thought that it is only controlled by one gene which is easily 'switched', like with the infraspecific variation in $R$. nessensis. Most of the forms of this species don't have a coherent distribution area and seem to originate every time from the nominate form of the species separately. 
4. Unstabilised swarms of putative hybridogenic biotypes and the derivatives thereof. The (sub-)montane to subalpine regions in central Europe and probably south-west Asia (Kurtto et al. 2010, p. 249) are inhibited by a swarm of brambles of both the series Glandulosi and Hystrix. This group, which consists of innumerable unstabilised singular or local biotypes is often referred to as Rubus hirtus sensu lato (Weber 1995), or Rubus hirtus group (Kurtto et al. 2010). It is a seemingly disentangible agglomerate of very similar biotypes, only slightly differing from place to place. Maurer (1994) described several generation of the offspring of the putative hybrid Rubus bifrons $\times R$. hirtus agg. The subsequent generations showed new combinations of characters in every generation from which the parental species could not even be estimated if they were not known, and which apparently were not fixed by apomixis. Also in the other groups in the Glandulosi, morphological variation seems to be more than in other series, hindering definition as well as delimitation of species. This makes it quite hard to understand what is meant by for instance $R$. serpens or $R$. teretiusculus, two Glandulosi species that were described from the Dutch-German-Belgian border region. The causes of the extreme variation in these groups is not yet clear, although it is thought that actual hybridisation plays an important role (Weber 1995; Loos 2008).

\section{Which Rubus species to describe?}

The categorical omission of locally distributed Rubus species as practiced in contemporary European Rubus taxonomy is basically a matter of convenience, as shown above. It has no scientific basis and has to be rejected, as was done by Loos (2008) before. Therefore, the status of biotypes with small distributions has to be reconsidered, as we will do in this paragraph. Which of the biotypes we mentioned above when sketching the four main problems should be described, and which should be left aside?

As is clear from the above, the biggest problem in Rubus taxonomy are swarms of only partially-stabilised brambles in the central and west European mountains, mainly belonging to the series Glandulosi and Hystrix. Within these swarms, stabilised apomict biotypes with large enough distribution areas are actually recognised as species, like $R$. guentheri en $R$. nigricatus (Kurtto et al. 2010). However, it is unclear even approximately which percentage of these groups consist of stabilised apomicts with only a local distribution, and what is the percentage of sexual forms and primary hybrids. What is the rate of backcrossing and how much of the hybridogenic derivates stabilise through apomixis? Although it might seem a Sisyphean labour, Rubus taxonomy has to unravel the internal structure of these groups as well as the causes of the variation within these swarms to identify the separately evolving lineages, which should be described as species. This includes the locally distributed apomicts, as well as the sexual cores of these swarms. Clearly a phenetic approach alone won't solve these problems, and DNA analyses are needed to unravel the systematics of this group, for instance by DNA fingerprinting 
(Nybom \& Schaal 1990; Nybom \& Kraft 1995; Nybom 1996). Also Holub (1997) advocated a further study of these groups, contrary to common belief that they could better left aside.

The second problem is formed by the variation which is found in widely distributed species. Dealing with this variation, at least a part of it appears to arise accidentally and independently from place to place. This is to be concluded from the distribution patterns of these "variants": whereas stabilised apomicts build up coherent distribution areas independent from the areas of their putative relatives, the meant "variants" are just found scattered in the distribution range of the principal species. They have no independent, nor a coherent distribution area. An example is Rubus scissoides which was considered to be a subspecies of $R$. nessensis (as subsp. scissoides) by Weber (1986b) before it was raised to species level; apparently Weber considers this taxon to be a cohesive and stabilised apomict. During our years of field work we never encountered $R$. scissoides in a coherent distribution area, and also Van der Beek (2011) questioned the status of this taxon. Only if such forms evolve independently from their putative parent do they deserve recognition as a separate species. Otherwise, formal description should be renounced.

The simplest of the problems mentioned are the primary hybrids: as in other genera, they just have to be treated as such. They are not considered on the species level, although they can be named with a binomial (like $R$. xpseudoidaeus). Ryde (2011) showed that these hybrids can well be distinguished from locally distributed stabilised biotypes on the basis of both morphological characteristics and chromosome counts. Only if the new form is stabilised by apomixis do they deserve to be described formally, but in such cases one wouldn't speak of hybrids anymore, but of locally-distributed apomictic biotypes. As argued above, there seem to be no scientific grounds to exclude these from our taxonomy, as was practised by Van de Beek (1974) in his dissertation already, and more recently by Loos (1998) and Ryde (2011). The existence of unstabilised swarms, intraspecific variation, as well as hybrids must prevent every batologist from describing new species too lightly though. A natural classification should reflect the structure of the genus, and the task for systematic biologists working on Rubus is to describe natural entities we call species, and not merely every possible variation under the species heading. Thus a profound understanding of the processes causing variation in Rubus subgen. Rubus is necessary for a significant systematic treatment of this complex group. In practice, there remains the question of how to distinguish stabilised biotypes from the multitude of singular forms which are the result of hybridisation and backcrossing, like those described by Maurer (1994). In this respect, bramble taxonomists ought to follow the recommendation by Holub: "... the description of a new species of brambles should follow after a somewhat longer study." Such a restrained attitude should prevent batology 
from falling back into a situation in which every possible bramble form is given a name, a situation to which the Weberian Reform with the pragmatic species approach brought the necessary overview, with great benefit.

\section{Conclusions}

From the above, we conclude that there are no sound scientific grounds for demanding a minimum distribution area when describing species, be it in amphimictic or apomictic genera. The pragmatic species concept used in contemporary Rubus taxonomy has been very useful for a first sorting of apomictic brambles in Europe, but now it hampers a full view of the species richness within the genus. When facing the problems in Rubus systematics, we think that all independently evolving lineages should be described as species. This includes apomictic lineages with very small distribution ranges from the mountain dwelling glandular series, as well as such lineages from the lowlands. Neither primary hybrids (which are not stabilised by apomixis), nor biotypes without an independent and coherent distribution area (which seem to originate rather erratically from wider distributed species) are independently evolving lineages, and should thus not be described as species. Of course, in supra-national or other larger overviews, species with limited distribution areas have not necessarily been taken into account but in smaller overviews and local floras, there must also be the possibility of describing the local species, so as to get a full account of local biodiversity. 


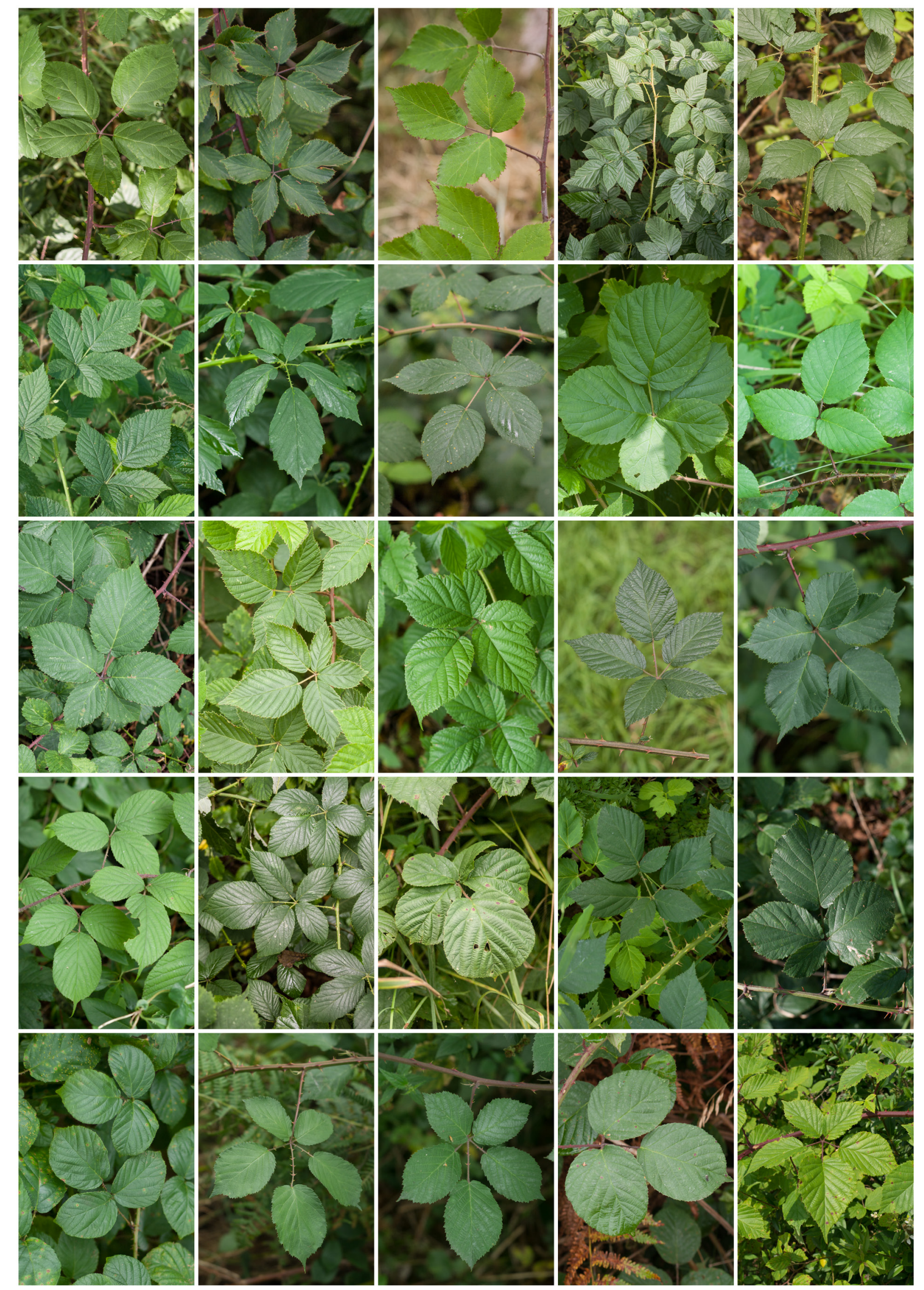


CHAPTER 4

Checklist and distribution data of Dutch brambles

(Rubus L. subgenus Rubus)

Translated and modified from:

Van de Beek, A., R.J. Bijlsma, R. Haveman, K. Meijer, I. de Ronde, A.S. Troelstra \& E.J. Weeda, 2014. Naamlijst en verspreidingsgegevens van de Nederlandse bramen (Rubus subgenus Rubus) - Gorteria 36: 108-171. 


\section{Abstract}

The taxonomy and distribution of brambles (Rubus L. subgenus Rubus) in northwestern Europe are well-known due to herbarium studies and extensive field work from the 1970s onwards. Most brambles are stabilized apomictic species that form fruits without fertilization. Therefore, offspring is genetically identical with the mother plant. In the Netherlands, the study of brambles didn't start until 1900, with a relatively active period after World War II. This resulted in the publication of the Rubi Neerlandici by W. Beijerinck in 1956, an overview based on the artificial species concept of $\mathrm{H}$. Sudre (Rubi Europae; 1908-1913). Modern research, based on the study of type material supplemented with field work began in the 1970s and lead to the recognition of several newly described regional species as well as new names for misapplied species. Most bramble experts in Europe agree on a species concept that includes a geographic constraint: taxa with a range less than $50 \mathrm{~km}$ in diameter are not described as species. We adhere to this concept too. The Dutch checklist of subgenus Rubus comprises 191 species in 4 sections: Rubus ('Rubus fruticosus agg.'; 147 species), Corylifolii ('Rubus corylifolius agg.'; 34 species), Caesii (2 species) and Subidaei (8 species). The latter section includes stabilized species with Rubus idaeus as an ancestor. Nomenclatural aspects of the Dutch taxa and the description of some new Corylifolii-taxa are dealt with in accompanying papers. All taxa on the checklist are provided with Dutch names, including sections, subsections and series. Since range size is taxonomically important, this feature has been classified and assigned to each species as W1 (very widespread; range diameter > $1500 \mathrm{~km}$ ), W2 (widespread; 500-1500 km), R2 (supraregional; 250-500 km) or R1 (regional; 50-250 km). The Dutch checklist contains 97 regional species (51\%); only 32 species $(17 \%)$ are very widespread. All digitally available distribution data for species of Rubus subgenus Rubus (excluding Rubus caesius) are included in a database, currently with about 43,000 records including 37,000 with an accuracy of at least one kilometre. National rarity of species (Rubus caesius excluded) has been coded according to Dutch red list criteria based on the number of occupied $5 \times 5 \mathrm{~km}$-squares. Almost 80 species are nationally very rare, 60 rare, 25 rather rare and about 20 rather common or common. Very common species are absent within the section Rubus, which is not only caused by the high contribution of regional species but also by the absence or low frequency of brambles on clay and peat soils in the western and northern part of the country. Hotspots of species richness with more than 40 species per $5 \times 5 \mathrm{~km}$ square occur in old woodland landscapes in physiogeographic gradients with sandy and loamy soils. The national species richness from a European point of view, the high numbers of regional species and the occurrence of hotspots of bramble diversity emphasize the central position of the Netherlands within the (sub-)Atlantic range of brambles in Europe. 


\section{Introduction}

In north-west Europe, the taxonomy of brambles is clarified to a great extent (Weber 1995), their distribution is well known (Kurtto et al. 2010), for many species ecological indicator values are available (Weber 1991), and brambles are explicitly taken into account in vegetation classifications (Weber 1997, 1998a; Haveman et al. 1999a; Haveman et al. 1999b; Weber 1999b; Haveman et al. 2012). However, the attitude of most field botanists, phytosociologists, and ecologists hasn't been changed much since Van de Beek (1976) typified it as a love-hate relationship. This attitude might be contributed to their thorniness and alleged indicator value for nitrification and disturbance. Another factor is the lack of an up-to-date checklist of the Dutch species. This paper satisfies this need: it gives a list of all bramble species known from the Netherlands belonging to both the Rubus fruticosus and the $R$. corylifolius aggregate.

The Netherlands is lying in the centre of bramble diversity in (sub-)Atlantic Europe (Kurtto et al. 2010), which is expressed in the strong regional species differentiation unique for the genus. We believe that the existing distribution patterns find their origin in the differences in historical geography, in combination with the ecological demands and tolerances of the bramble species. The contribution of brambles to the regional identity of landscapes is significant. We hope this checklist will serve as an onset to the wondering over, and more research into this contribution.

\section{Species concept}

Rubus is one of the largest genera of the Dutch flora, and it is considered one of the more difficult groups by most botanists. Only a minor part of the species, like Rubus idaeus and $R$. caesius, reproduce sexually. Most Dutch and European brambles form part of a polyploid apagamous complex (Weber 1995; Kurtto et al. 2010) which probably was formed only after the last glacial period (Matzke-Hajek 1997). The many stabilised apomicts in Rubus subgen. Rubus reproduce by facultative diplospory (Asker \& Jerlings 1992), a form of apomixis in which seed is formed from without fertilisation and recombination. The offspring of such apomictic plants are genetically identical to the mother plant. New combinations of characters can arise after the pollination of a sexual species with the pollen of an apomict, or occasionally when two (facultative!) apomicts cross. Hybrids partly reproduce sexually (Lidforss 1905, 1907; Werlemark \& Nybom 2003), but new forms can stabilise through apomixis, as was confirmed for the apomictic Swedish $R$. vestervicensis (Kraft et al. 1995), which originated from a crossing between the morphologically radically different $R$. grabowskii and $R$. bellardii. The apomict lineages are usually described as species (but see below for restrictions). DNA fingerprinting has shown that apomict Rubus lineages usually consist of only one genotype, even in the case of such widespread species as $R$. nessensis (Kraft \& Nybom 1995; Kraft et al. 1996). This suggests that one singular recombination event forms the 
starting point for every new apomictic species. Deviant banding patterns are probably the effect of somatic mutations, but the studied plants could not be distinguished on morphological grounds (Kraft et al. 1996).

From the above, it is understandable that bramble taxonomy has gone a long and winding road (see History). In modern (European) batology a pragmatic species concept is used, in which distribution area plays an important role (see Haveman \& De Ronde 2013 for a review; see also the paragraphs on History and Method). Apart from sexual bramble species, like Rubus caesius and R. ulmifolius, also stabilised apomictic lineages are treated as species, in case their distribution area has a diameter of at least $50 \mathrm{~km}$. Although species with a smaller distribution area can be very prominent in the landscape, they are usually not treated as object for a formal description. An example is formed by a biotype which is very common in the area of the Ratumse Beek north of Winterswijk (Rubus ceratus nom. prov.), which was depicted by Beijerinck (1956) as Plaat 43. Although more recently it was criticised by several authors (Hörandl 1998; Loos 2008; Haveman \& De Ronde 2013), in this checklist we use this pragmatic species concept, and we include only two local species.

\section{History of bramble taxonomy in NW-Europe and the Netherlands}

In his Species Plantarum, Linnaeus (1753) described only one species belonging to Rubus subgen. Rubus, viz. $R$. fruticosus $\mathrm{L}$. In the subsequent decennia several more species were described sporadically, but a systematic treatment was only published about 70 years later by Weihe \& Nees von Esenbeck (1822-1827). These authors are the first who stressed not only the diagnostic value of the panicles, but also of the first-years primocanes and leafs. Although their work was published under the pretentious name Rubi Germanici, most of the work was done around the domicile of Weihe, Menninghüffen in the Central-Weser area, and several of their species were restricted to only one location.

A broader treatment was given in the collection of exsiccata by P. Wirtgen from the Rhineland around Koblenz (Wirtgen 1854-61), and the description of brambles from several regions by P.J. Müller from Weissenburg, in the Alsace. Müller described the brambles from his own region (Müller 1858, 1859), as well as from Gérardmer (Müller 1861) and Forêt de Retz near Viller-Cotterets (Müller 1859), from where he received herbarium material collected by L.V. Lefèvre. He described dozens of species, many of which have a very limited distribution only. Müller was the first who applied sections within the subgenus. His work was persued by N. Boulay, who distributed collections of exsiccata from France, Belgium and Denmark, under supervision of Müller (Boulay 1864-1869). Later he worked independently, in cooperation with others (Boulay 18731894; Boulay \& Bouly de Lesdain 1895-1897). 
A refined arrangement in series was published by Focke (1877), who reduced the number of species described by Müller, using morphological and distribution area characteristics, and he rejected many local species of Weihe and Müller, thus creating a manageable overview. The basic ideas of his work still play an important role in contemporary Rubus taxonomy. In his later works, Focke $(1877,1902-1903)$ presented not only a detailed classification, but he also tried to implement a theory on the origin of species in his taxonomical treatment. He supposed that Rubus could play a key role in the theory on speciation, and tried to implement a dynamic species concept by using ranks like 'prospecies' - taxa on their way to species. With that, the overview lost the initial clarity, and as a result Focke's later works have had less influence.

Continental batology in the twentieth century was influenced heavily by the work of H. Sudre from Albi in Southern France, who comprised all known data on Rubus from Europe in one publication (Sudre 1908-1913). However, the result of his work is merely only a database. Sudre ranked all taxa under 109 principal species, which are subdivided in subspecies, microgenera, varieties, and formae, thus creating a completely artificial system. Closely related species often appear in very remote places in the system and taxa growing in complete different regions in Europe were described as varieties of one microspecies. As was described by Van de Beek (1988), Sudre's monograph made the identification of bramble species ultimately cumbersome: every new bush had to be identified separately, and bushes clearly belonging to one and the same species were often identified as different species because of minor morphological anomalies. The wide adaptation of Sudre's 'batological bible' brought batology in a blind alley and caused a longer period of stagnation (Haveman \& De Ronde 2013).

On the British Isles, Rubus taxonomy followed a more independent route. The first British botanist working on Rubus was J. Lindley. He was more reserved in publishing local species than continental batologists (Lindley 1829), and this approach was followed by the nineteenth century authority on Rubus taxonomy in England, C.C. Babington (1846, 1869). Babington's work was continued by W. Rogers, who corresponded with Sudre and exchanged material with the French batologist, but never adopted his artificial system. His Rubus monography (Rogers 1900) is exemplary, in a time where on the continent splitting was fashionable. Consequently, British batology didn't suffer from the stagnation caused by Sudre's pseudo-taxonomy. From the 1930-s onward, W.C.R. Watson studied original material, and he worked according to the type method and applied valid nomenclatural rules throughout his work. His monography was published posthumously (Watson 1958).

On the continent, a new phase started with the publication on the brambles of SleswigHolstein by H.E. Weber (1972). In this and numerous later publications, Weber critically 
examined original material and included phytogeographical aspects. In 1974, A. van de Beek published his dissertation on the brambles of the Gueldrian flora district in the Netherlands (Van de Beek 1974). He is the first who consequently designated types and strictly applied nomenclatural rules. In his dissertation, Van de Beek reintroduced the geographical division of species which was developed by Focke. Van de Beek still described locally distributed species, because scientifically there are no reasons to reject such species. For practical reasons, later authors used the above described pragmatic species concept (see the Species concept paragraph). From that moment on, critical Rubus taxonomy relies on a geographical evaluation of species, a strict application of the type method and nomenclatural rules, for instance in the monographs by Weber (1981b, 1986b, 1995) and in manifold papers by him and other authors (e.g. E.S. Edees, A. Newton, A. van de Beek, A. Pedersen, and G. Matzke-Hayek).

In the Netherlands, Rubus research had a late start. Only around 1900, L. Vuyck and A. de Wever worked on Rubus, using the natural classification of Focke. This system was applied in the first editions of the Heukels' Floras (Heukels 1900, 1909, 1922). A completely different approach was published by W.W. Schipper (1925). In the footsteps of several German authors, like O. Kuntze (1867), Schipper considered most taxa as (multiple) hybrids of only a few primary species. Luckily, this speculative route was abandoned after a short time. Only after WWII Rubus got renewed attention, in the persons of J.H. Kern and Th. J. Reichgelt from Nijmegen. They collected many specimens in a well-cared herbarium and tried to identify brambles in the tradition of De Wever and British batologists. However, they experienced many problems, as many taxa from the Netherlands didn't fit the descriptions of species from other regions. Therefore, W. Beijerinck, assisted by A.J. ter Pelckwijk, started a research project to critically treat the Dutch brambles. This work resulted in a monography of Dutch brambles (Beijerinck 1956), which actually was a step backwards as Beijerinck based his work on the Sudre's artificial system. In his treatment of the genus for the fifteenth edition of the Heukels' Flora, Reichgelt (1962) again adopted the natural method of De Wever, but still many taxa were not satisfactory identifiable with the existing literature. To gain clarity, J.H. Kern, F.M. Muller, and A. van de Beek, under direction of S.E. de Jongh, studied the genus extensively, using the monography of Sudre as sole source. The results of this research project is published in three typed books without taxonomical value (De Jongh 1971; Van de Beek et al. 1972b, a).

Around 1970, F.P. Jonker (Utrecht) stimulated Van de Beek to start a doctoral study of Rubus in the Netherlands. This resulted in the earlier mentioned dissertation by Van de Beek (1974). It can be seen as a modest begin of modern batological research in the Netherlands, although still many nomenclatural problems in older literature were not understood, and many names were misapplied. Only through the commitment by 
Weber in the succeeding years, international Rubus taxonomy reached its current level (Haveman \& De Ronde 2013), with the publication of the Rubus volume of the Atlas Flora Europaea (Kurtto et al. 2010) as (temporary) summit.

\section{Method}

\section{Taxonomy}

The realisation of the current standard list of Dutch brambles was preceded by a long period of inventories and field and herbarium studies. From the 1970s, systematic research has been carried out to get acquainted with the bramble species in the Netherlands and to identify them with already described species when possible. Unidentifiable species were described if they met criteria of the above mentioned pragmatic species concept. What was left were well-defined taxa which did not meet this criterion, as well as plants which differed from described species but which seem to be rather weak defined, especially in the section Corylifolii and in the glandular series like the Glandulosi. Further study and reflection is necessary to decide how these groups should be treated taxonomically (see also Haveman \& De Ronde 2013).

Most bramble species occurring in the Netherlands are considered to be indigenous, although some naturalised introduced species are included in the check list. From these, Rubus armeniacus can be considered as invasive, especially in the western part of the country which is devoid of indigenous bramble species. Apart from $R$. armeniacus, only some cultivated American species, as well as the lacinate form of $R$. nemoralis are included. It remains the question how long these introduced species will persist whenever their cultivation will come to an end.

The realisation of this list is based primarily on fieldwork done by all authors of the list, consisting of mapping projects and phytosociological inventories. During this field work thousands of herbarium collections are made, which are stored in the private herbaria of the authors mainly; only the herbaria of Bijlsma and Van de Beek are stored in public herbaria (WAG, and $\mathrm{L}$ respectively). Rubus collections in all Dutch herbaria were examined, containing the herbaria of amongst others A. de Wever (MAAS, esp. South-Limburg), J.L. van Soest (L, esp. Den Haag and Arnhem), J.H. Kern and Th.J. Reichgelt (L., Nijmegen and surroundings), W. Beijerinck and A.J. ter Pelckwijk (WAG, Drenthe and South-Limburg), F.M. Müller (L, country wide), and S.E. de Jongh (L.).

To understand the relation of the Dutch bramble flora with the Rubus flora of the adjacent countries, we corresponded with colleagues abroad, mutual herbarium material was examined, and collective excursions were arranged. Close contact was established with the German batologists H.E. Weber and G. Matzke-Hajek, and with the late A. Oredsson (Sweden), A. Newton (United Kingdom), D. Mercier (France), H. Vannerom, 
and the late E. Jacques and brother J. de Ruyver (all Belgium), as well as with the staff (esp. R. de Clercq) of the bramble garden at Schorisse (Belgium).

The first author visited many foreign herbaria in the search for type material, and many comparisons were made with herbarium material, especially with the very large collection in Paris (P). During these visits thousands of photos of herbarium material were made, amongst which original collections. Field work on many classical collection sites has contributed significantly to the knowledge of species and their variation. This fieldwork was not restricted to the directly adjacent regions, but also South-France (Tarn, Pyrenees, and Grenoble) and Italy (Bologna) were visited.

In this checklist, nomenclatural issues are resolved according to the International Code of Botanical Nomenclature (Vienna Code, see McNeill et al. 2007), except for a few well established names of widely distributed species for which older synonyms are available. Yet the validity of these synonyms has to be proven and probably it is better to propose conservation of the currently accepted names. Nomenclature of Rubus is full of pitfalls, and the first purpose of the Code is stability after all. Many older, mainly $19^{\text {th }}$ Century publications do not fulfil the demands of the Code, or, even worse, are borderline cases. The advises of J.F. Veldkamp were essential in taking the right decisions in many nomenclatural problems. An explanation of the decisions in taxonomical and nomenclatural issues is published separately by Van de Beek (2014b).

\section{Vernacular names}

In the original version of this checklist (Van de Beek et al. 2014), all taxa, including the (sub)sections and series, are given Dutch vernacular names. Within Rubus subgen. Rubus, 4 sections are distinguished: Rubus, Corylifolii, Caesii and Subidaei (Van de Beek 2014a). Section Corylifolii comprises the putative hybrids between $R$. caesius and biotypes from the section Rubus, which might or might not be stabilised by apomixis. The Subidaei comprise apomict lineages in which $R$. idaeus is supposed to be one of the ancestors. The series are given vernacular names on the basis of conspicuous features, and vernacular species names (omitted from this English version of the check list, Appendix 1) are variations on these sectional names.

\section{Descriptions, figures and synonyms}

For all listed species, references to reliable descriptions and figures are given in the original publication of this checklist (Van de Beek et al. 2014). For the Dutch situation, Rubi Westfalici (Weber 1986b) and the bramble volume of Hegi's Illustrierte Flora von Mitteleuropa (Weber 1995) are important comprehensive reference works in which determination keys are published. Good illustrations are to be found in Rubi Neerlandici 
(Beijerinck 1956). Several regional Dutch species are missing in these works though, and in the original version of this paper figures of these species are included.

We have been reticent to include synonyms in the original publication of the checklist (Van de Beek et al. 2014). Only names in the various editions of the Flora van Nederland and those used in recent literature are included (Table 4.1). An elaborate overview of accepted species names and synonyms is given by Kurtto et al. (2010).

Table 4.1. Most important synonyms of Dutch bramble species

\begin{tabular}{|c|c|}
\hline Synonym & Valid name \\
\hline R. aurora A.Beek, Bijlsma \& Muller & R. holerythros \\
\hline R. badius Focke & $R$. glandithyrsos \\
\hline$R$. candicans Weihe & R. montanus \\
\hline R. carpinifolius Weihe & R. adspersus \\
\hline R. ciliatus Lindeb. ex F.Aresch. & R. camptostachys \\
\hline R. contractipes H.E. Weber & R. calvus \\
\hline R. corymbosus P.J.Müll. & R. foliosus \\
\hline R. glandulosus Bellardi & R. bellardii \\
\hline R. inermis Pourret & R. ulmifolius \\
\hline R. laciniatus Willd. & R. nemoralis f. laciniatus \\
\hline R. laetus A.Beek & R. frederici \\
\hline R. mucronifer Sud. & R. mucronulatus \\
\hline R. nessensis Hall subsp. scissoides H.E.Weber & R. scissus \\
\hline R. obscurus Kalt. & $R$. cinerascens \\
\hline R. ochroacanthus H.E. Weber \& Sennikov & R. scissus \\
\hline R. pedemontanus Pinkwart & R. bellardii \\
\hline R. pseudoidaeus Weihe ex Lej. \& Courtois & $R . \times$ idaeoides \\
\hline R. pubescens Weihe & R. chloocladus \\
\hline R. pyramidalis Kalt. & R. umbrosus \\
\hline R. thyrsanthus Focke & R. grabowskii \\
\hline R. tuberculatus Bab. & $R$. horrefactus \\
\hline R. vigorosus Wirtg. & R. affinis \\
\hline R. viridis Kalt. & R. iuvenis \\
\hline
\end{tabular}

\section{Distribution data}

For the analysis of the Dutch distribution of Rubus species, an Access database is made with all available digitized data. Included are a.) data on $5 \times 5$ square $\mathrm{km}$ basis collected by Van de Beek in which also data collected by Bijlsma, Meijer, Troelstra, and Haveman is included (ca. 6,000 records), b.) data on square $\mathrm{km}$ to square $\mathrm{hm}$ basis (and from 2002 on square $\mathrm{m}$ basis) collected by Bijlsma and Troelstra (ca. 25,000 records), and c.) vegetation relevé data from the Dutch ministry of Defence, completed with data collected by Haveman and De Ronde (ca. 6,000 records). Several important sources are not included completely yet, like the collection in the Dutch National Herbarium (L) 
and the private herbaria of Meijer and Haveman. This shared database is managed by R.J. Bijlsma.

Rarity of all Dutch species of Rubus subgen. Rubus (excl. $R$. caesius) is determined on the basis of the number of $5 \times 5 \mathrm{~km}$ grid cells of the Dutch national grid, which is commonly used in flora and fauna inventories. To correct for observation intensity we followed the procedure in Aptroot et al. (2012). The Dutch grid comprises 1,674 (partly) terrestrial grid cells. In the clay areas, only $R$. caesius and the naturalised Rubus armeniacus are found, so these areas are excluded from the potential distribution area of native brambles. This resulted in a total potential distribution area of 1,247 grid cells. We calculated a correction factor from the distribution area of the 4 most frequent species in our database, viz. R. gratus, $R$. plicatus, $R$. nessensis, and $R$. affinis. In 858 of the 1,247 grid cells of the potential distribution area of brambles at least one of these species is recorded, which gives a correction factor of $1,247 / 858=1.45$. We assumed an even underrepresentation of all species in the database. For every species, $1.45^{*}$ (known number of grid cells in the database) is compared with the threshold for national distribution frequency classes (table 4.2). In the original Dutch version of this checklist (Van de Beek et al. 2014), for every species also the rarity in the various flora districts (Weeda 1989) was published.

Table 4.2. Dutch national frequency classes with absolute number and procentual thresholds of $5 \times 5$ $\mathrm{km}$ grid cells used in flora and fauna inventories.

\begin{tabular}{lrr}
\hline Frequency class & Number & \% (upper threshold) \\
\hline zzz: very rare & $1-16$ & 1 \\
zz: rare & $17-83$ & 5 \\
z: moderately rare & $84-209$ & 12.5 \\
a: moderately common & $210-553$ & 33 \\
aa: common & $554-1,259$ & 75 \\
aaa: very common & $1,260-1,674$ & 100 \\
\hline
\end{tabular}

Distribution area diameter is considered a rough measure of the age of bramble species (Matzke-Hajek 1997). Besides, Matzke-Hajek (1993) concluded that species with a regional distribution area seem to have a wider ecological amplitude than species with a wider distribution area. Therefore we included a code for the order of magnitude of the distribution areas of all species (Table 4.3), based on the thresholds given in Kurtto et al. (2010). Hereby, the commonly accepted category "widely distributed" is subdivided in "widely distributed" (distribution area 500-1,500 km) and "very widely distributed" (distribution area $>1,500 \mathrm{~km}$ ), and a new category is inserted for the species with a distribution area of 250-500 km ("supraregional"). These codes are derived from the 
Table 4.3. Distribution area categories

\begin{tabular}{lll}
\hline Code & Description & $\begin{array}{l}\text { Distribution area } \\
\text { diameter }(\mathbf{k m})\end{array}$ \\
\hline W1 & indigenous: very widely & $>1500$ \\
W2 & indigenous: widely & $500-1500$ \\
R1 & indigenous: supraregionally & $250-500$ \\
R2 & indigenous: regionally & $50-250$ \\
L & indigenous: locally & $<50$ \\
V & escaped & \\
\hline
\end{tabular}

maps in Kurtto et al. (2010) on the basis of the major distribution centres of the species concerned, disregarding the distribution outliers.

\section{Results and conclusions}

The taxonomical checklist with distribution frequency classes for the Netherlands is given in Appendix 1 at the end of this chapter. Listed are 191 species: 147 species of section Rubus, 34 species of section Corylifolii, 2 species of section Caesii, and 8 species of section Subidaei.

In the comprehensive overview by Kurtto et al. (2010), about 700 bramble species are listed and mapped. Compared to the Netherlands, only in Germany (400 species), Great Britain (more than 300 species), France and probably in Belgium more species are found (Kurtto et al. 2010). This is an illustration of the unmistakable (sub-)Atlantic-temperate distribution of Rubus subgen. Rubus, and the position of the Netherlands in the centre of diversity of this agamic complex. Also the ratio of regional species compared to widely distributed species is an indication thereof: almost 100 species have a regional distribution area (50-500 $\mathrm{km}$ in diameter) against only about 30 very widely distributed species (fig. 4.1). Strictly spoken, some species are endemics for the Netherlands, but we expect that these species will turn out to be present in Germany too, like $R$. erinulus and $R$. vadalis.

The number of relatively rare species is remarkable. Only 22 species are common; very common bramble species are lacking (fig. 4.1), due to the scarcity of brambles in peat and clay regions. A small number of nationally rare species are common in specific flora districts: Rubus discors in the Drenthian district, $R$. calothemnus in the Campine district and $R$. iuvenis, $R$. pugiungulosus, and $R$. rosaceus in the South-Limburg district (see Weeda 1989 for the floradistricts). The variation in distribution areas is exemplified in figures 4.2 and 4.3 for a selection of species. 
Hotspots of species diversity - grid cells with more than 40 species - are found in old woodland landscapes with transitions of glacial material, cover sands, or terrace material to loam, old river clays, or löss: Oude IJssel region (Hoog Keppel/Hummelo (cell 40.17), 51 species), Liemers region ('s Heerenberg (cell 40.47), 48 species), Nijmegen area (Groesbeek/Mook/Plasmolen (cell 46.23), 48 species), and Beek/Ubbergen/Berg en Dal (cell 40.53), 44 species), Winterswijk area (cell 41.26, 43 species), Veluwezoom region (Rheden/Velp (cell 40.17), 43 species), South Limburg (Epen/Vijlen (cell 62.43), 42 species), and the Twente region (Oldenzaal/De Lutte (cell 29.41), 42 species). These patterns, as well as the ecological amplitudes of brambles will be analysed elsewhere.
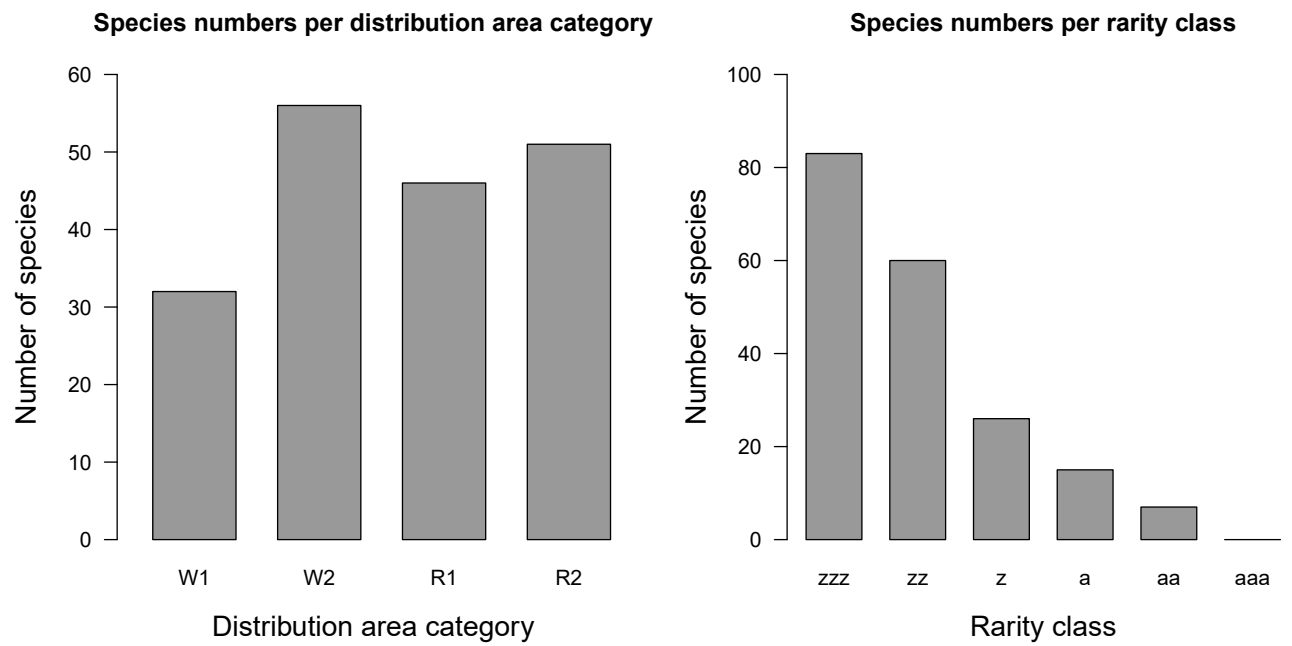

Figure 4.1. Number of bramble species (Rubus subgen. Rubus) in the Netherlands in different distribution area categories (left) and classes of rarity (right). W1 = very widely distributed; W2 = widely distributed; $\mathbf{R} 1$ = supraregionally distributed; $\mathbf{R 2}$ = regionally distributed (see also Table 4.3); $\mathbf{z z z}=$ very rare; $\mathbf{z z}=$ rare; $\mathbf{z}=$ moderately rare; $\mathbf{a}=$ moderately common; $\mathbf{a} a=$ common; $a a a=$ very common (see also Table 4.2). 


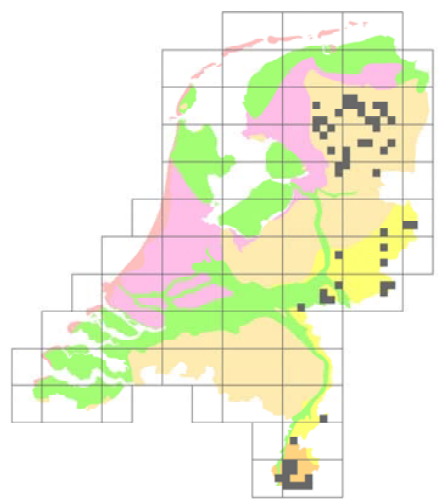

a

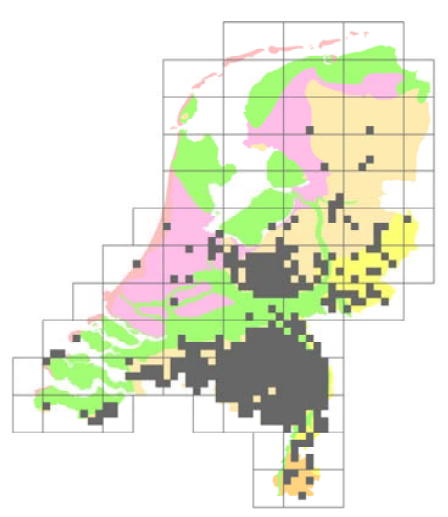

c

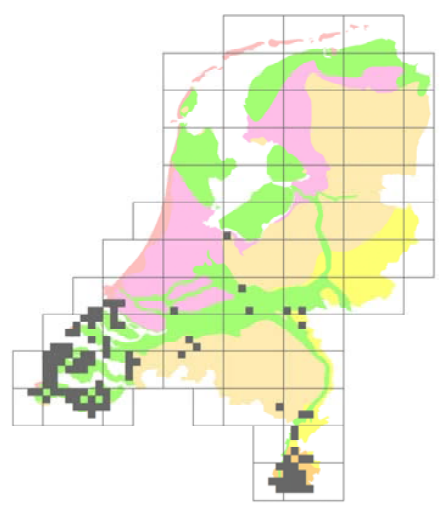

e

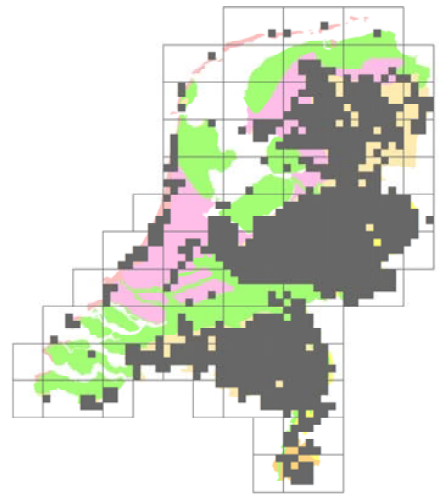

b

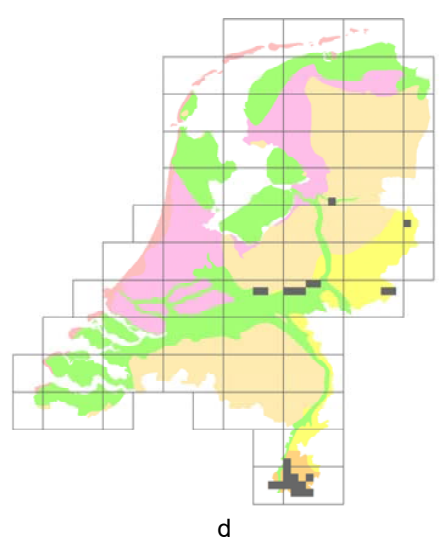

d

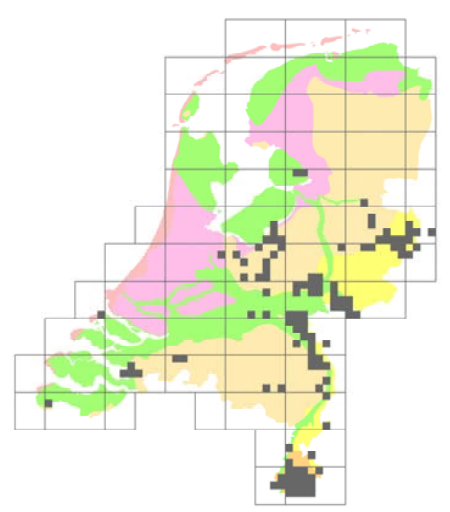

f

Figure 4.2. Distribution maps of a selection of very widely distributed Rubus species (distribution area category W1) in the Netherlands: Rubus bellardii (a), Rubus gratus (b), Rubus integribasis (c), Rubus raduloides (d), Rubus ulmifolius (e), and Rubus vestitus (f). 


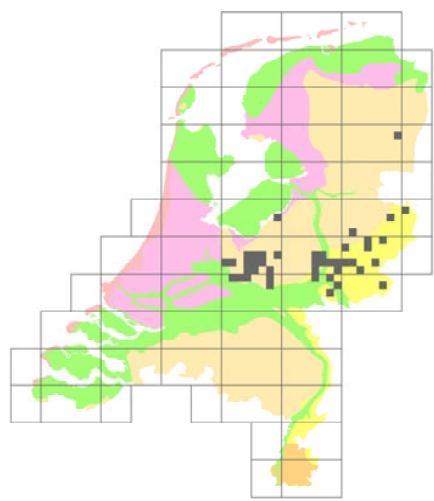

a

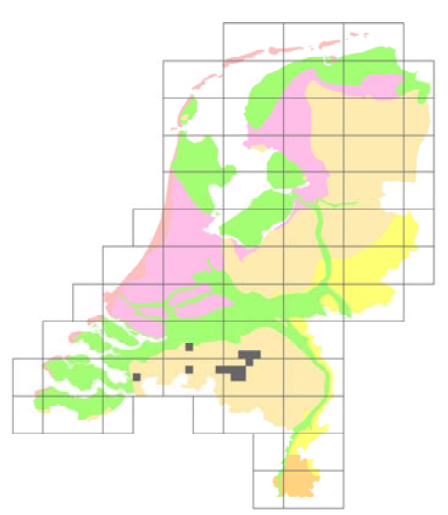

C

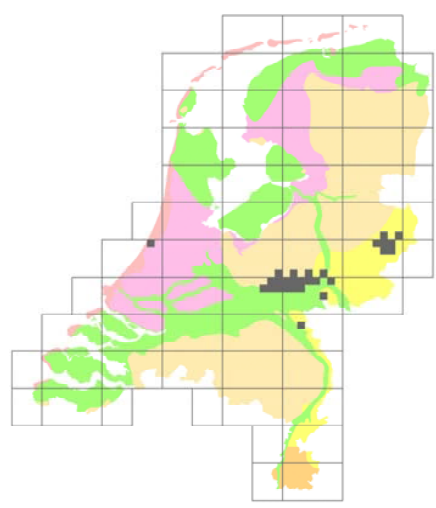

e

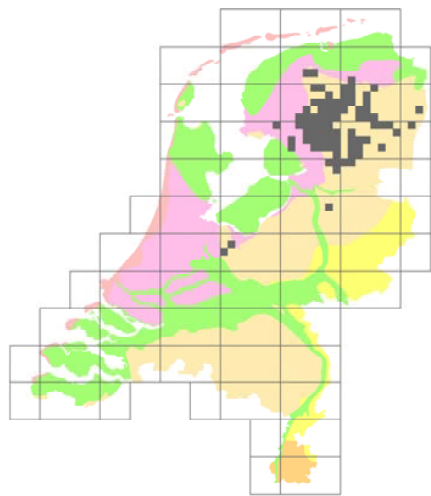

b

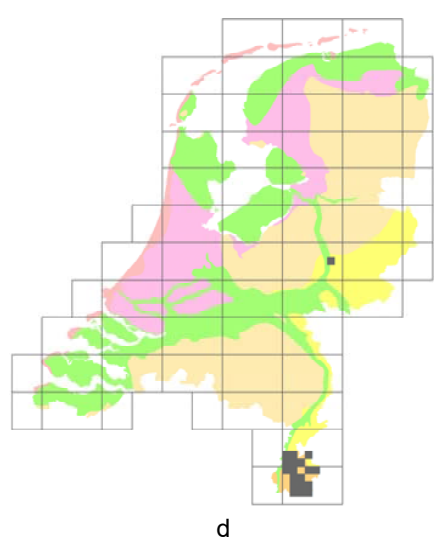

d

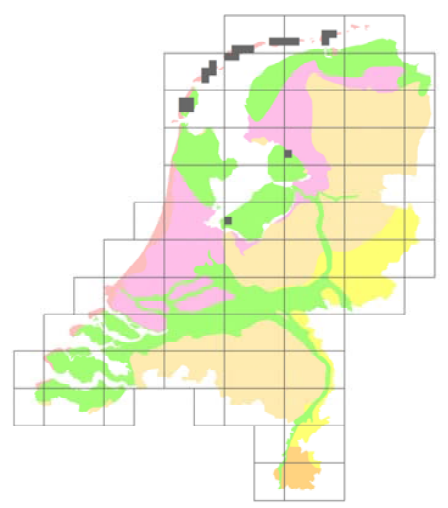

f

Figure 4.3. Distribution maps of a selection of regionally distributed Rubus species (distribution area category R2) in the Netherlands: Rubus bovinus (a), Rubus erinulus (b), Rubus gloriosus (c), Rubus rosaceus (d), Rubus trichanthus (e), and Rubus vadalis (f). 


\section{Appendix 1}

Annotated checklist of Dutch brambles (Rubus L. subgen. Rubus) with frequency data and distribution area characteristics. Within each series, the species are ordered alphabetically. Frequencies are given in numbers of $5 \times 5 \mathrm{~km}$ square grid cells of the Dutch national grid ('Amersfoort coordinates'). Rarity according to Table 4.2.

Taxon Frequency Rarity Distribution area

Genus Rubus L

Subgen. Rubus

Sect. Rubus

Subsect. Rubus

Ser. Alleghenienses (L.H. Bailey) H.E.Weber

Rubus allegheniensis Porter

2

Rubus alumnus L.H.Bailey

3

zZZ

V

$\mathrm{zzz}$

V

Ser. Canadenses (L.H. Bailey) H.E.Weber

Rubus canadensis $\mathrm{L}$.

5

zzz

V

Ser. Suberecti (Lindl.) Focke

Rubus ammobius Buchenau \& Focke

R1

Rubus nessensis Hall

Rubus scissus W.C.R.Watson

W1

Ser. Rubus

Rubus arrheniiformis W.C.R.Watson

45

Rubus bertramii G.Braun

75

W2

Rubus immodicus A.Schumach. ex H.E. Weber

1

W1

Rubus libertianus Weihe ex Lej. \& Courtois

5

Rubus planus A.Beek

36

Rubus plicatus Weihe \& Nees

Rubus sulcatus Vest

$\mathrm{R} 2$

36

R2

W1

Ser. Semisuberecti Focke

Rubus affinis Weihe \& Nees

490

W2

Rubus discors A.Beek

Rubus divaricatus P.J.Müll.

Rubus frederici A.Beek

Rubus holerythros Focke

20

Rubus integribasis P.J.Müll. ex Boulay

Rubus opacus Focke ex Bertram

Rubus senticosus Köhler ex Weihe

106

W1

Subsect. Apendiculati Genev.

Ser. Gypsocaulon (P.J.Müll. ex Sudre) W.C.R.Watson ex A.Beek 


\section{Ser. Candicantes Focke}

Rubus armeniacus Focke

Rubus canduliger Bijlsma \& Haveman

Rubus chloocladus W.C.R.Watson

Rubus geniculatus Kalt.

Rubus goniophorus H.E.Weber

Rubus grabowskii Weihe

Rubus lasiocladus (Focke) Foerster

Rubus montanus Lib. ex Lej.

Rubus nelliae A.Beek

Rubus phyllostachys P.J.Müll.

Rubus poliothyrsus A.Beek

Rubus procerus P.J.Müll. ex Boulay

Rubus spina-curva Boulay \& Gillot

Rubus winteri P.J.Müll. ex Focke

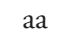

$\mathrm{ZZ}$

R2

W2

W2

$z Z z$

$\mathrm{R} 1$

W1

\section{Ser. Hayneani Tratt.}

Rubus adspersus Weihe ex H.E.Weber

Rubus amisiensis H.E. Weber

Rubus cardiophyllus Lefèvre \& P.J.Müll.

Rubus confusidens H.E. Weber

Rubus desarmatus A.Beek

Rubus edeesii H.E.Weber \& A.L.Bull

Rubus eglandulosus Lefèvre \& P.J.Müll.

9

Rubus elegantispinosus (A.Schumach.) H.E.Weber 49

Rubus gelertii Frid.

Rubus incarnatus P.J.Müll.

Rubus insularis Aresch.

Rubus langei Jensen ex Frid. \& Gelert

Rubus latiarcuatus W.C.R.Watson

Rubus lindebergii P.J.Müll.

Rubus lindleianus Lees

Rubus longior A.Beek

Rubus muenteri T.Marsson

Rubus nemoralis P.J.Müll.

Rubus nemoralis f. laciniatus (Willd.) A.Beek

Rubus neumannianus H.E. Weber \& Vannerom

Rubus platyacanthus P.J.Müll. \& Lefevre

Rubus scidularum A.Beek

Rubus scoliacanthus A.Beek

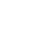

4

.

2

L

W1

R2

W1

R1

W1

W2

W2

W2

R1

W1

R2

R1

W2

R1

W2

R1

W2

W2

W2

R1

W2

W2

R2

W2

W1

V

W2

W2

R2

2

ZZZ

L 
Rubus stereacanthos P.J.Müll. ex Boulay

50

Rubus vadalis A.Beek

Rubus vulgaris Weihe \& Nees

22

1

$\mathrm{ZZ}$

$\mathrm{ZZ}$

ZZZ

Ser. Egregii (Frid. \& Gelert) Heukels

Rubus ceratifolius A.Beek

Rubus contritidens A.Beek \& K.Meijer

Rubus egregius Focke

Rubus erinulus A.Beek

Rubus laevicaulis A.Beek

Rubus polyanthemus Lindeb.

Rubus tubanticus A.Beek

Ser. Sylvatici (P.J. Müll.) Focke

Rubus braeuckeriformis H.E. Weber

Rubus calothyrsus A.Beek

Rubus chlorothyrsos Focke

Rubus macer H.E.Weber

Rubus silvaticus Weihe

\section{Ser. Piletosi (Genev.) Sudre}

Rubus adulans A.Beek

Rubus beijerinckii K.Meijer

Rubus gratus Focke

Rubus lasiandrus H.E. Weber

Rubus leptothyrsos G.Braun

Rubus leucandrus Focke

Rubus macrophyllus Weihe \& Nees

Rubus schlechtendalii Weihe ex Link

Rubus trichanthus A.Beek

\section{Ser. Sprengeliani Focke}

Rubus arrhenii (Lange) Lange

Rubus axillaris Lej.

Rubus sprengelii Weihe

$\begin{array}{cc}\text { zz } & \text { R2 } \\ \text { zz } & \text { R2 } \\ \text { zz } & \text { W2 } \\ \text { z } & \text { R2 } \\ \text { a } & \text { R1 } \\ \text { zz } & \text { W1 } \\ \text { zz } & \text { R2 }\end{array}$

W2

R2

W2

13

21

51

Ser. Vestiti (Chaboiss.) Focke

Rubus baronicus A.Beek

Rubus buhnensis (G.Braun ex Focke) G.Braun

Rubus cinerascens Weihe ex Lej. \& Courtois

Rubus conspicuus P.J.Müll.

Rubus crassidens H.E. Weber

Rubus eifeliensis Wirtg.

Rubus genevieri Boreau 
Rubus gloriosus A.Beek

Rubus guestphalicus (Focke) Utsch

Rubus umbrosus (Weihe \& Nees) Arrh.

Rubus rubrumcadaver A.Beek

Rubus splendidus P.J.Müll. \& Lefèvre

Rubus taxandriae Vannerom ex A.Beek

Rubus thalassarctos A.Beek

Rubus vestitus Weihe

\section{Ser. Nemorenses (Sudre ex Bouvet) Sudre}

Rubus condensatus P.J.Müll.

Rubus hypomalacus Focke

Rubus sciocharis (Sudre) Prain

\section{Ser. Grandifolii Focke}

$$
\text { Rubus dejonghii A.Beek }
$$

Rubus glandithyrsos G.Braun

Rubus neerlandicus A.Beek

\section{Ser. Mucronati (Focke) H.E. Weber}

Rubus bovinus A.Beek \& H.E.Weber

Rubus mucronulatus Boreau

Rubus prei (Sudre) Prain

\section{Ser. Anisacanti H.E. Weber}

\section{Rubus conothyrsoides H.E. Weber}

Rubus hastiferus H.E. Weber

Rubus siekensis Banning ex G.Braun

Rubus teretiusculus Kalt.

\section{Ser. Micantes Sudre}

Rubus raduloides (W.M.Rogers) Sudre

\section{Ser. Radula (T.B. Salter) Focke}

Rubus radula Weihe

Rubus rudis Weihe

Ser. Pallidi W.C.R. Waton

Rubus adornatus P.J.Müll. ex Wirtg.

Rubus calyculatus Kalt.

Rubus campaniensis Winkel ex A.Beek

Rubus caninitergi H.E. Weber

Rubus euryanthemus W.C.R. Watson

Rubus flexuosus P.J.Müll. \& Lefèvre

Rubus foliosus Weihe

Rubus fuscus Weihe

15

4

3

40

9

116
R2

R2

W1

W1 
Rubus glareosus W.M.Rogers

1

Rubus insectifolius Lefèvre \& P.J.Müll.

Rubus loehrii Wirtg.

Rubus pallidus Weihe

Rubus proiectus A.Beek

Rubus rufescens Lefèvre \& P.J.Müll.

8

\section{ZZZ}

ZZZ

$\mathrm{ZZ}$

ZZZ

ZZZ

$\mathrm{ZZ}$
W2

W2

W2

W1

W2

W2

\section{Ser. Feroces W.C.R. Watson}

Rubus distractus P.J.Müll. ex Wirtg.

1

Rubus diversus W.C.R. Watson

Rubus iceniensis A.Newton \& H.E.Weber

Rubus mucronipetalus P.J.Müll.

1

Rubus muridens A.Beek

Rubus schleicheri Weihe

$\begin{array}{cc}\text { zzz } & \text { W2 } \\ \text { zzz } & \text { W2 } \\ \text { zzz } & \text { R2 } \\ \text { zzz } & \text { R1 } \\ \text { zzz } & \text { R1 } \\ \text { zz } & \text { W2 }\end{array}$

Ser. Hystrix Focke

Rubus asperidens (Sudre \& Bouvet) Prain

Rubus dasyphyllus (W.M.Rogers) Marshall

Rubus henrici-weberi A.Beek

Rubus rosaceus Weihe

Ser. Glandulosi (Wimm. \& Grab.) Focke

Rubus bellardii Weihe

Rubus ignoratus H.E. Weber

Rubus iuvenis A.Beek

Rubus negatus A.Beek

Rubus oreades P.J.Müll. \& Wirtg.

Rubus picearum (A.Beek) A.Beek

Rubus praticolor A.Beek

$\mathrm{ZZ}$

W1

$\mathrm{R} 1$

W2

R1

$\mathrm{R} 1$

$\mathrm{R} 1$

\section{Sect. Corylifolii Lindl.}

\section{Ser. Suberectigeni H.E. Weber}

Rubus calotemnus A.Beek

Rubus cordiformis H.E.Weber \& Martensen

Rubus perdemissus H.E. Weber

Ser. Corylifolii (Lindl.) Focke

Rubus horridus C.F.Schultz

Rubus lobatidens H.E.Weber \& Stohr

Rubus mus A.Beek

Ser. Clivicola A. Beek

Rubus deweveri A.Beek 
$\underline{\text { Taxon }}$ Frequency Rarity

Rubus surrectus K.Meijer

17

Rubus vespicum P.J.Müll. ex Wirtg.

\section{Ser. Viatici H.E. Weber}

Rubus calviformis H.E. Weber

Rubus calvus H.E. Weber

Rubus camptostachys G.Braun

Rubus favillatus A.Beek

Rubus magnisepalus K.Meijer

Rubus nemorosus Hayne \& Willd.

Rubus paludosus A.Beek

Rubus placidus H.E. Weber

Rubus ubericus Matzk.

Rubus vanwinkelii A.Beek \& Vannerom

\section{Ser. Subcanescentes H.E. Weber}

Rubus foersteri Matzk.

Ser. Ferociores A. Beek

Rubus drenthicus A.Beek \& K.Meijer

Rubus ferocior H.E. Weber

\section{Ser. Vestitiusculi H.E. Weber}

Rubus neanias A.Beek

1

5

10

22

34

62

2

5

7

90

9

\section{$\mathrm{zZ}$}

ZZZ

111

362

238

Rubus griesiae H.E.Weber

Rubus horrefactus P.J.Müll. \& Lefèvre

Rubus pugiunculosus Matzk.

Rubus speculans K.Meijer

Rubus spiculus K.Meijer

Rubus vandermeijdenii A.Beek

7

2

20

16

18

4
R2

R1

R2

W2

W2

R2

R2

W1

R2

W2

R2

R1

R2

W2

R2

R1

W1

R2

R2

R2

R1

Ser. Hystricopses H.E. Weber

Rubus grandiflorus Kalt.

ZZZ

R2

Rubus histriculus H.E. Weber

Rubus luticola A.Beek

\section{Sect. Subidaei (Focke) A. Beek}

Rubus aphidifer A.Beek \& K.Meijer

Rubus coccinatus K.Meijer

Rubus inhorrens (Focke) Holzfuss

Rubus passionis A.Beek \& K.Meijer

Rubus phoenicacanthus A.Beek

Rubus pruinosus Arrh.

26 
$\underline{\text { Taxon }}$

Rubus rhytidophyllus H.E. Weber

Rubus schipperi A.Beek
Frequency

2

11
Rarity

Distribution area

Sect. Caesii Lej. \& Courtois

Rubus caesius L.

Rubus dumetorum Weihe
ZZZ

ZZZ

$\mathrm{R} 2$

R2
W1

zz R1



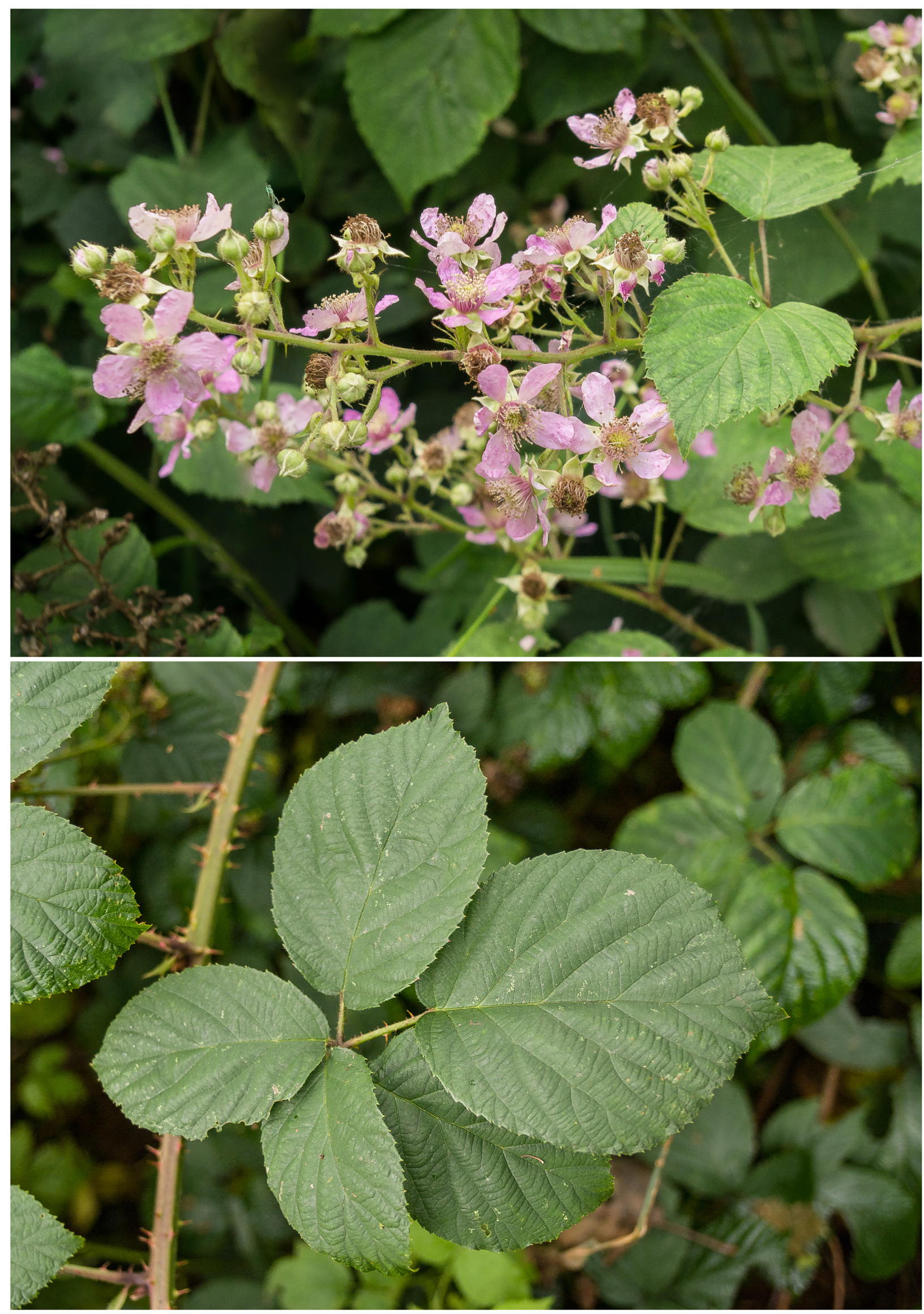
CHAPTER 5

Capricious, or tied to history's apron strings? Floristic regions in north-west European brambles (Rubus subgenus Rubus, Rosaceae)

Reprinted with permission from:

Haveman, R., R.J. Bijlsma, I. de Ronde \& J.H.J. Schaminée 2016. Capricious, or tied to history's apron strings? Floristic regions in north-west European brambles (Rubus subgenus Rubus, Rosaceae). - J. Biogeogr. 43: 1360-1371. 


\section{Abstract}

The goal of this paper is to classify and describe distribution patterns in apomictic Rubus subgenus Rubus in north-west Europe (Ireland, the United Kingdom, the Netherlands, Denmark and Germany) and to characterize the major regions by statistically derived character species. We used TWINSPAN analysis to distinguish hierarchically ordered phytogeographical regions using grid-based distribution patterns of bramble species, Dufrêne-Legendre indicator species analysis to define character species for the regions, and descriptive statistical analysis of broad-scale abiotic factors derived from the LANMAP landscape classification for each region. Grid cells were classified into 114 initial groups and 12 regions (florulas), forming three major bramble territories. Up to 15 indicator species could be assigned to each florula. The florulas in the British Isles are geographically isolated, unlike those on the continent. The florulas differ in minimum temperature in January, mean precipitation in August, and elevation. Although a clear view of the relationship between the bramble flora in the British Isles and the continental flora is obscured by the lack of data from Belgium and France, the major biogeographical patterns coincide with the genetic structure of the genus as published by Sochor et al. (2015). Other factors forming the basis for the observed patterns are isolation (especially in the British Isles), and arguably also landscape history and landscape patterns. We concluded that phytogeographical patterns in Rubus subg. Rubus are strongly influenced by historical factors and can be traced back to the hybridization of sexual Rubus ulmifolius, Rubus canescens and Rubus ser. Glandulosi especially. Geographical and ecological factors also play a role in the realization of large-scale patterns, but these factors seem to be closely tied to the history and genetic structure of the genus through inherited ecology from the ancestral species.

\section{Electronic appendix}

Additional Supporting Information may be found in the online version of this article: Appendix S1. Map of the initial Twinspan groups of Rubus occurrences. 


\section{Introduction}

For a long time, recurrent patterns in the distributions of plants have attracted the attention of naturalists. Two ways to study these patterns are the identification of floristic elements, groups of species with a similar distribution, and the description of floristic regions, areas characterized by a broadly similar flora (McLaughlin 1994; Finnie et al. 2007). These floristic phytogeographical approaches, essentially two sides of the same coin, provide spatially explicit frameworks for many fields of research $-e . g$. historical and ecological biogeography, systematics and evolutionary biology - but also for more applied questions, such as planning and conservation (Kreft \& Jetz 2010).

Floristic phytogeographical studies generally exclude apomictic groups in the genera Rubus, Taraxacum and Hieracium, often without explicit arguments (Andersson 1988; Preston \& Hill 1997; Dahl 1998). Reasons for their exclusion may include incomplete taxonomic knowledge, the absence of reliable distribution data, or simply the opinion that 'microspecies' are not real species and that their large numbers would influence the analysis in an unacceptable way. Other authors emphasize scientific opportunities for the study of biogeographical patterns in apomictic genera (Tyler 2000; Bijlsma \& Haveman 2007). Interestingly, the distributions of many apomictic species probably reflect different processes from those that operate in the ranges of amphimictic species. Many European vascular plant species remigrated from remote areas in the south or east during the Holocene, and their current ranges have no simple relationship with the areas where the species survived during the last glaciation (Dahl 1998). On the contrary, most apomictic species have to be regarded as neospecies in the sense of Levin (2000) and are supposed to have their origin in their current distribution areas and to be still in the phase of range expansion.

In this paper, we focus on Rubus L. subgenus Rubus (bramble) in north-western Europe. This is one of the largest apomictic complexes in Europe, with only a few sexual diploids and probably over 1000 apomictic polyploids. Weber (1995) estimated there to be 300-400 sexual Rubus species worldwide, fewer than 10 of which are found in western Eurasia. The main centres of diversity in the genus are south-east Asia, the Andes in South America, the coastal regions of North America, and the Atlantic and sub-Atlantic region of temperate Europe (Weber 1995). The European blackberry flora is made up of a polyploid series $(x=7)$, with ploidy levels from $2 x$ up to $6 x$ and perhaps $7 x$ (Grant 1971). Diploids are found to be $100 \%$ amphimictic, whereas triploids are obligate apomicts; tetraploid Rubus plants have varying degrees of sexuality. Rubus ser. Glandulosi, comprising mainly glandular, mountain-dwelling polyploids of woodlands, is especially characterized by a high degree of retained sexuality (Šarhanová et al. 2012). Gustafsson (1943) hypothesized that apomixis in Rubus subg. Rubus originated as a result of hybridization events between (now extinct) ancestral species and subsequent 
polyploidisation after the last glaciation, a hypothesis that was largely confirmed by a recent broad-scale molecular study of European brambles (Sochor et al. 2015). In that study, it was shown that the European apomictic brambles probably originated from only six ancestral species, largely after the retreat of the Pleistocene ice sheets. It was argued, however, that the first large polyploidisation events that generated the recent apomictic lineages (e.g. in Rubus ser. Rubus) must have occurred during a glaciation cycle earlier than the Last Glacial Maximum. The findings are consistent with Stebbins' secondary-contact hypothesis, (Stebbins 1986) which explains the high proportion of polyploids from hybridization events in formerly glaciated areas after the rapid expansion of distribution ranges of remigrating species. Speciation and range expansion of most Rubus species are thought to have taken place in man-made landscapes, and still continue (Matzke-Hajek 1997).

In this paper, we consider the biotypes stabilized by apomixis and with distribution ranges $>50 \mathrm{~km}$ as species, in concordance with authors such as Weber (1995) and Kurtto et al. (2010) Each of these apomictic species probably consists of only one or a few clones with limited genetic variation (Kraft \& Nybom 1995; Nybom 1998) and are morphologically well defined, as well as possessing distinct phytogeographical and ecological features (Haveman 2013). Although there are reasons to consider even the stabilized apomictic biotypes with smaller distribution ranges as species (Haveman \& De Ronde 2013), they are omitted from this study because insufficient (distribution) data are available. Ecologically, the distribution ranges of the species within Rubus subg. Rubus in Europe are thought to be constrained by winter cold and summer drought (Weber 1995, p. 296), which explains their scarcity or even absence in large parts of the Nordic countries, at lower elevations in eastern Europe, and in southern Europe (Kurtto et al. 2010). In the Atlantic and sub-Atlantic zone, the highest diversity is found in the lowlands and lower hills, on loam and loamy sands (Matzke-Hajek 1997).

In the Atlas Flora Europaeae, Kurtto et al. (2010) mapped about 750 Rubus species, but distribution data are very scarce over large areas, such as France and south-eastern Europe (Kurtto et al. 2010, p. 31). Range size and structure differ considerably among bramble species; Kurtto et al. (2010) grouped the species into five categories, based only on range diameter: very widely distributed (W1, range diameter $>1500 \mathrm{~km}$ ), widely distributed (W2, 500-1500 km), supraregional (R1, 250-500 km), regional (R2, 50$500 \mathrm{~km})$ and local $(\mathrm{L},<50 \mathrm{~km})$. This last category of locally distributed species is usually not treated taxonomically (Kurtto et al. 2010, p. 29), and is not included in the Atlas Flora Europaea. Bijlsma \& Haveman (2007) also discerned five categories, but they also took the internal structure of the distribution ranges into account. 
Even between adjacent regions, the Rubus flora may differ significantly. The Rubus floras of two adjacent regions in Germany (Westphalia and Eifel / Niederrheinische Bucht) have only 64 species in common out of a total of 147 species, whereas 53 species are unique for Westphalia and 30 for the Eifel / Niederrheinische Bucht (Weber 1986; Matzke-Hajek 1993). In an attempt to summarize the distribution patterns of Rubus in Great Britain and Ireland, Newton (1980) and Newton \& Randall (2004) proposed six main Rubus regions ('florulas', small floras), which were divided into many regional complexes. Newton (1980) noticed that the species diversity in Rubus subg. Rubus decreased northwards, probably as a result of lower winter temperatures. Furthermore, some seemingly omnipresent species were unexpectedly absent from certain areas (e.g. Rubus dasyphyllus), probably caused by the vigorous development of regional and local taxa in these areas (Newton 1980). Gustafsson (1943, p. 157) lamented over similar observations: 'There rests something capricious, sometimes even enigmatic, over the dispersal of the blackberries'.

No attempts have been made so far to analyse the distribution patterns of Rubus species in north-west Europe. The central objective of our study is to classify and describe the spatial patterns of Rubus species, based on grid data from the Republic of Ireland, the UK, the Netherlands, Denmark and Germany. These countries lie in the centre of species diversity of the subgenus (Matzke-Hajek 1997; Kurtto et al. 2010), and sufficient distribution data are available from these countries. We characterize the resulting phytogeographical regions by means of indicator species analysis. Furthermore, we examine the internal structure of the regions distinguished. We summarize broadscale ecological factors (climate, soil and elevation) for each region, derived from the European landscape classification in LANMAP (Mücher et al. 2010), and propose some preliminary explanations for the observed spatial patterns.

\section{Materials and methods}

\section{Survey area}

The area of this study comprises the national territories of Ireland, Great Britain, the Netherlands, Denmark and Germany, for which national grid-based distribution data for Rubus were available. Unfortunately, Belgium and France, both countries with high Rubus species diversity, could not be included because of a lack of data (Kurtto et al. 2010). The study area thus extends from the westernmost part of Ireland to the border between Germany and Poland, and from the Germany's southern border to the Shetland Islands. Elevation ranges from $2800 \mathrm{~m}$ in the German Eastern Alps to $10 \mathrm{~m}$ below sea level in the Netherlands (Mücher et al. 2010). The climate is north Atlantic (humid with rather low temperatures in summer and winter, but not extremely cold) in the northern part of the survey area, and central Atlantic in the southern parts of Ireland, Great Britain, the Netherlands and adjacent Germany (moderate climate where the average 
winter temperature does not go far below $0{ }^{\circ} \mathrm{C}$ and the average summer temperatures are relatively low). The eastern and southern part of Germany is characterized by a relatively continental climate (warm summers and rather cold winters) (based on LANMAP; Mücher et al. 2010).

\section{Distribution data}

The operational geographical units (OGUs) in this study are grid cells with at least one Rubus occurrence. Rubus distribution data from Britain and Germany were obtained from the Botanical Society of the British Isles and the Bundesamt für Naturschutz, respectively (date December 2007). The basis for the distribution maps in the British database are the $10 \mathrm{~km} \times 10 \mathrm{~km}$ grid of the Ordnance Survey and the similar Irish grid, which are based on the OSGB36 map datum. The basis for the distribution maps of German species was the degrees-based grid on the TK25 (the so-called 'Messtischblatt'). Its projection causes a slightly variable OGU area, varying from approximately $121 \mathrm{~km}^{2}$ in the north to $136 \mathrm{~km}^{2}$ in the south. Danish Rubus data were digitized from the atlas published by Martensen et al. (1983). The grid used in this publication is an extension of the German grid with cells of approximately $11 \mathrm{~km} \times 11 \mathrm{~km}$. For the Dutch data, we used the national database described by van de Van de Beek et al. (2014). The Dutch grid has $5 \mathrm{~km} \times 5 \mathrm{~km}$ cells based on the WSG84 map datum used for floristic inventories, which have been rescaled to $10 \mathrm{~km} \times 10 \mathrm{~km}$ for this study. All grid cells in the border area of the Netherlands and Germany are included in the analysis, even if they are overlapping.

Species not belonging to Rubus subg. Rubus (e.g. R. chamaemorus, $R$. saxatilis and $R$. idaeus; nomenclature throughout this paper follows Kurtto et al. 2010) were excluded from the dataset. Distribution-area categories for the Rubus species were derived from the distribution maps in Atlas Flora Europaeae (Kurtto et al. 2010) and classified into four classes according to Table 5.1. OGUs with three or fewer species were omitted from the analysis, because testing of the method (see below) gave ambiguous results for such species-poor OGUs. The final dataset consisted of 618 species, 2839 classified OGUs and 22,451 species occurrences.

\section{Floristic regionalization}

Classification of the OGUs was carried out with a modified version of TwINSPAN. The original version of the program (Hill 1979) is strictly dichotomous: in each subsequent step, it divides every existing groups into two new groups, resulting in $1,2,4,8,16$, etc. groups, unless the threshold for the minimum group size or for the number of groups is reached. In the modified version of TWINSPAN (Roleček et al. 2009), implemented in the classification program JUICE 7.0.45 (Tichý 2002), only the most heterogeneous group is split in two new groups at each step, resulting in 1, 2, 3, 4, etc. groups, until a user-set 
Table 5.1. Rubus distribution categories used in this study (based on the categories given in Kurtto et al., 2010, p. 29)

\begin{tabular}{lll}
\hline Code & Category & Diameter of distribution area $(\mathbf{k m})$ \\
\hline W1 & Very widely distributed & $>1,500$ \\
W2 & Widely distributed & $500-1,500$ \\
R1 & Supraregional & $250-500$ \\
R2 & Regional & $50-250$ \\
\hline
\end{tabular}

threshold of group heterogeneity or a user-defined number of groups or minimum group size is reached. These stopping rules tend to avoid imposed divisions of homogeneous groups at the higher levels. For our initial analysis, the minimum group size was set to 15. TWINSPAN was forced to stop when the total inertia (the sum of all eigenvalues and a measure of heterogeneity) in the group reached a maximum of 4.0. This resulted in a total number of 114 'initial groups', which are more or less equivalent to the regional complexes defined by Newton \& Randall (2004). To arrive at geographically coherent Rubus florulas, we analysed the TWINSPAN dendrogram, after which we set the final minimum group size to 350 and the maximum number of groups/florulas to 13 .

\section{Indicator species and distribution characteristics}

JUICE was used to compute indicator species for each division step in the final analysis, following the method of Dufrêne \& Legendre (1997), with a threshold of $20 \%$. On the basis of the TwINSPan table, we computed the total number of species in each distribution-area category for each region.

\section{Environmental characteristics}

Descriptive statistics for the environmental factors were derived from LANMAP (Mücher et al. 2010). Using the centroids of each grid cell in the analysis, corresponding data for soil features, elevation and climate were extracted from the LANMAP dataset, using ArcGIS 10.1 (ESRI 2011). We used the R package (R Development Core Team 2011) for the construction of graphs of broad-scale ecological factors: minimum temperature of the coldest month (T_MIN_JAN in LANMAP), maximum temperature of the warmest month (T_MAX_AUG), mean precipitation of the warmest month (P_MEAN_AUG), and mean elevation (ALT_MEAN), as well as geological parent material (Parent_Mat).

\section{Results}

The TWINSPAN analysis resulted in 12 florulas (Fig. 5.1a, Table 5.2). On the basis of the first and third divisions, three major bramble territories were distinguished (Fig. 5.2): the British Isles territory (BI, red in Fig. 5.2), the south-east continent territory (SEC, blue) and the north-west continent territory (NWC, green). It should be noted that the BI territory extends into the extreme south-western part of the Netherlands. The SEC territory comprises upland regions in the southern part of Germany (the Alpine foreland 

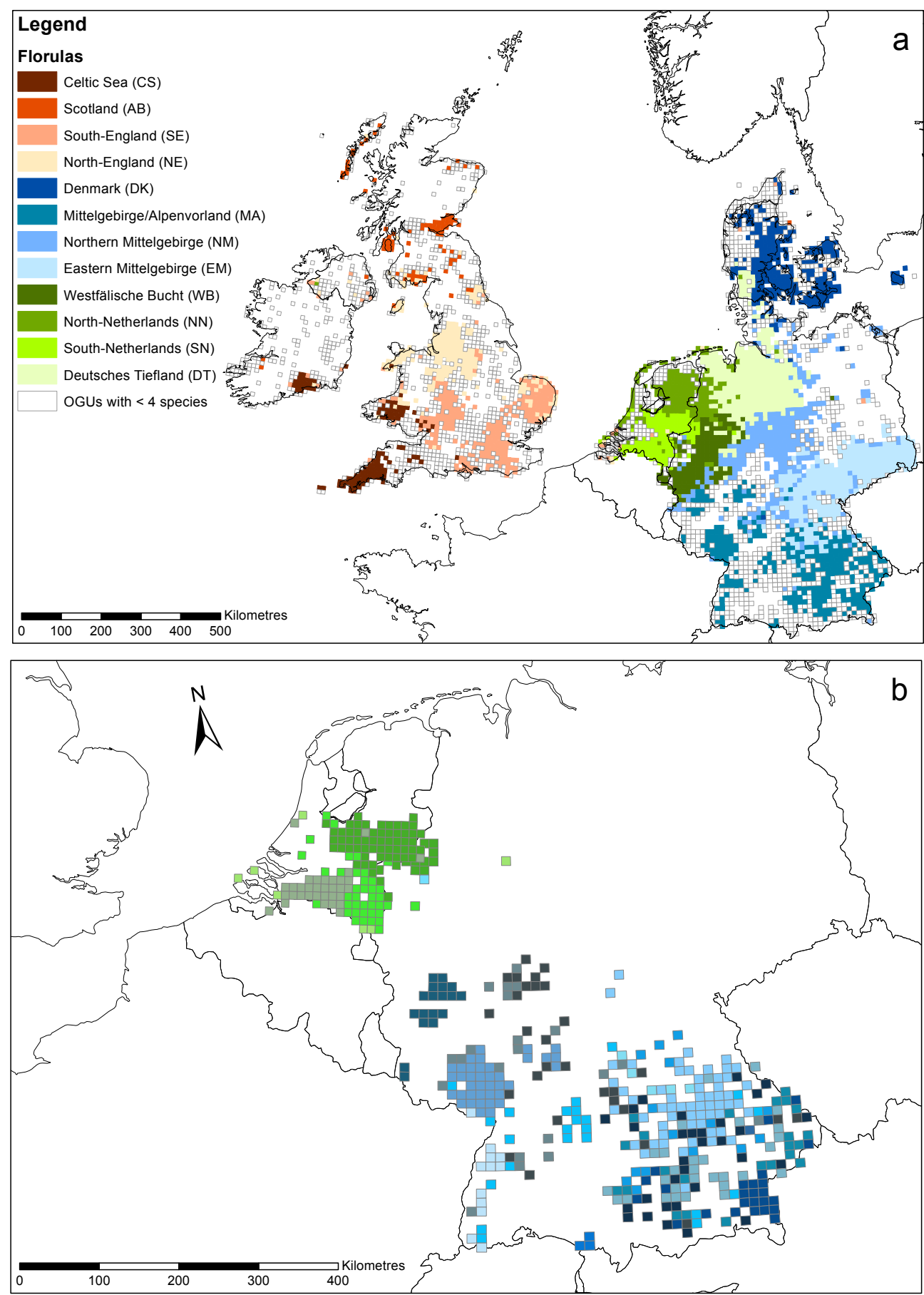

Figure 5.1. Map of the 12 distinguished florulas on the basis of the TWINSPAN analysis of the OGUs with four or more Rubus species in Ireland, Great Britain, the Netherlands, Denmark and Germany (a) and of the initial TWINSPAN groups in SN and MA (all 114 groups in Fig. S1 in Appendix S1) on the basis of OGUs with four or more species (b). 
Table 5.2. Levels of distinguished biogeographical regions based on the TWINSPAN analysis of grid data of the occurrences of Rubus subg. Rubus in north-west Europe.

\begin{tabular}{lll}
\hline Territory & Florula & Initial groups \\
\hline British Isles (BI) & Celtic Sea (CS) & $1-5$ \\
& Scotland (AB) & $6-9$ \\
& South England (SE) & $10-37$ \\
& North England (NE) & $38-52$ \\
\hline South-east continent (SEC) & Denmark (DK) & $53-60$ \\
& Mittelgebirge and Alpenvorland (MA) & $61-73$ \\
& Northern Mittelgebirge (NM) & $74-87$ \\
& Eastern Mittelgebirge (EM) & $88-95$ \\
\hline North-west continent (NWC) & Westfälische Bucht (WB) & $96-98$ \\
& North Netherlands (NN) & $99-105$ \\
& South Netherlands (SN) & $106-109$ \\
& Deutsches Tiefland (DT) & $110-114$ \\
\hline
\end{tabular}

as well as most regions belonging to the central uplands and South German Scarplands on both sides of the Rhine valley), the eastern parts of the North German lowlands, as well as large parts of Denmark. The NWC territory is compact, comprising the western sand areas of the North German lowlands and the Netherlands, as well as the uplands of the Rhenish Massif. Each of these bramble territories is divided into four florulas. From the differences in geographical homogeneity of the florulas (Fig. 5.1b), it is clear that the initial groups in the $\mathrm{SN}$ (South Netherlands) florula form relatively well-defined 'nuclei', whereas in the MA (Mittelgebirge and Alpenvorland), such nuclei appear next to scattered initial groups. Apart from the South England (SE), Denmark (DK) and MA florulas, all florulas are internally rather homogeneous, with groups in coherent nuclei (see Electronic Appendix S1).

There is a striking difference in the numbers of indicator species in the florulas (Fig. 5.3). Several florulas are characterized by only one or a few indicator species, like the South England florula (SE), the northern Mittelgebirge florula (NM), MA, and the North Netherlands florula (NN). Other florulas are very rich in indicator species, such as the Celtic Sea florula (CS), and the South Netherlands florula (SN), both with 10 or more indicator species. Another remarkable outcome of the indicator species analysis was the difference in structure of the indicator species groups between BI on one side, and SEC and NWC on the other side, going from higher to lower hierarchical levels. In the BI territory, every step in the TWINSPAN division, except the 'England' intermediate region (see Fig. 5.3), consisted only of indicator species that did not appear at lower levels (shown in bold in Fig. 5.3), whereas in the SEC and NWC territory step several indicator species that reach higher indicator values at subordinate levels occurred in each intermediate division. In other words, the florulas and the intermediate steps in the SEC and NWC territories both shared indicator species on a higher level, whereas the 


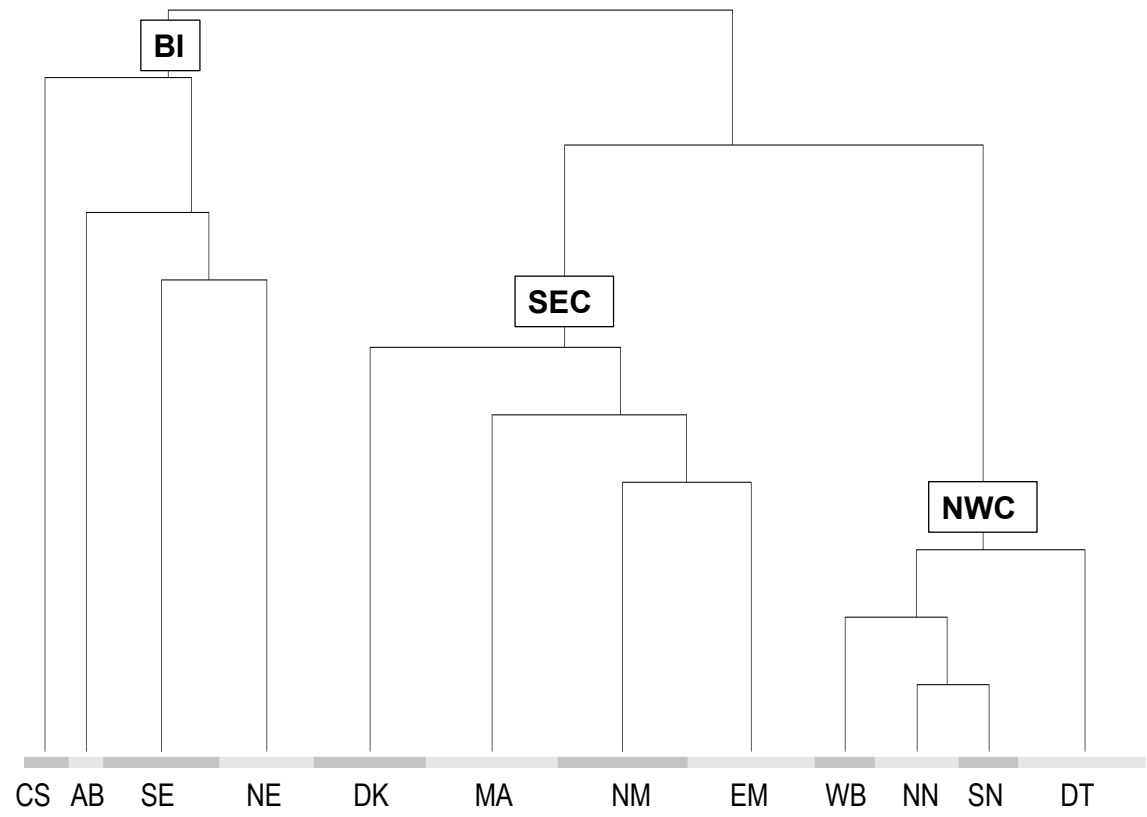

Figure 5.2. TWINSPAN dendrogram of the classification of grid data of occurrences of Rubus subg. Rubus in north-western Europe with the codes of the distinguished territories and florulas.

florulas and the intermediate steps in the BI territory were more independent in terms of indicator species.

We found a considerable difference in total species numbers and proportion of species distribution area classes between the florulas (Fig. 5.4). The Scotland florula (AB) and DK both consist of fewer than 100 species, whereas the SE florula, the NM florula and the Westfälische Bucht florula (WB) are very rich in species, each with over 180 species. $\mathrm{AB}, \mathrm{DK}$ and the Eastern Mittelgebirge florula (EM) have low numbers of regionally distributed species, with summarized percentages for the R1 and R2 categories below $30 \%$. The remaining florulas (WB, NN, SN, and the Deutsches Tiefland florula, DT) had a relatively high number of regionally distributed species (R1 + R2 > 40\%).

Mean precipitation in August and minimum temperature in January were the two climatic characters that showed the largest differences between the florulas (Fig. 5.5). As expected, the florulas in $\mathrm{BI}$ had a minimum temperature above $0{ }^{\circ} \mathrm{C}$ in January, whereas

Figure 5.3. (next page) Stepwise Dufrêne-Legendre indicator species for the groups at each branch in the TWINSPAN analysis (Dufrêne \& Legendre, 1997) with significant $(P \leq 0.01)$ indicator values $\geq$ $20 \%$ in parenthesis, until they have reached their maximum indicator value. Species are given in bold where their indicator value reaches a maximum value; species with an asterisk are regionally distributed species (R1 and R2; Table 1). The sequence of branching is given with numbers. Underlined groups are treated in the text. 


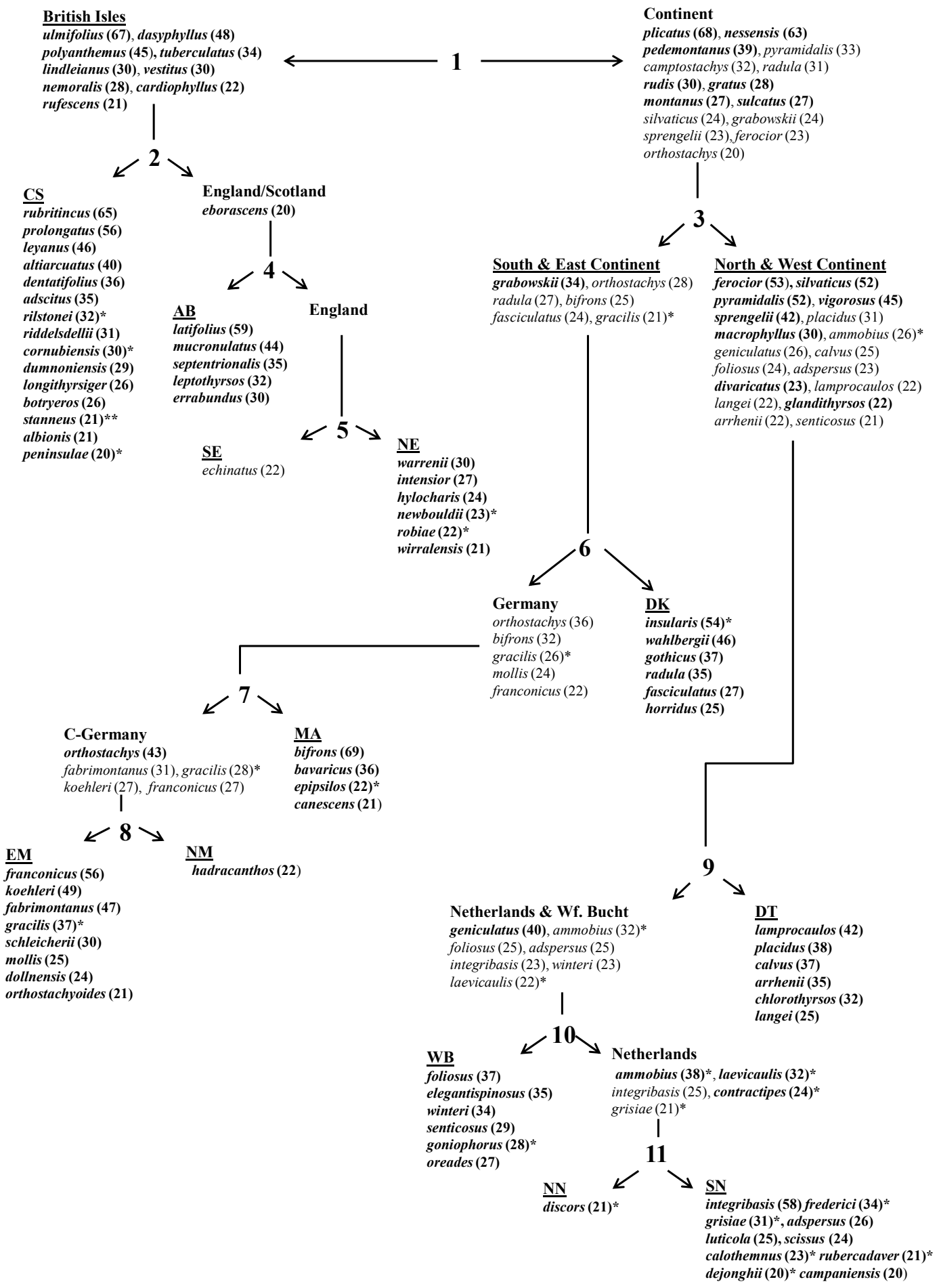




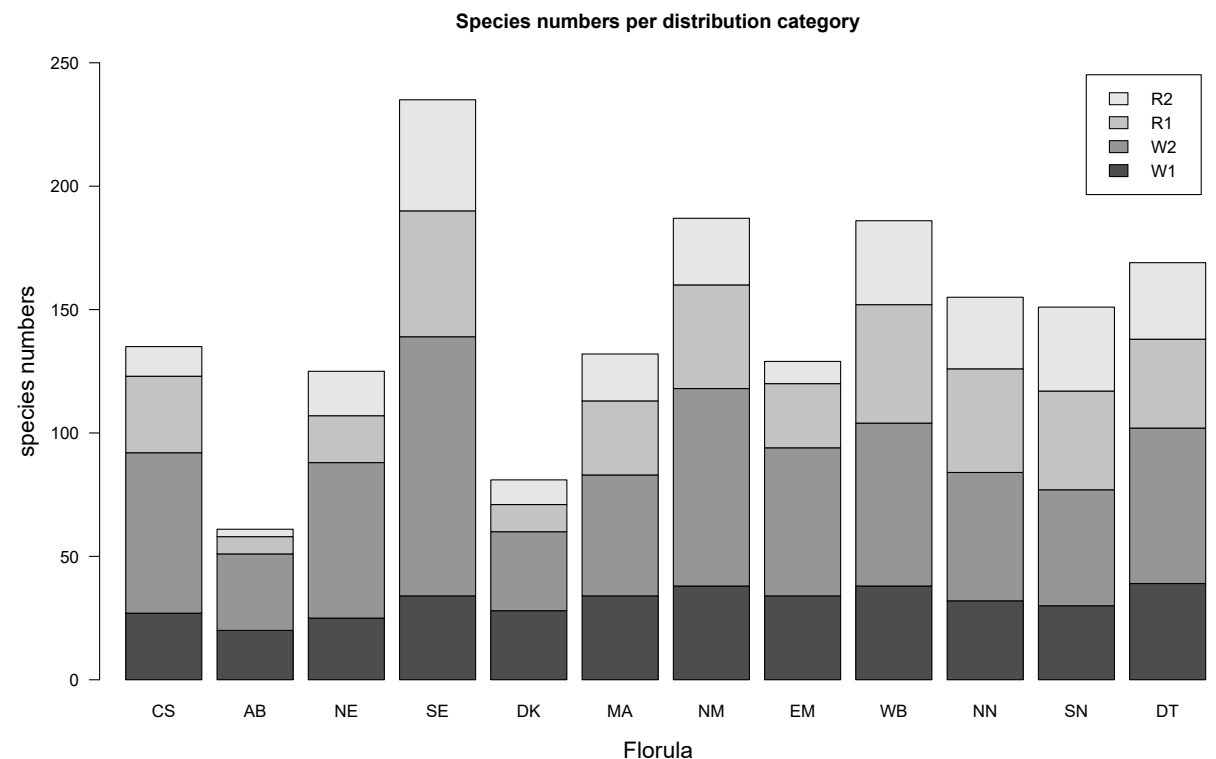

Figure 5.4. Species numbers of Rubus subg. Rubus per distribution-area category (Table 5.1) for each florula (based on distribution data in Kurtto et al., 2010). See Table 5.2 for the used abbreviations for the florulas.

in the SEC florulas the median of the temperature in January was below $0{ }^{\circ} \mathrm{C}$; the NWC florulas were intermediate for this variable. Precipitation in the driest month showed the greatest variation between the two 'Atlantic' florulas in the BI territory at one extreme (with the median above $85 \mathrm{~mm}$; $\mathrm{CS}$ and $\mathrm{AB}$ ) and the southern florula in $\mathrm{BI}$ at the other (with the median just above $60 \mathrm{~mm}$; the SE florulas). All other florulas showed intermediate values for the precipitation in August, with a large spread in the values in the large MA in the SEC territory. Mean elevation was highest in the florulas belonging to the SEC territory: well over $250 \mathrm{~m}$ a.s.l. in the northern and eastern Mittelgebirge florulas (NM and EM, respectively), and over $400 \mathrm{~m}$ a.s.l. in MA, although there was considerable variation in elevation in these florulas. Typical lowland florulas (well below $100 \mathrm{~m}$ a.s.l.) were DK, NN, SN and DT (Fig. 5.5).

Parent material varied greatly within the florulas (Fig. 5.6), but in several florulas one type of parent material was dominant: crystalline rocks and migmatites in CS, glaciofluvial deposits in NE and DK, and sands in NN, ZN and DT.

\section{Discussion}

\section{Quality and availability of data}

The aim of this study was to classify and describe distribution patterns in Rubus subg. Rubus in north-western Europe on the basis of grid-based occurrences of bramble species. Using TWINSPAN, we distinguished three bramble territories, divided into 12 florulas, all 

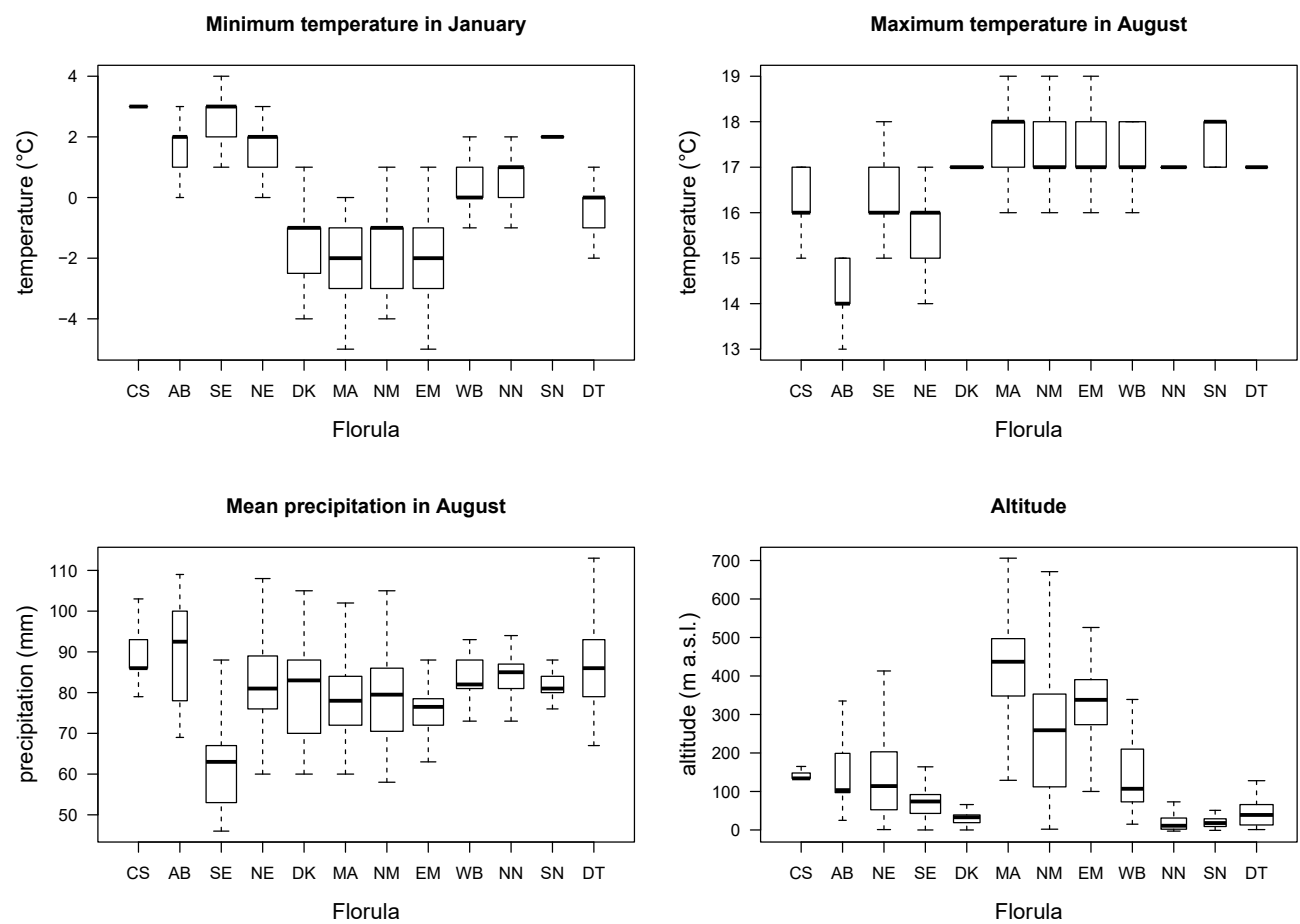

Figure 5.5. Box-and-whisker plots of the minimum temperature in January, mean temperature in August, mean precipitation in August, and mean elevation for the OGUs per florula (based on data from Mücher et al., 2010). See Table 5.2 for the used abbreviations for the florulas.

positively characterized by indicator species. Although the available data were collected over many years by different specialists, we believe that the results in this study largely reflect real patterns. Our florulas are consistent with the intuitive regionalisations by Newton (1980) and Newton \& Randall (2004) of the bramble flora of the British Isles, and with our own experiences in the Netherlands. Another cause for concern could be the incompleteness of the data: several newly described species are missing from the dataset, such as Rubus wittigianus (Weber 2002), R. uncimontanus (Van de Beek \& Troelstra 2013), and R. paludosus and R. favillatus (Van de Beek et al. 2014). Most of these species have small distribution areas and are limited to only one florula, such that their absence from the database is likely to make little difference to the final results.

The empty (white) regions, especially in the BI territory, are not determined by a lack of data, but reflect the unsuitability of larger regions for brambles (Newton \& Randall 2004; Kurtto et al. 2010). An exception and a more serious problem is the underrepresentation of data from Ireland, as already stated by Newton \& Randall (2004), and the results for this island have to be interpreted with reservations. The lack of data from Belgium and France can also be considered a serious drawback of our analysis, since it obstructs the view of the connection between the flora in the south-westernmost part of the 
Netherlands and the flora of the BI territory. This can only be resolved by a systematic inventory of bramble species in both countries.

\section{The historical basis of the florulas}

In a recent, rather provocative paper, Heads (2015) argued that species' present environment and biology (including their means of dispersal) largely fail to explain their current distribution, and that the histories of clades often give better explanations of the patterns found. Heads illustrates this with many examples based on old taxa, but it can be argued that it is even more likely for young species such as those in Rubus subg. Rubus. Most Rubus species are neospecies (Levin 2000) with unsaturated distribution areas, and at least the regional (R2) and supraregional (R1) species are thought to have broad ecological requirements, occurring in a variety of habitats on a wide range of soil types (Weber 1981; Matzke-Hajek 1997). This hypothesis is supported by the success of introductions outside species' natural ranges in areas with contrasting climates (Bijlsma \& Haveman 2007). It is tempting to attribute the range borders of more widely distributed species to ecological factors, but it appears that differences in climate are probably too small to directly explain differences in species composition between the florulas in SEW and NWC (Fig. 5.5), with the possible exception of the precipitation in August in MA in the SEW flora. On the contrary, the results of a broad-scale genetic analysis of Rubus in Europe by Sochor et al. (2015) suggest a historical background to the major patterns presented in this paper. A comparison of the maps with the distribution of haplotypes presented by Sochor et al. (2015) and our Fig. 5.1 shows a remarkable coincidence of the border between the NWC and SEC territory and dominance by 'ulmifolius' and 'canescens' haplotypes: the Rubus flora in NWC is an 'ulmifolius flora', whereas the Rubus flora in SEC can be defined as a 'canescens flora'. Rubus ulmifolius and R. canescens are among the six sexual ancestral species of the European apomictic Rubus flora. Based on the distribution of haplotypes, Sochor et al. (2015) hypothesized that after the retreat of the Pleistocene ice sheets, $R$. ulmifolius migrated from the Atlantic-Mediterranean area northwards, where it met and hybridized with (amongst others) $R$. canescens and sexual tetraploid representatives of Rubus ser. Glandulosi (such as $R$. hirtus), emerging from the Balkans. These two geographical descent lines are the basis for the present Rubus flora, reflected in the florulas distinguished here.

\section{Ecological patterns - or history after all?}

At a small scale, ecological processes may play an important role in the distribution patterns of Rubus species (Heads 2015) and thus in the observed patterns. To examine this, we will discuss some examples: the isolation and the existence of physical barriers, geology and landscape patchiness, and landscape and occupation history. 
It is clear that the florulas in BI are physically isolated by large areas which are poor in brambles (Fig. 5.1a). Both the high splitting levels in the dendrogram (indicating relatively large differences in species composition, Fig. 5.2) and the lack of transgredient indicator species (i.e. species indicative for several different levels of the classification; Fig. 5.3) in BI imply that these florulas are effectively isolated. Apparently, the blank areas between the florulas in BI, consisting of larger upland regions, moorlands and agricultural landscapes on calcareous soils (Newton \& Randall 2004), are not only devoid of brambles, but also represent effective dispersal barriers which can be overcome only with great difficulty despite the fact that bramble seeds are dispersed rather effectively even over large distances (Weber 1987). Isolation is not only a function of the environment and dispersal capacity: it is also determined by the age of the species. Given the high dispersal capacity of at least most of the bramble species, the florulas represent young to very young species pools (probably < 6,000 years; Matzke-Hajek 1997), which makes the observed pattern at least partly an effect of the particular breeding system in Rubus subg. Rubus.

On such a small scale, between the florulas and even more so within the florulas, the distribution of abiotic factors might have a pronounced influence. This is most clear from the difference in parent material between WB on the one hand and DT, SN and $\mathrm{NN}$ on the other (all in the NWC flora, Fig. 5.6); in other florulas, it is somewhat less clear. The scattering of initial groups in MA for instance (Fig. 5.1b) might be related to edaphic and mesoclimatic factors. This region is characterized by a relatively high mean elevation, and the range in elevation is large, a topography that will arguably result in a wide range of site conditions. It is tempting to also conclude this from the lack of a dominance of one of the types of parent material in MA (Fig. 5.6), but it could likewise be attributed to the vastness of the region. Another, more genus-specific explanation for the lack of coherent nuclei in parts of MA and SE could be the distribution of woodland remnants in the landscape. (Beijerinck \& Ter Pelkwijk 1952) observed a difference between Rubus species growing exclusively in old forest remnants and typical inhabitants of open agricultural landscapes, a difference that was confirmed by later ecological and phytogeographical studies (Matzke-Hajek 1997; Bijlsma 2002, 2004). We hypothesize that this gross difference in species ecology might influence the observed patterns, which is conceivable especially when it is related to the genetic background of the ancestral species and the 'inherited ecology' of the species groups that form the species pools in SEC and NWC respectively. Ecologically, the three ancestral species that gave birth to the Rubus species pools of these larger areas can be characterized as 'cool and humid' (Rubus ser. Glandulosi), 'warm and humid' (R. ulmifolius), and 'warm and dry' ( $R$. canescens), and their descendants will have inherited these characteristics. As demonstrated by Sochor et al. (2015), the Central European flora, coinciding with our SEC territory, is characterized by the two extremes in this, the descendants of Rubus ser. 


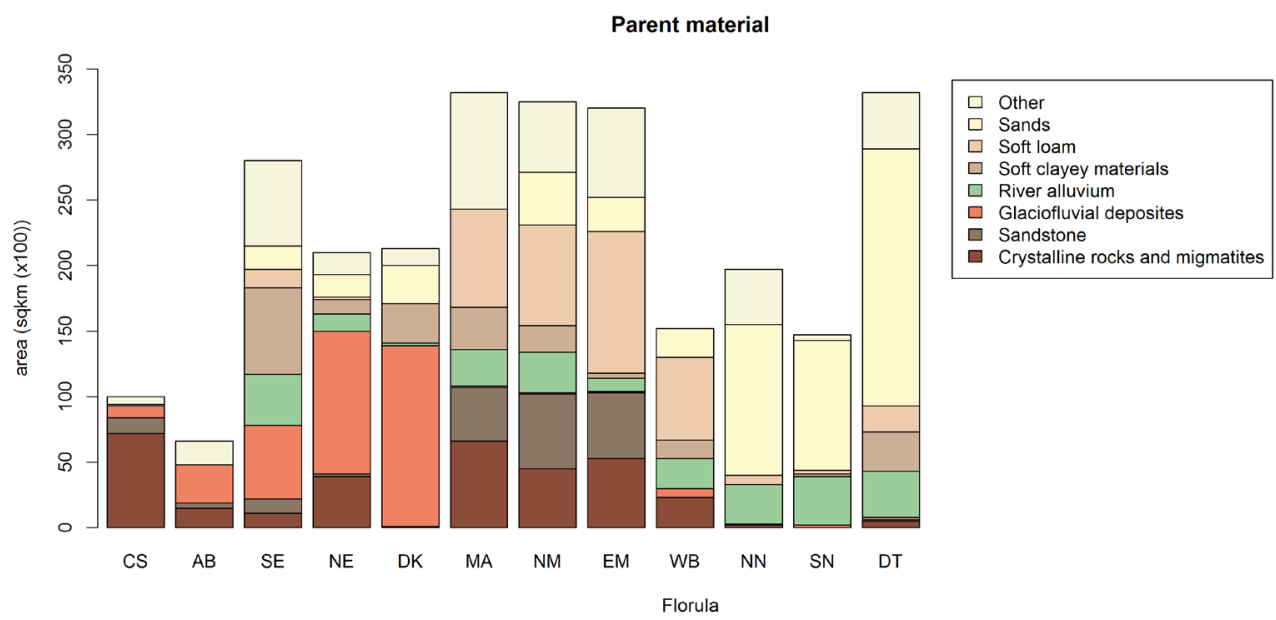

Figure 5.6. Parent material in the 12 Rubus florulas, as numbers of OGUs (based on data from Mücher et al., 2010). See Table 5.2 for the used abbreviations for the florulas.

Glandulosi and those of $R$. canescens, whereas north-west Europe (our NWC territory) has an ecologically more 'even' Rubus flora, derived particularly from $R$. ulmifolius. A landscape with cool, humid habitats as well as warm, dry habitats at a similar scale to our OGUs could therefore cause the observed patterns, and this is imaginable in upland areas like MA. The hypothesized process might be reinforced by the relatively high percentage of retained sexuality in Rubus ser. Glandulosi which are typically ancient woodland inhabitants, resulting in high rates of speciation (Šarhanová et al. 2012) and high numbers of young species with small distribution areas. Retained sexuality is regarded as a motor of diversity in apomictic genera through hybridization, as was reported for instance for the Ranunculus auricomus aggregate (Hörandl et al. 2009), but also for Rubus ser. Glandulosi, especially in some montane areas (Šarhanová et al. 2012; Haveman \& De Ronde 2013). A final examination of these hypotheses (through scaling of distribution patterns) is only possible if more species are tested on their provenance.

A third complex of factors influencing the differences in Rubus species composition at the scale of florulas might be landscape history, including land use (Bijlsma \& Haveman 2007; Haveman et al. 2012; Haveman et al. 2014). Evidence for landscape history and occupation patterns as factors in the realization of the florulas and initial groups can be derived from the distribution of initial groups, from which we take the well-defined nuclei in SN as an example (Fig. 5.1b). The first of these is a well-established regional complex north of the Rhine flood-plain, suggesting that the river and flood-plains act as a barrier to the spread of Rubus species. South of these flood-plains, two initial groups form two nuclei, a western Brabant nucleus and an eastern Brabant-Limburg nucleus. As described by Haveman et al. (2014) in a study of the geographical variation in bramble scrub types, the relatively species-rich western nucleus consists of old agricultural 
landscapes, whereas the more species-poor eastern nucleus consists of relatively young heathland afforestations and former peat areas. The species in the species-rich areas might consist of vicariant species that originated in these areas, whereas the species in the poor areas are more likely to have migrated into these areas after the landscape became available. In the Netherlands, the species pools in such poor areas are often dominated by taxa from Rubus subsect. Rubus (Haveman et al. 2014). This might be attributed to the general ecology of the species of this subsection, which prefer acidic soils, and their ability to grow in microclimatically less favourable, i.e. less humid, conditions (Bijlsma 2004). This is likely to make them the early colonists of young landscapes. Many species in other groups avoid the harsh conditions in such young landscapes, preferring more humid microclimates and better soils.

\section{Conclusions}

Although ecological factors certainly have their bearing on the observed patterns, as is clear from examples given, the influence of the history of Rubus subg. Rubus plays an important role through all these factors. This is most striking for the difference between the NWC and SEC territories, which seem to be genetically determined by the dominant influence of $R$. ulmifolius and $R$. canescens, respectively. Studying distribution patterns in the relatively early, expansive stages of a species complex like Rubus subg. Rubus (Matzke-Hajek 1997) might prove to be valuable for understanding distribution patterns in older clades, for instance with regard to the expansion and stabilization of species or species groups. This paper is only a start, however, and many questions remain on the relationships between history and ecology in the realization of Rubus distribution ranges.

For a better understanding of the realization of the distribution patterns in Rubus subg. Rubus, more information on the provenance of the apomictic species will prove invaluable. Until now, the ancestral background is known for only a small fraction of the species (Sochor et al. 2015), but the combination with the floristic Rubus regions and knowledge of the ecology of species has already provided new insights. Phytogeographical studies at different scales could show the tenability - or otherwise - of the hypothesized causes of the observed patterns in this paper. These patterns might appear to be less capricious than perceived by Gustafsson (1943, p. 157), having their background in the combined history and ecology of the genus after all. Once the species are known, and their provenance is clarified, their capers might be understood. 


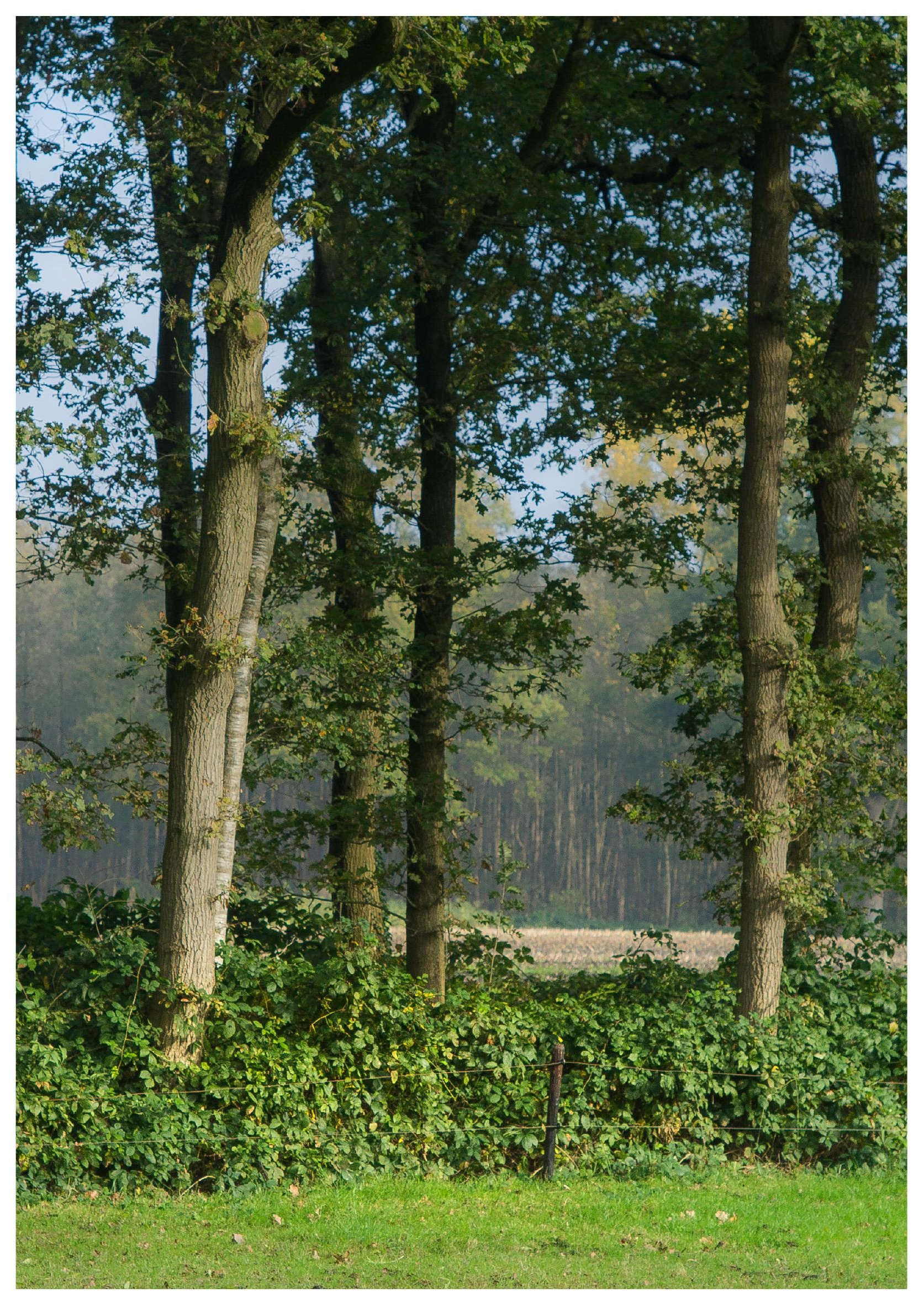


CHAPTER 6

\section{Systematic randomised sampling along three landscape transects in the Netherlands reveals the geographically structured variation in Rubus scrubs}

Reprinted with permission from:

Haveman, R., I. de Ronde, R.J. Bijlsma \& J.H.J. Schaminée 2014. Systematic randomised sampling along three landscape transects in the Netherlands reveals the geographically structured variation in Rubus scrubs - Phytocoenologia 44: 31-44. 


\begin{abstract}
Rubus scrubs belong to the least known and understood vegetation types in Europe. At least in part this is due to the complicated taxonomy and species richness of the main genus in these scrubs. In this study, we explored the regional diversity of Rubus scrubs in the Netherlands. In order to get a clear picture on their species composition free from personal preferences, we used a systematic-randomised sampling scheme to collect data in the three main Rubus regions in the Netherlands along three $100 \mathrm{~km}$ long transects. In 185 relevés we recorded 67 known (and three unknown) Rubus species. The relevés could be assigned to seven units described in the Dutch national vegetation classification: the Rubetum grati, Rubetum silvatici, Lonicero-Rubion silvatici, DicranoJuniperetum, Pruno-Rubetum vestiti, Pruno-Rubion radulae, and the Basal Community Rubus armeniacus. From our study we conclude that the regional variation in Rubus scrubs is substantial, and that only a part of this variation was described in the Dutch national vegetation overview. Especially within the Rubetum silvatici and the PrunoRubion radulae regionally distributed types can be distinguished, which seem to be confined to old landscapes, whereas younger landscapes only harbour common types, or are even devoid of bramble scrubs. The density of relevés made in this study emphasize the importance of bramble scrubs in the landscape of north-western Europe, and we advocate more awareness of the value represented by bramble dominated communities. The vast number of Rubus species, many of which having a (very) restricted distribution area, complicate the classification of these scrubs, and can easily lead to the description of countless vegetation types with only a regional distribution. On the other hand, such regionally distributed communities can be of importance for nature conservation because they can harbour rare species, and they add to the regional identity and $\gamma$-diversity, and therefore should be recognised at some level.
\end{abstract}

Nomenclature: Van de Beek et al. (2014) for Rubus, Van der Meijden (2005) for all other vascular plants, Siebel \& During (2006) for the mosses and hepatics

Abbreviations: $\mathrm{DNVC}=$ Dutch national vegetation classification

Appendix 1: Full structured table with the relevés of Rubus scrubs along three landscape transects. Included in the online version at www.schweizerbart.de/journals/phyto 


\section{Introduction}

Bramble scrubs are among the least known and understood vegetation units in Europe with respect to both species composition and ecology. The major causes are to be found in the specialist knowledge that is required because of the species richness and taxonomical complexity of the most important taxon in these scrubs, Rubus L subgen. Rubus (Weber 1981a). An estimated number of about 1000 native Rubus species exist in Europe, from which more than 240 can be found in the area of Hegis Flora from Mitteleuropa alone (Weber 1995). The recently published Rubus volume of the Atlas Florae Europaeae treats 746 species (Kurtto et al. 2010), and the recent standard list of the bramble flora of the Netherlands comprises 191 species (Van de Beek et al. 2014). Many of these species have wide distribution areas (> $500 \mathrm{~km}$ diameter), but at least as many are classified as 'regional species' ("Regionalarten” according to Weber 1986b; Weber 1995) in modern Rubus taxonomy, having distribution areas of about $50-250 \mathrm{~km}$ in diameter. Taxa with distribution area diameters under $50 \mathrm{~km}$ are usually not treated taxonomically, and considered as irrelevant local or singular biotypes (Weber 2002a; and Loos 2008 for a critical evaluation of this so-called 'pragmatic species concept'; see however Haveman $\&$ De Ronde 2013).

For major parts of Central and Western Europe, bramble taxonomy has been clarified to a large extent (Weber 2002a; Kurtto et al. 2010). The centre of diversity of subgen. Rubus in Europe is found in the lowlands and lower mountains of Atlantic and subAtlantic north-west Europe: northern Germany, the Netherlands, southern Britain, Belgium and (at least) the northern part of France, with up to 50 or even 60 species per $100 \mathrm{~km}^{2}$ (unpublished data). Most of the species are found on loamy sands and loams (Matzke-Hajek 1997; Kurtto et al. 2010 pp. 13, 42). A recent inventory of the Netherlands (Van de Beek et al. 2014) showed that the highest species diversity (> 40 species per $25 \mathrm{~km}^{2}$ ) is found in old woodland landscapes with cover sand, fluvial terrace deposits or glacial deposits as well as loam, old river clay or loess.

In the centre of diversity of the genus in Europe, not only species numbers, but also the contribution of Rubus to the actual vegetation is high. Until now, a classification of scrubs in which the Rubus species are identified at species level is only made for parts of Germany (Weber 1998a, 1999b, 2003b) and the Netherlands (Haveman et al. 1999a; Haveman et al. 1999b; Haveman \& Van Haperen 2008; Haveman et al. 2012).

In the classification scheme in the Dutch national vegetation classification (from here on abbreviated as DNVC; Haveman et al. 1999a; Haveman et al. 1999b), hardly any attention was paid to the influence of regionally distributed Rubus species on the classification. For Germany, next to the Rubetum silvatici Weber in Pott 1995 (LoniceroRubion silvatici Tüxen et Neumann ex Wittig 1977, Lonicero-Rubetea plicati) a more 
northern distributed Rubetum sciocharitis Weber in Pott 1995 was distinguished on the basis of regionally distributed Rubus species $(1990,1998$ a). Such regionally distributed bramble communities can be of high importance for nature conservation, since they add to $\gamma$-diversity and regional identity of the landscape, and often host species with a very limited distribution (Weeda et al. 2005, p. 77). Besides, unravelling the regional variation of these bramble scrubs is a first necessary step to a better understanding and a possible comparative ecological study of Rubus communities.

Concerning the classification of Rubus scrubs, there are two problems associated with the high species diversity of the genus. Most Rubus species are able to dominate the vegetation, thus forming independent (almost) mono-dominant scrub. It is easy to distinguish dozens of vegetation types which have no Rubus species in common with other such types on the basis of such mono-dominant scrubs (see Passarge 1982 for examples from eastern Germany), leading to an unwieldy and devaluated syntaxonomical system without internal coherence (Haveman 1997). On the other hand, in mixed stands the high species diversity could easily cause a random (or continuous) variation by the virtually endless gradual replacement of bramble species. For a sensible classification, we need to know how the main floristic variation in the Rubus scrubs is structured, discarding the 'noise' of rare combinations and mono-dominant stands. Once the main floristic variation is known, an evaluation of the existing classification scheme is possible, and a good solution can be found for the possible regional bramble scrub types.

In this paper we will explore the regional diversity of the Rubus scrubs in the Netherlands. Our question is two-fold: 1.) how is the main variation in Rubus scrubs structured, and 2.) does the classification of Rubus scrubs in the DNVC (Haveman et al. 1999a; Haveman et al. 1999b) reflect the main variation of these scrubs adequately? To answer these questions, we developed a sampling scheme in which the relevés were unbiased by personal preferences, and which detects the main variation in species composition, viz. a systematic-randomised sampling in landscape transects.

\section{Study area}

We sampled the bramble scrubs in three regions in the Netherlands, roughly between the towns of Heerenveen and Almelo in the north-eastern part, Maarsbergen and Winterswijk in the central part, and Breda and Venlo in the southern part of the country, covering the three main sand landscapes and major centres of Rubus distribution in the Netherlands (Fig. 6.1). The climate in the main meteorological station in De Bilt (near the western end of the central study region) is sub-Atlantic, with a mean annual temperature of $10.1{ }^{\circ} \mathrm{C}$, a mean annual precipitation of $832 \mathrm{~mm}$, and a mean annual precipitation surplus of $273.6 \mathrm{~mm}$ (Sluijter 2011). In all three transects, the substrate consists of sands mainly (Fig. 6.1), which were pushed by the glaciers during the Saale 
glaciation especially in the central part of the country. In the northern part, till is found near the surface on many places. In the southern part, which was never covered by the glaciers during the Pleistocene, cover sand is the main substrate. Locally, especially along rivers and brooks, other substrates (especially clay and peat) are predominant, and in larger parts of the central transect the soil consists of old river clay. Land-use is mainly agricultural in all three transects (pastures as well as agricultural fields), but the central transects crosses the extensive forests of the 'Veluwe' sand massive.

\section{Methods}

\section{Transects and relevés}

For the compilation of a database of relevés of Rubus scrubs unbiased by personal preferences, we developed a GIS-based systematically randomised method in which the location of relevés was dictated by three unidimensional transects of about $100 \mathrm{~km}$. Each start- and endpoint of these transects was chosen randomly within an area of 25 $\mathrm{km}^{2}$ using the function 'random points' (Hawth Tools) in ArcGIS 9, making sure that the three main Rubus areas in the Netherlands (the northern, central and southern sand areas) were covered (Fig. 6.1). The transects were exported as maps to TurbovegCE (Hennekens \& Dirkse 2008) to be used during the collection of data.

Relevés were collected by the first author (assisted by each one of the co-authors, A. van der Berg or M. van Ravensberg on various field days) between August $4^{\text {th }}$ and August $9^{\text {th }} 2008$ in the northern transect, October $17^{\text {th }}$ and November $9^{\text {th }} 2009$ in the southern transect, and August $11^{\text {th }}$ and October $29^{\text {th }} 2010$ in the central transect, using TurbovegCE (Hennekens \& Dirkse 2008). Relevés were made where the transects intersected (floristic and structural homogeneous) bramble scrubs of at least $30 \mathrm{~m}^{2}$, being the area used for the relevés. Smaller scrubs, inhomogeneous stands, and scrubs just aside the transects were skipped. Plot shape varied from $6 \times 5 \mathrm{~m}^{2}$ to $30 \mathrm{x} 1 \mathrm{~m}^{2}$. In the first year, a HP iPAQ handheld computer with a separate Adapt AD-750 Bluetooth GPS receiver was used, in the second and third year the relevés were recorded with the help of a Trimble Juno SB field computer with internal GPS. In the relevés, layers were distinguished when appropriate (tree, shrub, lower shrub (bramble), herb, and moss layer), and all plant species were recorded in all these layers. Abundance was estimated using the (modified) scale of Braun-Blanquet in which the ' 2 ' was subdivided in $2 \mathrm{~m}, 2 \mathrm{a}$, and 2b (Barkman et al. 1964; Westhoff et al. 1995, p. 72). Herbarium specimens were collected whenever Rubus species couldn't be identified in the field, and stored in the herbarium of the first author (5 exsiccata in total). The relevés were stored in the Dutch National Vegetation Database (Schaminée et al. 2012), using TurboVeg (Hennekens \& Schaminée 2001). 


\section{Classification}

The relevés were exported to JUICE (Tichý 2002) to perform a guided classification. Since the main objective in this study was a regional classification on the basis of Rubus species and species in the shrub layer, we omitted all the species in tree, herb, and moss layer from the analysis. The relevés were assigned manually to the units in the DNVC (Haveman et al. 1999a; Haveman et al. 1999b) on the basis of the occurring Rubus species and species in the shrub layer, and clustered accordingly. The relevés that couldn't be assigned to one of the existing associations were classified on alliance, order, or class level subsequently. Within these broad clusters (representing the associations in the DNVC, or alliances in case of the absence of character species of the associations) we manually clustered the relevés on the basis of the (co-)occurrence of Rubus species. For the distinguished clusters, distribution maps were made using ArcGIS 9. For the synoptic and full table, the shrub species were ordered according their diagnostic value in the DNVC (Haveman et al. 1999a; Haveman et al. 1999b), or the Synopsis (Weber 1998a, 1999b) and the Hegi (Weber 1995) insofar the species were not mentioned in the DNVC.

\section{Results}

\section{Relevés and species}

In total, 185 relevés were made in the three transects: 68 in the northern, 66 in the central, and 51 in the southern transect (Fig. 6.1). The relevés were not evenly distributed in the landscape, as is clear from Fig. 6.1. We identified 67 Rubus species, and three more species remained unnamed. The frequency-distribution of the Rubus species in the dataset follows a reversed J-curve as expected (Fig. 6.2), with few species with high frequencies, and a long tail of species with only one or few occurrences. The 15 Rubus species occurring in ten or more relevés are listed in Table 6.1. Rubus gratus is the most frequent species in the data set, occurring in 149 of the 185 relevés; according to Van de Beek et al. (2014), R. gratus is the most frequent Rubus species in the Netherlands. A remarkable species is $R$. euryanthemus, which was found for the first time in the Netherlands during this study (in the westernmost relevé of the central transect). This species is common in the British Isles, Belgium, and Sleswig-Holstein and Lower-Saxony in Germany (Newton \& Randall 2004; Kurtto et al. 2010).

In Table 6.2 the bramble diversity per region is given. In all three transects the number of bramble species per relevé ranges from 1 to 7 . The total number of bramble species is highest in the Central transect, although the average number of species per relevé tends to be lower in the Central transect than in the other two transects (not significant). 


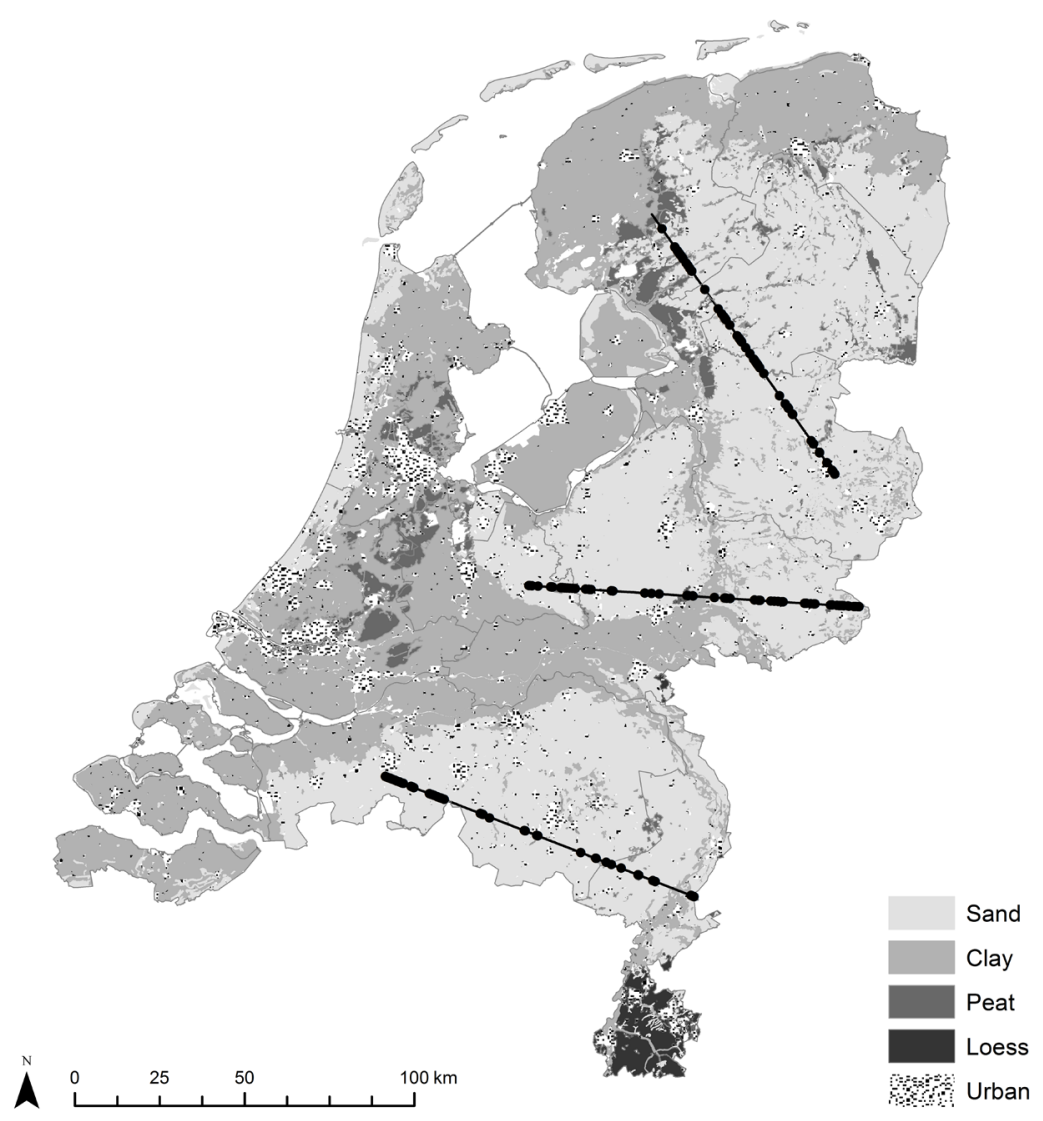

Figure 6.1. Location of the three randomised transects and 185 relevés of Rubus scrubs. Soil map after Kemmers et al. (2002, simplified).

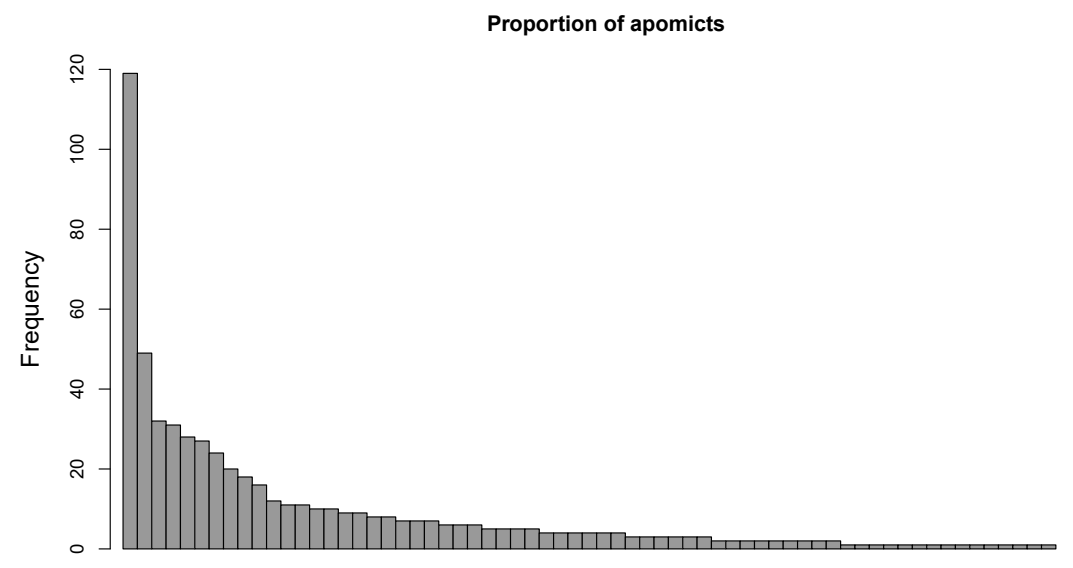

Species

Figure 6.2. Frequency distribution of the 67 Rubus species which were found in the relevés 
Table 6.1. Rubus species found in 10 or more relevés $(n=185)$ along the three transects.

\begin{tabular}{lr}
\hline Species & Frequency \\
\hline Rubus gratus & 119 \\
Rubus plicatus & 49 \\
Rubus affinis & 32 \\
Rubus nessensis & 31 \\
Rubus integribasis & 28 \\
Rubus macrophyllus & 27 \\
Rubus idaeus & 24 \\
Rubus ammobius & 20 \\
Rubus nemoralis & 18 \\
Rubus adspersus & 16 \\
Rubus glandithyrsos & 12 \\
Rubus umbrosus & 11 \\
Rubus scissus & 11 \\
Rubus calvus & 10 \\
Rubus sprengelii & 10 \\
\hline
\end{tabular}

Table 6.2. Bramble diversity in the three transects $(\mathrm{N}=$ North, $\mathrm{C}=$ Central, $\mathrm{S}=$ South). Given are the total number of Rubus species for the transects (between brackets the number of unidentified species), the minimum and maximum number of Rubus species per relevé for each transect, and the average number of Rubus species (and standard deviation) per relevé for each transect.

\begin{tabular}{l|rrr}
\hline & $\mathbf{N}$ & $\mathbf{C}$ & $\mathbf{S}$ \\
\hline total \# species & $33(+1)$ & $43(+2)$ & $33(+1)$ \\
min. \# species/relevé & 1 & 1 & 1 \\
max. \# species/relevé & 7 & 7 & 7 \\
avg. \# species/relevé (+ sd) & $3.3(1.5)$ & $3.0(1.5)$ & $3.2(1.5)$ \\
\hline
\end{tabular}

\section{Classification}

The classification of the relevés is given in Table 6.3 (see also Electronic Appendix 1). The relevés in our dataset could be assigned to 7 different vegetation units as circumscribed in the DNVC (indicated with capitals in Table 3): the Rubetum grati (A), the Rubetum silvatici (B), the Lonicero-Rubion silvatici (C), the Dicrano-Juniperetum (D), the PrunoRubetum vestiti (E), the Pruno-Rubion radulae (F), and the basal community of Rubus armeniacus of the Galio-Urticetea (G) (Haveman et al. 1999a; 1999b; Hommel et al. 1999; Weeda et al. 1999). In total, 107 of the 185 relevés could be assigned to one of the mentioned associations, whereas the remaining 78 could only be assigned at the level of alliance or higher.

Most of these units, except the Dicrano-Juniperetum (1 relevé), the Pruno-Rubetum vestiti ( 2 relevés), and the Rubus armeniacus community (2 relevés), could be subdivided 
Table 6.3. Synoptic table (strongly shortened) of the 21 distinguished Rubus scrub clusters, with the frequency in percentages. Only the Rubus species and the diagnostic shrub species of the RhamnoPrunetea are included. The first column (Synt.) comprises the synsystematic place of the species according to the Dutch national vegetation classification (Haveman et al. 1999a, Haveman et al. 1999b, Hommel et al. 1999, Weeda et al. 1999): $\mathrm{Rg}=$ Rubetum grati s.I., $\mathrm{Rs}=$ Rubetum silvatici s.I., L-R = Lonicero-Rubion silvatici, $\mathrm{P}-\mathrm{Rv}=$ Pruno-Rubetum vestiti, $\mathrm{P}-\mathrm{R}=$ Pruno-Rubion radulae, $\mathrm{R}-\mathrm{P}=$ RhamnoPrunetea/Prunetalia, BC Ra = Basal community Rubus armenicus, DJ = Dicrano-Juniperetum. * indicates that the species is not included in the tables in the Dutch national vegetation classification, syntaxon between brackets indicates that the species is mentioned in German literature only. Freq. = absolute frequency. See electronic appendix 1 for the full table.

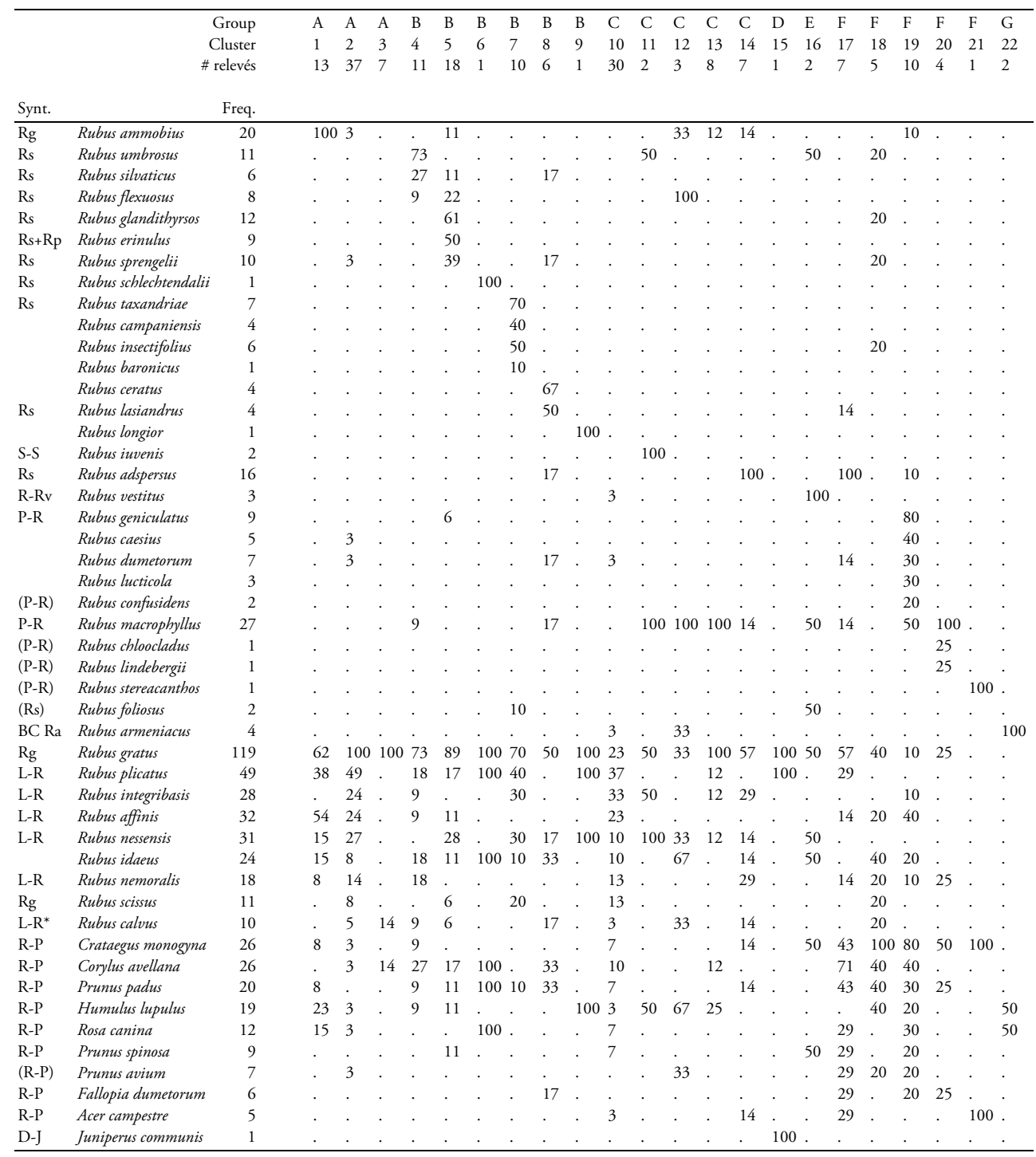




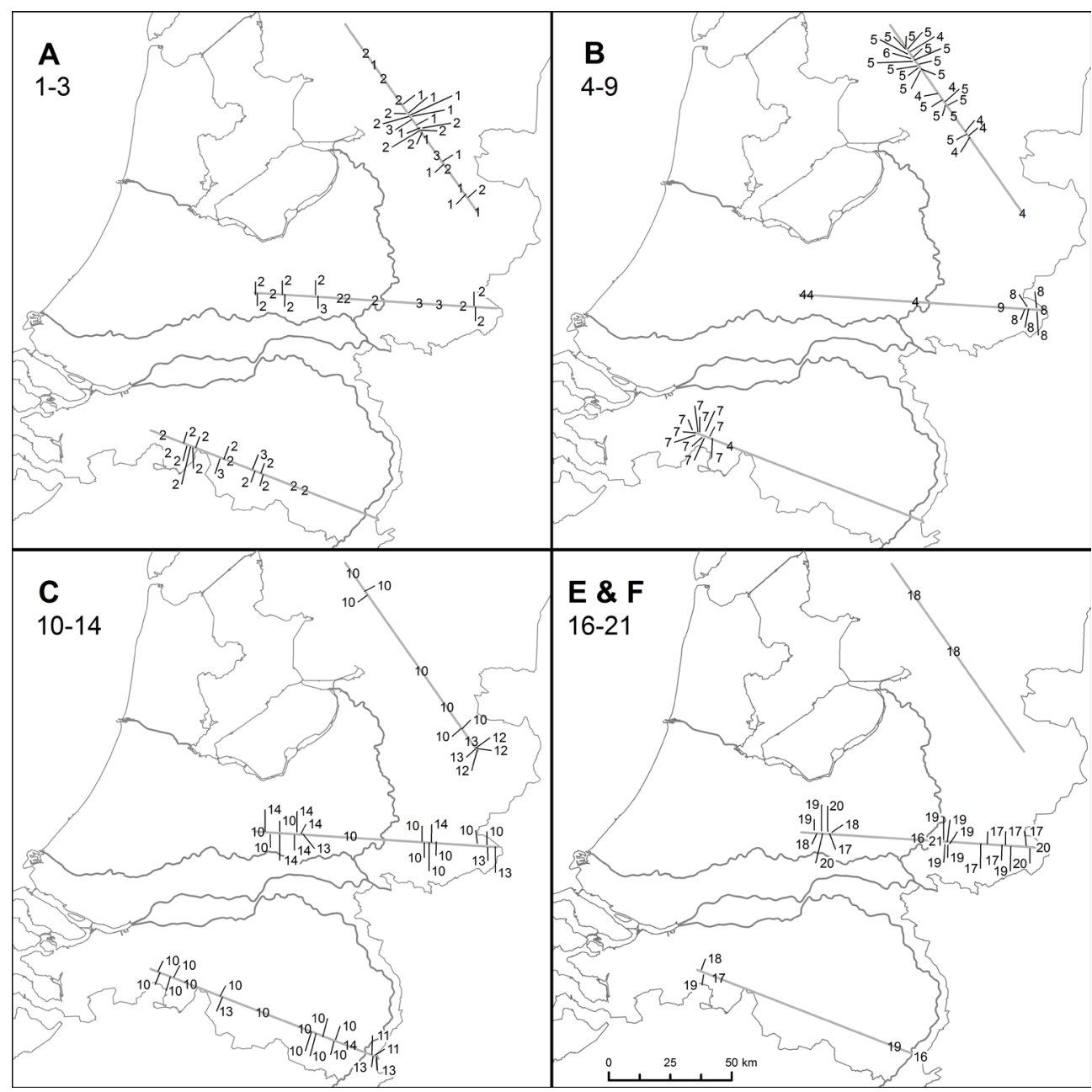

Figure 6.3. Distribution of the clusters along the transects. Numbers in the maps refer to the clusters in the classification, capitals to the principal groups. $\mathrm{A}=$ Rubetum grati, $\mathrm{B}=$ Rubetum silvatici, $\mathrm{C}=$ Lonicero-Rubion silvatici, E+F = Pruno-Rubetum vestiti + Pruno-Rubion radulae; groups D (DicranoJuniperetum) and G (BC Rubus armeniacus) are not shown.

on the basis of the (co-)occurrence of Rubus species, so that eventually 22 clusters were distinguished (Table 6.3).

\section{Distribution}

The uneven distribution of the bramble scrubs in the landscape is clearly shown in the map with the distribution of relevés (Fig. 6.1). Also the distribution of the various clusters is uneven, with some being present along most of the length of all three transects, but other clusters being restricted to relatively small parts of only one transect (Fig. 6.3). 
Cluster 1 is found along the northern transect only, the other two clusters of group A $(2 \& 3)$ are recorded along most of the length of all three transects. Cluster 5, 7, and 8 (group B) all have very limited distribution, being present along certain parts of one transect only, and the same holds true for cluster 11 and 12 (group C). Cluster 4 and 18 are rarely recorded along all three transects, and cluster 17 was frequently found along the central, but not along the north and only once along the southern transect (group E+F). Group F, the Pruno-Rubion radulae was frequently recorded along the central transect, whereas it is rare in the north and south.

\section{Discussion}

\section{Methodology}

The results show a clear regional variation in species composition in Rubus scrubs. Because the use of random or randomised-systematic relevés is questioned by several authors especially for classification purposes (Dierschke 1994; Glavac 1997), we will examine this approach a bit further. Dierschke (1994, p. 150) mentioned two drawbacks: randomly placed relevés are often not homogeneous in their floristic content, and therefore not suitable for classification purposes, and rare community types are easily missed, unless a huge number of relevés is made. The first drawback doesn't hold for this study, because our sampling scheme required homogeneous stands. The second drawback, the underrepresentation of rare community types, might be a serious problem in overviews or mapping projects in which all vegetation types are to be described, but it is considered less important in our study, which aimed to reveal the major spatial structure in the bramble communities. In a separate study, missing types could be looked for, but probably these will be of less importance on the landscape level (see further in the paragraph 'syntaxonomic considerations'). We therefore conclude that the used method is perfectly suited to detect the main floristic variation in the Rubus scrubs. The classification presented here is based on the presence of species in the shrub layer only. This is justified from the growth form of the Rubus species, which plays an important role in the succession from other early successional stages to Rubus scrubs. Rubus polycorms easily invade surrounding vegetation, either by rhizomes (subsection Rubus) or by rooting tops of the first years primocanes (turiones; subsection Apendiculati). Although the herb and moss layer under bramble scrubs is often only very scarce (Weber 1998a), the undergrowth of the scrubs can be very diverse and shows succession history more than other things. The undergrowth of a Rubetum grati in the edge of a woodland consists of other species than the undergrowth of a Rubetum grati along a meadow. The delimitation of such ecologically defined vegetation (sub-)types was not the scope of this paper.

The use of randomised-systematic relevés in this study guaranteed a sample free of personal bias, but in the synthetic phase we chose to apply a highly subjective classification 
method. We think this is justified by one of the major questions in this study, the evaluation of the classification given in the DNVC. By 'rebuilding' the classification given in the DNVC it was possible to evaluate the remaining variation, and compare our classification with the one in the DNVC.

\section{Rubus diversity}

The average number of Rubus species per relevé, as well as the minimum and maximum number of Rubus species per relevé, were similar in all three transects. The total number of Rubus species in the central transect was considerably higher than in the other two transects though, implying that the turnover in the central transect ( $\beta$-diversity) is higher than in the other two transects. Most probably this is the consequence of the medium-scale diversity in geology, which is larger in the central than in the other two transects. Especially on the old river clay of the 'Oude IJssel' region many species are found which are absent in the rest of the central transect (e.g. R. luticola, R. loehrii, and R. stereacanthus).

\section{Regional diversity}

This study was done to explore the regional diversity in Rubus scrubs in the Netherlands, and from the results we conclude that it is possible to distinguish regionally distributed bramble scrub types on the basis of randomised-systematic relevés. Most of the relevés could be assigned to rather well defined clusters. Some clusters however consist of only a few relevés and they probably can be considered 'noise' in the light of a nation-wide or international classification.

All three transects have their own 'character', with one or more community types restricted to or predominantly along one of the transects. Apart from the clusters with only one or two relevés, the clusters 1, 5, 7, 8, and 17 represent regional Rubus scrub types. The main areas with regionally distributed Rubus scrub types are the Drenthian-Frisian border area (the northern part of the northern transect), the Winterswijk region (the easternmost part of the central transect), and the Baronie/Campine area (the westernmost end of the southern transect). The regionally distributed clusters coincide fairly well with the Rubus 'florulae' described by Veeken \& Haveman (2008): regions with a more or less coherent Rubus flora (Newton 1980; Newton \& Randall 2004). A more detailed study of these florulae should be carried out to reveal whether the characteristic species of the florulae and these regional distributed vegetation types are the same. The cause of these Rubus florulae might be the historical isolation of these regions, from which the young Rubus species were not able to disperse yet after they evolved.

Most of the Rubus species characterising the regionally distributed clusters are either species with a wide distribution, like $R$. glandithyrsos, $R$. sprengelii, $R$. campaniensis, and 
$R$. insectifolius, or regionally distributed species with a tendency to a wider distribution (the supraregional species (R1) as given by Van de Beek et al. 2014), like $R$. taxandriae, $R$. baronicus, and R. lasiandrus (cf. Kurtto et al. 2010 for the distribution areas of these species). Only two of the differential taxa don't reach this status: Rubus erinulus, a regional species of Drenthe in the northern part of the Netherlands, and $R$. ceratus nom. prov., a local biotype along the German border near Winterswijk. The Rubus species characterising the widespread clusters (e.g. cluster 2, 3 and 4), like $R$. gratus, $R$. plicatus, and $R$. integribasis, are in fact really widespread species, and regionally distributed species are lacking in these clusters.

Our results show (Fig. 6.3) that regionally distributed vegetation types as such are only present along some parts of the transects, and that large parts of the transects are devoid of regionally distributed clusters, like the large central part of the southern transect, large parts of the central transect and, to certain extent, the southern part of the northern transect (although cluster 1 is found along almost all the length of this transect). Although we didn't study this in detail, we have the strong impression that the regionally distributed shrub types are only found in older landscapes, but absent in young landscapes. Such young landscapes are mostly represented by heathland and raised bog reclamation areas which were cultivated in the first decennia of the $20^{\text {th }}$ century, especially in the 1920 's and 1930's (Diemont 1996). Apparently most regional Rubus species, which arose and spread as a result of human impact on the landscape (Matzke-Hajek 1997), have a restricted dispersion capacity in comparison to the widespread species forming Rubus scrubs in these younger landscapes. A similar positive correlation between age and plant species diversity was shown for instance for calcareous (alvar) grasslands (Pärtel et al. 2007), and forest patches and afforested sunken roads (Honnay et al. 1999; Deckers et al. 2005). The mechanisms in both systems are different though: old grassland areas and forest patches are thought to accumulate widely distributed grassland or forest species invading the landscape over ages, but the accumulation of endemic Rubus species most probably is at least in part the result of speciation in loco in suitable 'landscape islands' (followed by subsequent regional dispersion). Both mechanisms were mentioned by Eriksson (1993) already as possible causes for larger species pools.

Other parts of the landscape, the 'blank areas' in Figure 6.1, seem to be completely unsuitable for bramble scrubs, but the causal factors are not yet clear. Possible causes are intensive grazing, like in parts of the central transect (viz. Oates 1996), or land reclamation activities resulting in young landscapes which are not yet invaded by brambles or which are devoid of suitable habitats (as was suggested by Haveman et al. 2012). A comprehensive study of Rubus diversity in the landscape and the causal factors determining the species richness has to shed light on this question. 


\section{Syntaxonomical considerations}

The treatment of the Rubus scrubs in the Dutch national vegetation classification (Haveman et al. 1999a; Haveman et al. 1999b) relies heavily on the classification of bramble scrubs in Germany by Weber (1977a, 1981a, 1986b; Pott 1995), with one major difference: the three accepted associations on nutrient and base poor soils are not included in the Franguletea Doing ex Westhoff 1969 but in the Lonicero-Rubetea plicati Haveman et al. 1999, as proposed some years before by Haveman (1997; see also Haveman et al. 2012 for a discussion). Within the Rhamno-Prunetea Rivas Goday \& Borja Carbonell ex Tüxen 1962, comprising the scrub vegetation on nutrient rich and/or base rich soils, Haveman et al. (1999b) distinguished two bramble associations, which were placed in the Pruno-Rubion radulae Weber 1974. Other scrub types in which brambles play an important role are the Roso-Juniperetum Tüxen 1974 (Haveman et al. 1999b), and the later successional stages of Hippophae rhamnoides scrubs in the coastal dunes (Haveman \& Van Haperen 2008; Van Haperen 2009).

The question remains whether the treatment of the Rubus scrubs in the DNVC (Haveman et al. 1999a; Haveman et al. 1999b) adequately reflects the existing variation we found in this study? To evaluate this question, we will make some syntaxonomical remarks for every principal group in Table 6.3 (indicated by a capital).

\section{A. Rubetum grati (column 1-3, Table 6.3)}

Column 1 in the table comprises relevés in which Rubus ammobius is (sub-)dominant. Weber (1998a) assigns mixed stands of Rubus ammobius and $R$. gratus to the Rubetum grati rubetosum ammobii Weber 1976, a scrub type which in Germany is restricted to the western part of Lower-Saxony and the north-western part of Westphalia. The Rubetum grati rubetosum ammobii, like the subassociation typicum (represented by columns 2 and 3), is characteristic for dry and nutrient poor, sandy soils. This community was not included in the DNVC, because only a few relevés from a very restricted area were available at the time of writing (Haveman et al. 1999a, p. 98). Although a number of the relevés made in this study can be assigned to this community, Rubus ammobius has its optimum in the transition zone between sandy soils and the lower peat lands in the northern part of the country. Here, the species forms a ruricolous (= with its main presence outside woodlands, see Weber 1986b) community along ditches and roads, typically with Alnus glutinosa in the tree layer, and moisture-indicating species in the field layer. A further analysis of this community has to reveal whether it can be distinguished as a separate association, or should be included in the Rubetum grati rubetosum ammobii.

The other two columns of group A comprise the classical Rubetum grati, described in the DNVC. 


\section{B. Rubetum silvatici (column 4-9, Table 6.3)}

Column 4 represents the 'classical' Rubetum silvatici, with three of the four character species mentioned by Weber (1998a): Rubus silvaticus, $R$. umbrosus (syn. R. pyramidalis), and $R$. flexuosus. In several publications, Weber (1986b, 1995) mentioned many other species growing in the Rubetum silvatici, and this was interpreted by Haveman et al. (1999a) as species being character species of this association: $R$. glandithyrsos, $R$. drenthicus, $R$. schlechtendalii, $R$. mucronulatus, $R$. lasiandrus, $R$. rubercadaver, $R$. taxandriae, and $R$. adspersus. In this study, these species are characteristic for separate communities in different parts of the country (columns 5-9, Table 6.3). On the basis of the results in this study and complementary observations during vegetation mapping projects, cluster 7 can best be considered as a separate association with a restricted regional distribution, the Rubetum taxandriae Haveman et al. (2012). The status of the other clusters is not yet clear, but probably they can be best considered as geographical races (cf. Dierschke 1994, p. 312-320) of the Rubetum silvatici. Especially the $R$. glandithyrsos- $R$. erinulus form (column 5, Table 6.3) is entangled with the classical Rubetum silvatici, although the area of the latter is extending more to the south, where the $R$. glandithyrsos- $R$. erinulus form is lacking.

Two of the clusters belonging to this principal group could not be assigned to an already described association, viz. cluster 6 and 9. They both consist of one relevé each, with a dominant Rubus species with an yet unknown sociological preference: $R$. schlechtendalii and $R$. longior respectively. More detailed studies of the bramble scrubs in the regions where these species occur have to shed light on the synsystematic place of these scrubs.

\section{Lonicero-Rubion silvatici (column 10-14, Table 6.3)}

Column 10 in Table 3 comprises those relevés in which characters species of associations are lacking, but in which character species of the Lonicero-Rubion silvatici are dominating, like Rubus plicatus, $R$. integribasis, $R$. affinis or $R$. nemoralis. This column could be split up in several different clusters to reflect the variation in the abundance of Rubus species, but this variation is not geographically structured (not shown). Probably such species poor stands can be included in the Rubetum grati, which classically consists of rather dense scrubs with $R$. gratus as the dominant species (Weber 1977a; Pott 1995; Weber 1998a). According to our table, $R$. gratus is not at all restricted to this kind of scrubs though, but can be found in almost all bramble scrubs on nutrient poor soils in the Netherlands (and most probably in most of the bramble scrubs in the northwest European lowlands). Therefore, $R$. gratus could better be concerned as a character species of the alliance Lonicero-Rubion silvatici. As a consequence, the Rubetum grati could at best be regarded the central association (Dierschke 1997) of this alliance. This amended Rubetum grati consequently has to include the other communities of the alliance without own character species in which the species of the alliance are abundant, 
like our community 10 . We abstain from a final decision here until more is clear about the ecology of the different forms of such an amended Rubetum grati.

Clusters 11 to 13 are characterised by the abundant occurrence of Rubus macrophyllus. Usually, this species is considered as character species of the Pruno-Rubion radulae (Weber 1990, 1995), and in the Netherlands, this species is common in Pruno-Rubion radulae scrubs. However, as Haveman et al. (1999b, p. 162) have pointed out, this species lost his diagnostic character for any of the Rhamno-Prunetea communities to a large extent, due to the spread in formerly nutrient poor regions as a result of atmospheric deposition of nitrogen. In this respect, $R$. macrophyllus resembles Sambucus nigra (Weber 1999b, 2003b). In the DNVC, communities dominated by $R$. macrophyllus were mentioned, but not documented with tables. Cluster 11 differs from the other two clusters by the dominance of $R$. iuvenis, a species that is thought to be characteristic for the Senecioni-Rubetum ignorati Weber 1985 prov. (Sambuco racemosae-Salicion capreae Tx. et Neumann in Tx. 1950; Weber 1986b). The Sambuco-Salicion was discussed by Haveman et al. (1999b, p. 128-129), but relevés were lacking at the time, so it was not treated in detail in the DNVC. Recent studies in the Sauerland and South-Limburg, where the Senecioni-Rubetum ignorati is common, have shown that our cluster 11 cannot be assigned to this association (not published). ${ }^{2}$

Cluster 14 comprises Rubus adspersus-rich stands of the Lonicero-Rubion silvatici. Although this species was considered to be characteristic for the Rubetum silvatici in the DNVC, there is hardly any connection between this community and the clusters which were unequivocally assigned to the Rubetum silvatici (4-9). Rubus adspersus can be common in certain forms of the Pruno-Rubion radulae too (e.g. cluster 13).

\section{Dicrano-Juniperetum (column 15, Table 6.3)}

Cluster 11 isn't a Rubus scrub as such, but a Rubus-rich (late successional) stage of the Dicrano-Juniperetum Barkman 1985. Such stadia were not accounted for in the DNVC.

\section{E.-F. Pruno-Rubetum vestiti \& Pruno-Rubion radulae (columns 16-21, Table 6.3)}

Clusters 16-21 can unequivocally be assigned to the alliance Pruno-Rubion radulae, on the basis of the species in the higher shrub layer, such as Crataegus monogyna, Prunus spinosa, and Rosa canina. Clusters 17, with Rubus adspersus, and sparse Crataegus monogyna, Prunus spinosa, and Rosa canina, and cluster 18, with these spiny scrub species and

2 After the publication of this paper, Haveman et al. (2014) described the Rubus community of forest clearings in the Sauerland and South-Limburg as Senecioni ovati-Rubetum iuvenis Haveman \& De Ronde, which was placed in the validated Athyrio felicis-feminae-Rubion idaei Passarge ex Haveman, De Ronde \& Weeda (Rhamno-Prunetea). See also the general discussion in this thesis (chapter 8). 
Rubus species with their optimum in the Lonicero-Rubion silvatici, belong to the PrunoRubetum sprengelii. Surprisingly, the Pruno-Rubetum sprengelii was recorded in all three transects, in the vicinity of lowland rivulets and - in the northern transect - in areas with base rich bolder clay, although this association was not described by Haveman et al. (1999b). It was mentioned as being probably present (Haveman et al. 1999b, p. 133), but at the time of publication, relevés were lacking.

The assignment of the clusters 19-21 to one of the associations of the Pruno-Rubion is unclear. Comparison of the descriptions of the associations of the Pruno-Rubion radulae in various publications (e.g. Weber 1999b; Preising et al. 2003) makes clears that the species compositions of the associations are remarkably differing between regions. More relevés and an supra-regional treatment of the alliance have reveal which associations can be recognised eventually.

\section{G. BC Rubus armeniacus}

The lack of species from both the Lonicero-Rubion and the Pruno-Rubion in cluster 22, with the dominant invasive neophyte Rubus armeniacus, make the placement of this scrub type in one of these alliances problematic. Pott (1995) considered similar thickets as communities without syntaxonomic position, Weeda et al. (1999) in the DNVC included them as a derived community of the Galio-Urticetea.

From the above, it is clear that only a part of the observed diversity is covered by the DNVC (Haveman et al. 1999a; Haveman et al. 1999b), and that several regional, undescribed Rubus scrub types can be distinguished. Their formal description would be contrary to the trend to recognise only over-regional associations, which was described by Dierschke (1994, p. 301-302) already. This trend is intensified by the availability of databases with hundreds of thousands of digitised relevés, making international overviews on the basis of original material possible for the first time (see e.g. Bruelheide \& Chytry 2000; BottaDukát et al. 2005; Illyés et al. 2007). The recognition of vegetation types with limited distribution is to some extent given with the specific structure of the genus though, with many regionally distributed species. Our results show that the major variation in bramble scrubs is not random, but formed by regular occurring combinations of species, and which we believe should be recognised in a formal classification system at some level.

\section{Notes on nature conservation}

The density of relevés in this study (Fig. 6.1) emphasizes the importance of Rubus scrubs in the sand landscapes of north-western Europe. Despite the late discovery as independent communities, they form a characteristic element in large parts of the landscape, and they add to the regional biodiversity and regional landscape identity. Due 
to practical problems concerning the complex taxonomy and recognition of apomicts and the ignorance of nature conservation practitioners, apomict lineages are often not considered in either nature conservation practice nor policy (Gregor \& Matzke-Hajek 2002; Haveman et al. 2002), although several German 'Länder' have included Rubus species in their Red Lists (Frank et al. 2004; Jansen 2006). In contrast to Britain, where special conservation action plans are developed for rare Rubus species (Randall \& Rich 2000, 2001), brambles are considered a nuisance and an indication of environmental deterioration in the Netherlands in most cases (see for some discussion on this topic Bijlsma 2004). Especially bramble scrubs on loamy soils can harbour rare and only regionally distributed (endemic) Rubus species though (Matzke-Hajek 1997; Weeda $e t$ al. 2005, p. 77), as was shown in this paper too. Other places of special interest for Rubus diversity are margins of ancient forest remnants and old wooded banks. Already in the early fifties of last century, Beijerinck \& Ter Pelkwijk (1952) noted that amongst the woodland dwelling bramble species several are confined to old forests. As such, communities in which brambles play an important role deserve more attention in nature conservation than until now is given.

\section{Conclusion}

From this study we conclude that the regional variation in Rubus scrubs is substantial. The high number of Rubus species doesn't lead to a random variation with countless combinations of species: with the help of a systematically-randomised sampling scheme we were able to show that regular combinations of Rubus species form distinct scrub types, several of which have a regional distribution.

Only a part of the observed diversity is covered by the treatment of the bramble scrubs in the DNVC (Haveman et al. 1999a; Haveman et al. 1999b). Especially within the Lonicero-Rubion silvatici, the regional diversity is high. Surprisingly, Pruno-Rubion radulae communities were found at a rather high density in the central transect; these scrub types are largely overlooked in the DNVC. More relevés are needed before a final decision can be made on the status of most of the regionally distributed scrub types and the types belonging to the Pruno-Rubion radulae. The same holds true for the scrubs with dominant rare species. Several regions seem to be devoid of Rubus scrubs, but the specific causes for this are not yet clear (landscape history and heavy grazing are hypothesised as causes in this paper). The density of relevés made in this study emphasize the importance of bramble scrubs in the landscape of north-western Europe, and we advocate more awareness of the value represented by bramble dominated communities. 
CHAPTER 7

The Rubetum taxandriae ass. nov. (Lonicero-Rubion silvatici, Lonicero-Rubetea plicati), a new bramble association from the Belgian and Dutch Campine

Slightly modified from:

Haveman, R., I. de Ronde \& E.J. Weeda, 2012. The Rubetum taxandriae ass. nov. (LoniceroRubion silvatici, Lonicero-Rubetea plicati), a new bramble association from the Belgian and Dutch Campine. - Tuexenia 32: 55-65. 


\section{Abstract}

Bramble scrubs are among the least known and understood vegetation types in Europe. In the Dutch National Vegetation Overview, three associations belonging to the Lonicero-Rubion silvatici were distinguished, viz. the Rubetum grati, Rubetum silvatici, and Rubetum pedemontani. During several vegetation mapping projects and Rubus excursions, a distinct type of bramble scrub was recorded repeatedly in the Campine in the province Noord-Brabant in the southern part of the Netherlands. In this paper, this scrub is described as a new association, the Rubetum taxandriae Haveman, De Ronde \& Weeda, with $R$. taxandriae, $R$. campaniensis, and $R$. baronicus as character species, and $R$. insectifolius as regional character species. Variation, ecology and distribution of this new association are given and discussed, and two subassociations are distinguished. The differences with the Rubetum silvatici, to which this community was believed to belong, are discussed. Based on an earlier analysis of the centres of diversity of the genus Rubus in the Netherlands, it is supposed that the Rubetum silvatici in its circumscription in the Dutch National Vegetation Overview can be divided in more regionally distributed communities, partly as subassociations of the Rubetum silvatici, partly as independent associations. 


\section{Introduction}

Bramble scrubs are among the least known and understood vegetation types in Europe. In the comprehensive overview of the scrubs in the temperate and boreal parts of Europe given by Weber $(1997,1998 b)$, relevés in which apomictic Rubus species were adequately identified had almost only been made in Germany. The bramble scrubs of north-western Europe were placed in separate alliances and in two separate classes. The scrubs of relatively nutrient rich and/or base rich soils are united in the PrunoRubion radulae Weber 1974, an alliance of the Rhamno-Prunetea Rivas Goday \& Borja Carbonell ex Tüxen 1962, whereas the Lonicero-Rubion silvatici Tüxen et Neumann ex Wittig 1977, containing scrubs of nutrient poor and acidic soils, were placed in the Franguletea Doing 1962 ex Westhoff in Westhoff \& Den Held 1969 (Weber 1990; Pott 1995; Weber 1998a, 1999b, 2003b). In the Dutch national vegetation overview, this classification scheme was adopted for the greater part, and several Rubus associations were documented shortly after Weber published his overview (Haveman et al. 1999a; Haveman et al. 1999b). A remarkable difference was the description of a separate class Lonicero-Rubetea plicati Haveman et al. 1999 for the scrubs on nutrient poor acidic soils, as advocated by Haveman (1997) some years before.

Haveman et al. (1999a) distinguished three associations within the Lonicero-Rubetea plicati for the Netherlands: the Rubetum grati Tüxen et Neumann ex Weber 1976, the Rubetum silvatici Weber in Pott 1995, and the Rubetum pedemontani Weber in Pott 1995. According to Weber (1998a), the character species of the Rubetum silvatici are Rubus silvaticus, $R$. pyramidalis (=R. umbrosus), $R$. flexuosus, and $R$. sprengelii but Haveman et al. (1999a) and Weeda et al. (2005) considered many more species as such: $R$. adspersus, $R$. campaniensis, $R$. drenthicus, $R$. erinulus, $R$. foliosus $R$. glandithyrsos, $R$. lasiandrus, $R$. mucronulatus, $R$. rubrumcadaver, $R$. schlechtendalii and $R$. taxandriae. However, the authors suggested that when more relevés would become available from the Netherlands, the Rubetum silvatici in the given circumscription would probably appear to be a 'composite association', comprising of a number of more clearly defined, regionally distributed vegetation types (Haveman et al. 1999a, p. 96).

During the vegetation mapping projects of military training areas, and a study of the bramble scrubs along three landscape transects (Haveman et al. 2014a) a distinct bramble scrub was recorded repeatedly in the Campine in the province Noord-Brabant, in the southern part of the Netherlands. The two most frequent Rubus species in this scrub type are $R$. campaniensis and $R$. taxandriae, which were among the species considered to be character species of the Rubetum silvatici by Haveman et al. (1999a). Two other species occurring in these scrubs are $R$. baronicus and $R$. insectifolius. These four species are lacking in the North-German lowlands, which is the distribution centre of the Rubetum silvatici. At least the first two are frequently found in the southern part of the 
Netherlands and the adjacent part of Flanders/Belgium. Reversely, the character species of the Rubetum silvatici s.str. are virtually absent in the scrubs formed by $R$. campaniensis and $R$. taxandriae.

In this paper we describe this bramble scrub from the Campine as a new association, belonging to the Lonicero-Rubion silvatici.

\section{Area}

The Campine is the area between the rivers Scheldt and Meuse, roughly situated between Antwerpen and Hasselt in Belgium and Eindhoven in the Netherlands (Fig. 7.1). The area was never covered by the ice caps during the Pleistocene, in contrast with more northern parts of the Netherlands. The area is largely covered by Pleniglacial aeolian cover sands from the Weichselian $(116,000-11,500 \mathrm{BP})$, incised by many rivulets and brooks draining the area towards the two mentioned large rivers. Although the area is slightly undulating, the differences in altitude are small $(0-50 \mathrm{~m}$ above sea level). The climate is sub-Atlantic, with a precipitation surplus in all months (Fig. 7.2), a total annual precipitation of $707 \mathrm{~mm}$, and an annual average temperature of $9.8^{\circ} \mathrm{C}$. (Sluijter 2011).

\section{Material and methods}

\section{Relevés}

For this study 38 relevés were used in which Rubus taxandriae, $R$. campaniensis, $R$. baronicus, and $R$. insectifolius reach a combined cover of at least 5\%. They were collected between 1998 and 2011 in several mapping projects of military ranges, during several excursions in the region, and in a study of the species composition of bramble scrubs along three landscape transects (Haveman et al. 2014a). The relevés are all stored in the Dutch National Vegetation Database (Jansen et al. 2011) using TurboVeg (Hennekens \& Schaminée 2001).

All phanerogam and cryptogam species were recorded in as many layers as necessary to describe the vegetation structure. Species names are according Van de Beek et al. (2014) or the Rubus species, Van der Meijden (2005) for the other phanerogams, and Siebel $\&$ During (2006) for the mosses. The abundance of the species was recorded using the modified scale of Braun-Blanquet (Barkman et al. 1964). Due to the diverse origin of the data, the area of the used relevés varies considerably (from 15 to $70 \mathrm{~m}^{2}$ ), but all relevés are considered to be homogeneous as to the species composition.

For a comparison with the Rubetum silvatici, we selected relevés from the Dutch National Vegetation Database (Schaminée et al. 2006; Jansen et al. 2011) which met the following three conditions: 1.) the combined abundance of the four character species 


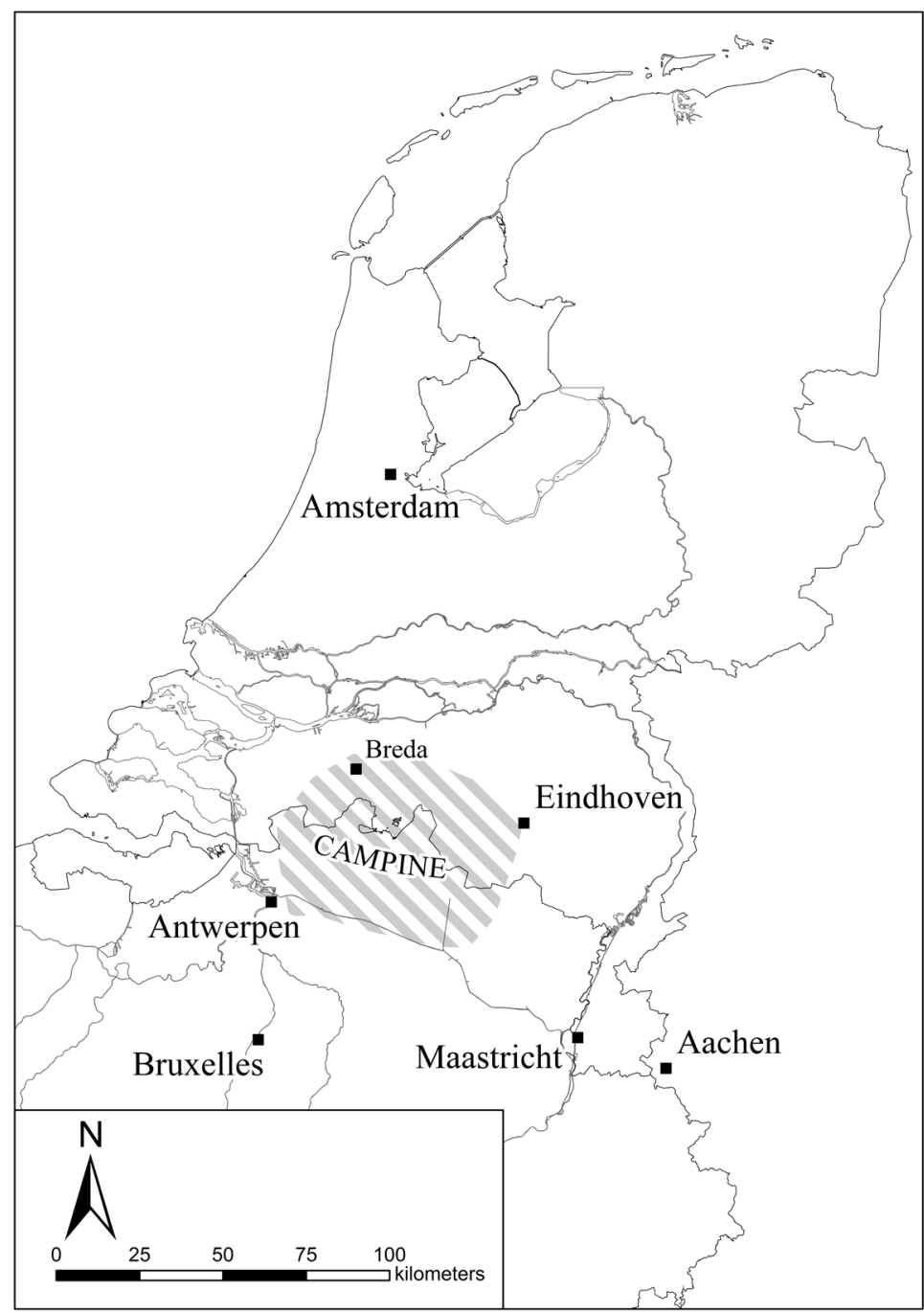

Figure 7.1: The Benelux countries with some major towns and an indication of the location of the Campine.

(Rubus silvaticus, R. umbrosus, R. flexuosus, and R. sprengelii) $>5 \%$, 2.) relevé area $10-50$ $\mathrm{m}^{2}$, and 3.) the combined abundance of species of the Rhamno-Prunetea (e.g. Crataegus monogyna, Prunus spinosa) $<5 \%$.

\section{Synthetic phase}

Both the subdivision of the new association and the comparison with the Rubetum silvatici were performed in JUICE (Tichý 2002). For these analyses, we combined high, middle, and low tree layer into one tree layer, and we used two shrub layers (high for 


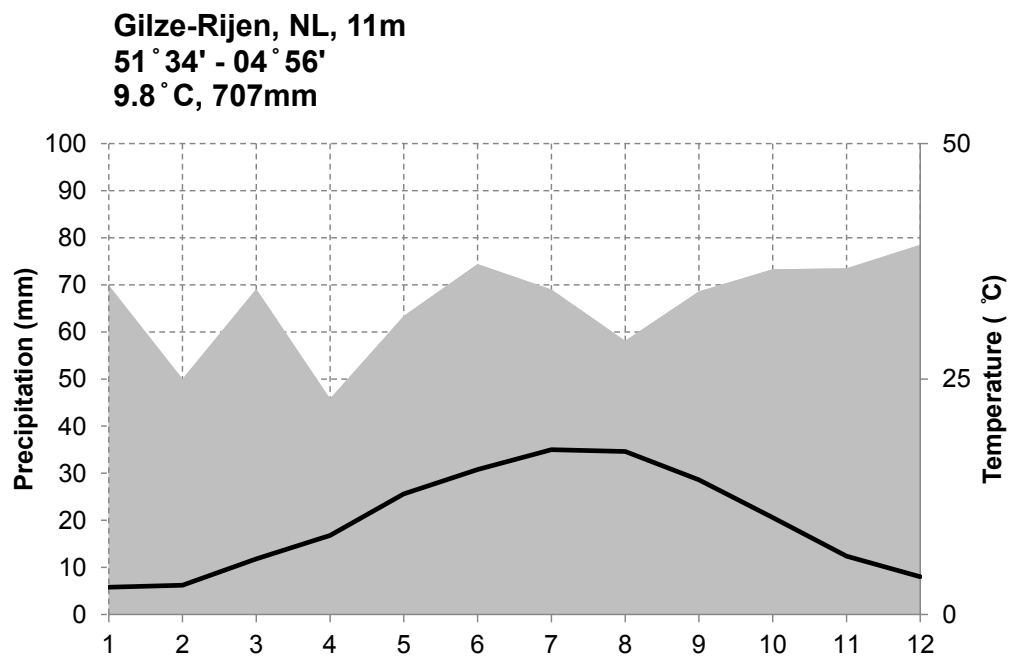

Figure 7.2: Walter \& Lieth climate diagram Gilze-Rijen (Sluijter 2011). Given in the title are the name and location of the station, elevation $(\mathrm{m})$, mean annual temperature $\left({ }^{\circ} \mathrm{C}\right)$, and annual precipitation $(\mathrm{mm})$ for the 30 yrs normal period 1981-2010.

the scrubs excl. Rubus and lianas, low for the Rubus species and lianas), one herb layer (combining herbs, juveniles and saplings of trees and shrubs), and a moss layer.

To detect patterns in the species composition in the used dataset, we used the modified TWINSPAN algorithm as suggested by Roleček et al. (2009); only one subdivision was recognised and the results given by TWINSPAN were refined subjectively on the basis of expert judgement. To compare differences in species composition, we made a combined synoptic table (in percentages, see the recommendations by Dengler et al. 2006, p. 84) of the new association and the Rubetum silvatici. For the identification of differential species of the Rubetum taxandriae and the Rubetum silvatici frequency classes (Dierschke 1994) were used: species are considered to be differential if they differ at least two classes between the columns.

\section{Rubetum taxandriae Haveman, De Ronde \& Weeda ass. nova}

Holotypus: relevé 31 (September $8^{\text {th }} 2009$, western border Ulvenhoutse Bos, authors R. Haveman 09-515 and J.H.J. Schaminée 09-120), Table 7.1 of this publication.

\section{Species composition, structure, and variation}

Table 7.1 shows the species composition of the newly described Rubetum taxandriae. Rubus taxandriae and $R$. campaniensis are the character species, and most probably the same holds for the rare $R$. baronicus. Rubus insectifolius can only be considered as regional character species, since it has a much wider distribution than the aforementioned three species. Character species of the Rubetum silvatici rarely occur together with those of 


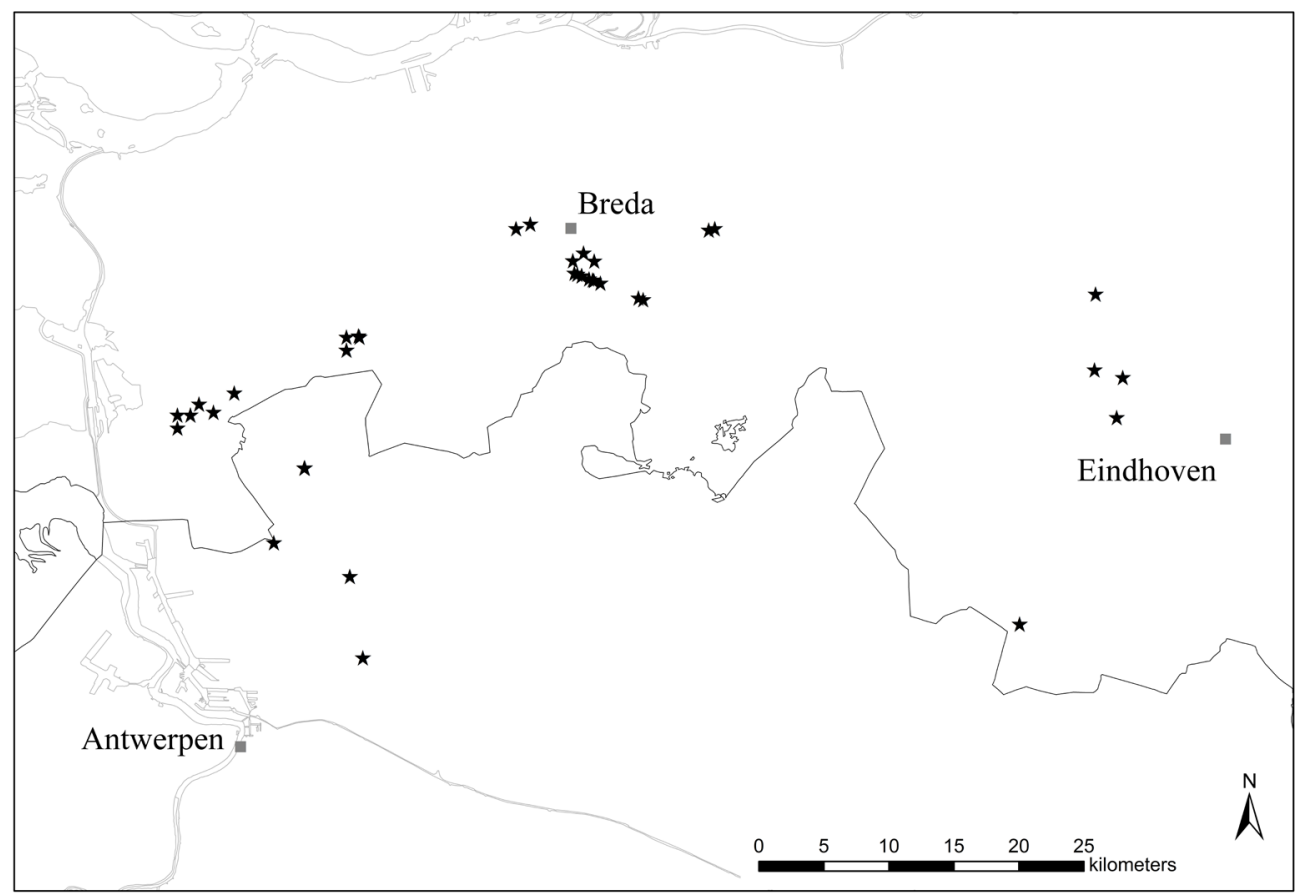

Figure 7.3: Location of vegetation relevés of the Rubetum taxandriae used in this study.

the Rubetum taxandriae, and vice versa (Table 7.2); until now only $R$. umbrosus has sometimes been recorded in the Rubetum taxandriae.

Frequent companions among other Rubus species are $R$. gratus, $R$. plicatus, $R$. integribasis, $R$. nessensis, $R$. frederici, $R$. calotemnus, and $R$. macrophyllus. As is clear from table 7.2, $R$. frederici, $R$. integribasis, $R$. macrophyllus, $R$. calotemnus, $R$. geniculatus, $R$. bertramii, and $R$. planus have a higher frequency in the Rubetum taxandriae than in the Rubetum silvatici, and can be regarded as differential species of the new association. They either have their optimum in Pruno-Rubion radulae communites ( $R$. macrophyllus, $R$. geniculatus) (Weber 1995; Haveman et al. 1999b; Weber 1999b, 2003b), or have a broad sociological amplitude and may be regarded as character species of the LoniceroRubion silvatici occurring in the southern part of the area of this alliance (Weber 1995, 1998a; Haveman et al. 1999a; Weber 2003b; Haveman et al. 2014a). On the other hand, $R$. drenthicus, $R$. glandithyrsos, $R$. erinulus, $R$. discors, $R$. idaeus, $R$. ammobius, and $R$. schlechtendalii are more frequent in the Rubetum silvatici. While $R$. ammobius, $R$. discors, and $R$. drenthicus can probably be regarded as character species of the LoniceroRubion silvatici, the sociological optimum of the other species is not yet clear. Probably they have their optimum in the Rubetum silvatici, characterising regional subassociations (see also the last section of this paper). 


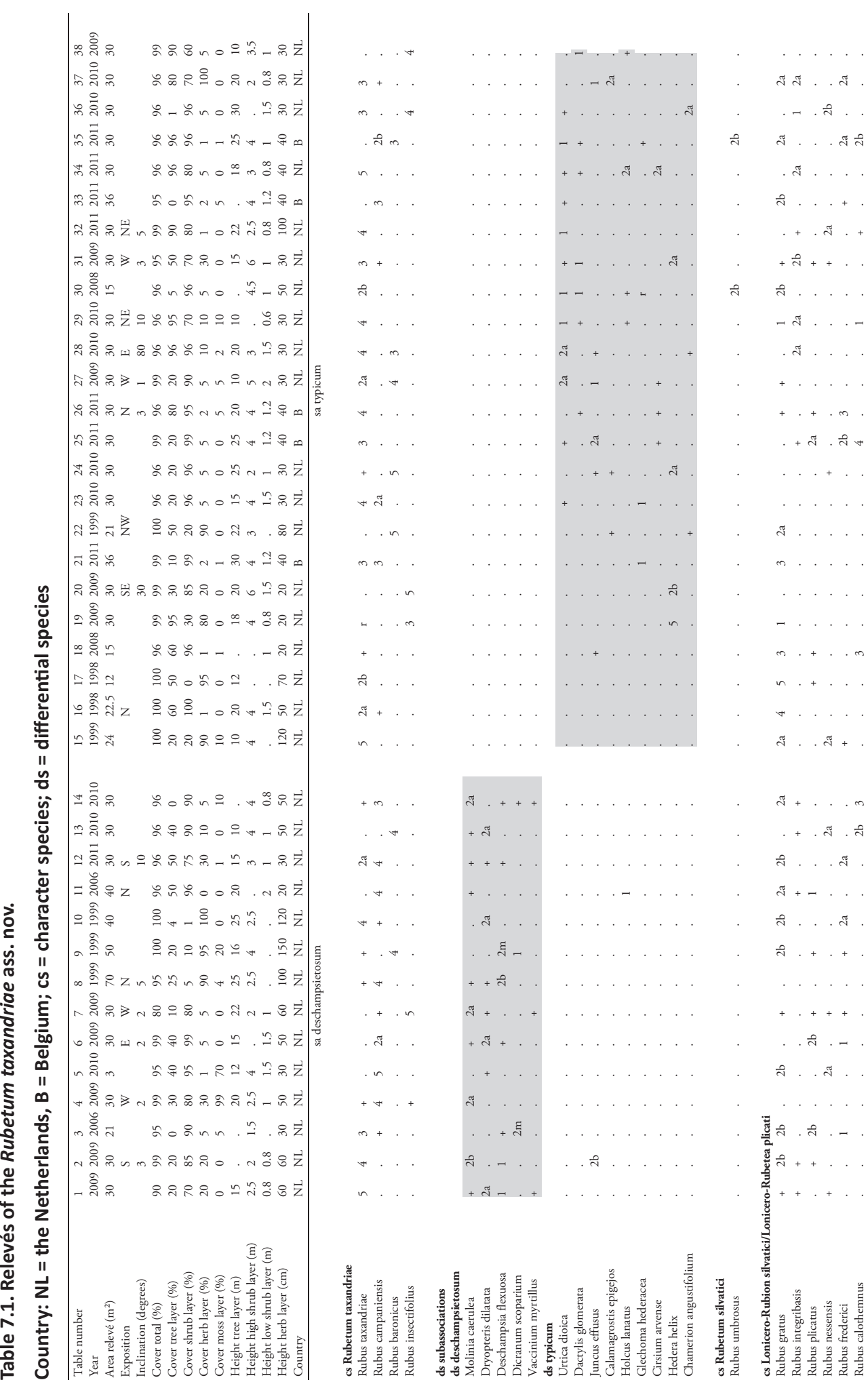




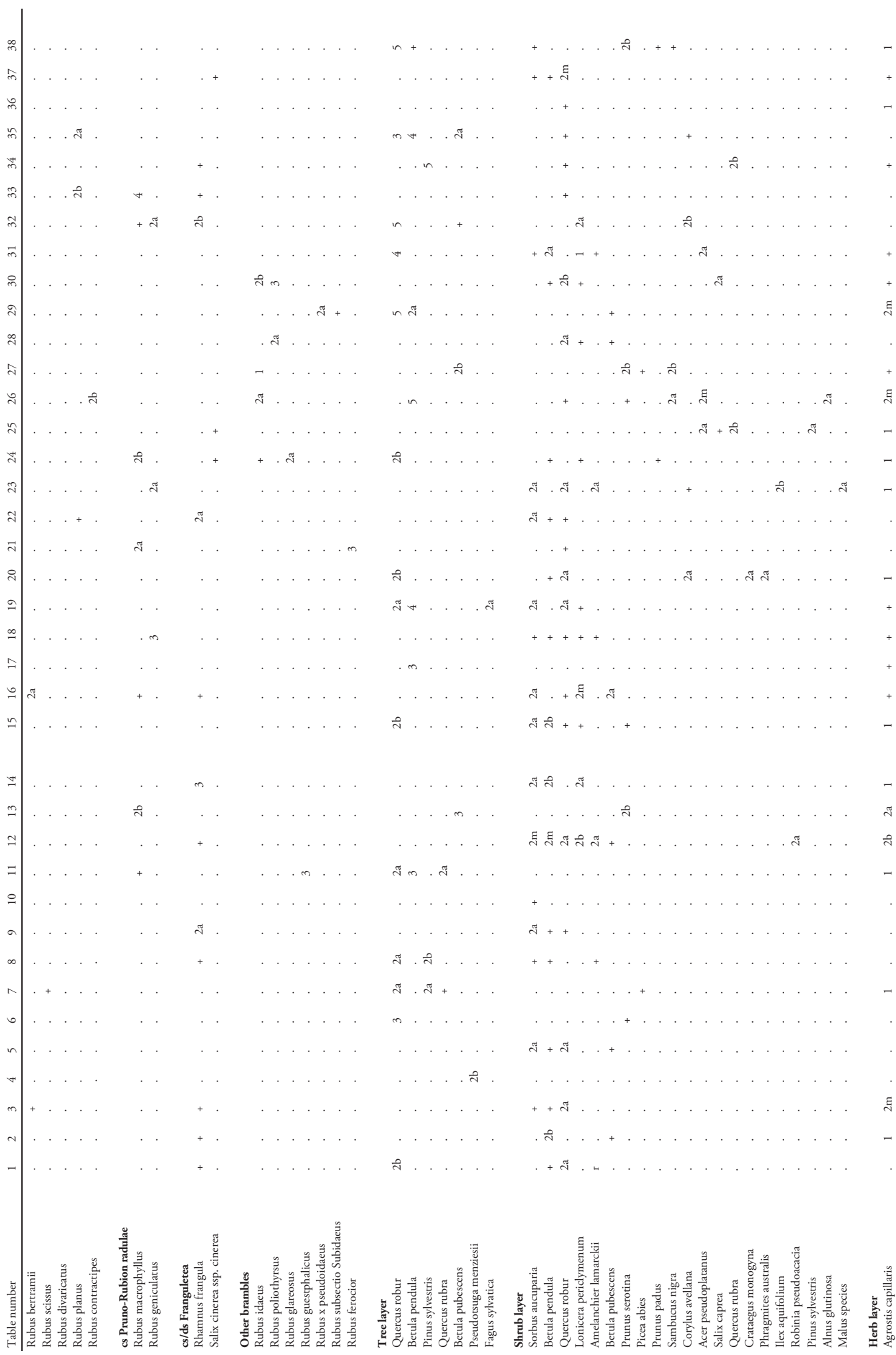




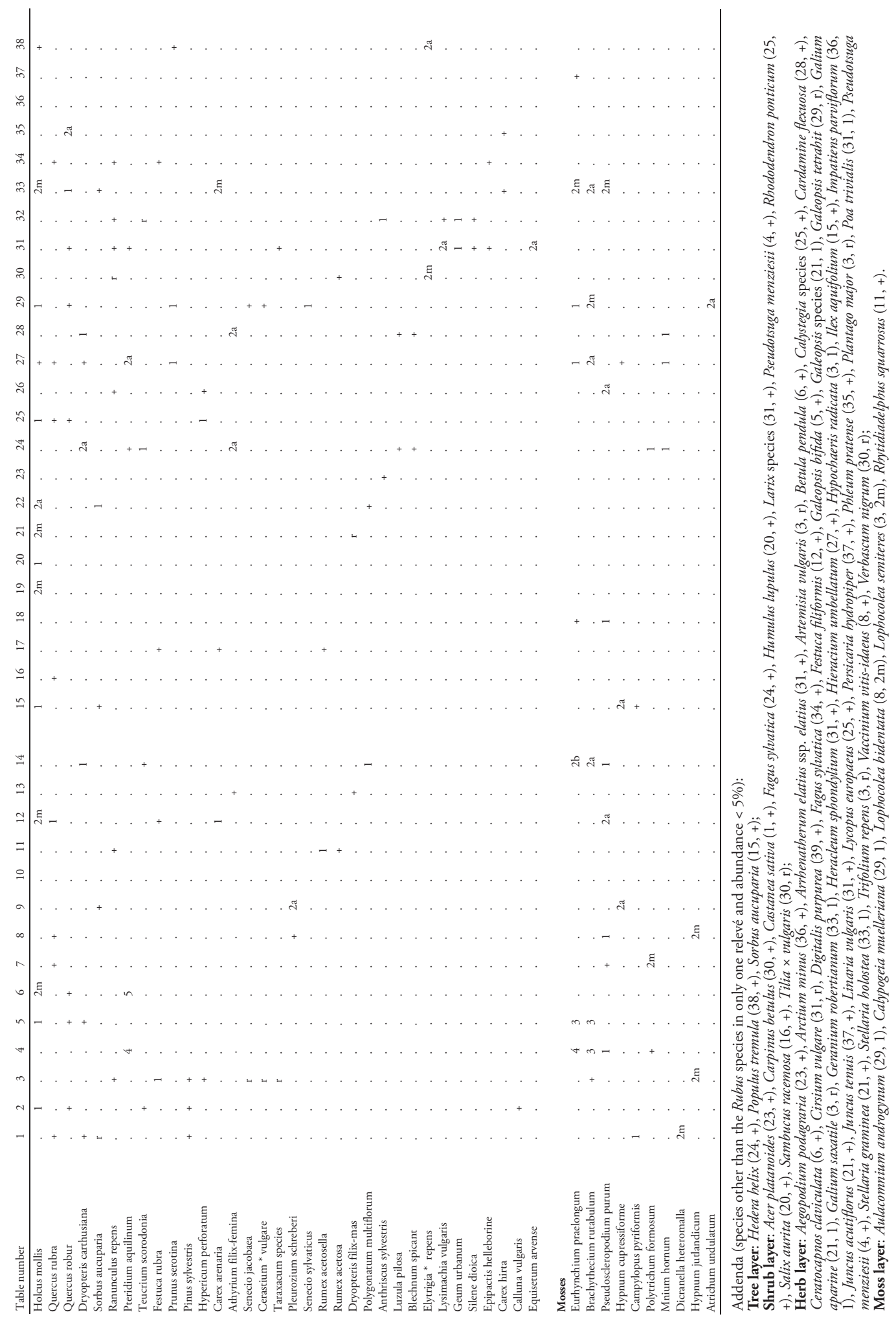


Frequently accompanying species are Quercus robur and Betula pendula in the tree and shrub layers, and Sorbus aucuparia, Lonicera periclymenum, Rhamnus frangula, and Amelanchier lamarckii in the shrub layer. Typically, the herb and moss layer are not well developed because of the dense bramble layer. Agrostis capillaris, Molinia caerulea, and Holcus mollis are the most frequent species in the herb layer, while Kindbergia praelonga, Brachythecium rutabulum, Hypnum cupressiforme, and Pseudoscleropodium purum can be found more or less frequently in the moss layer. Betula pendula is a weak differential species of the Rubetum taxandriae in comparison to the Rubetum silvatici. The opposite holds for Sorbus aucuparia and Holcus mollis, which occur more often in the Rubetum silvatici (Table 7.2).

Typically, the Rubetum taxandriae is a dense thicket of about $1 \mathrm{~m}$ height in which two or more Rubus species grow together under an open tree layer and higher shrub layer. Coenoses with only one of the character species without accompanying Rubus species are considered as association fragments. Such fragments can be found throughout the distribution area of the association, and also beyond the border of the main distribution area in the Campine, for instance in the Peel region (see under "Distribution").

Two subassociations can be distinguished:

Rubetum taxandriae typicum subass. nova

Holotypus: as association.

The Rubetum taxandriae typicum is negatively characterised by the absence of the species of the deschampsietosum subassociation. Besides this, it has several rather weak differential species: Lonicera periclymenum, Urtica dioica, Dactylis glomerata, Holcus lanatus, Calamagrostis epigejos, and Hedera helix. Among the brambles, Rubus idaeus, $R$. macrophyllus, and $R$. poliothyrsus show a clear preference for this subassociation (table 7.1).

Rubetum taxandriae deschampsietosum flexuosae subass. nova

Holotypus: relevé 12 (May 30 ${ }^{\text {th }}$ 2011, military air field Woensdrecht, author R. Haveman 11-019 and I. De Ronde 11-015), table 7.1 of this publication.

The Rubetum taxandriae deschampsietosum flexuosae is characterised by the occurrence of Deschampsia flexuosa, Molinia caerulea, Dryopteris dilatata, Vaccinium myrtillus, Brachythecium rutabulum, and Dicranum scoparium. Rubus campaniensis is more frequent in this subassociation than in the Rubetum taxandriae typicum (table 7.1). 
Table 7.2. Shortened frequency table of the Rubetum taxandriae (column 1) and the Rubetum silvatici (column 2). Frequencies are given in percentages. Except for the Rubus species, species with a frequency $<20 \%$ in both columns are omitted. Character species and differential species (with a frequency class difference of at least two classes) are boxed.

\begin{tabular}{|c|c|c|}
\hline Column & 1 & 2 \\
\hline Number of relevés & 39 & 67 \\
\hline \multicolumn{3}{|l|}{ ca Rubetum taxandriae } \\
\hline Rubus taxandriae & 73 & . \\
\hline Rubus campaniensis & 45 & . \\
\hline Rubus baronicus & 18 & . \\
\hline Rubus insectifolius & 15 & . \\
\hline \multicolumn{3}{|l|}{ ca Rubetum silvatici } \\
\hline Rubus flexuosus & . & 51 \\
\hline Rubus umbrosus & 5 & 39 \\
\hline Rubus silvaticus & . & 33 \\
\hline Rubus sprengelii & . & 31 \\
\hline \multicolumn{3}{|c|}{ optimum in Rubetum taxandriae (partly da) } \\
\hline Rubus integribasis & 33 & 3 \\
\hline Rubus frederici & 33 & . \\
\hline Rubus calothemnus & 18 & 1 \\
\hline Rubus macrophyllus & 18 & 4 \\
\hline Rubus geniculatus & 8 & . \\
\hline Rubus planus & 8 & . \\
\hline Rubus bertramii & 8 & . \\
\hline \multicolumn{3}{|c|}{ optimum in Rubetum silvatici (partly da) } \\
\hline Rubus drenthicus & . & 21 \\
\hline Rubus idaeus & 10 & 36 \\
\hline Rubus glandithyrsos & . & 15 \\
\hline Rubus erinulus & . & 10 \\
\hline Rubus discors & . & 10 \\
\hline Rubus ammobius & . & 4 \\
\hline Rubus schlechtendalii & . & 4 \\
\hline \multicolumn{3}{|l|}{ da associations } \\
\hline Betula pendula & 60 & 19 \\
\hline Sorbus aucuparia & 50 & 81 \\
\hline Holcus mollis & 35 & 61 \\
\hline \multicolumn{3}{|l|}{ bramble layer } \\
\hline Rubus gratus & 68 & 79 \\
\hline Rubus plicatus & 30 & 24 \\
\hline Rubus nessensis & 23 & 16 \\
\hline Rubus contractipes & 3 & 6 \\
\hline Rubus scissus & 3 & 4 \\
\hline Rubus poliothyrsus & 5 & 1 \\
\hline Rubus vigorosus & . & 4 \\
\hline Rubus ferocior & 3 & 1 \\
\hline Rubus laevicaulis & . & 3 \\
\hline Rubus nemoralis & . & 3 \\
\hline Rubus guestphalicus & 3 & . \\
\hline Rubus glareosus & 3 & . \\
\hline Rubus $x$ pseudoidaeus & 3 & . \\
\hline Rubus subsectio Subidaeus & 3 & . \\
\hline Rubus contritidens & . & 1 \\
\hline Rubus arrhenii & . & 1 \\
\hline Rubus adspersus & . & 1 \\
\hline Rubus trichanthus & . & 1 \\
\hline Rubus camptostachys & . & 1 \\
\hline Rubus calvus & . & 1 \\
\hline Rubus speculans & . & 1 \\
\hline \multicolumn{3}{|l|}{ other species } \\
\hline \multicolumn{3}{|l|}{ tree and scrub layer } \\
\hline Quercus robur & 83 & 75 \\
\hline Lonicera periclymenum & 28 & 52 \\
\hline Rhamnus frangula & 33 & 30 \\
\hline Betula pubescens & 25 & 19 \\
\hline Quercus rubra & 25 & 4 \\
\hline Pinus sylvestris & 20 & 3 \\
\hline \multicolumn{3}{|l|}{ herb layer } \\
\hline \multicolumn{3}{|l|}{ grasses } \\
\hline Agrostis capillaris & 65 & 69 \\
\hline Molinia caerulea & 30 & 18 \\
\hline Deschampsia flexuosa & 25 & 21 \\
\hline
\end{tabular}




\begin{tabular}{|c|c|c|}
\hline Column & 1 & 2 \\
\hline Elytrigia repens & 5 & 22 \\
\hline \multicolumn{3}{|l|}{ herbs } \\
\hline Urtica dioica & 30 & 49 \\
\hline Galeopsis tetrahit & 3 & 24 \\
\hline Ceratocapnos claviculata & 3 & 19 \\
\hline Cirsium arvense & 10 & 1 \\
\hline Teucrium scorodonia & 10 & . \\
\hline \multicolumn{3}{|l|}{ ferns } \\
\hline Dryopteris dilatata & 25 & 42 \\
\hline Pteridium aquilinum & 13 & 4 \\
\hline Dryopteris carthusiana & 18 & 1 \\
\hline \multicolumn{3}{|l|}{ moss layer } \\
\hline Hypnum cupressiforme & 13 & 27 \\
\hline Eurhynchium praelongum & 20 & 6 \\
\hline Pseudoscleropodium purum & 20 & 3 \\
\hline
\end{tabular}

\section{Ecology}

The Rubetum taxandriae is a mesophilous and silvicolous (i.e. confined to the direct influence of woodlands) bramble scrub in woodland edges and forest clearings on loamy to loam-poor, rather nutrient poor, sandy soils. Far less often it is found in hedges, wooded banks or between agricultural tracts. The Rubetum taxandriae deschampsietosum is confined to heathland afforestations from the late $19^{\text {th }}$ and early $20^{\text {th }}$ century, and is mainly found along woodland paths and in woodland clearings ("Innensäume"). The Rubetum taxandriae typicum grows on sites with a slightly better nutrient availability, especially at the outer borders of forests, and in old forest remnants. Under a dense canopy the brambles die back, since the light demands of characteristic Rubus species are no longer met. Only in woodlands with an open canopy, especially in Pinus sylvestris and Quercus robur forests, both Rubus campaniensis and $R$. taxandriae can form a dense, species poor knee-high bramble layer in the undergrowth (cf. Bijlsma 2004); the synsystematic position of such Rubus-rich forests still has to be settled. On very nutrient-poor soils the Rubetum taxandriae is replaced by the Rubetum grati.

\section{Distribution}

The distribution area of the Rubetum taxandriae includes the Dutch part of the Campine and the Baronie (Western Noord-Brabant, eastwards to the Eindhoven area) and at least parts of the Belgian Campine; the latter area has not yet been explored extensively. Fig. 7.2 gives the distribution of the relevés used in this paper. Association fragments can also be found in the "Peel" region, northeast of the Campine, where Rubus campaniensis is the only character species of the association. Distribution maps of the character species of the association (Kurtto et al. 2010) suggest that it can be found south of the Campine, but relevés are lacking.

According to our observations, the Rubetum taxandriae is much more common in the western part of the Campine, between the towns of Antwerpen and Breda, than in the eastern part, around Turnhout and Eindhoven. Probably this has its background in the landscape history of the region. The western part was developed much earlier than 
the eastern part. This is obvious from the military topographical map of around 1850 (Anonymus 1995): the development of the western part of the Campine has led to a small scale landscape pattern with fields, meadows, woodlands and hedgerows, whereas the region of Eindhoven is characterised mainly by large scale heathlands which are devoid of brambles to a large extent, with agricultural activity only along the brooks and rivulets. Heathland reclamation took place between 1875 and 1950 mainly, after which bramble species spread into the reclaimed area. Although both Rubus taxandriae and $R$. campaniensis have a wide distribution in the eastern part of the Campine, they are much more abundant in the western part, which might lead to the conclusion that the colonisation of the eastern part of the Campine by these species has not yet come to an end: the distribution area seems to be unsaturated, as might be expected for most species in this agamic complex (Weber 1987).

\section{Some considerations on the classification of the Lonicero-Rubion silvatici}

The syntaxonomic place of the bramble scrubs united in the Lonicero-Rubion silvatici is subject to discussion. After its publication it was placed in the Epilobietea Tüxen \& Preising in Tüxen 1950, but as Weber (1977a) argued there are strong objections concerning the vegetation structure: the Epilobietea are dominated by herbs and grasses, and the Lonicero-Rubion by scrub species. On the basis of the frequent occurrence of Rhamnus frangula and the occurrence of Salix cinerea and $S$. aurita on somewhat moister soils, Weber (1998a, 2003b) places this alliance in the Franguletea. As mentioned in the introduction, Haveman et al. (1999a) placed the alliance in a new class, the Lonicero-Rubetea plicati. In the more (sub-)Atlantic parts of north-western Europe, both mentioned Salix species play hardly any role in the bramble scrubs, and their occurrence in the German examples of the Lonicero-Rubion communities could be a first indication that the Rubus species tend to grow in more tempered, humid conditions in less Atlantic climates, retracting in woodlands completely further to the east. This stresses the fact that the bramble scrubs of the Lonicero-Rubion have their optimum in the (sub-)Atlantic parts of north-western Europe, and that alliance is less typical developed in northern Germany, thereby intermingling with the Franguletea. Therefore, we prefer to place the bramble scrubs of the Lonicero-Rubion silvatici in a separate class, the Lonicero-Rubetea plicati.

The lowland sand areas in north-west Europe form a centre of diversity of Rubus subgen. Rubus (cf. Matzke-Hajek 1997; Kurtto et al. 2010, pp. 42). In an analysis of the centres of diversity of Rubus in the Netherlands (Veeken \& Haveman 2008), three regions could be distinguished in the major Dutch sand landscapes, which fall apart in seven subregions. The distribution area of the Rubetum taxandriae in the Netherlands corresponds remarkably well with the subregion of western Noord-Brabant. This raises the question about a probable further subdivision of the Rubetum silvatici in the Netherlands: is it 
possible to distinguish further communities within the Rubetum silvatici, characteristic for the various regions and/or subregions? There are indications that this is indeed the case. In the northern region, lying on the Drenthian bolder-clay plateau, a bramble community occurs for which the combination of Rubus glandithyrsos, $R$. erinulus and $R$. flexuosus is very characteristic. In the central subregion, the first two species are practically absent in the Rubetum silvatici, and their place is taken by $R$. lasiandrus instead, while $R$. umbrosus is much more prominently present. Unlike the Rubetum taxandriae, these communities show a rather high frequency of character species of the Rubetum silvatici, so that they can therefore probably better be distinguished as regional subassociations of this association. Further investigations must make clear whether more Rubus scrub types can be distinguished in the north-west European sand landscapes, and what the underlying mechanisms and causes of the regional variation are. 
CHAPTER 8

General discussion, with some additional notes on nature conservation 


\section{Introduction}

The subject of this thesis is the diversity of Rubus subgen. Rubus (bramble). In the introductory chapter (chapter 1 ), the following questions were raised:

I. What are the arguments to distinguish apomict lineages in Rubus as species, and how many species can be distinguished (especially in the Netherlands) based on this?

II. What are the main factors in the realisation of large scale spatial patterns in Rubus subgen. Rubus, and are these patterns primarily ecological or historical confounded?

III. Which factors determine the spatial distribution and species assemblage of bramble scrubs and what is the importance of ecology and history herein?

IV. What is the nature conservation value of brambles and bramble scrubs, considering the gained insights in the taxonomy, phytogeography and phytosociology?

The previous six chapters of this thesis are grouped around two main themes, viz. taxonomical issues (chapter 2 to 4 ) and the description of patterns (chapter 5 to 7 ). Chapter 2 is a literature review on species concepts, resulting in the idea how apomict lineages should be treated taxonomically. In chapter 3, the history and elements of current taxonomical practice in batology are sketched, and arguments are given for the description of species with limited distribution areas. Chapter 4 is an annotated checklist of bramble species in the Netherlands, based on decennia of taxonomical field work.

In chapter 5, a phytogeographical analysis of distribution patterns of Rubus species in north-west Europe resulted in a regionalisation of Rubus distributions, and the possible causes for the found patterns are discussed. Chapter 6 and 7 are phytosociological studies of bramble scrubs in the Netherlands. In chapter 6, three landscape transects revealed the spatially structured variation in species composition in Rubus scrubs. In chapter 7, a regional Rubus scrub type was described.

In the chapter in hand, the results of the previous chapters will be discussed in connection. Again, the two mentioned main themes (taxonomy (paragraph 8.2) and patterns (paragraph 8.3)) are used to structure the discussion, but a third theme is added, viz. the nature conservation value of brambles and bramble scrubs (paragraph 8.4). This last theme doesn't necessarily follows from the other themes, but it is added here to underline the practical implications of the findings in this thesis. I will conclude this chapter with some general considerations on brambles and bramble diversity. 


\section{Apomict Rubus species and taxonomy \\ Recapitulation}

In chapter 2, it was concluded that the species category cannot satisfactory be defined, but that species are separately evolving (segments of) metapopulation lineages, which can only be perceived. They are salient phenomena, which have to be explained, rather than be defined. Apomict Rubus species are such salient phenomena, with their own morphology, genetic identity, ecology, and distribution ranges. In this respect, there is no fundamental difference between Rubus species with large distribution ranges and species with small, or even very small distribution ranges (chapter 3). The current standard list of Rubus species in the Netherlands contains 191 species in Rubus subgenus Rubus, of which 2 sexual species ( $R$. ulmifolius and $R$. caesius), and 189 apomict lineages (chapter 4). In the following, this theme will be elaborated a bit further, to understand the need for a proper taxonomic treatment of apomicts generally, and Rubus more explicitly.

\section{Treatment of apomicts in recent taxonomical works}

In recent national floras and standard lists of north-west European countries, the taxonomical treatment of apomicts is rather diverse. In the United Kingdom, there is a strong tendency to distinguish numerous species in apomict genera: both in standard lists (Dandy 1958; Kent 1992) and in the recently published critical flora (Sell \& Murrell 2006, 2014) hundreds of apomict species are distinguished. In his field flora, Stace (2001) gives a comprehensive treatment of several apomict genera distinguishing numerous species (Alchemilla, Sorbus), but other genera are only divided into sections (Rubus, Hieracium, Taraxacum). Like in the UK, in Germany apomict lineages are often considered species in the standard list (Wisskirchen \& Haeupler 1998) as well as in common floras (Oberdorfer 1994; Jäger \& Werner 2002). In Hieracium, however, the system of Zahn is followed, in which aggregate principal and intermediate species are distinguished, under which the apomict lineages are grouped as subspecies (which are not included in the mentioned works). In the Belgian flora, the apomict genera are not treated very consistently: within Taraxacum and Alchemilla, numerous species are distinguished, but in the other genera only the most common species (Rubus) or aggregate species (Hieracium) are mentioned (Lambinon et al. 1998; Lambinon \& Verloove 2012).

The treatment of apomicts in the subsequent editions of the Dutch flora seems really haphazard, and the fortunes of Rubus can make that clear. Between the $14^{\text {th }}$ and the $25^{\text {th }}$ edition of this flora, the treatment of the genus has been very variable, changing several times from only accepting one or few large aggregates to the inclusion of some selection of apomict Rubus lineages as species. The treatment of Hieracium and Alchemilla has been more constant: in Hieracium, aggregate species or sections are recognised, whereas all known Alchemilla species are included in all subsequent editions of the flora since 
1956. In the subsequent standard lists of the Dutch flora, published in semi-regular intervals between 1970 and 2003 (Mennema 1976; Van der Meijden et al. 1984; Van der Meijden et al. 1991; Van der Meijden et al. 1996; Tamis et al. 2004), apomicts are merely treated at the section or higher levels, and no microspecies are distinguished, except in Alchemilla. In Flora Neerlandica, the work on Taraxacum was done by the internationally recognised specialist Van Soest, amongst others, and all known Dutch dandelion species are described and illustrated (Hagendijk et al. 1975, 1982). Other volumes which had to contain apomicts were never published.

It can be concluded that in the Dutch floras and overviews, Rubus and other apomict groups are treated rather inconsistently, although apomicts in most floras and overviews in the surrounding European countries are included in some detail.

\section{The taxonomist's responsibility}

This neglect or inconsistent taxonomical treatment over the years might have serious drawbacks for the conservation of a substantial part of north-west European plant species (Gregor \& Matzke-Hajek 2002; Haveman et al. 2002). Lumping of species in one collective species was called 'nominal extinction' by Leme (2003) in a paper on Amazonian bromeliads. As soon as species are lumped, they disappear from check lists, conservation programmes and ecological and geographical studies. Like Mace (2004) articulated: "We cannot necessarily expect to conserve organisms that we cannot identify, and our attempts to understand the consequences of environmental change and degradation are compromised fatally if we cannot recognize and describe the interacting components of natural ecosystems." Erroneous application of synonyms contributes to impoverished assessment of biodiversity, and therefore enhances the likelihood of bona fide extinction. On the basis of several examples, Leme sketched the implications of errors in taxonomical decisions on the conservation of narrow endemics.

This fully applies to the treatment of apomicts in the Dutch flora. As long as professional taxonomists neglect apomict groups, there is no motive for agencies or volunteers to pay any attention to the diversity involved. This will sustain a situation in which only a few specialists can recognise the species in apomict groups, which hampers an adequate monitoring. An example of this effect is given by Haveman \& De Ronde (2014), who described the lack of specific attention for Hieracium, which subsequently has led to unawareness of the high biodiversity values of chalk rock faces in the southernmost part of the Netherlands. This in turn resulted in a shortage of conservation effort and the apparent extinction of several narrow (neo-)endemics. It perfectly illustrates why taxonomists should be aware of their responsibility and the effects of their (sometimes seemingly arbitrary) taxonomic choices. Especially in the light of the current 'biodiversity crisis', an era characterised by man-induced mass extinction (Western 1992), it is the 
taxonomist's responsibility to give an exact as possible account of the existing species (Cracraft 2002; Leme 2003; Cracraft \& Donoghue 2004). Therefore, apomict species should at least be included in the Dutch standard list and Red List of vascular plants.

Most critical floras in Europe (are planning to) give a full account of most apomict species groups (Monasterio-Huelin 1998; Jonsell 2004; Sell \& Murrell 2006, 2014). For the Netherlands, a modern critical scientific flora is not available, but recently, the Royal Botanical Society of the Netherlands (KNBV) started an initiative that must lead to a multi-volume critical flora of the Netherlands (Nova Flora Neerlandica 2015). In this flora, it is planned to treat the apomictic genera in full, including Rubus.

\section{Conclusion and outlook}

The whole quest for a universal species concept since the Modern Synthesis illustrates a deep and widely felt need to have one set of generally accepted rules to evaluate the species status of organismal populations. In the introduction of his book The species problem, Richards (2010) illustrated this need referring to the disparities in species counts, for instance in worldwide bird species numbers, ranging from 9,000 to 20,000. The author interprets this quest in the light of the tension field between Aristotelian philosophy, in which species are seen as kinds with essences, and Darwinian biology, in which species are not longer eternal and unchanging (Richards 2010, p. 2). In the light of this, the search for one universal species concept which is applicable to all species is nothing more than an ultimate attempt to fit the old static understanding of species in a new - dynamic - system. In the light of evolution, to make an explicit reference to Dobzhanzky's famous essay (Dobzhansky 1973), this makes no sense though, because every single species has its own evolutionary path along which it came to existence. Species come in kinds, and evolutionary biology should explain how and why certain groups come in species and others don't, instead of arguing over obligatory characters, essences, of species. Why do Taraxacum biotypes act as species, and biotypes in the Ranunculus auricomus agg. so much less? Why did Rubus subgenus Rubus split up in so many species in western Europe, but not in the Caucasus (Sochor \& Trávníček 2016)? What are the evolutionary backgrounds and pathways of the existing diversity?

The primary task of alpha taxonomy is to sort and describe species, truly an immense task which is even more urgent in the light of the biodiversity crisis (Cracraft 2002; Mayo et al. 2008). Kim \& Byrne (2006) even speak of a 'taxonomic bottleneck' when discussing the time needed to describe all still unknown species and the rate of the worldwide extinction of species. It is obvious that the largest gaps in our knowledge of biodiversity are neither to find in the plant kingdom, nor in temperate Europe, but in the arthropods in the Tropics and the Southern Hemisphere (Platnick 1991; Gaston 2000; Basset et al. 2012). Biodiversity is more than species numbers alone though, as 
was argued by several authors who pointed at the value of endemism in biodiversity conservation (Platnick 1991; Hobohm 2003; Ennos et al. 2005; Kier et al. 2005; Orme et al. 2005). Temperate Europe is rich in apomict endemic species, but they are often omitted from biogeographical and biodiversity studies (see e.g. Andersson 1988; Preston \& Hill 1997; Dahl 1998; Frodin 2004; Hobohm et al. 2014). Although it is obvious that a large clade with many neo-endemics, like Rubus in western Europe, has to be evaluated differently than a small monotypic genus with one paleo-endemic species, Hojsgaard \& Hörandl (2015) recently presented an evolutionary model which stresses the importance of polyploid apomict complexes in the evolution of sexual species. According to the authors, apomicts act as facilitators for range expansion and pioneer explorers of new niches. In the later phases of the development of the polyploid complex, reversals to complete sexuality would allow for the establishment of new sexual populations, which can evolve to new sexual species. As such, apomicts are not to be considered 'evolutionary dead ends'; instead, the conservation of apomict polyploids might be of great importance for the conservation of biodiversity on the long term. This highlights the importance to fully consider apomicts in biodiversity research and taxonomy, and not in the least in conservation.

\section{Spatial patterns and Rubus dynamics}

\section{Recapitulation}

The regionalisation of Rubus distribution areas in chapter 5 of this thesis resulted in three major bramble territories in north-west Europe, each of which is formed by four florulas: areas with more or less homogeneous bramble floras. These territories are not only separated by large Rubus-hostile areas, but it was shown that the large-scale patterns have an evolutionary-historical background: the bramble flora of the British Isles and Northwest-Continent territories bear a obvious 'ulmifolius-stamp', whereas in the origin of the bramble flora of the Southeast-Continent Rubus canescens played a major role. Even on a smaller scale, the evolutionary history arguably plays an important role in the distribution of bramble lineages, albeit via the way of 'inherited ecology'. The transect study in chapter 6 showed that the species composition of bramble scrubs isn't random, but that floristically defined Rubus scrub types can inhabit limited parts of the landscape, whereas other such scrubs are widely distributed. It was concluded that the variation in Rubus scrubs in the landscape is only partially accounted for in the current phytosociological literature (Weber 1997, 1998a; Haveman et al. 1999a; Haveman et al. 1999b; Weber 1999b). On this basis, a new scrub type, the Rubetum taxandriae was described, which is found mainly in the Dutch and Flandrian Campine (chapter 7).

Large-scale phytogeographical patterns have a serious bearing on the species composition of local communities, thus effecting the phytosociological classification, which will be 
shown in the following paragraphs. It will be followed by some considerations on the dynamics of Rubus in the landscape.

\section{Current Rubus scrub classification in Germany and the Netherlands}

Modern phytosociological research of Rubus scrubs started in 1967, when Weber published a phytosociological study of the 'Knicks' (hedgerows) in Sleswig-Holstein, Germany (Weber 1967). In this work, the Rubus-rich hedgerows are placed in two new associations, viz. the Pruno-Rubetum sprengelii Weber 1967, on relatively nutrient and base poor soils, and the Pruno-Rubetum radulae Weber 1967, on relatively nutrient and base rich soils. Both associations are placed in the Rubion subatlanticum Tüxen 1952 (class Rhamno-Prunetea). Weber commented that both associations probably better could be considered separate alliances, and he mentioned that both associations have a more continental form and a more Atlantic form.

In several keystone publications, Weber modified his initial system, 1) distinguishing more and more associations based on studies by himself and others (Wittig 1976, 1977; Reif 1983, 1985; Rosskamp 1999), and 2) changing the status of the initially distinguished associations to alliance level (the Pruno-Rubion sprengelii Weber 1974 and Pruno-Rubion radulae Weber 1974; Weber 1974), and later to suballiance level (the Pruno-Rubenion sprengelii Weber 1981, and Pruno-Rubenion radulae Weber 1981 respectively; Weber 1981a, 1990, 1999b). All these communities were placed in the Prunetalia Tüxen 1952. Additionally, in Rubi Westfalici (Weber 1986b), a provisional classification of the Rubus scrubs of the Sambucetalia racemosae Oberdorfer 1957 was given, which was strongly revised in the Synopsis (Weber 1999b). Furthermore, the bramble scrubs of the most nutrient and base poor (sandy) soils, comprised in the Lonicero-Rubion silvatici Tüxen \& Neumann 1950 (in Tüxen 1950), were placed in the Franguletea Doing 1962 from 1977 onwards (Weber 1977a, 1986b, 1990, 1998a).

In the Netherlands, bramble scrubs are described in some detail for the first time in $D e$ vegetatie van Nederland (Haveman et al. 1999a; Haveman et al. 1999b). Largely, Weber's system was adopted, but the Rubus scrubs of nutrient poor soils were placed in the Lonicero-Rubetea plicati Haveman et al. 1999 (see also Haveman 1997). This class was thought to be represented in the Netherlands by the Rubetum grati, Rubetum silvatici Weber in Pott 1995 and the Rubetum pedemontani Weber in Pott 1995 (Haveman et al. 1999a). For an adequate description of Sambucetalia racemosae scrubs, data were too sparse. In the Pruno-Rubion radulae, two associations were distinguished and for the first time documented with tables for the Netherlands, viz. the Pruno-Rubetum elegantispinosi Weber 1974 and the Pruno-Rubetum vestiti Weber 1974. The Pruno-Rubetum sprengelii was mentioned as certainly present, but there were not sufficient data for an adequate description (Haveman et al. 1999b, p. 133). It was noted however, that the classical 
Rubus-species of the Pruno-Rubion radulae, like R. montanus, R. radula, and R. bifrons, are completely lacking in the tables (Haveman et al. 1999b, p. 131). Rubus grabowskii, which was noted in the Dutch relevés, turned out to be a misidentification: the Dutch $R$. grabowski was few years later described as a new regional species, $R$. canduliger (Bijlsma \& Haveman 2007).

After the publication of De vegetatie van Nederland, several new Rubus scrub types were described, partly as a result of (and included in) the thesis in hand. Already mentioned is the Rubetum taxandriae, which is placed in the Lonicero-Rubion silvatici. Haveman et al. (2014b) published a fist account of bramble scrubs belonging to the Sambucetalia racemosae in the Netherlands, with the documentation of the Sambuco-Rubetum rudis Tüxen \& Neumann ex Weber 1999 and the description of the Senecioni ovati-Rubetum iuvenis Haveman \& De Ronde 2014. These associations were placed in the validated Athyrio felicis-feminae-Rubion idaei Passarge ex Haveman et al. 2014. On the basis of its species composition, Haveman \& De Ronde (in press) transferred the Rubetum pedemontani from the Lonicero-Rubion to the Athyrio-Rubion. Besides, they will publish a new association in the Lonicero-Rubion, the Lysimachio vulgaris-Rubetum ammobii De Ronde \& Haveman 2017.

\section{Reconsidering the classification}

There are two problems concerning the described classification of the Pruno-Rubion communities, which are becoming manifest now data is becoming available from a wider area. The first problem is mentioned already: the incongruence of alliance character species in different regions. In the Synopsis, Weber (1999b) mentioned Rubus radula, $R$. montanus en $R$. bifrons as such, and, additionally in the overview of scrubs in Niedersachsen (Weber in Preising et al. 2003, p. 100), R. goniophorus, R. orthostachys and $R$. hadracanthos. These species are very rare or even completely lacking in the Netherlands (chapter 4 of this thesis; Van de Beek et al. 2014), and they play no role in the relevés of Dutch bramble scrubs. In contrast, $R$. lindleianus, $R$. macrophyllus, and $R$. geniculatus are frequently occurring, next to Rubus confusidens, $R$. egregius, $R$. winteri, $R$. conspicuus en $R$. stereacanthos (Haveman \& De Ronde in press). At the time of the publication of De vegetatie van Nederland, it was thought that this difference between the regions could be attributed to a gradual subsequent turn-over of species from east to west, but from chapter 5 it is clear now that these differences are founded in a relatively fundamental, evolutionary-historical difference between the Rubus floras of the Southeast Continent territory (SEC) and the Northwest-Continent territory (NWC; Haveman et al. 2016). Arguing from this, Haveman \& De Ronde in press suggested to consider the Dutch Prunetalia bramble scrubs part of an (ammended) Pruno-Rubion sprengelii. Contrary to Weber (1974; 1999b, in the latter publication as suballiance), they consider the PrunoRubion radula and Pruno-Rubion sprengelii not as ecological units but as vicariant units, 
the difference being based in the evolutionary background of the Rubus floras of central and north-west Europe.

The second problem revealed by a growing number of relevés from different regions is the lack of stable species combinations over a wider region. This is illustrated by the species composition of the Pruno-Rubetum vestiti and the Pruno-Rubetum elegantispinosi in various publications. According to Weber in the Synopsis (Weber 1999b), the first association is first and for all characterised by Rubus vestitus (Weber 1999b, p. 75). Rubus radula, as a character species of the alliance, has a high frequency in this association. The Pruno-Rubetum elegantispinosi on the other hand, is characterised by $R$. elegantispinosus, $R$. lindleianus, $R$. winteri, and $R$. macrophyllus, and, in one of the subassociations, by $R$. raduloides and $R$. lindebergii. Rubus radula is almost absent in the table of the PrunoRubetum elegantispinosi in the Synopsis, which is mainly based on relevés from Westphalia. On the other hand, in the overview of plant communities of Niedersachsen (Weber in Preising et al. 2003), the Pruno-Rubetum vestiti is characterised by $R$. vestitus alone, but in the table, $R$. lindleianus, $R$. winteri, $R$. geniculatus, and $R$. chloocladus are mentioned with low frequencies. The Pruno-Rubetum elegantispinosi in Niedersachsen is characterised by $R$. eleganispinosus and $R$. raduloides, and $R$. radula is mentioned as rarely occurring character species of the Pruno-Rubion radulae. In De vegetatie van Nederland, Haveman et al. (1999b) mentioned several species in both associations, viz. $R$. macrophyllus, $R$. rudis, $R$. geniculatus, $R$. ulmifolius and $R$. rufescens. Here, the Pruno-Rubetum vestiti is characterised by $R$. vestitus alone, whereas $R$. elegantispinosus, $R$. raduloides and $R$. winteri are characterising the Pruno-Rubetum elegantispinosi.

The conclusion from this example is that the Rubus species seem to occur in ad hoc combinations, and that the species combinations cannot be explained by ecological factors alone. The species composition of Rubus scrubs can only be understood fully in the light of evolutionary founded regional species pools. This is clear when the regions of origin of the relevés in the mentioned studies are compared to the regionalisation in chapter 5: the relevés of the Pruno-Rubetum vestiti in the Synopsis are mainly recorded in Angeln and the region north of Lehsahn-Plön in Schleswig-Holstein (see Weber 1967, p. 158), areas that are assigned to the Denmark (DK) florula, and thus in the PrunoRubion radulae area, whereas the 'Pruno-Rubetum vestiti' from Niedersachsen and the Netherlands are made in various regions in the NWC territory, and the Pruno-Rubion sprengelii area. Since associations cannot be assigned to more than one alliance and the typical Pruno-Rubetum vestiti clearly belongs to the Pruno-Rubion radulae, the Rubus vestitus scrubs in the NWC territory cannot longer be considered to belong to this association. 
Based on these considerations, Haveman \& De Ronde (in press) distinguished rather broad, ecologically defined associations within the Pruno-Rubion sprengelii in which the various Rubus species are considered characteristic for regional races. Apart from the Pruno-Rubetum sprengelii, in the Netherlands confined to the Pleistocene sand areas where it inhabits relatively nutrient and base poor sandy soils, they distinguish a Corno sanguinaea-Rubetum vestiti Haveman \& De Ronde 2017, which can be considered the western vicariant of the Pruno-Rubetum vestiti, as well as a Roso rubiginosae-Rubetum affinis Haveman \& De Ronde 2017. The Corno-Rubetum vestiti is typical for relatively nutrient and base rich loam and clay in the higher flood plains of the large rivers (especially the river Meuse) and South Limburg. The Roso-Rubetum affinis is a local, yet very distinctive association of (superficially) decalcified coastal dunes.

The described evolutionary patterns don't have consequences for the classification of the Lonicero-Rubion silvatici and the Athyrio-Rubion idaei. The Lonicero-Rubion is an alliance with a narrow distribution (with an unclear southern distribution border), restricted largely to the NWC territory; most of the characteristic species have a western distribution (cf. Kurtto et al. 2010). In comparison to the Pruno-Rubion scrubs, the Lonicero-Rubion scrubs are poor in accompanying species, and therefore their classification heavily relies on the occurrence of Rubus species. The scrubs of the AthyrioRubion belong to the least known and understood systems (Passarge 1982; Weber 1998a), and their species composition is only investigated in a relatively limited region, and large scale patterns are therefore not yet visible. In these scrubs, glandular species of the series Hystrix and Glandulosi play an important role, contrary to the Pruno-Rubion sprengelii and Pruno-Rubion radulae, which are characterised by brambles of the series Candicantes and Hayneani. The maps of haplotypes published by Sochor et al. (2015) show that the GLA-haplotype, dominant in the Hystrix and Glandulosi, has a rather even distribution over the whole of Europe north of the Alps, covering most of the diversity centre of the genus, contrary to the CAN- and ULM-haplotypes, which are dominant in the Candicantes and Hayneani. Therefore, it is expected that the AthyrioRubion doesn't possess such a strong regional differentiation at the alliance level as the Rubus scrubs belonging to the Prunetalia. The resulting classification of the syntaxa of the classes Rhamno-Prunetea spinosae and Lonicero-Rubetea plicati in which Rubus species play an important role, is given in Box 8.1.

\section{Some remarks on the Braun-Blanquet school of phytosociology}

One of the strongholds of the French-Swiss or Braun-Blanquet school of phytosociology is the inductive classification, based on the floristic composition of the vegetation (Tüxen 1970; Westhoff \& Van Der Maarel 1978; Dierschke 1994). The generally accepted procedure to gain synthesised results comprises the consecutive 1) collection of a sufficient number of relevés, 2) some method to sort both species and plots in 
Box 8.1. Revised classification of the bramble-rich syntaxa of the classes Rhamno-Prunetea spinosae and Lonicero-Rubetea plicati (De Ronde \& Haveman in press; Haveman \& De Ronde in press).

Class: Rhamno-Prunetea SPINOSAE Rivas Goday et Borja Carbonell ex Tüxen 1952

Ord.: Prunetalia SPINOSAE Tüxen 1952

All.: PRUNO-RUBION RADUlaE Weber 1974

All.: PRUNO-RUBION SPRENGELII Weber 1974

Ass.: Corno sanguinei-Rubetum vestiti Haveman \& De Ronde 2017

Ass.: Pruno-Rubetum sprengelii Weber 1967

Ass.: Roso rubiginosae-Rubetum affinis Haveman \& De Ronde 2017

Ord.: SAMBUCETALIA RACEMOSAE Oberdorfer 1957

All.: ATHYRIO FELICIS-FEMINAE-RUBION IDAEI Passarge ex Haveman, De Ronde \& Weeda 2014

Ass.: Senecioni ovati-Rubetum iuvenis Haveman \& De Ronde 2014

Ass.: Sambuco racemosae-Rubetum rudis Tüxen \& Neumann ex Weber 1999

Ass.: Rubetum pedemontani Weber in Pott 1995

Class: LONICERO PERICLYMENI-RUBETEA PLICATI Haveman, Schaminée \& Stortelder 1999

Ord.: Rubetalia Plicati Weber in Pott 1995

All.: LONICERO PERICLYMENI-RUBION SILVATICI Tüxen \& Neumann ex Wittig 1977

Ass.: Rubetum grati Tüxen \& Neumann ex Weber 1976

Ass.: Lysimachio vulgaris-Rubetum ammobii De Ronde \& Haveman 2017

Ass.: Rubetum silvatici Weber in Pott 1995

Ass.: Rubetum taxandriae Haveman \& De Ronde 2012

order to get a structured table, 3) the identification of differential species, and 4) the comparison with already described units in literature. One of the big advantages of this method is that it doesn't need any foreknowledge of the vegetation and as such can be applied in whole new regions, or completely unknown systems, while still resulting in a useful classification. An astounding example is the overview of plant communities of north-west Germany (Tüxen 1937) only nine years after the publication of the first print of Braun-Blanquet's standard work on the method (Braun-Blanquet 1928)! However, this has proved to be one of the main set-backs of the method as well, since many of the units which are described in the early years are based on local conditions with local species combinations only. It is easy to find many examples of the problems this is causing when vegetation descriptions from larger areas are compared, or when larger overviews are to be made (see e.g. De Ronde \& Haveman 2014 for an example concerning the Polygalo-Nardetum, a grassland community which was overlooked for a long time in the Netherlands because its initial description was based on a dataset from a very limited area). Similar problems are manifest in the classification of bramble scrubs, and here they are even magnified by the occurrence of the many Rubus species with 
small, 'capricious' distribution areas, obscuring large-scale patterns. Examples are the numerous associations described by Weber (1999b), based on only one or a few Rubus species, and the newly described associations from France (Royer et al. 2006; Royer \& Ferrez 2012; Royer 2013; de Foucault \& Royer 2014) which appear to represent merely local species combinations.

This lack of synthesis easily obscures the understanding of general patterns and processes that lead to these patterns. Recent developments in phytosociology, following the virtually unlimited disposal of powerful computers, provide a solution for this problem though, since storage and processing of large quantities of relevés are no longer limited. For the storage of relevés, the database management system TurboVeg (Hennekens \& Schaminée 2001) is used internationally on a wide scale, thus serving as a platform for the combination of data from a wider area. In the last 15 years, large vegetation plot databases have proved to be useful for the study of fundamental and practical issues (e.g. Chytrý 2001; Vandenbussche \& Hoffmann 2001; Chytry \& Rafajov 2003; Kuzelová \& Chytrý 2004; Botta-Dukát et al. 2005; Holeksa \& Wozniak 2005; Knollová et al. 2005; Wesche et al. 2005; Haveman \& Janssen 2008). Recently, as an initiative of the European Vegetation Survey working group, a harmonisation of plot relevés has led to one European vegetation plot database, the European Vegetation Archive (JiménezAlfaro et al. 2013; Chytrý et al. 2015). Especially in combination with other databases, this might prove to be a powerful tool for the solution of many questions (Ozinga et al. 2009; Bartish et al. 2010; Bartish et al. 2016).

\section{The success and dynamics of Rubus subgenus Rubus}

Chapter 6 describes the obvious success of Rubus in the sand landscape of Atlantic north-west Europe (Haveman et al. 2014a). Generally, bramble species are thought to be expansive, with progressive area dynamics (Matzke-Hajek 1997; Loos 2008). Their success can be attributed to their effective long-distance dispersal (Weber 1987), in combination with a rapid vegetative spread with underground stolons or fast-growing above-ground tip-rooting canes (Jennings 1988). Long-distance dispersal is mostly by ornithochorous vectors, but numerous cases of unintended anthropogeneous introductions are reported, or at least suspected (Weber 1986b; Matzke-Hajek 1993; Oredsson 1998, 2002, 2004; Bijlsma \& Haveman 2007).

In the present landscape, Rubus range dynamics seem rather limited though. In canopygaps in forests, bramble-thickets form a well-known stage in the succession (Dierschke 1988; Gilgen 1994; Pancer-Koteja et al. 1998; Kelemen et al. 2012; Dierschke 2014). Open spaces are colonised within one or two seasons through regeneration from the soil seed-bank and shade-surviving individuals monopolising the vegetation through pithfilled, tip-rooting canes. Establishment of incoming species is very limited, although not 
completely absent (Haveman et al. 2014b). In the course of succession, the thickets in these gaps will be overshadowed and replaced by dense stands of young trees, which will be replaced by a more mature forest community in which only shade-tolerant brambles play a subordinate role.

In our study, we almost only sampled more stable bramble scrubs in forest edges, hedgerows and other permanent linear structures. Succession, in the sense of replacement of vegetation units with a more complex structure (Dierschke 1994), is virtually absent in these situations. However, species composition is not (necessarily) stable. This was extensively studied in the Westfälische Bucht, Germany, by Huwer \& Wittig (2012), who compared the species composition of Rubus scrubs between 1970 (Wittig 1976) and 2010. They found a shift in species towards communities with a higher nutrient demand, and contributed this to a shift from traditional management, combined with a eutrophication of the landscape. This shift not only concerned herbaceous species, but also some bramble species, viz. Rubus gratus (declined in the Rubetum grati) and $R$. elegantispinosus (increased in the Rubetum silvatici).

Despite their supposed progressive distribution tendencies, only few documented cases of natural range expansion of bramble species exist. Weber (1977b, 2003a) mentioned the cases of Rubus tuberculatus ( $=R$. horrefactus) and the newly described $R$. ehrnsbergerii in the vicinity of Mennighüffen, which were unknown by Weihe in the late 1900s. Another example might be Rubus wittigianus, a conspicuous species growing in Westphalia, which was omitted in the overview by Weber (1986b), but which recently was found in a wider area. It was also found in the Netherlands by Rienk-Jan Bijlsma in nature reserve De Brand near Udenhout (Van de Beek 2014-2016) after the publication of the check-list of Dutch brambles (Van de Beek et al. 2014). The reported expansion of 14 species in the highly urbanised and industrial Kamen-Methler region in the Ruhrgebiet in Central-Westphalia between 1998 and 2008 (Loos 2008) are hardly to be related to real range expansion, since all except one of these species were present in the studied region in 1998. However, it shows the high dynamics of local occurrences of bramble species in such urbanised regions. As was shown by Loos (2008), especially thermo- and thamnophilous species from nutrient rich soils belonging to series Discolores (= Candicantes) as well as ruderal Corylifolii species seem to be able to use the windows of opportunity readily, invading new sites. Especially the regionally and locally distributed Corylifolii species tend to dominate the vegetation completely (Loos 2008). More nemophilous species increased in forests, but it remains unclear whether these species - except $R$. macrophyllus and $R$. adspersus - occupied new sites. Probably these woodland inhabiting species could increase locally in reaction on changed light conditions, as was shown for Rubus species in forests in the Netherlands (Bijlsma 2004). 
A new habitat for brambles in the Netherlands and Belgium is formed by abandoned arable land and pastures (Kuiters \& Slim 2003; Uytvanck 2011). Although abandonment of traditionally managed agricultural landscapes following rural depopulation is considered an almost Europe-wide problem for the conservation of biodiversity (Queiroz et al. 2014), this is hardly the case in the Netherlands. Only in (new) nature conservation areas, where locally traditional management is replaced by ungulate grazing or ceasing of all management, abandonment is an issue. Jackson (2001) reported a very high 'immigration potential score' and 'colonisation success score' for Rubus species. Unpublished observations of the development of bramble scrubs at the St. Jansberg near Groesbeek show that the dominant bramble species in abandoned grasslands and agricultural fields not necessarily are the dominant ones at the landscape level (pers. obs. R.J. Bijlsma). In other cases though, the invading brambles are omnipresent, as in the Crayelheide area near Venlo (pers. obs.). Although in both cases mentioned, the species must have reached the new sites via seeds. It remains to be studied what is the mutual contribution of recent invasions (through zoochory) and historically built up seed banks.

The opposite tendency, i.c. the decline of Rubus species, is less reported. Rubus constrictus, an eastern species lacking from the Netherlands, is mentioned by several authors as species with a relic, decreasing distribution (Matzke-Hajek 1997; Loos 2008). Besides, Loos (2008) mentioned several other species with a remarkable decline in the Central Westphalia, viz. $R$. fasciculatus, $R$. grabowskii, and the undescribed local ' $R$. dahmsianus'. Noteworthy is that all declining species are characteristic for the Southeast-Continent flora (SEC) as defined by Haveman et al. (2016), whereas several of the increasing species mentioned by Loos (2008) are characteristic for the Northwest-Continent flora (NWC), e.g. R. adspersus, R. elegantispinosus, R. geniculatus, and R. macrophyllus. Weber (1977b, 1986a) mentioned the local extinction of several species near Mennighüffen, the locus classicus of many species described by Weihe in the late 1800s.

In the Netherlands, hardly any data is available to evaluate a possible decline of Rubus species. From an extensive mapping of Rubus species in the wider surroundings of Ede by Rienk-Jan Bijlsma in the 1970s-1980s (not published), it can be concluded that many of the populations of the scarce $R$. chloocladus have disappeared due to expansion of the towns of Ede and Bennekom. This is in accordance with Weber (1986a), who noted the clearance of hedges and scrubs (following building activities and reclamation programs) as a major cause of the decline of Rubus species. According to Loos (2008), the decline of $R$. grabowskii and $R$. fasciculatus in Central-Westphalia is caused largely by the expansion of Urtica dioica as a result of hypertrophication. Other mentioned causes include the change of woodlands in conifer plantations, increasing grazing by wild herbivores, and the use of herbicides (Weber 1986a). 
The observed patterns give the impression that in well-established, historical agricultural landscapes, Rubus species can increase only locally in reaction on changing conditions, like the availability of light in forests and hedgerows. Generally spoken, in such landscapes, Rubus range dynamics seem to be very limited, and it is there that the given classification of bramble scrubs makes sense. In more dynamic landscapes, especially in highly urbanised regions and in abandoned landscapes, distribution ranges of brambles are more dynamic, which especially seems to be true for the typical species of open areas, e.g. members of the section Corylifolii and series Candicantes, and in the Netherlands probably also the series Rhamnifolii s.l. In the few examples of declining Rubus species, mainly the same groups are involved, which underlines the raised dynamics of the urbanised landscape. In these landscapes, the given classification is of less value, and it remains an open question how the bramble scrubs in these landscape will develop.

\section{Conclusion and outlook}

In the current chapter, we combined data from the Dutch National Vegetation Database (Schaminée et al. 2012) and the results of the regionalisation of Rubus distribution data to explain the vegetation patterns found in bramble scrubs in north-west Europe. Heads (2015) argued that present biology and ecology of species fail to explain existing biogeographical patterns, and that evolutionary history is a better predictor. Although the universal truth of this claim can be disputed - see e.g. the narrative examples in Alan de Queiroz's (2014) The Monkey's Journey - in this thesis is shown that evolutionary processes are important in the realisation of phytogeographical patterns in northwest European brambles indeed. What is more, the results also strongly suggest that evolutionary processes are an important predictor for the species composition of Rubus scrubs, at least at the regional level, as is clear from the phytosociological overview given here. The species composition of Rubus scrubs can only be understood fully in the light of evolutionary founded regional species pools.

It would be rather presumptuous to consider the presented classification scheme in this paragraph as the final scheme - if such scheme would exist anyway. As long as the state of taxonomy and the mapping of the Rubus flora in the Central Atlantic Biogeographical region in Europe (Metzger et al. 2005), especially Belgium and France, is not at level, and no phytosociological treatment from larger areas in these countries is available, an ultimate classification cannot be given. As was concluded by Haveman et al. (2016), more data on the evolutionary background of separate Rubus species is needed to fully understand the general distribution patterns in this genus, and this touches on phytosociological patterns too. Besides, Rubus dynamics in urban as well as abandoned rural areas might very well result in community patterns not congruent with the current phytosociological classification. 


\section{Nature conservation value}

One of the questions asked in the introductory part of this thesis was how the insights in the taxonomy, phytogeography and phytosociology of Rubus have impact on the nature conservation value of brambles and bramble scrubs. Until now, Rubus and Rubus scrubs haven't received much attention in nature conservation in the Netherlands. Obviously, this is at least in part the effect of the intricate, notoriously critical taxonomy of the genus, combined with its omnipresence in the landscape. Seen as one species, Rubus fruticosus s.l., the group is very common and even slightly increasing, now occurring in almost all map raster squares in the Netherlands (FLORON 2015). As was shown in chapter 4 though, at species level only about 25 of the almost 200 Dutch bramble species are regarded moderately common to common, whereas a little more than 140 are rare or very rare (Van de Beek et al. 2014), reflecting the regional distribution of many species and emphasising the nature conservation value of brambles and bramble scrubs. According to Mortimer et al. (2000), scrubs might have a high nature conservation value for one or more of the following three reasons: 1) the conservation value of the shrub species present, 2) the conservation of other species (fauna) associated with the scrub type, and 3) the conservation value of the scrub as a landscape element in a mosaic including other elements. Although these reasons do not especially relate to bramble scrubs, they are used here as a useful scheme to clarify the different nature conservation facets of these scrubs.

\section{Shrub species in bramble scrubs}

Several rare shrub species can (preferentially or occasionally) be found in Rubus scrubs. First of all, this applies to the bramble species themselves, as sketched above, but also shrubby taxa belonging to other genera can have a refugium in bramble scrubs. Maes (2002) mentioned Malus sylvestris, Pyrus pyraster, Crataegus $\times$ macrocarpa, Crataegus $\times$ subsphaerica, Salix oleifolia, as well as several taxa of Rosa for hedges, hedgerows and forest edges, all typical bramble scrub environments. According to Haveman \& De Ronde (2016 in press), Malus sylvestris, both Crataegus hybrids as well as the Rosa species have their main stands in Pruno-Rubion sprengelii scrubs in the Netherlands, but relevés to substantiate this allegation are very scarce: Crataegus $\times$ macrocarpa is only noted once, and Rosa caesia is the only rare Rosa species that was noted in the relevés with certainty. An additional problem is the taxonomy of the mentioned taxa: Malus sylvestris and Pyrus pyraster are not distinguished from Malus domestica and Pyrus communis respectively in the latest editions of the standard Dutch flora (Van der Meijden 1990, 2005), and Salix oleifolia is often not distinguished from Salix cinerea. Both Crataegus hybrids are often not recognised due to the taxonomical confusion in the genus Crataegus, which was only solved rather recently (Christensen 1992). Until recently, no elaborate treatment of Dutch Rosa species was available, and all species were summarised in a limited number of species aggregates (Van der Meijden 2005). Only recently, Bakker et al. (2011) published 
an overview of all Rosa species in the Netherlands using the taxonomical scheme of Henker \& Schulze (1993). Therefore, accounts in older relevés are not reliable. Besides, the used species concept in the overview by Bakker et al. (2011) was fundamentally criticised recently (Haveman 2016).

Table 8.1 gives a list of the rare Rubus species (Van de Beek et al. 2014) in the ten bramble scrub associations distinguished by Haveman $\&$ De Ronde (in press) and De Ronde \& Haveman (in press) based on the tables in these publications and Figure 8.1 summarises the frequency of occurrence rare brambles in the associations. A relatively high frequency of rare Rubus species is found in the Senecioni-Rubetum iuvenis, all associations of the Pruno-Rubion sprengelii (and especially in the Corno-Rubetum vestiti), and the Rubetum taxandriae, whereas the frequency of such rare brambles is very low in the Rubetum grati and the Lysimachio-Rubetum ammobii. There might be several factors contributing to these patterns. First of all, the Senecioni-Rubetum iuvenis and the Rubetum taxandriae are characterised for a large part by nationally rare species which are rather widespread and abundant in the region where the association is found though. Examples are $R$. iuvenis and $R$. oreades in the Senecioni-Rubetum iuvenis and $R$. taxandriae and $R$. insectifolius in the Rubetum taxandriae. This is a typical feature of the genus Rubus, referred to in the introduction of this thesis already: the regional distribution of many species.

For a part, the associations with a high occurrence of rare Rubus species are restricted to historical landscape structures, like ancient forests or old hedges and hedgerows, and this might be a second factor explaining the observed patterns. This is obvious for the Senecioni-Rubetum iuvenis, which is characterised almost completely by species of old forest-remnants (Bobbink et al. 2008; Haveman et al. 2014b). Evidently, the scarcity of ancient forests in the Dutch landscape (Buijs 1993) results in the scarcity of these Rubus species. The Pruno-Rubetum sprengelii and Corno-Rubetum vestiti are typical communities of open, agricultural landscapes (ruricoulus scrubs ssu. Weber 1999b, 2003b), developed optimally in hedgerows and other linear structures. The decline of hedge-like structures in the Netherlands due to land reclamation, reallocation and town development in the $20^{\text {th }}$ Century might have had a negative impact on the distribution of the typical species of these communities. Nooren (1981) estimated the total length of hedges in the Netherlands in 1900 to be 55,000 km, whereas Maes (2002) estimated the total length in 2000 to be about $21,000 \mathrm{~km}$. Already mentioned is the supposed decline of Rubus chloocladus in the surroundings of Ede at the South-Veluwe. A similar fate might have hit other typical Pruno-Rubion species in the process of clearance of the Dutch agricultural landscape, but actual data on the decline (or increase) of bramble species are lacking. The decline of woody linear structures and the supposed simultaneous decline of thamnophilous Rubus species is not easily compensated for by the replanting of new hedges. As was shown in several studies (Hooper 1970; Willmot 1980; Hetherington 
Table 8.1. Rare and very rare Rubus species in the Dutch bramble scrub associations as distinguished by De Ronde \& Haveman (in press) and Haveman \& De Ronde (in press).

\begin{tabular}{|c|c|c|c|c|c|c|c|c|c|c|}
\hline & 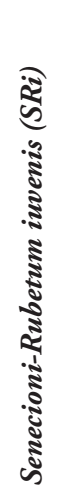 & 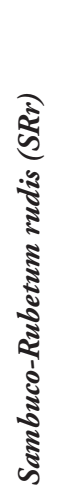 & 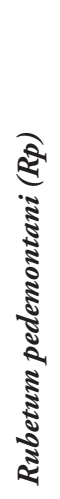 & 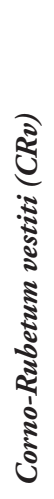 & 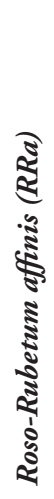 & 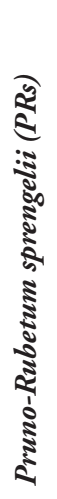 & 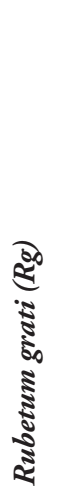 & 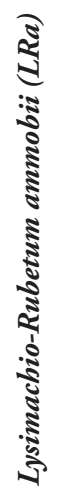 & 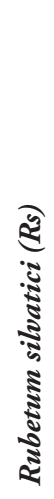 & 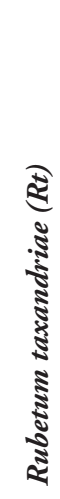 \\
\hline R. adornatus & & & & & & & & & $\mathrm{x}$ & \\
\hline R. adulans & & & & & & $\mathrm{x}$ & & & & \\
\hline R. arrhenii & & & & & & $\mathrm{x}$ & & & $\mathrm{x}$ & \\
\hline R. asperidens & & & & & & & & & $\mathrm{x}$ & \\
\hline R. baronicus & & & & & & & & & & $\mathrm{x}$ \\
\hline R. calothyrsus & & & & & & $\mathrm{x}$ & & & & \\
\hline R. calviformis & & & & & & $\mathrm{x}$ & $\mathrm{x}$ & & $\mathrm{x}$ & $\mathrm{x}$ \\
\hline R. calyculatus & $\mathrm{x}$ & & & & & & & & & \\
\hline R. canduliger & & & & & & $\mathrm{x}$ & & & & \\
\hline R. caninitergi & $\mathrm{x}$ & & $\mathrm{x}$ & & & & & & & \\
\hline R. ceratifolius & & & & & $\mathrm{x}$ & & & & $\mathrm{x}$ & \\
\hline R. cinerascens & $\mathrm{x}$ & & & & & & & & & \\
\hline R. confusidens & & & & $\mathrm{x}$ & & $\mathrm{x}$ & & & & \\
\hline R. conspicuus & $\mathrm{x}$ & & & $\mathrm{x}$ & & & & & & \\
\hline R. contridens & & & $\mathrm{x}$ & & & $\mathrm{x}$ & & & $\mathrm{x}$ & \\
\hline R. cordiformis & & & & & $\mathrm{x}$ & & & & & \\
\hline$R$. deweveri & & & & $\mathrm{x}$ & & & & & & \\
\hline R. egregius & & & & $\mathrm{x}$ & & $\mathrm{x}$ & & & $\mathrm{x}$ & \\
\hline R. elegantispinosus & $\mathrm{x}$ & & & $\mathrm{x}$ & $\mathrm{x}$ & $\mathrm{x}$ & & & $\mathrm{x}$ & \\
\hline R. gloriosus & & & & & & & & & $\mathrm{x}$ & \\
\hline R. grandiflorus & & & & $\mathrm{x}$ & & & & & & \\
\hline R. guestphalicus & & & & & & & & & & $\mathrm{x}$ \\
\hline R. holerytrhos & & & & & & $\mathrm{x}$ & & & & \\
\hline R. horrefactus & & & & & & & & & $\mathrm{x}$ & \\
\hline R. imbricatus & & & & & & & & & & $\mathrm{x}$ \\
\hline R. immodicus & $\mathrm{x}$ & $\mathrm{x}$ & & & & & & & & \\
\hline R. incarnatus & & & & & & & & & $\mathrm{x}$ & \\
\hline$R$. insectifolius & & & & & & $\mathrm{x}$ & & & & $\mathrm{x}$ \\
\hline
\end{tabular}




\begin{tabular}{|c|c|c|c|c|c|c|c|c|c|c|}
\hline & $\ddot{\tilde{\xi}}$ & ङे & शे & క్తి & ฐั & $\stackrel{\Sigma}{\Sigma}$ & 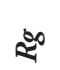 & $\Xi$ & 2 & ฉี \\
\hline R. iuvenis & $\mathrm{x}$ & & & & & & & & & \\
\hline R. lasiocladus & $\mathrm{x}$ & & & & & & & & & \\
\hline R. leucandrus & & & & & & & & & $\mathrm{x}$ & $\mathrm{x}$ \\
\hline R. libertianus & & & & & & & & & & $\mathrm{x}$ \\
\hline R. lobatidens & & & & & & $\mathrm{x}$ & & & & \\
\hline R. loehrii & & $\mathrm{x}$ & & & & & & & & \\
\hline R. longior & & & & $\mathrm{x}$ & & & & $\mathrm{x}$ & & \\
\hline R. mucronulatus & & & & & & & & & $\mathrm{x}$ & \\
\hline R.mus & & & & & & & $\mathrm{x}$ & & & \\
\hline$R$. negatus & & & $\mathrm{x}$ & & & & & & & \\
\hline R. nemorosus & & & & & $\mathrm{x}$ & $\mathrm{x}$ & $\mathrm{x}$ & & & \\
\hline R. opacus & & & & & & & $\mathrm{x}$ & & & $\mathrm{x}$ \\
\hline$R$. oreades & $\mathrm{x}$ & & & $\mathrm{x}$ & & & & & & \\
\hline R. pallidus & & $\mathrm{x}$ & & & & & & & & \\
\hline$R$. passionis & & & & & & $\mathrm{x}$ & & $\mathrm{x}$ & & \\
\hline$R$. phyllostachys & & & & & & $\mathrm{x}$ & & & & \\
\hline R. picearum & $\mathrm{x}$ & & & & & & & & & \\
\hline$R$. planus & & & & & & & $\mathrm{x}$ & & & $\mathrm{x}$ \\
\hline R. platyacanthus & $\mathrm{x}$ & & $\mathrm{x}$ & $\mathrm{x}$ & & $\mathrm{x}$ & & & & \\
\hline$R$. poliothyrsus & $\mathrm{x}$ & & & & & & & & $\mathrm{x}$ & $\mathrm{x}$ \\
\hline R. polyanthemus & & & & & & $\mathrm{x}$ & & & & \\
\hline$R$. procerus & & & & $\mathrm{x}$ & & & & & & \\
\hline$R$. pugiungulosus & & & & $\mathrm{x}$ & & $\mathrm{x}$ & & & & \\
\hline R. raduloides & $\mathrm{x}$ & & & $\mathrm{x}$ & & $\mathrm{x}$ & & & & \\
\hline R. rosaceus & $\mathrm{x}$ & & & & & & & & & \\
\hline R. rufescens & $\mathrm{x}$ & $\mathrm{x}$ & & $\mathrm{x}$ & & & & & & \\
\hline R. sciocharis & & & & & & & & & & $\mathrm{x}$ \\
\hline R. stereacanthus & & & & $\mathrm{x}$ & & & & & & \\
\hline R. sulcatus & & & & $\mathrm{x}$ & & $\mathrm{x}$ & & & & \\
\hline R. taxandriae & & & & & & & & & & $\mathrm{x}$ \\
\hline R. thalassarctos & & & & & $\mathrm{x}$ & & & & & \\
\hline R. trichanthus & & & & $\mathrm{x}$ & & & & & $\mathrm{x}$ & \\
\hline R. tubanticus & & & & & & $\mathrm{x}$ & & & & \\
\hline R. vadalis & & & & & $\mathrm{x}$ & & & & & \\
\hline R. vandermeijdenii & $\mathrm{x}$ & & & & & & & & & \\
\hline
\end{tabular}


Rare Rubus species in bramble scrub associations

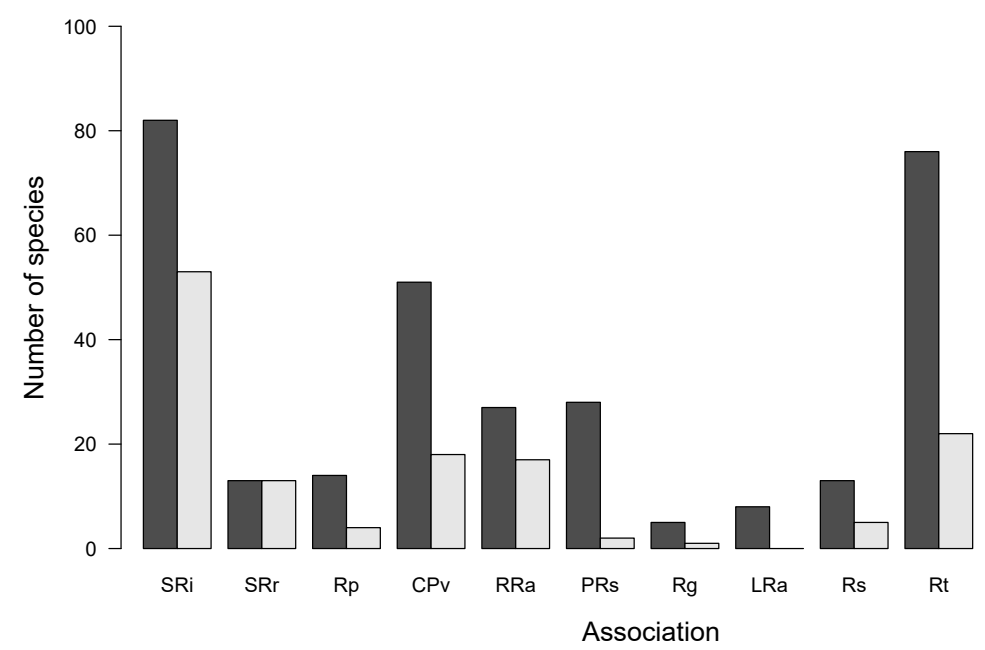

Figure 8.1: Total frequency of rare and very rare Rubus species in ten associations belonging to the Rhamno-Prunetea and Lonicero-Rubetea, based on tables published by Haveman \& De Ronde (in press) and De Ronde \& Haveman (in press).

1986), the number of woody species in hedgerows increases with the age of the hedge, in compliance with the Island Theory of Biogeography (MacArthur \& Wilson 1967). Although this increase is confounded by other factors, like the availability of vectors (Kollmann \& Schneider 1999) and the availability of nearby source populations (Jackson 2001), it might be expected that for every one or two decades one additional woody species can be found in every 30 meter hedgerow (Hooper 1970; Willmot 1980; Hetherington 1986). Whether this figure holds for Rubus species too is not clear due to the neglect of Rubus species in the mentioned studies.

In contrast, the community types with a low frequency of rare Rubus species are restricted to young landscapes, or landscapes in which only a few bramble species find suitable habitats. The former ones include former heath landscapes and bog landscapes which are turned into large agricultural landscapes after the land reclamation activities in the late $19^{\text {th }}$ and early $20^{\text {th }}$ century, the latter are found in the peatland transition zone between the Pleistocene sand deposits and marine marsh landscapes. Young landscapes have until now been invaded mainly by species of section Rubus, like $R$. plicatus, $R$. scissus and $R$. integribasis, as was shown in chapter 6 of this thesis. Apart from age, unfavourable growing conditions (nutrient and loam poor soils, lack of a sufficiently developed humus layer, high water tables) are the reason for the low overall Rubus species diversity in this landscape, resulting in low numbers of rare species in communities such as the Rubetum grati and the Lysimachio-Rubetum ammobii. 


\section{Rubus diversity as facilitator of fauna diversity}

In their ability to dominate the vegetation completely, Rubus subgenus Rubus can be considered both a system engineer (Jones et al. 1994) and a resource for many organisms. Weeda et al. (2006) used the term innkeeper (Dutch: herbergier) for this group of providing organisms. In a study of the insect species richness of Rosaceae in Britain, Leather (1986) found that the best explanation of the number of insect species on the Rosaceae species was the present day abundance of the host species. Given the high abundance of Rubus scrubs in the Dutch sand landscape (see chapter 6), a high number of Rubus feeding insects can be expected. Taylor (2005) gives a long list of phytophagous insects and mites feeding on Rubus. The flowers provide nectar and pollen and frequent flower visitors in Rubus species include Coleoptera, Hymenoptera, Diptera, and Lepidoptera, whereas Rubus flower abundance has shown to be one of the main predictors of butterfly diversity on arable land (Dover 1996). Rubus canes are used as nesting sites by solitary bees and wasps (e.g. Höppner 1910; Linsley 1958; Danks 1971; Petrischak 2014). However, there are no studies on the effect of Rubus diversity on fauna diversity, or on the prevalence of insects species to one or more Rubus species.

May June July August September

Rubetum grat
$R$. gratus
$R$. plicatus
$R$. nemoralis

Rubetum silvatici

$R$. nessensis

$R$. idaeus

R. plicatus

R. gratus

R. sprengelii

R. glandithyrsos

$R$. erinulus

R. flexuosus

$R$, drenticus

R. discors

R. silvaticus
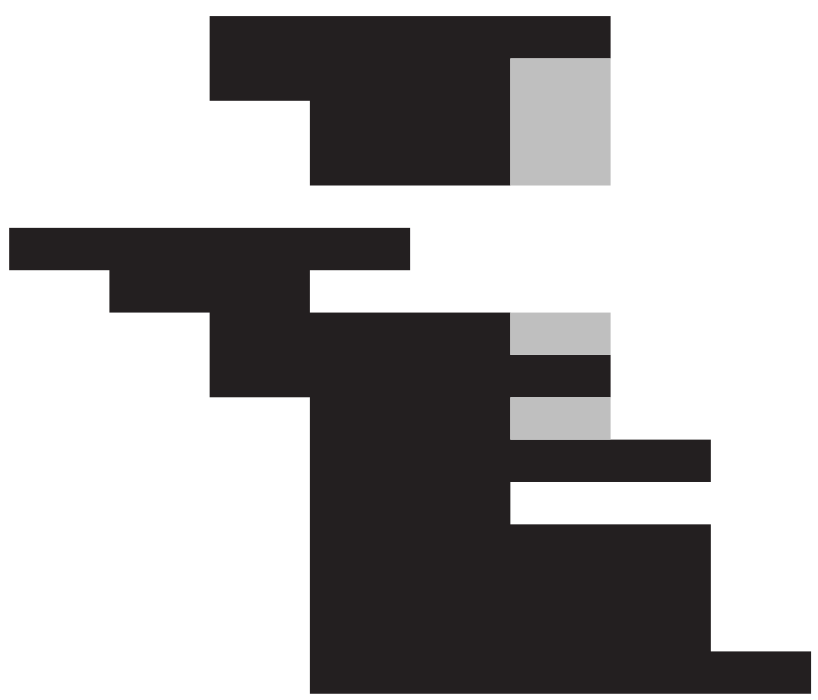

Figure 8.2. Flowering profiles of the Rubetum grati and the northern form of the Rubetum silvatici, based on phytosociological data published by De Ronde \& Haveman (in press) and phenological data in Weber (1995) and Van de Beek (2014-2016). Only Rubus species with a frequency $>20 \%$ are included. Black = normal flowering period, grey $=$ prolonged flowering period. SRi $=$ SenecioniRubetum iuvenis, $\mathrm{SRr}=$ Sambuco-Rubetum rudis, $\mathrm{Rp}=$ Rubetum pedemontani, $\mathrm{CPv}=$ Corno-Rubetum vestiti, $\mathrm{RRa}=$ Roso-Rubetum affinis, $\mathrm{PRs}=$ Pruno-Rubetum sprengelii, $\mathbf{R g}=$ Rubetum grati, $\mathrm{LRa}=$ Lysimachio-Rubetum ammobii, Rs = Rubetum silvatici, $\mathrm{Rt}=$ Rubetum taxandriae. 
In the following, I will briefly sketch the significance of Rubus diversity on a local scale for flower visiting and nesting insects using phenological and morphological characteristics of Dutch Rubus species (example 1 and 2). In a third example, I will sketch the role of the species composition of Rubus scrubs for the suitability for scrub nesting birds.

\section{Example 1: Flower phenology and flower visiting insects and mites}

As mentioned above, Rubus subgenus Rubus is an important source of pollen and nectar for flower visiting insects and mites (Gyan \& Woodell 1987b; Fussell \& Corbet 1992; e.g. Coffey \& Breen 1997; Keller et al. 2005; Taylor 2005). Phenological studies in Britain showed that brambles (Rubus fruticosus agg.) are flowering throughout summer, from mid May until mid September, with a clear peak at the beginning of July (Gyan \& Woodell 1987a; Fussell \& Corbet 1992). The flowering period of Rubus species varies considerably though, hence stands rich in Rubus species are likely to provide nectar and pollen during a longer period in summer.

Only rough phenological data are available for Dutch Rubus species. Flowering periods are given by Van de Beek (2014-2016), but no precise information is given, e.g. on the dates of opening of first flower buds, or the date of optimum flowering, or last flowers. Similar information is given by Weber (1995). Figure 8.2 shows the flowering periods for the most important bramble species in the Rubetum grati and the northern form of the Rubetum silvatici based on the data used by De Ronde \& Haveman (in press) and the data on phenology from the above literature. Only species with a frequency $>20 \%$ in the concerning association are included. From this figure, it is clear that the flowering periods of bramble species indeed vary considerably, with a main flowering period from mid June to mid August. However, especially in the Rubetum silvatici early and late flowering species are found, like $R$. nessensis, $R$. idaeus, and $R$. silvaticus. A higher diversity in Rubus scrubs therefore results in a higher chance of a prolonged period in which nectar and pollen are available to flower visiting insects. This might be crucial for the survival of insect populations, since changes in nectar supply are probably an important cause for the decline of flower visiting insects, e.g. butterflies (Wallis de Vries et al. 2012).

\section{Example 2: Primocane diameter and nesting Hymenoptera}

Although the use of Rubus canes as nesting place by solitary Hymenoptera has been known for a long time (Höppner 1910), no literature is known in which the prevalence of Hymenoptera species for particular Rubus species has been described. Bee and wasp species can only profitably use a selection of holes because of their body size. Large species can use fewer stems than small species, and small species must make modifications to stem holes much larger than themselves to make them available as nesting site (Michener 1970; Tepedino \& Parker 1983; Peterson et al. 2006). Although there is a large overlap 
and the metrics are influenced by environmental factors, the primocane diameter range in Rubus is species specific, which makes the suitability as nesting place for Hymenoptera species dependent on the occurring Rubus species. According to Matzke-Hajek (1993), the stem diameter ranges of $R$. macrophyllus and $R$. oreades, two frequently occurring species in the Senecioni-Rubetum iuvenis, are 6-9 $\mathrm{mm}$ and 3.5-6 $\mathrm{mm}$ respectively. For $R$. ulmifolius, a stem diameter of $5-10 \mathrm{~mm}$ is given, and for the invasive $R$. armeniacus even 10-25 mm (Matzke-Hajek 1993). Evidently, these Rubus species could provide nesting places for very different bees and wasp species, which makes the Rubus species composition of scrubs one of the factors that determines the potential Hymenoptera community.

\section{Example 3: Growth form and nesting birds}

For birds, scrubs can function as food source (fruits, and a high abundance of herbivorous insects) and as nesting habitat. Bird species using scrubs as nesting habitat are e.g. Prunella modularis, Sylvia borin, S. curruca, S. communis, and Luscinia megarhynchos (Sierdsema 1999). The suitability of bramble scrubs for nesting birds might probably be depending on the architecture or growth form of the constituting Rubus species, since this influences vegetation, a factor that has shown to influence the suitability as nesting habitat to a large extent (see e.g. Wilson et al. 2005). Low growing species, like $R$. iuvenis, $R$. oreades, $R$. bellardii, $R$. picearum and $R$. ignoratus can form dense knee- or even only ankle-high 'blanket' scrubs in clearings of ancient forests (Haveman et al. 2014b). Similar low-growing scrubs are formed by the thamnophilous species from the section Corylifolii. Contrarily, high arching species, like $R$. macrophyllus, $R$. gratus, $R$. winteri, $R$. ulmifolius, and the invasive $R$. armeniacus usually form breast- to more than man-high scrubs. A third category is formed by the species of subsection Rubus, and especially the series Suberecti and Rubus, since these species have a more erect habit, forming less dense scrubs. An example is $R$. ammobius, which is the main species in the recently described Lysimachio-Rubetum ammobii (De Ronde \& Haveman in press). Consequently, Rubus species composition of the scrub community plays a key role in the realisation of the vegetation structure, and therefore has to be accounted for to predict or explain the suitability as nesting habitat.

\section{Bramble scrubs as landscape element}

Although the term 'bramble scrubs' is used regularly in the preface, strictly spoken brambles dominated vegetation could better be considered 'semi-scrubs'. In contrast to scrubs proper, the vegetation dominated by brambles isn't formed by species with longliving above-ground lignified parts, but by annual and bi-annual lignified shoots. This makes them weak competitors for light when compared to most shrub species, and in the vegetation complex with dense scrubs, the brambles are characteristic for the outer parts (Weber 1967, 1974, 1990, 1999b, 2003b). One could speak of a cuff vegetation, 
to distinguish from the mantle vegetation formed by long-living shrub species; in the British NVC such scrubs are classified 'under-scrubs' (Rodwell 1998). Only in linear landscape structures, such as hedges, hedgerows and wooded banks, these formations are often so closely entangled that they can't be distinguished properly. In a regional context, this formation of semi-scrubs formed by lignified perennial species with bi-annual aboveground shoots is a highly characteristic feature for the north-west European landscape. In more continental parts of Europe, bramble scrubs are strictly confined to the buffered climate of forests (forest clearings), whereas to the south, Rubus species are part of the more open retamoid scrubs or Mediterranean maquis (Costa et al. 2003; Jasprica et al. 2007; Asensi \& Díez-Garretas 2011; Pinto-Gomes et al. 2012; de Foucault et al. 2013).

The lack of appreciation for (or even hostility against) bramble scrubs in nature conservation circles, although they can be rather species rich, is striking. An analysis of vegetation relevés and plant distribution patterns between the periods 2000-2003 and 2004-2007 by Statistics Netherlands (Centraal Bureau voor de Statistiek 2008) showed that the abundance of 'Rubus fruticosus' in linear landscape structures like hedgerows and dykes increased with $31 \%$, along with an increase of e.g. Galium aparine (29\%), Urtica dioica (6\%), and Cirsium vulgare (19\%). These increases were attributed to the general eutrophication of the landscape, and it was concluded that over the years, the quality of the countryside and the quality of the flora at the countryside had declined. In several other studies, Rubus subgenus Rubus is seen as an indicator of high nutrient levels (e.g. Van Tol et al. 1998). Already Bijlsma (2004) warned for an oversimplification when using Rubus in ecological studies though, since various bramble species can have very different ecological demands. A short look at the Ellenberg Indicator Values (EIV) for nutrients (Weber 1991) quickly shows large differences between various species usually lumped into one $R$. fruticosus (e.g. $R$. scissus $\left(\mathrm{N}_{\mathrm{EIV}}=2\right), R$. gratus $\left(\mathrm{N}_{\mathrm{EIV}}=3\right), R$. silvaticus $\left(\mathrm{N}_{\mathrm{EIV}}=4\right)$, and $R$. macrophyllus $\left(\mathrm{N}_{\mathrm{EIV}}=6\right)$ ). According to Bijlsma (2004), the increase of Rubus in forest understorey vegetation has to be attributed to changes in forest management after the Second World War, a conclusion that was confirmed by a large-scale European study recently (Verheyen et al. 2012).

Another problem in the mentioned study by Statistics Netherlands (Centraal Bureau voor de Statistiek 2008) caused by poor Rubus taxonomy might well be the underestimation of the effect of the enormous increase of the invasive $R$. armeniacus, which is masked by the seeming omnipresence of Rubus in the Dutch landscape. This species is indigenous in the Caucasus and introduced in central Europe around 1800 (Weber 1995). Rubus armeniacus (sometimes referred to as $R$. praecox, which is a different species) is worldwide considered an invasive species, threatening natural ecosystems in several temperate regions (Caplan \& Yeakley 2006; Pfeiffer \& Ortiz 2007; Astley 2010; Caplan \& Yeakley 2010; Richardson \& Rejmánek 2011; Clark et al. 2013). Figure 8.3 


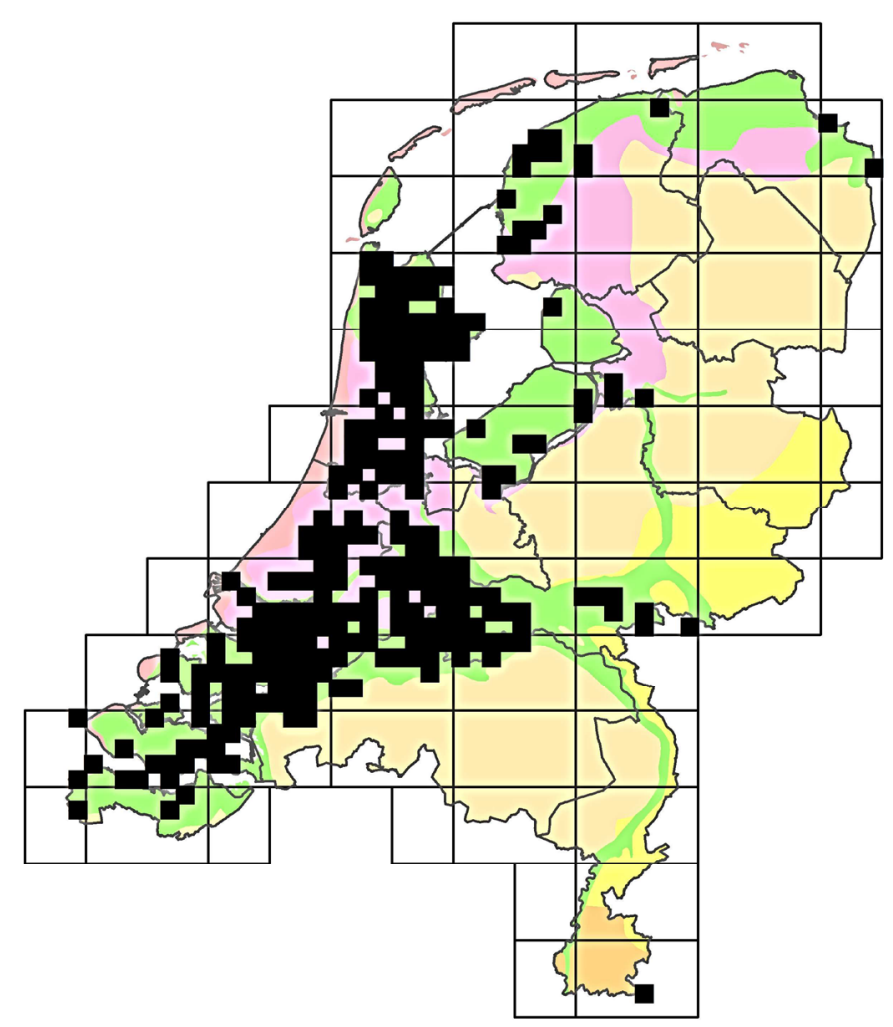

Figure 8.3. Distribution map of Rubus armeniacus in the Netherlands in grid cells $(5 \times 5 \mathrm{~km})$ where other Rubus species (except Rubus caesius and/or Rubus idaeus) are lacking.

shows the distribution of this species in the Netherlands in the map grid cells where other Rubus species are lacking. From the interactive map of ' $R$. fruticosus' at the online distribution atlas of Dutch phanerogams (FLORON 2015) it becomes clear that Rubus in most of these grid cells appeared after 1975, and field observations show that $R$. armeniacus here still increases, especially in man-made biotopes. The main increase of supposed nitrophilous species in the mentioned Statistics Netherlands study took place at dykes, a landscape element of exactly those parts of the landscape inhabited by $R$. armeniacus. Evidently, it can be concluded that the found increase of brambles at least for an important part can be attributed to the increase of this species. In the Netherlands, no studies are executed to understand the causes and consequences of the strong increase of $R$. armeniacus. However, from the already mentioned studies there is no direct evidence that the increase of $R$. armeniacus is directly linked to, or mainly caused by eutrophication. 


\section{Conclusion and outlook}

As was asserted above, brambles and bramble scrubs are typical elements of the northwest European landscape. They represent an important part of the natural biodiversity at several levels, and it is time to revaluate brambles as such not only in taxonomy, nature conservation management and policy, but also in biodiversity studies. Much research has to be done to understand the patterns and functional relationships of Rubus, Rubus dominated scrubs and other plant and animal species. Especially the function of Rubus diversity in the preservation of arthropod diversity through food or nesting supply appears to be a promising field of research. In ecological studies, more attention should be paid to the differences between the various Rubus species, because an oversimplification of Rubus taxonomy could easily lead to dubious conclusions.

\section{General conclusions}

The various studies in this thesis highlight some philosophical, taxonomical, phytogeographical and phytosociological aspects of a taxonomically problematic group of phanerogams, i.c. Rubus subgenus Rubus (bramble). Here, I want to come back to the questions raised in the introduction of this thesis and draw some general conclusions. In north-west Europe, Rubus subgenus Rubus consists of a polyploid series with a limited number of diploid sexual species and numerous polyploid obligate and facultative apomicts. The species status of these apomict lineages is questioned from time to time, or they are neglected completely. It was concluded that no a priori 'essentials' can be determined which define species and that species can only be discovered using biological characteristics. When evidence from independent morphological, cytological, molecular, evolutionary, ecological and biogeographical sources is combined in an integrative taxonomical approach, the apomictic lineages in Rubus subgen. Rubus have to be considered species. This holds true for the stabilised lineages with a large distribution area, but also for such with a small area, which usually are not considered taxonomic taxa in modern Rubus taxonomy. In the Netherlands, 191 Rubus species are found until now, but some well-known locally distributed species still remain undescribed.

Large-scale phytogeographical patterns in Rubus subgenus Rubus are partly caused by large distribution barriers (like the North-Sea, and mountain ranges), but the evolutionary history of the genus, i.c. the ancestry of the individual species, is still prominent in the distribution patterns. A regionalisation of distribution patterns of individual Rubus species lead to the conclusion that ecological factors are probably subordinate to historical factors in the realisation of general distribution patterns in the genus in north-west Europe.

On a lower scale, at the landscape and community level, it is likely that patterns can be explained by ecological and landscape historical factors. We showed that Rubus species 
composition of bramble scrubs in the landscape does not vary randomly, but instead occurs spatially clustered, a pattern which is confounded by landscape history mainly. Species rich bramble scrubs and bramble scrubs with narrowly distributed regional species are almost confined to landscapes with old elements, e.g. old hedges, hedgerows, and ancient woodlands. In young landscapes, like heathland and bog reclamations, only species poor bramble scrubs with widely distributed species are found. However, these landscape patterns are confounded by important ecological factors, like soil development, which likely have an important bearing on the species composition of bramble scrubs.

On the basis of these findings, a new classification of bramble scrubs is given, in which ten associations are distinguished for the Netherlands. Bramble communities are a particular and distinctive feature of the north-west European landscape, and they locally harbour many rare and endangered shrub species, apart from many narrowly distributed Rubus species. It was argued that bramble scrubs rich in Rubus species are an important facilitator of invertebrate and vertebrate species, which was illustrated by the influence of phenology and morphology of different Rubus species on flower visiting and nesting insects and birds. Much research is needed though to better understand the importance of the Rubus diversity in bramble scrubs in faunal community diversity.

The success and omnipresence of Rubus in the Dutch and north-west European landscape make the group a perfect subject for phytogeographical and ecological studies. In contrast to other large apomict complexes like Taraxacum and Hieracium, the taxonomy of Rubus is cleared to a large extent. As system engineers, Rubus species are able to form conspicuous semi-scrubs. These scrubs can harbour many rare and narrowly distributed species and are of great importance for many other species, including (in-)vertebrates. As such, brambles deserve a revaluation both in taxonomy and nature conservation. 


\section{References}

Almquist SOI (1881) Studier öfver slägtet Hieracium. P.A. Norstedt \& Söner, Stockholm.

Andersson P-A (1988) Ordination and classification of operational geographic units in Southwest Sweden. Pl. Ecol, 74:95-106.

Anonymus (1995) Grote historische atlas van Nederland 1:50.000. 4. Zuid-Nederland 1838-1857. Wolters-Noordhoff bv., Groningen.

Antonius K, Nybom H (1995) Discrimination between sexual recombination and apomixis/automixis in a Rubus plant breeding progamme. Hereditas 123:205-213.

Aptroot A, Van Herk CM, Sparrius L (2012) Basisrapport voor de Rode Lijst korstmossen. Buxbaumiella 92:1-117.

Arnold ML (1997) Natural hybridization and evolution. Oxford University Press, New York, Oxford.

Arvet-Touvet CJM (1888) Les Hieracium des Alpes françaises ou occidentales de l'Europe. Henry Georg, Lyon, Genève, Bâle.

Arvet-Touvet CJM (1913) Hieraciorum praesertim Galliae et Hispanicae catalogus systematicus. Lib. des Sc. nat. Léon Lhomme, Paris.

Asensi A, Díez-Garretas B (2011) The Tamaricetalia order in the Western Mediterranean region. Plant Biosyst. 145:123-131.

Asker S, Jerlings L (1992) Apomixis in plants. CRC Press, Inc., Boca Raton.

Astley C (2010) How does Himalayan blackberry (Rubus armeniacus) impact breeding bird diversity? A case study of the lower mainland of British Columbia. Thesis Royal Roads University,

Avise JC, Ball R (1990) Principles of genealogical concordance in species concepts and biological taxonomy. Oxford Surveys in Evolutionary Biology 7:45-67.

Babington CC (1846) A Synopsis of the British Rubi. J. van Voorst, London.

Babington CC (1869) The British Rubi: an attempt to discriminate the species of Rubus known to inhabit the British Isles. J. van Voorst, London.

Backhouse J (1856) Monograph of the British Hieracia. W. Simpson, York.

Bakker PA, Maes NCM, Kruijer JD (2011) De wilde rozen (Rosa L.) van Nederland. Gorteria 35:1-173.

Barkman JJ, Doing H, Segal S (1964) Kritische Bemerkungen und Vorschläge zur quantitativen Vegetationsanalyse. Acta Bot. Neerl. 13:394-419.

Barthlott W, Hostert A, Kier G, Küper W, Kreft H, Mutke J, Rafiqpoor MD, Sommer JH (2007) Geographic patterns of vascular plant diversity at continental to global scales. Erdkunde 61:305-315.

Bartish IV, Hennekens S, Aidoud A, Hennion F, Prinzing A (2010) Species pools along contemporary environmental gradients represent different levels of diversification. J. Biogeogr. 37:2317-2331.

Bartish IV, Ozinga WA, Bartish MI, Wamelink GWW, Hennekens SM, Prinzing A (2016) Different habitats within a region contain evolutionary heritage from different epochs depending on the abiotic environment. Glob. Ecol. Biogeogr. 25:274-285.

Basset Y, Cizek L, Cuénoud P, Didham RK, Guilhaumon F, Missa O, Novotny V, Ødegaard F, Roslin T, Schmidl J (2012) Arthropod diversity in a tropical forest. Science 338:1481-1484. 
Bayerisches Staatsministerium für Umwelt GuVS (2005) Rote Liste der gefährdeten Tiere und Gefäßpflanzen Bayerns: Kurzfassung. Bayerisches Staatsministerium für Umwelt, Gesundheit und Verbraucherschutz, München.

Beaman JH (1990) Revision of Hieracium (Asteraceae) in Mexico and Central America. Syst. Bot. Monogr. 29:1-77.

Beijerinck W (1953) On the habit, ecology and taxonomy of the brambles of the Netherlands. Acta Bot. Neerl. I:523-545.

Beijerinck W (1956) Rubi Neerlandici. N.V. Noord-Hollandsche Uitgevers Maatschappij, Amsterdam.

Beijerinck W, Ter Pelkwijk AJ (1952) Rubi in the northeastern part of the Netherlands (A floristic and vegetational study). Acta Bot. Neerl. 1:325-360.

Bengtsson BO (2009) Asex and evolution: A very large-scale overview. In: Schön I, Martens K, Van Dijk P (eds), Lost Sex: 1-19. Springer Netherlands,

Bertoloni A (1842) Miscellanea Botanica I. Bononiae, Bologna.

Bickford D, Lohman DJ, Sodhi NS, Ng PK, Meier R, Winker K, Ingram KK, Das I (2007) Cryptic species as a window on diversity and conservation. Trends Ecol. Evol. 22:148-155.

Bierzychudek P (1985) Patterns in plant parthenogenesis. Experientia 41:1255-1264.

Bijlsma RJ (2002) Bosrelicten op de Veluwe. Een historisch-ecologische beschrijving. Alterra, Wageningen.

Bijlsma RJ (2004) Verbraming: oorzaken en ecologische plaats. Levende Nat. 105:138-144.

Bijlsma RJ (2006) Mantingerbos- en weiden: de bramen (Rubus fruticosus agg.). Vereniging Natuurmonumenten, 's Graveland.

Bijlsma RJ, Haveman R (2007) Rubus canduliger sp. nov., a new regional species from the Netherlands, with notes on the range structure and dynamics of brambles (Rubus L., Rosaceae). Folia Geobot. 42:315329.

Blackwelder RE (1967) Taxonomy: a text and reference book. Wiley, New York.

Bobbink R, Bijlsma RJ, Brouwer E, Eichhorn K, Haveman R, Hommel P, Van Noordwijk T, Schaminée J, Verberk W, de Waal R, Wallis de Vries M (2008) Preadvies hellingbossen in Zuid-Limburg. Directie Kennis, Ministerie van Landbouw, Natuurbeheer en Voedselkwaliteit, Ede.

Boreau A (1857) Flore du centre de la France et du Bassin de la Loire. Ed. 3. Librairie encyclopédique de Roret, Paris.

Botta-Dukát Z, Chytrý M, Hájková P, Havlová M (2005) Vegetation of lowland wet meadows along a climatic continentality gradient in Central Europe. Preslia 77:89-111.

Boulay N (1864-1869) Ronces Vosgiennes. Trotot, St. Dié.

Boulay N (1873-1894) Association rubologique exiccati. Nos. 1-1201. (exsiccata collection).

Boulay N, Bouly de Lesdain M (1895-1897) Rubi praesertim Gallici exsiccati. (exsiccata collection).

Braun-Blanquet J (1928) Pflanzensoziologie. Grundzüge der Vegetationskunde. Springer, Berlin.

Bräutigam S, Greuter W (2007) A new treatment of Pilosella for the Euro-Mediterranean flora [Notulae ad floram euro-mediterraneam pertinentes 24]. Willdenowia 37:123-137.

Bruelheide H, Chytry M (2000) Towards unification of national vegetation classifications: A comparison of two methods for analysis of large data sets. J. Veg. Sci. 11:295-306.

Buijs J (1993) Holland Houtland. Een geschiedenis van het Nederlandse bos. Prometeus, Amsterdam. 
Caplan JS, Yeakley JA (2006) Rubus armeniacus (Himalayan blackberry) occurrence and growth in relation to soil and light conditions in western Oregon. Northwest Science 80:9.

Caplan JS, Yeakley JA (2010) Water relations advantages for invasive Rubus armeniacus over two native ruderal congeners. Pl. Ecol, 210:169-179.

Centraal Bureau voor de Statistiek: Meer braam en brandnetel op het platteland, https://www.cbs.nl/nl-nl/ nieuws/2008/52/meer-braam-en-brandnetel-in-natuur-platteland, 2016.

Chambers G (2012) The species problem: seeking new solutions for philosophers and biologists. Biol. Philos. 27:755-765.

Christensen KI (1992) Revision of Crataegus sect. Crataegus and nothosect. Crataeguineae (RosaceaeMaloideae) in the Old World. Syst. Bot. Monogr. 35:1-199.

Chrtek J, Marhold K (1998) Species concept in agamic and autogamic complexes. Folia Geobot. 33:317318.

Chrtek J, Mráz P (2007) Taxonomic revision of Hieracium nigrescens agg. in the Western Carpathians. Preslia 79:45-62.

Chrtek J, Mráz P, Zahradníčk J, Mateo G, Szelag Z (2007a) Chromosome numbers and DNA ploidy levels of selected species of Hieracium s. str.(Asteraceae). Folia Geobot. 42:411-430.

Chrtek J, TonkovÁ M, MrÁZ P, Marhold K, PlaČKovÁ I, KrahulcovÁ A, Kirschner JAN (2007b) Morphological and allozyme diversity in the Hieracium nigrescens group (Compositae) in the Sudety Mountains and the Western Carpathians. Bot. J. Linn. Soc. 153:287-300.

Chrtek J, Zahradníček J, Krak K, Fehrer J (2009) Genome size in Hieracium subgenus Hieracium (Asteraceae) is strongly correlated with major phylogenetic groups. Ann. Bot. 104:161-178.

Chytrý M (2001) Phytosociological data give biased estimates of species richness. J. Veg. Sci. 12:439.

Chytrý M, Hennekens SM, Jiménez-Alfaro B, Knollová I, Dengler J, Jansen F, Landucci F, Schaminée JHJ, Aćić S, Agrillo E, Ambarlı D, Angelini P, Apostolova I, Attorre F, Berg C, Bergmeier E, Biurrun I, Botta-Dukát Z, Brisse H, Campos JA, Carlón L, Čarni A, Casella L, Csiky J, Ćušterevska R, Dajić Stevanović Z, Danihelka J, De Bie E, de Ruffray P, De Sanctis M, Dickoré WB, Dimopoulos P, Dubyna D, Dziuba T, Ejrnæs R, Ermakov N, Ewald J, Fanelli G, Fernández-González F, FitzPatrick Ú, Font X, García-Mijangos I, Gavilán RG, Golub V, Guarino R, Haveman R, Indreica A, Işık Gürsoy D, Jandt U, Janssen JAM, Jiroušek M, Kącki Z, Kavgacı A, Kleikamp M, Kolomiychuk V, Krstivojević Ćuk M, Krstonošić D, Kuzemko A, Lenoir J, Lysenko T, Marcenò C, Martynenko V, Michalcová D, Moeslund JE, Onyshchenko V, Pedashenko H, Pérez-Haase A, Peterka T, Prokhorov V, Rašomavičius V, Rodríguez-Rojo MP, Rodwell JS, Rogova T, Ruprecht E, Rūsiña S, Seidler G, Šibík J, Šilc U, Škvorc Ž, Sopotlieva D, Stančić Z, Svenning J-C, Swacha G, Tsiripidis I, Turtureanu PD, Uğurlu E, Uogintas D, Valachovič M, Vashenyak Y, Vassilev K, Venanzoni R, Virtanen R, Weekes L, Willner W, Wohlgemuth T, Yamalov S (2015) European Vegetation Archive (EVA): an integrated database of European vegetation plots. Appl. Veg. Sci. 19:173-180.

Chytry M, Rafajov M (2003) Czech National Phytosociological Database: basic statistics of the available vegetation-plot data. Preslia 75:1.

Claridge MF, Dawah HA, Wilson MR (1997) Species. The units of biodiversity. Chapman \& Hall, London, Weinheim, New-York, Tokyo, Melbourne, Madras. 
Clark LV, Evans KJ, Jasieniuk M (2013) Origins and distribution of invasive Rubus fruticosus L. agg. (Rosaceae) clones in the Western United States. Biol. Invasions 15:1331-1342.

Coffey MF, Breen J (1997) Seasonal variation in pollen and nectar sources of honey bees in Ireland. J. of Apic. Res. 36:63-76.

Cohan FM (2002) What are bacterial species? Ann. Rev. Microbiol. 56:457-487.

Costa JC, Aguiar C, Capelo J, Lousā M, Antunes J, Honrado JJ, Izco J, Ladero M (2003) A classe Cytisetea scopario-striati em Portugal Continental. Quercetea 4:45-70.

Cotterill FPD (1999) Toward exorcism of the ghost of W. T. Thistleton-Dyer: A comment on "overduplication" and the scientific properties, uses and values of natural science specimens. Taxon 48:35-39.

Cotterill FPD (2003) Species concepts and the real diversity of antelopes. In: Plowman A (ed), Proceedings of the ecology and conservation of mini-antelope: An international symposium on Duiker and Dwarf Antelope in Africa: 59-118. Filander Verlag, Fürth.

Cracraft J (1992) Species concepts and speciation analysis. In: Ereshefsky M (ed), The units of evolution. Essays on the nature of species: 93-120. Massachusetts Institute of Technology, Massachusetts.

Cracraft J (2002) The seven great questions of systematic biology: an essential foundation for conservation and the sustainable use of biodiversity. Ann. Mo. Bot. Gard. 89:127-144.

Cracraft J, Donoghue MJ (2004) Assembling the tree of life. Oxford University Press, New York, Oxford.

Crawford DJ, Archibald JK, Kelly JK, Mort ME, Santos-Guerra A (2010) Mixed mating in the 'obligately outcrossing' Tolpis (Asteraceae) of the Canary Islands. Plant Species Biol. 25:114-119.

Dahl E (1998) The phytogeography of northern Europe: British Isles, Fennoscandia and ajacent areas. Cambridge University Press, New York.

Dandy JE (1958) List of British vascular plants. British Museum (Natural History), London.

Danks HV (1971) Populations and nesting-sites of some aculeate Hymenoptera Nesting in Rubus. J. Anim. Ecol. 40:63-77.

Darlington C (1939) The evolution of genetic systems. Cambridge University Press, London.

Davis WH (1958) Apomixis, hybridization, and speciation in Rubus. Castanea 23:52-55.

de Candolle AP (1813) Catalogus Plantarum Horti Botanici Monspeliensis. Koenig, Paris, Strassbourg.

de Foucault B, Lazare J-J, Bioret F (2013) Contribution au prodrome des végétations de France : les Cytisetea scopario-striati Rivas-Mart. 1975. J. Bot. 64:69-90.

de Foucault B, Royer J-M (2014) Contribution au prodrome des végétations de France: les Franguletea alni Doing ex V. Westh. in V. Westh. \& den Held 1969. J. Bot. Soc. Bot. Franc. 66:83-106.

De Jongh SE (1971) Overzicht der Nederlandse bramen. I. . Rijksherbarium, Leiden.

De Kovel CGF, De Jong G (2000) Selection on apomictic lineages of Taraxacum at establishment in a mixed sexual-apomictic population. J. Evol. Biol. 13:561-568.

de Pinna MCC (1999) Species concepts and phylogenetics. Rev. Fish Biol. Fisher. 9:353-373.

de Queiroz A (2014) The monkey's voyage: how improbable journeys shaped the history of life. Basic Books, New York.

de Queiroz K (1998) The general lineage concept of species, species criteria, and the process of speciation: a conceptual unification and terminological recommendations. In: Howard DJ, Berlocher SH (eds), Endless Forms: species and speciation: 57-75. Oxford University Press, Oxford. 
de Queiroz K (1999) The general lineage concept of species and the defining properties of the species category. In: Wilson RA (ed), Species: new interdissiplinary essays: 49-89. MIT Press, Cambridge.

de Queiroz K (2005a) Different species problems and their resolution. BioEssays 27:1263-1269.

de Queiroz K (2005b) Ernst Mayr and the modern concept of species. Proc. Nat. Acad. Sci. USA 102:66006607.

de Queiroz K (2005c) A unified concept of species and its consequences for the future of taxonomy. Proc.

Calif. Ac. Sci. 56, Supplement I, No. 18:196-215.

de Queiroz K (2007) Species concepts and species delimitation. Syst. Biol. 56:879-886.

De Ronde I, Haveman R (2014) Op het randje - een plantensociologische analyse van heischraal grasland op defensieterreinen. Stratiotes 47:76-96.

De Ronde I, Haveman R (in press) Lonicero-Rubetea plicati. Stratiotes.

Deckers B, De Becker P, Honnay O, Hermy M, Muys B (2005) Sunken roads as habitats for forest plant species in a dynamic agricultural landscape: effects of age and isolation J. Biogeogr. 32:99-109.

Dengler J, Eisenberg M, Schröder J (2006) Die grundwasserfernen Saumgesellschaften Nordostniedersachsens im europäischen Kontext - Teil I: Säume magerer Standorte (Trifolio-Geranietea sanguinei). Tuexenia 26:51-93.

Dickinson TA (1998a) Species concepts in agamic complexes. In: van Raamsdonk LWD, den Nijs HCM (eds) VIIth International IOPB Symposium: Plant Evolution in Man-made Habitats. Hugo de Vries Laboratory, Amsterdam, pp 319-339.

Dickinson TA (1998b) Taxonomy of agamic complexes in plants: a role for metapopulation thinking. Folia Geobot. 33:327.

Diemont WH (1996) Survival of Dutch heathlands. Alterra, Wageningen.

Dierschke H (1988) Pflanzensoziologische und ökologische Untersuchungen in Wäldern SüdNiedersachsens. IV. Vegetationsentwicklung auf langfristigen Dauerflächen von BuchenwaldKahlschlägen. Tuexenia 8:307-326.

Dierschke H (1994) Pflanzensoziologie: Grundlagen und Methoden. Ulmer, Stuttgart.

Dierschke H (1997) Zur Benennung zentraler Syntaxa ohne eigene Kenn- und Trennarten. Tuexenia 8:381382.

Dierschke H (2014) Sekundärsukzession auf Kahlschlagflächen eines Buchenwaldes. Dauerflächenuntersuchungen 1971-2013. Tuexenia 34:107-130.

Dobzhansky T (1935) A Critique of the species concept in biology. Phil. Sci. 2:344-355.

Dobzhansky T (1950) Mendelian populations and their evolution. Am. Nat. 84:401-418.

Dobzhansky T (1973) Nothing in biology makes sense except in the light of evolution. The American Biol. Teach. 35:125-129.

Doing H (1962) Systematische Ordnung und floristische Zusammensetzung niederländischer Wald- und Gebüschgesellschaften. Wentia VIII:1-85.

Dover JW (1996) Factors affecting the distribution of satyrid butterflies on arable farmland. J. Appl. Ecol. 33:723-734.

Du Rietz GE (1930) The fundamental units of biological taxonomy. Sven. Bot. Tidskr. 24:333-428. 
Dufrêne M, Legendre P (1997) Species assemblages and indicator species: the need for a flexible asymmetrical approach. Ecol. Monogr. 67:345-366.

Edees ES, Newton A (1988) Brambles of the British Isles. The Ray Society, London.

Eldredge N, Cracraft J (1980) Phylogenetic patterns and the evolutionary process. Method and theory in comparative biology. Columbia Univ. Press, New York.

Ennos RA, French GC, Hollingsworth PM (2005) Conserving taxonomic complexity. Trends Ecol. Evol. 20:164-168.

Erben M (1993) Limonium Mill. In: Castroviejo S (ed), Flora Iberica vol. 3: 2-143. Real Jardín BotánicoCSIC, Madrid.

Ereshefsky M (2010) Microbiology and the species problem. Biol. Philos. 25:553-568.

Ereshefsky M (2011) Mystery of mysteries: Darwin and the species problem. Cladistics 27:67-79.

Ericsson S (1992) The microspecies of the Ranunculus auricomus complex treated at the species level. Ann. Bot. Fenn. 29:123-158.

Eriksson O (1993) The Species-Pool Hypothesis and plant community diversity. Oikos 68:371-374.

ESRI (2011) ArcGIS Desktop: Release 10. In: Environmental Systems Research Institute, Redlands, CA

Fehrer J, Krahulcová A, krahulec F, Chrtek J, Rosenbaumová R, Bräutigam S (2007) Evolutionary aspects in Hieracium subgenus Pilosella. In: Hörandl E, Grossniklaus U, Van Dijk PJ, Sharbel TF (eds), Apomixis. Evolution, Mechanisms and Perspectives: 360-390. A.R.G. Gantner Verlag, Rugell.

Fehrer J, Krak K, Chrtek J (2009) Intra-individual polymorphism in diploid and apomictic polyploid hawkweeds (Hieracium, Lactuceae, Asteraceae): disentangling phylogenetic signal, reticulation, and noise. BMC Evol. Biol. 9:239.

Fehrer J, Šimek R, Krahulcová A, Krahulec F, Chrtek J, Bräutigam E, Bräutigam S (2005) Evolution, hybridisation, and clonal distribution of apo- and amphimictic species of Hieracium subgen. Pilosella (Asteraceae, Lactuceae) in a Central European mountain range. In: Bakker FT, Chatrou LW, Gravendeel B, Pelser PB (eds), Plant Species-Level Systematics: New Perspectives on Pattern \& Process: 175-201. Koeltz, Königstein.

Finnie TJ, Preston CD, Hill MO, Uotila P, Crawley MJ (2007) Floristic elements in European vascular plants: an analysis based on Atlas Florae Europaeae. J. Biogeogr. 34:1848-1872.

Fisher RA (1958) The genetical theory of natural selection. Dover, New York.

FLORON: Verspreidingsatlas planten, http://www.verspreidingsatlas.nl/planten, 2015.

Focke WO (1877) Synopsis Ruborum Germaniae. Die deutschen Brombeerarten ausführlich beschrieben und erläutert. C. E. Muller's Verlagsbuchhandlung Bremen.

Focke WO (1902-1903) Rubus L. In: Ascherson P, Graebner P (eds), Synopsis der mittel-europäischen Flora VI, 1: 440-648. Wilhelm Engelmann, Leipzig.

Focke WO (1910-1914) Species Ruborum. Monographiae generis Rubi Prodromus 1-3. E. Schweizerbart'sche Verlagsbuchhandlung, Stuttgart.

Frank D, Herdam H, Jage H, John H, Kison H-U, Korsch H, Stolle J (2004) Rote Liste der Farn- und Blütenpflanzen (Pteridophyta et Spermatophyta) des Landes Sachsen-Anhalt. Ber. Landesamt. Umweltsch. Sachs.-Anhalt 39:91-110.

Fries E (1862) Epicrisis generis Hieraciorum. Edquist \& Berglund, Upsala. 
Frodin DG (2004) History and concepts of big plant genera. Taxon 53:753-776.

Fröhner SE (1995) Alchemilla L. In: Scholtz H, Conert HJ, Jäger EJ, Kadereit JW, Schultze-Motel W, Wagenitz G, Weber HE (eds), Gustav Hegi Illustrierte Flora von Mitteleuropa. Band IV. Teil 2B. Spermatophyta: Angiospermae: Dicotyledones 2(2): 13-242. Blackwell, Berlin.

Frost DR, Kluge AG (1994) A consideration of epistemology in stystematic biology, with special reference to species. Cladistics 10:259-294.

Fussell M, Corbet SA (1992) Flower usage by bumble-bees: A basis for forage plant management. J. Appl. Ecol. 29:451-465.

Garland MA (1990) Infrageneric names applicable to Hieracium subgenus Chionoracium (Compositae: Lactuceae). Taxon 39:119-124.

Gaston KJ (2000) Global patterns in biodiversity. Nature 405:220-227.

Genevier G (1869) Essai monographique sur les Rubus du Bassin de la Loire. Lachèse, Belleuvre et Dolbeau, Angers.

George TN (1956) Biospecies, chronospecies and morphospecies. In: Sylvester-Bradley PC (ed), The species concept in paleontology: 123-137. Systematics Association, London.

Ghiselin MT (1974) A radical solution to the species problem. Syst. Zool. 23:536-544.

Ghiselin MT (1987) Species concepts, individuality, and objectivity. Biol. Philos. 2:127-143.

Ghiselin MT (1997) Metaphysics and the origin of species. State University of New York Press, New York.

Gilgen R (1994) Pflanzensoziologisch-ökologische Untersuchungen an Schlagfluren im schweizerischen Mittelland über Würmmoränen. Veröffentl. Eidgen. Tech. Hochsch. St. Rübel 116:1-127.

Glavac V (1997) Vegetationsökologie. Springer-Verlag, Heidelberg.

Goodfellow M, Manfio GP, Chun J (1997) Towards a practical species concept for cultivable bacteria. In: Claridge MF, Dawah HA, Wilson MR (eds) The Units of Biodiversity. Chapman \& Hall, London, pp 25-60.

Gottschlich G, Raabe U (1991) Zur Verbreitung, Ökologie und Taxonomie der Gattung Hieracium L. (Compositae) in Westfalen und angrenzenden Gebieten. Abh. Westf. Mus. Naturk. 53:1-140.

Gottschlich G, Raabe U, Schou J-C (1998) Die Gattung Hieracium L. (Compositae) auf der Insel Rügen und ihre pflanzengeographische Beziehung zur skandinavischen Hieracium-Flora - nebst ergaenzenden bio- und bibliographischen Angaben zur Rügen-Floristik. Bot. Rundbr. Mecklenbg-Vorpommer. 31:194.

Govaerts R (2001) How many species of seed plants are there? Taxon 50:1085-1090.

Grant V (1971) Plant speciation. Columbia University Press, New York/London.

Gregor T (2013) Apomicts in the vegetation of Central Europe. Tuexenia 33:233-257.

Gregor T, Matzke-Hajek G (2002) Apomikten in roten Listen: Kann der Naturschutz einen Grossteil der Pflanzenarten übergehen? Nat. Landsch. 77:64-71.

Grime JP, Hodgson JG, Hunt R (2007) Comparative plant ecology. A functional approach to common British species. Castlepoint Press, Colvend.

Gustafsson $\AA$ (1943) The Genesis of the European Blackberry Flora. Lunds Univ. Aarskr. 39:1-199.

Gustafsson Å (1946a) Apomixis in higher plants. Part I. The Mechanism of apomixis. Lunds Univ. Aarskr.

N.F. 42:3-66. 
Gustafsson $\AA$ (1946b) Apomixis in higher plants. Part II. The causal aspect of apomixis. Lunds Univ. Aarskr. N.F. 43:71-178.

Gustafsson $\AA$ (1947) Apomixis in higher plants. Part III. Biotype and species formation. Lunds Univ. Aarskr. N.F. 43:184-370.

Gyan KY, Woodell SRJ (1987a) Flowering phenology, flower colour and mode of reproduction of Prunus spinosa L. (Blackthorn); Crataegus monogyna Jacq. (Hawthorn); Rosa canina L. (Dog Rose); and Rubus fruticosus L. (Bramble) in Oxfordshire, England. Funct. Ecol. 1:261-268.

Gyan KY, Woodell SRJ (1987b) Nectar production, sugar content, amino acids and potassium in Prunus spinosa L., Crataegus monogyna Jacq. and Rubus fruticosus L. at Wytham, Oxfordshire. Funct. Ecol. 1:251-259.

Haag CR, Ebert D (2004) A new hypothesis to explain geographic parthenogenesis. Ann. Zool. Fenn. 41:539-544.

Hagendijk A, Van Soest JL, Zevenbergen HA (1975) 123. Compositae: Taraxacum (behalve Sectie Vulgaria). In: Mennema J, Muller FM, Van Ooststroom SJ, Stafleu FA, Westhoff V, De Wit HCD (eds), Flora Neerlandica. Flora van Nederland. Deel IV, aflevering 9.: 1-52. Koninklijke Nederlandse Botanische Vereniging, Amsterdam.

Hagendijk A, Van Soest JL, Zevenbergen HA (1982) Taraxacum sectie Vulgaria Dahlstedt. In: Adema F, Mennema J, Sterk AA, Weeda EJ, Westhoff V, Willemse MTM (eds), Flora Neerlandica. Flora van Nederland. Deel IV, aflevering 10: 79-303. Koninklijke Nederlandse Botanische Vereniging, Amsterdam.

Hausdorf B (2011) Progress towards a general species concept. Evolution 65:923-931.

Haveman R (1997) Het Rubetum grati (Lonicero-Rubetea plicati classis nova) in Nederland. Stratiotes 14:4151.

Haveman R (2013) Freakish patterns - species and species concepts in apomicts. Nord. J. Bot. 31:257-269.

Haveman R (2016) Gestolen kenmerken: het soortconcept in Rosa sect. Caninae. Gorteria 38:11-19.

Haveman R, Bijlsma RJ, De Ronde I, Schaminée JHJ (2016) Capricious, or tied to history’s apron strings? Floristic regions in north-west European brambles (Rubus subgenus Rubus, Rosaceae). J. Biogeogr. 43:1360-1371.

Haveman R, De Ronde I (2013) The role of the Weberian Reform in European Rubus research and the taxonomy of locally distributed species - which species should we describe? Nord. J. Bot. 31:145-150.

Haveman R, De Ronde I (2014) Vroegbloeiende havikskruiden in het Beneden-Geuldal: diversiteit, achteruitgang en beheer. Natuurhist. Maandbl. 103:183-189.

Haveman R, De Ronde I (in press) Rhamno-Prunetea. Stratiotes.

Haveman R, De Ronde I, Bijlsma RJ, Schaminée JHJ (2014a) Systematic randomised sampling along three landscape transects in the Netherlands reveals the geographically structured variation in Rubus scrubs. Phytocoenologia 44:31-44.

Haveman R, De Ronde I, Weeda EJ (2012) The Rubetum taxandriae ass. nov. (Lonicero-Rubion silvatici, Lonicero-Rubetea plicati), a new bramble association from the Belgian and Dutch Campine. Tuexenia 32:55-65. 
Haveman R, De Ronde I, Weeda EJ (2014b) Ecologie, verspreiding en syntaxonomie van Nederlandse struwelen. II. Bramenrijke kapvlaktebegroeiingen. Stratiotes 46:5-40.

Haveman R, Janssen JAM (2008) The analysis of long term changes in plant communities using large databases: the effect of stratified re-sampling. J. Veg. Sci. 19:355-362.

Haveman R, Schaminée JHJ, Stortelder AHF (1999a) Lonicero-Rubetea plicati. In: Stortelder AHF, Schaminée JHJ, Hommel PWFM (eds), De vegetatie van Nederland. Deel 5. Plantengemeenschappen van ruigten, struwelen en bossen: 89-104. Opulus Press, Uppsala, Leiden.

Haveman R, Schaminée JHJ, Weeda EJ (1999b) Rhamno-Prunetea. In: Stortelder AHF, Schaminée JHJ, Hommel PWFM (eds), De vegetatie van Nederland. Deel 5. Plantengemeenschappen van ruigten, struwelen en bossen: 121-164. Opulus Press, Uppsala, Leiden.

Haveman R, Schaminée JHJ, Weeda EJ (2002) Apomicten: het belang van een genuanceerde taxonomie voor plantensociologisch onderzoek en natuurbeheer. Stratiotes 25:3-25.

Haveman R, Van Haperen AMM (2008) Braamrijke duinstruwelen in Nederland. Stratiotes 36/37:63-86.

Heads M (2015) The relationship between biogeography and ecology: envelopes, models, predictions. Biol. J. Linn. Soc. 115:456-468.

Henker H, Schulze G (1993) Die Wildrosen des norddeutschen Tieflandes. Gleditschia 21,1:3.

Hennekens SM, Dirkse GM (2008) TurbovegCE 1.4. Turboveg Compact Edition voor PocketPC en WindowsCE. Een programma om vegetatieopnamen en floristische streeplijsten in te voeren op een veldcomputer - Handleiding. Alterra, Wageningen.

Hennekens SM, Schaminée JHJ (2001) TURBOVEG, a comprehensive data base management system for vegetation data. J. Veg. Sci. 12:589-591.

Hennig W (1950) Grundzuge einer Theorie der phylogenetischen Systematik. Berlin.

Hetherington M (1986) Studies of hedgerow dating and hedgerow loss in two Warwickshire parishes. Arboricult. J. 10:319-329.

Heukels H (1900) Geillustreerde schoolflora voor Nederland. Noordhoff, Groningen.

Heukels H (1909) De Flora van Nederland 2. Brill/Noordhoff, Leiden/Groningen.

Heukels H (1922) Geillustreerde schoolflora voor Nederland. Noordhoff, Groningen.

Hey J (2001) The mind of the species problem. Trends Ecol. Evol. 16:326-329.

Hey J, Waples RS, Arnold ML, Butlin RK, Harrison RG (2003) Understanding and confronting species uncertainty in biology and conservation. Trends Ecol. Evol. 18:597-603.

Hill MO (1979) TWINSPAN: a FORTRAN program for arranging multivariate data in an ordered twoway table by classification of the individuals and attributes. Section of Ecology and Systematics, Cornell University, Ithaca, New York.

Hillis DM (2007) Asexual evolution: Can species exist without sex? Curr. Biol. 17:R543-R544.

Hobohm C (2003) Characterization and ranking of biodiversity hotspots: centres of species richness and endemism. Biodiv. Cons. 12:279-287.

Hobohm C, Janišová M, Jansen J, Bruchmann I, Deppe U (2014) Biogeography of endemic vascular plants - overview. In: Hobohm C (ed), Endemism in vascular plants: 85-163. Pringer, Dordrecht. 
Hojsgaard D, Hörandl E (2015) Apomixis as a facilitator of range expansion and diversification in plants. In: Pontarotti P (ed), Evolutionary biology: biodiversification from genotype to phenotype: 305-327. Springer International Publishing, Basel.

Holeksa J, Wozniak G (2005) Biased vegetation patterns and detection of vegetation changes using phytosociological databases. A case study in the forests of the Babia Góra National Park (the West Carpathians, Poland). Phytocoenologia 35:1-18.

Holub J (1997) Some considerations and thoughts on the pragmatic classification of apomictic Rubus taxa. Osnabr. Naturwiss. Mitt. 23:147-155.

Hommel PWFM, Van Dort KW, Schaminée JHJ (1999) Vaccinio-Piceetea. In: Stortelder AHF, Schaminée JHJ, Hommel PWFM (eds), De vegetatie van Nederland. Deel 5. Plantengemeenschappen van ruigten, struwelen en bossen: 229-254. Opulus Press, Uppsala/Leiden.

Honnay O, Hermy M, Coppin P (1999) Effects of area, age and diversity of forest patches in Belgium on plant species richness, and implications for conservation and reforestation. Biol. Cons. 87:73-84.

Hooper M (1970) Dating hedges. Area 2:63-65.

Höppner H (1910) Zur Biologie der Rubusbewohner. II. Die Konkurrenz um die Nistpätze. Zeitschrift für wissenschaftliche Insektenbiologie VI:93-97; 133-136; 161-167; 219-224.

Hörandl E (1998) Species concepts in agamic complexes: applications in the Ranunculus auricomus complex and general perspectives. Folia Geobot. 33:335.

Hörandl E (2006) The complex causality of geographical parthenogenesis. New Phytol. 171:525-538.

Hörandl E, Greilhuber J (2002) Diploid and autotetraploid sexuals and their relationships to apomicts in the Ranunculus cassubicus group: insights from DNA content and isozyme variation. Plant Syst. Evol. 234:85.

Hörandl E, Greilhuber J, Klímová K, Paun O, Temsch E, Emadzade K, Hodálová I (2009a) Reticulate evolution and taxonomic concepts in the Ranunculus auricomus complex (Ranunculaceae): insights from analysis of morphological, karyological and molecular data. Taxon 58:1194-1216.

Hörandl E, Grossniklaus U, Van Dijk PJ, Sharbel TF (2007) Apomixis. Evolution, Mechanisms and Perspectives. A.R.G. Gantner Verlag, Rugell.

Hörandl E, Gutermann W (1998) Der Ranunculus auricomus-Komplex in Östereich. 1. Methodik; Gruppierung der mitteleuropäischen Sippen. Bot. Jahrb. Syst. 120:1-44.

Hörandl E, Jakubowsky G, Dobes C (2001) Isozyme and morphological diversity within apomictic and sexual taxa of the Ranunculus auricomus complex. Plant Syst. Evol. 226:165-185.

Hörandl E, Paun O (2007) Patterns and sources of genetic diversity in apomictic plants: implications for evolutionary potentials. In: Hörandl E, Grossniklaus U, Van Dijk PJ, Sharbel TF (eds), Apomixis: evolution, mechanism, and perspectives: 169-194. International Association for Plant Taxonomy and A.R.G. Gantner Verlag K.G., Vienna/Rugell.

Hörandl E, Schön I, Martens K, Dijk P (2009b) Geographical parthenogenesis: Opportunities for asexuality. In: Schön I, Martens K, Van Dijk P (eds), Lost Sex - The Evolutionary Biology of Parthenogenesis: 161186. Springer Netherlands, Dordrecht.

Huwer A, Wittig R (2012) Changes in the species composition of hedgerows in the Westphalian Basin over a thirty-five-year period. Tuexenia 32:31-53. 
Huxley J (1942) Evolution: the Modern Synthesis. Allen \& Unwin, London.

Illyés E, Chytrý M, Botta-Dukát Z, Jandt U, Škodová I, Janišová M, Willner W, Hájek O (2007) Semi-dry grasslands along a climatic gradient across Central Europe: Vegetation classification with validation. J. Veg. Sci. 18:835-846.

Jackson JI (2001) Spatial and temporal dynamics of plants colonizing species-poor hedgerows. Thesis University of Leicester, Leicester.

Jäger EJ, Werner K (2002) Rothmaler Exkursionsflora von Deutschland. Bd4. Gefäßpflanzen: Kritischer Band - 9. Aufl. Spektrum, Akademisches Verlag, Heidelberg/Berlin.

Jalas J, Suominen J (1989) Atlas Florae Europaeae. Distribution of Vascular Plants in Europe, vol. 8, Nymphaeaceae to Ranunculaceae. The Committee for Mapping the Flora of Europe \& Societas Biologica Fennica Vanamo, Helsinki.

Jansen F, Dengler J, Glöckler F, Chytrý M, Ewald J, Oldeland J, Schaminée JHJ (2011) Die mitteleuropäischen Datenbanken im Global Index of Vegetation-Plot Databases (GIVD). Tuexenia 31:351-367.

Jansen W (2006) Die Farn- und Blütenpflanzen Schleswig-Holsteins. Rote Liste Band 2 - Brombeeren. Landesamt für Natur und Umwelt des Landes Schleswig-Holstein, Flintbek.

Jasprica N, Ruščić M, Kovačić S (2007) The Chrysopogono grylli-Nerietum oleandri association in Croatia as compared with other Rubo ulmifolii-Nerion oleandri communities (Tamaricetalia, Nerio-Tamaricetea) in the Mediterranean. Plant Biosyst. 141:40-50.

Jennings D (1988) Raspberries and blackberries: their breeding, diseases and growth. Academic press, London.

Jiménez-Alfaro B, Apostolova I, Carni A, Chytrý M, Csiky J, Dengler J, Dimopoulos P, Font X, Golub V, Hennekens S (2013) Unifying and analysing vegetation-plot databases in Europe: the European Vegetation Archive (EVA) and the Braun-Blanquet project. In: Arctic Vegetation Archive (AVA) Workshop, Krakow, Poland, April 14-16, 2013. pp 50-51.

Jones CG, Lawton JH, Shachak M (1994) Organisms as ecosystem engineers. Oikos 69:373-386.

Jonsell B (2004) Principles and conventions. In: Jonsell B (ed), Flora Nordica. General Volume: 161-175. The Bergius Foundation. The Royal Swedish Academy of Sciences, Stockholm.

Juxip AY (2002) Hieracium L. In: Shishkin BK, Bobrov EG (eds), Flora of the USSR, Volume XXX, English edition: 1-884. Amerind Publishing Co. Pvt. Ltd., New Delhi.

Kearney M (2005) Hybridization, glaciation and geographical parthenogenesis. Trends Ecol. Evol. 20:495502.

Kelemen K, Mihók B, Gálhidy L, Standovár T (2012) Dynamic response of herbaceous vegetation to gap opening in a central European beech stand. Silva Fenn. 46:53-65.

Keller I, Fluri P, Imdorf A (2005) Pollen nutrition and colony development in honey bees: part 1. Bee World 86:3-10.

Kent DH (1992) List of vascular plants of the British Isles. Botanical Society of the British Isles, London.

Kier G, Mutke J, Dinerstein E, Ricketts TH, Küper W, Kreft H, Barthlott W (2005) Global patterns of plant diversity and floristic knowledge. J. Biogeogr. 32:1107-1116.

Kim KC, Byrne LB (2006) Biodiversity loss and the taxonomic bottleneck: emerging biodiversity science. Ecol. Res. 21:794-810. 
Király G, Trávníček B, Žila V (2013a) Revision of Rubus ser. Micantes occurring in Hungary and reevaluation of the neglected Rubus balatonicus. Preslia 85:505-526.

Király G, Trávníček B, Žila V (2013b) A szeder (Rubus L.) nemzetség modern taxonómiai koncepciója. Erdészettudományi Közlemények 3:147-156.

Kluge AG (1990) Species as Historical Individuals. Biol. Philos. 5:417-431.

Knollová I, Chytrý M, Tichý L, Ondrej H (2005) Stratified resampling of phytosociological databases: some strategies for obtaining more representative data sets for classification studies. J. Veg. Sci. 16:479-486.

Kollmann J, Schneider B (1999) Landscape structure and diversity of fleshy-fruited species at forest edges. Plant Ecol. 144:37-48.

Kollmann J, Steinger T, Roy BA (2000) Evidence of sexuality in European Rubus (Rosaceae) species based on AFLP and allozyme analysis. Am. J. Bot. 87:1592-1598.

Koltunow AM, Bicknell RA, Chaudhury AM (1995) Apomixis: molecular strategies for the generation of genetically identical seeds without fertilization. Plant Physiol. 108:1345.

Kornet D (1993) Permanent splits as speciation events: a formal reconstruction of the internodal species concept. J. Theor. Biol. 164:407-435.

Kornet DJ, McAllister J (2005) The Composite Species Concept: A rigorous basis for cladistic practice. In: Reydon TAC, Hemerik L (eds), Current Themes in Theoretical Biology: 95-127. Springer, Dordrecht.

Kornet DJ, McAllister JW (1993) The composite species concept. In: Kornet, D. J., Reconstructing species : demarcations in genealogical networks. Thesis University Leiden, Leiden.

Kottler MJ (1978) Charles Darwin's biological species concept and theory of geographic speciation: the transmutation notebooks. Ann. Sci. 35:275-297.

Kraft T, Nybom H (1995) DNA fingerprinting and biometry can solve some taxonomic problems in apomictic blackberries (Rubus subgen. Rubus). Watsonia 20:329-343.

Kraft T, Nybom H, Werlemark G (1995) Rubus vestervicensis (Rosaceae) — its hybrid origin revealed by DNA fingerprinting. Nord. J. Bot. 15:237-242.

Kraft T, Nybom H, Werlemark G (1996) DNA fingerprint variation in some blackberry species (Rubus subg. Rubus, Rosaceae). Plant Syst. Evol. 199:93-108.

Krahulcová A, Krahulec F, Chapman HM (2000) Variation in Hieracium subgen. Pilosella (Asteraceae): what do we know about its sources? Folia Geobot. 35:319-338.

Krahulcová A, Rotreklová O, Krahulec F, Rosenbaumová R, Plačková I (2009a) Enriching ploidy level diversity: the role of apomictic and sexual biotypes of Hieracium subgen. Pilosella (Asteraceae) that coexist in polyploid populations. Folia Geobot. 44:281-306.

Krahulcová A, Trávníček B, Šarhanová P (2013) Karyological variation in the genus Rubus, subgenus Rubus: new data from the Czech Republic and synthesis of the current knowledge of European species. Preslia 85:19-39.

Krahulcová A, Vladimirov V, Krahulec F, Bräutigam S (2009b) The agamic complex of Pilosella (Asteraceae) in Bulgaria and SW Romania: variation in ploidy level and breeding systems. Phytol. Balcanica 15:377384 . 
Krahulec F, Krahulcová A, Fehrer J, Bräutigam S, Bräutigam E (2008) The structure of the agamic complex of Hieracium subgen. Pilosella in the Šumava Mts and its comparison with other regions in Central Europe. Preslia 80:1-26.

Kreft H, Jetz W (2010) A framework for delineating biogeographical regions based on species distributions. J. Biogeogr. 37:2029-2053.

Kuiters A, Slim P (2003) Tree colonisation of abandoned arable land after 27 years of horse-grazing: the role of bramble as a facilitator of oak wood regeneration. Forest Ecol. Manag. 181:239-251.

Kuntze O (1867) Reform deutscher Brombeeren. Beitraege zur Kenntnis der Eigenschaften der Arten und Bastarde des Genus Rubus L. W. Engelmann, Leipzig.

Kurtto A, Weber HE, Lampinen R, Sennikov AN (2010) Atlas Florae Europaeae. Distribution of vascular plants in Europe. Rosaceae (Rubus). The Committee for Mapping the Flora of Europe \& Societas Biologica Fennica Vanamo, Helsinki.

Kuzelová I, Chytrý M (2004) Interspecific associations in phytosociological data sets: how do they change between local and regional scale? Plant Ecol, 173:247-257.

Lambinon J, De Langhe J-E, Delvosalle L, Duvigneaud J (1998) Flora van België, het Groothertogdom Luxemburg, Noord-Frankrijk en de aangrenzende gebieden (Pteridofyten en Spermatofyten). Nationale Plantentuin van België, Meise.

Lambinon J, Verloove F (2012) Nouvelle flore de la Belgique, du Grand-Duché de Luxembourg, du Nord de la France et des Régions voisines (Pteridophytes et Spermatophytes). Sixième edition. Jardin botanique national de Belgique, Meise.

Leather SR (1986) Insect species richness of the British Rosaceae: the importance of host range, plant architecture, age of establishment, taxonomic isolation and species-area relationships. The Journal of Animal Ecology:841-860.

Leme EMC (2003) Nominal extinction and the taxonomist's responsibility: the example of Bromeliaceae in Brazil. Taxon 52:299-302.

Levin DA (2000) The origin, expansion, and demise of plant species. Oxford University Press, New York, Oxford.

Lidforss B (1905) Studier öfer artbildningen inom släktet Rubus. I. Ark. Bot. 4:1-41.

Lidforss B (1907) Studier öfer artbildningen inom släktet Rubus. II. Ark. Bot. 6:1-43.

Lindley L (1829) A Synopsis of the British Flora. Longman, Rees, Orme, Brown \& Green, London.

Linnaeus C (1753) Species Plantarum. Impensis Laurentii Salvii, Stockholm.

Linsley EG (1958) The ecology of solitary bees. Hilgardia 27:543-599.

Loos GH (1998) Vier neue Brombeerarten aus dem mittleren Westfalen. Flor. Rundbr. 32:44-56.

Loos GH (2008) Pflanzengeographische Beiträge zur chorologischen, taxonomischen und naturschutzfachlichen Bewertung der Sippendiversität agamospermer (apomiktischer) Blütenpflanzenkomplexe: das Beispiel Rubus subgenus Rubus (Rosaceae). Ruhr-Universität, Bochum.

Löve A (1962) The biosystematic species concept. Preslia 34:127-139.

Lynch M (1984) Destabilizing hybridization, general-purpose genotypes and geographic parthenogenesis. Q. Rev. Biol. 59:257-290. 
MacArthur RH, Wilson EO (1967) The theory of island biogeography. Princeton University Press, Princeton, New York.

Mace GM (2004) The role of taxonomy in species conservation. Phil. Trans. R. Soc. Biol. Sci. 359:711-719.

Maes NCM (2002) Bomen en struiken in Nederland. Inheems, autochtoon, exoot en archeofiet. Gorteria 28:1-20.

Mallet J (1995) A species definition for the modern synthesis. Trends Ecol. Evol. 10:294-299.

Mallet J (2013) Darwin and species. In: Ruse M (ed), The Cambridge Encyclopedia of Darwin and Evolutionary Thought: 109-115. Cambridge University Press, Cabridge.

Marklund G (1961) Der Ranunculus auricomus-Komplex in Finland I. Diagnosen und Fundortlisten einiger Sippen des R. auricomus L. coll. (s.str.). Fl. Fenn. 3:1-128.

Marklund G (1965) Der Ranunculus auricomus-Komplex in Finland II. Diagnosen und Fundortlisten einiger Sippen von $R$. fallax (W. \& Gr.) Schur., R. monophyllus Ovcz. und R. cassubicus L. Fl. Fenn. 4:1-104.

Matzke-Hajek G (1993) Die Brombeeren (Rubus fruticosus-Agg.) der Eifel und der Niederrheinischen Bucht. Decheniana Beih. 32:1-212.

Matzke-Hajek G (1997) Zur Evolution und Ausbreitung apomiktischer Rubus-Arten (Rosaceae) in Offenland-Ökosystemen. Bull. Geobot. Inst. ETH 63:33-44.

Maurer W (1994) Die Nachkommen einer Brombeer-Hybride (Rubus bifrons x hirtus agg.) als Ergebnis mehrjähriger Kulturversuche. Mitt. Naturwiss. Ver. Steiermark 124:151-157.

Mayden RL (1997) A hierarchy of species concepts: The denouement in the saga of the species problem. In: Claridge MF, Dawah HA, Wilson MR (eds), Species: The units of biodiversity: 381-424. Chapman and Hall, London.

Mayden RL (1999) Consilience and a Hierachy of Species Concepts: Advances Toward Closure on the Species Puzzle. J. Nematol. 3:95-116.

Mayden RL (2002) On biological species, species concepts and individuation in the natural world. Fish Fish. 3:171-196.

Mayo SJ, Allkin R, Baker W, Blagoderov V, Brake I, Clark B, Govaerts R, Godfray C, Haigh A, Hand R, Harman K, Jackson M, Kilian N, Kirkup DW, Kitching I, Knapp S, Lewis GP, Malcolm P, von RaabStraube E, Roberts DM, Scoble M, Simpson DA, Smith C, Smith V, Villalba S, Walley L, Wilkin P (2008) Alpha e-taxonomy: responses from the systematics community to the biodiversity crisis. Kew Bull. 63:1-16.

Mayr E (1940) Speciation phenomena in birds. Am. Nat. 74:249-278.

Mayr E (1942) Systematics and the Origin of Species. Columbia University Press, New York.

Mayr E (1957) Species concepts and definitions. In: Mayr E (ed), The species problem: 1-22. American Association for the Advancement of Science, Washington DC.

Mayr E (1987) The ontological status of species: scientific progress and philosophical terminology. Biol. Philos. 2:145-166.

Mayr E (1992) A local flora and the Biological Species Concept. Am. J. Bot. 79:222-238.

Mayr E (1996) What is a species, and what is not? Phil. Sci. 63:262-277.

McKitrick MC, Zink RM (1988) Species concepts in ornithology. Condor:1-14. 
McLaughlin SP (1994) Floristic plant geography: the classification of floristic areas and floristic elements. Prog. Phys. Geogr. 18:185-208.

McNeill J, Barrie FR, Burdet HM, Demoulin V, Marhold K, Nicolson DH, Prado J, Silva PC, Skog JE, Wiersema JH, Turland NJ (2007) International Code of Botanical Nomenclature (Vienna Code) adopted by the Seventeenth International Botanical Congress Vienna, Austria, July 2005. Regn. Veg. 146:1-568.

Mennema J (1976) Standaardlijst van de Nederlandse Flora 1975. Gorteria 8:75-76.

Metzger MJ, Bunce RGH, Jongman RHG, Mücher CA, Watkins JW (2005) A climatic stratification of the environment of Europe. Glob. Ecol. Biogeogr. 14:549-563.

Michener CD (1970) Nest sites of stem and twig inhabiting African bees (Hymenoptera: Apoidae). J. Entom. Soc. S. Afr. 33:1-22.

Mishler BD, Brandon RN (1987) Individuality, pluralism, and the phylogenetic species concept. Biol. Philos. 2:397.

Mishler BD, Budd AF (1990) Species and evolution in clonal organisms - Introduction. Syst. Bot. 15:7985.

Mogie M, Britton NF, Stewart-Cox JA (2007) Asexuality, polyploidy and the male function. In: Hörandl E, Grossniklaus U, Van Dijk PJ, Sharbel TF (eds), Apomixis: evolution, mechanisms and perspectives: 195-214. A.R.G. Gantner Verlag, Rugell.

Monasterio-Huelin E (1998) Rubus 1. Flora iberica 6:16-71.

Mortimer S, Turner A, Brown V, Fuller R, Good J, Bell S, Stevens P, Norris D, Bayfield N, Ward L (2000) The nature conservation value of scrub in Britain. Joint Nature Conservation Committee, Peterborough.

Mráz P, Chrtek J, Fehrer J (2011) Interspecific hybridization in the genus Hieracium s. str.: evidence for bidirectional gene flow and spontaneous allopolyploidization. Plant Syst. Evol. 293:237-245.

Mráz P, Chrtek J, Kirschner J (2001) Genetic variation in the Hieracium rohacsense group (Hieracium sect. Alpina). Phyton 41:269-276.

Mráz P, Chrtek J, Šingliarová B (2009) Geographical parthenogenesis, genome size variation and pollen production in the arctic-alpine species Hieracium alpinum. Bot. Helv. 119:41-51.

Mráz P, Chrtek Jr J, Plačková I (2005) Rare recent natural hybridization in Hieracium s.str. - evidence from morphology, allozymes and chloroplast DNA. Plant Syst. Evol. 255

Mücher CA, Klijn JA, Wascher DM, Schaminée JHJ (2010) A new European Landscape Classification (LANMAP): A transparent, flexible and user-oriented methodology to distinguish landscapes. Ecol. Indic. 10:87-103.

Müller PJ (1858) Beschreibung der in der Umgegend von Weissenburg wildwachsenden Arten der Gattung Rubus. Flora 41:129-140, 149-157, 163-174, 177-185.

Müller PJ (1859) Versuch einer monographischen Darstellung der gallo-germanischen Arten der Gattung Rubus. Jahresber. Pollichia 16/17:74-298.

Müller PJ (1861) Rubologische Ergebnisse einer dreitägigen Exkursion in die granitischen Hochvogesen der Umgegend von Gérardmer. Bonplandia 9:276-314.

Newton A (1980) Progress in British Rubus studies. Watsonia 13:35-40. 
Newton A, Randall RD (2004) Atlas of British and Irish brambles, a phytogeographical analysis of microspecies of Rubus sect. Rubus \& sect. Corylifolii. Botanical Society of the British Isles, London.

Nooren MJ (1981) Ouderdom en cultuurhistorische waarden van houtwallen en heggen in Nederland. RIN-rapport 81/13. Rijksinstituut voor Natuurbeheer, Arnhem.

Nova Flora Neerlandica: Nova Flora Neerlandica - een kritische flora van Nederland, http://www. novafloraneerlandica.nl/,

Nybom H (1995) Evaluation of interspecific crossing experiments in facultatively apomictic blackberries (Rubus subgen. Rubus) using DNA-fingerprinting. Hereditas 122:57-65.

Nybom H (1996) DNA Fingerprinting - a useful tool in the taxonomy of apomictic plant groups. Fol. Geobot. Phytotax. 31:295-304.

Nybom H (1998) Biometry and DNA fingerprinting detect limited genetic differentiation among populations of the apomictic blackberry Rubus nessensis (Rosaceae). Nord. J. Bot. 18:323-333.

Nybom H, Kraft T (1995) Application of DNA fingerprinting to the taxonomy of European blackberry species. Electrophor. 16:1731-1735.

Nybom H, Schaal BA (1990) DNA “Fingerprints" reveal genotypic distributions in natural populations of Blackberries and Raspberries (Rubus, Rosaceae). Am. J. Bot. 77:883-888.

Oates M (1996) The demise of butterflies in the New Forest. Br. Wildl. 7:205-216.

Oberdorfer E (1957) Süddeutsche Pflanzengesellschaften. Gustav Fischer Verlag, Jena.

Oberdorfer E (1994) Pflanzensoziologische Exkursionsflora. Ulmer, Stuttgart.

Oredsson A (1998) Rubus lasiandrus introduced into Sweden with pulpwood from West Germany. Flora 193:165-171.

Oredsson A (2002) Mit Holztransporten eingeschleppte Rubus-Arten in Schweden. Ber. Bayer. Bot. Ges. 72:169-173.

Oredsson A (2004) Two new members of the Swedish flora: Rubus echinatus and R. sciocharis. Sven. Bot. Tidskr. 98:232-237.

Orme CDL, Davies RG, Burgess M, Eigenbrod F, Pickup N, Olson VA, Webster AJ, Ding T-S, Rasmussen PC, Ridgely RS, Stattersfield AJ, Bennett PM, Blackburn TM, Gaston KJ, Owens IPF (2005) Global hotspots of species richness are not congruent with endemism or threat. Nature 436:1016-1019.

Ostenfeld CH (1912) Experiments on the origin of species in the genus Hieracium (apogamy and hybridism) 1. New Phytol. 11:347-354.

Ozinga WA, Römermann C, Bekker RM, Prinzing A, Tamis WLM, Schaminée JHJ, Hennekens SM, Thompson K, Poschlod P, Kleyer M, Bakker JP, Van Groenendael JM (2009) Dispersal failure contributes to plant losses in NW Europe. Ecol. Lett. 12:66-74.

Pancer-Koteja E, Szwagrzyk J, Bodziarczyk J (1998) Small-scale spatial pattern and size structure of Rubus hirtus in a canopy gap. J. Veg. Sci. 9:755-762.

Park SJ, Korompai EJ, Francisco-Ortega J, Santos-Guerra A, Jansen RK (2001) Phylogenetic relationships of Tolpis (Asteraceae: Lactuceae) based on ndhF sequence data. Plant Syst. Evol. 226:23-33.

Pärtel M, Helm A, Reitalu T, Liira J, Zobel M (2007) Grassland diversity related to the Late Iron Age human population density. J. Ecol. 95:574-582.

Passarge H (1982) Rubus-Coenosen. Feddes Repertorium 93 (5):369-403. 
Paterson HEH (1985) The recognition concept of species. In: Vrba EE (ed), Species and Speciation: 21-29. Transvaal Museum, Pretoria.

Paterson HEH, in S.F. McEvey (1993) Evolution and the recognition concept of species: collected writings of H.E.H. Paterson. Johns Hopkins University Press, Baltimore, Maryland.

Paun O, Greilhuber J, Temsch EM, Hörandl E (2006a) Patterns, sources and ecological implications of clonal diversity in apomictic Ranunculus carpaticola (Ranunculus auricomus complex, Ranunculaceae). Mol. Ecol. 15:897-910.

Paun O, Stuessy TF, Hörandl E (2006b) The role of hybridization, polyploidization and glaciation in the origin and evolution of the apomictic Ranunculus cassubicus complex. New Phytol. 171:223-236.

Peterson JH, Roitberg BD, Peterson J (2006) Impacts of flight distance on sex ratio and resource allocation to offspring in the leafcutter bee, Megachile rotundata. Behav. Ecol. Sociobiol. 59:589-596.

Petrischak H (2014) Beobachtungen an solitären Wespen und Wildbienen an ihren Nistplätzen in Brombeerstängeln (Insecta: Hymenoptera). Delattiana 40:299-307.

Pfeiffer JM, Ortiz EH (2007) Invasive plants impact California native plants used in traditional basketry. Fremontia 35:7-13.

Pigliucci M (2003) Species as family resemblance concepts: the (dis-)solution of the species problem? BioEssays 25:596-602.

Pimm S, Jenkins C, Abell R, Brooks T, Gittleman J, Joppa L, Raven P, Roberts C, Sexton J (2014) The biodiversity of species and their rates of extinction, distribution, and protection. Science 344:1246752.

Pimm SL, Joppa LN (2015) How many plant species are there, where are they, and at what rate are they going extinct? Ann. Mo. Bot. Gard. 100:170-176.

Pinto-Gomes C, Cano-Ortiz A, Quinto-Canas R, Vila-Viçosa C, Martínez Lombardo MC (2012) Analysis of the Cytisetea scopario-striati scrubs in the south-west-centre of the Iberian Peninsula. Act. Bot. Gal. 159:251-266.

Platnick NI (1991) Patterns of biodiversity: tropical vs temperate. J. Nat. Hist. 25:1083-1088.

Pott R (1995) Die Pflanzengesellschaften Deutschlands. 2., überarb. Auflage. Ulmer, Stuttgart.

Pratt C, Einset J (1955) Development of the embryo sac in some American blackberries. Am. J. Bot. 42:637-645.

Preising E, Weber HE, Vahle H-C (2003) Die Pflanzengesellschaften Niedersachsens - Bestandsentwicklung, Gefährdung und Schutzprobleme. Wälder und Gebüsche. Niedersächsisches Landesamt für Ökologie - Abt. Naturschutz, Hildesheim.

Preston CD, Hill MO (1997) The geographical relationships of British and Irish vascular plants. Bot. J. Linn. Soc. 124:1-120.

Preston CD, Pearman DA, Dines TD (2002) New atlas of the British and Irish flora. An atlas of the vascular plants of Britain, Ireland, the Isle of Man and the Channel Islands. Oxford University Press,

Queiroz C, Beilin R, Folke C, Lindborg R (2014) Farmland abandonment: threat or opportunity for biodiversity conservation? A global review. Front. Ecol. Environ. 12:288-296.

R Development Core Team (2011) R: A language and environment for statistical computing. R Foundation for Statistical Computing, Vienna. 
Randall RD, Rich TCG (2000) Conservation of Britain's biodiversity: Rubus trelleckensis (Rosaceae), Trelleck Bramble. Watsonia 23:317-322.

Randall RD, Rich TCG (2001) Conservation of Britain's biodiversity: Rubus dasycoccus (Rosaceae), Thickberried Bramble. Watsonia 23:437-442.

Ray J (1686) Historiae Plantarum. Vol. I. Mariae Clark, London.

Reichgelt T (1962) Rubus L. In: Van Ooststroom SJ (ed), Flora van Nederland: 311-322. Noordhoff, Groningen.

Reif A (1983) Nordbayerische Heckengesellschaften. Hoppea 41:3-205.

Reif A (1985) Flora und Vegetation der Hecken des Hinteren und Südlichen Bayerischen Wäldes. Hoppea 44:179-276.

Rich T, Houston L (2000) Conservation of Britain's biodiversity: Hieracium tavense (Asteraceae), Black Mountain Hawkweed. Watsonia 23:311-316.

Rich TCG (2002) Conservation of Britain's biodiversity: Hieracium asteridiophyllum and H. cillense (Asteraceae). Watsonia 24:101-106.

Rich TCG (2003) Conservation of Britain's biodiversity: Hieracium snowdoniense (Asteraceae), Snowdonia Hawkweed. Watsonia 24:513-515.

Rich TCG, McDonnell EJ, LledÓ MD (2008) Conservation of Britain’s biodiversity: the case of Hieracium cyathis (Asteraceae) and its relation to other apomictic taxa. Bot. J. Linn. Soc. 156:669-680.

Richards AJ (1973) The origin of Taraxacum agamospecies. Bot. J. Linn. Soc. 66:189-211.

Richards AJ (2003) Apomixis in flowering plants: an overview. Phil. Trans. Roy. Soc.: Biol. Sci. 358:10851093.

Richards AJ, Kirschner J, Stepanek J, Marhold K (1996) Apomixis and taxonomy: An introduction. Fol. Geobot. Phytotax. 31:281-282.

Richards AR (2010) The species problem: a philosophical analysis. Cambridge University Press, Cambridge.

Richardson DM, Rejmánek M (2011) Trees and shrubs as invasive alien species-a global review. Div. Distr. 17:788-809.

Ridley M (1989) The cladistic solution to the species problem. Biol. Philos. 4:1-16.

Rieseberg LH, Burke JM (2001) The biological reality of species: gene flow, selection, and collective evolution. Taxon 50:47-67.

Rieseberg LH, Wood TE, Baack EJ (2006) The nature of plant species. Nature 440:524-527.

Robertson A, Newton AC, Ennos RA (2004) Multiple hybrid origins, genetic diversity and population genetic structure of two endemic Sorbus taxa on the Isle of Arran, Scotland. Mol. Ecol. 13:123-134.

Rodwell JS (1998) British Plant Communities. Volume 1. Woodlands and scrub. Cambridge University Press, Cambridge.

Rogers WM (1900) Handbook of British rubi. Duckworth \& Co., London.

Roleček J, Tichý L, Zelený D, Chytrý M (2009) Modified TWINSPAN classification in which the hierarchy respects cluster heterogeneity. J. Veg. Sci. 20:596-602.

Ronikier M, Szeląg Z (2008) Differentiation among disjunct populations of agamospermous species of Hieracium section Cernua (Asteraceae) in Central European subalpine habitats. Bot. J. Linn. Soc. 158:93-105. 
Rosen DE (1978) Vicariant patterns and historical explanation in biogeography. Syst. Biol. 27:159-188. Rosskamp T (1999) Die Vegetation der Feld- und Wallhecken in Niedersachsen. Galunder-Verlag, Wiehl. Royer J-M (2013) Étude phytosociologique de quelques ronciers péri- et intraforestiers des environs de Chaumont. Bull. Soc. Sci. Nat. Arch. Ht-Marne 21:10-20.

Royer J-M, Felzines J-C, Misset C, Thévenin S (2006) Synopsis commenté des groupements végétaux de la Bourgogne et de la Champagne-Ardenne. Bull. Soc. Bot. cent.-ouest N.S. 25:1-394.

Royer J-M, Ferrez Y (2012) Le Rubetum nessensi-integribasis, association nouvelle de roncier acidiphile des Vosges et du Morvan. Nouv. Arch. Flore Jura. Nord-Est Fr. 10:25-29.

Ryde U (2011) Arguments for a narrow species concept in Rubus sect. Corylifolii. Nord. J. Bot.:708-721.

Šarhanová P, Vašut RJ, Dančák M, Bureš P, Trávníček B (2012) New insights into the variability of reproduction modes in European populations of Rubus subgen. Rubus: how sexual are polyploid brambles? Sex. Plant Repr. 25:319-335.

Schaminée JHJ, Hennekens SM, Ozinga WA (2012) The Dutch National Vegetation Database. Biodiv. Ecol. 4:201-210.

Schaminée JHJ, Janssen JAM, Haveman R, Hennekens SM, Heuvelink GBM, Huiskes HPJ, Weeda EJ (2006) Schatten voor de natuur. Achtergronden, inventaris en toepassingen van de Landelijke Vegetatie Databank. KNNV Uitgeverij, Utrecht.

Schipper WW (1925) Beschrijving van inheemse intermediaire Rubus-bastaarden. Nederl. Kruidk. Arch. jaargang 1924:148-186.

Schott HW (1818) Auszüge aus den Berichten und Briefe der auf befehl Sr. Majestät des Kaisers nach Brasilien abgeschickten österreichisschen Naturforscher an den Direktor des k.k. Hof-Naturkabinette Herrn Karl von Schreibers als Referenten des wissenschaftlichen Anteiles der Expedition. Vaterl. Blat. Österr. Kaiserstat I:37-44.

Schou JC (2001) Danmarks Høgeurter (Hieracium, Pilosella). Aarhus Universitet, Aarhus.

Schreber JCD (1766) Icones et descriptiones plantarum minus cognitarum. Halle.

Schuhwerk F (2002) Some thoughts on the taxonomy of Hieracium. Ber. Bayer. Bot. Ges. 72:193-198.

Sell P, Murrell G (2006) Flora of Great Britain and Ireland. Volume 4. Campanulaceae - Asteraceae. Cambridge University Press, Cambridge.

Sell P, Murrell G (2014) Flora of Great Britain and Ireland. Volume 2. Capperaceae - Rosaceae. Cambridge University Press, Cambridge.

Sell PD, West C (1976) Hieracium L. In: Tutin TG, Heywood VH, Burges NA, Moore DM, Valentine DH, Walters SM, Webb DA (eds), Flora Europaea. Volume 4, Plantaginaceae to Compositae (and Rubiaceae): 358-410. Cambridge University Press, Cambridge.

Shi Y, Gornall RJ, Draper J, Stace CA (1996) Intraspecific Molecular Variation in Hieracium sect. Alpina (Asteraceae), an Apomictic Group. Fol. Geobot. Phytotax. 31:305-313.

Shull GH (1923) The species concept from the point of view of a geneticist. Am. J. Bot. 10:221-228.

Siebel H, During H (2006) Beknopte Mosflora van Nederland en Belgie. KNNV Uitgeverij, Utrecht.

Sierdsema H (1999) Broedvogels en Beheer.Het gebruik van broedvogelgegevens in het beheer van bos- en natuurterreinen. Staatsbosbeheer/SOVON, Driebergen/Beek-Ubbergen. 
Simpson GG (1943) Criteria for genera, species, and subspecies in zoology and paleozoology. Ann. N.Y. Ac. Sci. 44:145-178.

Simpson GG (1951) The species concept. Evolution 5:285-298.

Šingliarová B, Chrtek J, Plačková I, Mráz P (2011) Allozyme variation in diploid, polyploid and mixedploidy populations of the Pilosella alpicola Group (Asteraceae): relation to morphology, origin of polyploids and breeding system. Folia Geobot. 46:387-410.

Sites Jr JW, Jonathon CM (2004) Operational criteria for delimiting species. Annu. Rev. Ecol. Evol. Syst. 35:199-227.

Sluijter R (2011) De Bosatlas van het klimaat. KNMI \& Noordhoff Atlasproducties, De Bilt.

Sneath P (1976) Phenetic taxonomy at the species level and above. Taxon 25:437-450.

Sochor M, Trávníček B (2016) Melting pot of biodiversity: first insights into the evolutionary patterns of the Colchic bramble flora (Rubus subgenus Rubus, Rosaceae). Bot. J. Linn. Soc. 181:610-620.

Sochor M, Vašut RJ, Sharbel TF, Trávníček B (2015) How just a few makes a lot: Speciation via reticulation and apomixis on example of European brambles (Rubus subgen. Rubus, Rosaceae). Mol. Phylogenet. Evol. 89:13-27.

Soltis DE, Soltis PS (1999) Polyploidy: recurrent formation and genome evolution. Tree 14:348-352.

Soltis DE, Soltis PS, Schemske DW, Hancock JF, Thompson JN, Husband BC, Judd WS (2007) Autopolyploidy in angiosperms: have we grossly underestimated the number of species? Taxon 56:1330.

Soltis PS, Soltis DE (2009) The role of hybridization in plant speciation. Ann. Rev. Plant Biol. 60:561-588.

Soltis PS, Soltis DE, Chase MW (1999) Angiosperm phylogeny inferred from multiple genes as a tool for comparative biology. Nature 402:402-404.

Stace CA (1989) Plant taxonomy and biosystematics. Second edition. Cambridge University Press, Cambridge.

Stace CA (1998) Species recognition in agamosperms - the need for a pragmatic approach. Folia Geobot. 33:319-326.

Stace CA (2001) New Flora of the British Isles. Second Edition. Cambridge University Press, Cambridge.

Stebbins GL (1941) Apomixis in the Angiosperms. Bot. Rev. VII:507-542.

Stebbins GL (1959) The role of hybridization in evolution. Proc. Am. Phil. Soc. 103:231-251.

Stebbins GL (1986) The origin and success of polyploids in the boreal circumpolar flora: a new analysis. Trans. Bot. Soc. Edinb. 45, supl. 1:17-31.

Stebbins GL (1987) Species concepts: Semantics and actual situations. Biol. Philos. 2:198-203.

Štorchová H, Chrtek Jr J, Bartish IV, Tetera M, Kirschner J, Stepanek J (2002) Genetic variation in agamospermous taxa of Hieracium sect. Alpina (Compositae) in the Tatry Mts. (Slovakia). Plant Syst. Evol. 235:1-17.

Sudre H (1908-1913) Rubi Europae vel Monographia Iconibus illustrata Ruborum Europae. Librairie des Sciences Naturelles, Paris.

Suzuki W (1997) Germination responses of Rubus palmatus var. coptophyllus and Rubus parvifolius seeds with different burial durations to a variable light and temperature regime. Ecol. Res. 12:167-174. 
Syme JTB (1864) Rubus L. In: Smith JE, Sowerby J (eds), English botany, vol. 3, Ed. 3: 157-197. Cox \& Wyman, London.

Tamis W, van der Meijden R, Runhaar J, Bekker R, Ozinga W, Odé B, Hoste I (2004) Standaardlijst van de Nederlandse flora 2003. Gorteria 30:101-195.

Taylor K (2005) Biological flora of the British Isles: Rubus vestitus Weihe. J. Ecol. 93:1249-1262.

Templeton AR (1989) The meaning of species and speciation: a genetic perspective. In: Ereshefsky M (ed), The Units of Evolution: essays on the nature of species: 159-183. The MIT Press, Cambridge.

Tepedino VJ, Parker FD (1983) Nest size, mortality, and sex ratio in Osmia marginata Michener (Hymenoptera: Megachilidae). Southwest. Entomol. 8:154-167.

The Plant List: The Plant List, a working list of all plant species, version 1.1, http://www.theplantlist.org/, 2015.

Thompson SL, Whitton J (2006) Patterns of recurrent evolution and geographic parthenogenesis within apomictic polyploid Easter daises (Townsendia hookeri). Mol. Ecol. 15:3389-3400.

Tichý L (2002) JUICE, software for vegetation classification. J. Veg. Sci. 13:451-453.

Turesson G (1929) Zur Natur und Begrenzung der Arteinheiten. Hereditas 12:323-334.

Tüxen R (1937) Die Pflanzengesellschaften Nordwestdeutschlands. Mitt. Flor-soz. Arbeitsgem. 3:1-170.

Tüxen R (1950) Grundriß einer Systematik der nitrophilen Unkrautgesellschaften in der Eurosibirischen Region Europas. Mitt. Flor-soz. Arbeitsgem. N.F. 2:94-175.

Tüxen R (1952) Hecken und Gebüsche. Mitt. Geogr. Ges.Hambg. 50:85-117.

Tüxen R (1970) Pflanzensoziologie als synthetische Wissenschaft. Miscellaneous Papers 5:141-157.

Tyler T (2000) Detecting migration routes and barriers by examining the distribution of species in an apomictic species complex. J. Biogeogr. 27:979.

Tyler T (2001) Förslag till ny taxonomisk indelning av stångfibblorna (Pilosella) i Norden (The genus Pilosella in the Nordic countries). Sven. Bot. Tidskr. 95:39-67.

Tyler T (2005) Patterns of allozyme variation in Nordic Pilosella. Plant Syst. Evol. 250:133-145.

Tyler T (2006) Patterns of morphometric variation and a new supraspecific classification of apomictic taxa of Hieracium (Asteraceae) from Denmark and southern Sweden. Plant Syst. Evol. 261:39-88.

Tyler T (2011) Hieracium sect. Oreadea (Asteraceae) in Sweden - from a complete mess to a preliminary taxonomic classification. Nord. J. Bot. 29:538-589.

Tyler T, Jönsson J (2009) Ploidy level analysis of apomictic Hieracium (Asteraceae) reveal unexpected patterns and variation. Nord. J. Bot. 27:490-502.

Tyler T, Jönsson J (2013) Patterns of plastid and nuclear variation among apomictic polyploids of Hieracium: evolutionary processes and taxonomic implications. Ann. Bot. 111:591-609.

Uytvanck JV (2011) Grote grazers sturen de ontwikkeling van nieuwe boslandschappen op voormalige landbouwgronden. Levende Nat. 112:132-137.

Van de Beek A (1974) Die Brombeeren des geldrischen Distriktes innerhalb der Flora der Niederlande. Med. Bot. Mus. Rijksuniv. Utrecht 415:1-195.

Van de Beek A (1976) Rubus, een moeilijk geslacht? Rijksherbarium, Leiden

Van de Beek A (1988) Batologische notities 4 - Nieuwe gegevens over Rubus L. Gorteria 14:19-23. 
Van de Beek A (2014a) De sectie Corylifolii Lindley en verwanten van het genus Rubus L. in Nederland. Gorteria 36:89-107.

Van de Beek A (2014b) Nomenclatorische en taxonomische toelichting op de naamlijst van de Nederlandse bramen (Rubus L.). Gorteria 36:172-193.

Van de Beek A: Rubus-Nederland.nl, www.rubus-nederland.nl, 2016.

Van de Beek A, Bijlsma RJ, Haveman R, Meijer K, De Ronde I, Troelstra A, Weeda EJ (2014) Naamlijst en verspreidingsgegevens van de Nederlandse bramen (Rubus L.). Gorteria 36:108-171.

Van de Beek A, De Jongh SE, Muller FM (1972a) Overzicht der Nederlandse bramen 2a. Rijksherbarium, Leiden.

Van de Beek A, De Jongh SE, Muller FM (1972b) Overzicht der Nederlandse bramen 2b. Rijksherbarium, Leiden.

Van de Beek A, Troelstra AS (2013) Rubus uncimontanus spec. nov., eine neue Brombeerart in den Niederlanden und Westfalen. Osnabr. Naturwiss. Mitt. 39:77-80.

Van der Beek A (2011) On the identities of Rubus nessensis and Rubus scissus (Rosaceae). N. J. Bot. 1:43-47.

Van der Meijden R (1990) Heukels' Flora van Nederland. Wolters-Noordhoff, Groningen/Houten.

Van der Meijden R (2005) Heukels' Flora van Nederland. Wolters-Noordhoff, Groningen/Houten.

Van der Meijden R, Arnolds EJM, Adema F, Weeda EJ, Plate CL (1984) Standaardlijst van de Nederlandse Flora 1983. Rijksherbarium, Leiden.

Van der Meijden R, Van Duuren L, Duistermaat H (1996) Standaardlijst van de Nederlandse flora 1996. Gorteria 22:1-5.

Van der Meijden R, Van Duuren L, Weeda EJ, Plate CL (1991) Standaardlijst van de Nederlandse Flora 1990. Gorteria 17:75-130.

Van Dijk PJ (2007) Apomixis: Basics for non-botanists. In: Schön I, Martens K, Van Dijk P (eds), Lost Sex. The Evolutionary Biology of Parthenogenesis: 47-62. Springer, Dordrecht.

Van Dijk PJ, Vijverberg K (2005) The significance of apomixis in the evolution of the Angiosperms: a reappraisal. Regnum Veg. 143:101-117.

Van Haperen A (2009) Een wereld van verschil. Landschap en plantengroei van de duinen op de Zeeuwse en Zuid-Hollandse Eilanden. KNNV Uitgeverij, Zeist.

Van Regenmortel MHV (2010) Logical puzzles and scientific controversies: The nature of species, viruses and living organisms. Syst. Appl. Microbiol. 33:1-6.

Van Soest JL (1926) Het geslacht Hieracium in Nederland I. Nederl. Kruidk. Arch. 1925:138-210.

Van Soest JL (1927) Het geslacht Hieracium in Nederland II. Nederl. Kruidk. Arch. 1926:163-217.

Van Soest JL (1928) Het geslacht Hieracium in Nederland III. Nederl. Kruidk. Arch. 1927:171-215.

Van Soest JL (1929) Het geslacht Hieracium in Nederland IV. Nederl. Kruidk. Arch. 1929:103-141.

Van Soest JL (1939) Het geslacht Taraxacum in Nederland I. (Obliqua, Dissimilia, Erythrosperma). Nederl. Kruidk. Arch. 1949:213.

Van Soest JL (1957) Taraxacum sectio Obliqua Dt. en sectio Erythrosperma Dt. em Lb. in Nederland. Acta Bot. Neerl. 6:74-92.

Van Tol G, Dobben Hv, Schmidt P, Klap J (1998) Biodiversity of Dutch forest ecosystems as affected by receding groundwater levels and atmospheric deposition. Biodiversity \& Conservation 7:221-228. 
Van Valen L (1976) Ecological species, multispecies, and oaks. Taxon 25:233-239.

Vandel A (1928) La parthénogenese geographique. Contribution a l'étude biologique et cytologique de la parthénogenese naturelle. Bull. Biol. Fr. Belg. 62:164-182.

Vandenbussche V, Hoffmann M (2001) De Vlaamse Vegetatie Databank (VLAVEDAT): eerste aanzet tot een overzich van natuurtypen en plantengemeenschappen in Vlaanderen. Stratiotes 22:36-44.

Veeken J, Haveman R (2008) Plantengeografische en ecologische aspecten van apomicten. In: Schaminée JHJ, Weeda EJ (eds), Grenzen in Beweging. Beschouwingen over vegetatiegeografie: 73-88. KNNV Uitgeverij, Utrecht.

Verduijn MH, Van Dijk PJ, Van Damme JMM (2004) Distribution, phenology and demography of sympatric sexual and asexual dandelions (Taraxacum officinale s.l.): geographic parthenogenesis on a small scale. Biol. J. Linn. Soc. 82:205-218.

Verheyen K, Baeten L, De Frenne P, Bernhardt-Römermann M, Brunet J, Cornelis J, Decocq G, Dierschke H, Eriksson O, Hédl R, Heinken T, Hermy M, Hommel P, Kirby K, Naaf T, Peterken G, Petř́k P, Pfadenhauer J, Van Calster H, Walther G-R, Wulf M, Verstraeten G (2012) Driving factors behind the eutrophication signal in understorey plant communities of deciduous temperate forests. J. Ecol. 100:352-365.

Von Naegeli C, Peter A (1885-1889) Die Hieracien Mittel-Europas. München.

Von Nägeli C, Peter A (1885) Die Hieracien Mitteleuropas. Monographische Bearbeitung der Piloselloiden mit besonderer Berücksichtigung der mitteleuropäischen Sippen. R. Oldenbourg, München.

Wallis de Vries MF, Van Swaay CA, Plate CL (2012) Changes in nectar supply: a possible cause of widespread butterfly decline. Curr. Zool. 58:384-391.

Waples RS (1996) Evolutionary significant units and the conservation of biological diversity under the Endangered Species Act. In: Nielsen JL (ed) Evolution and the aquatic ecosystem: defining unique units in population conservation. American Fisheries Society, Bethesda, Maryland, pp 8-27.

Watson WCR (1958) Rubi of Great Britain and Ireland. University Press, Cambridge.

Weber HE (1967) Über die Vegetation der Knicks in Schleswig-Holstein. Arbeitsgemeischaft für Floristik in Schleswig-Holstein und Hamburg, Kiel.

Weber HE (1972) Die Gattung Rubus L. (Rosaceae) im nordwestlichen Europa vom Nordwestdeutschen Tiefland bis Skandinavien mit besonderer Berücksichtigung Schleswig-Holsteins. Verlag von J. Cramer, Lehre.

Weber HE (1974) Eine neue Gebüschgesellschaft in Nordwestdeutschland und Gedanken zur Neugliederung der Rhamno-Prunetea. Osnabr. Naturwiss. Mitt. 3:143-150.

Weber HE (1977a) Beiträge zur Systematik der Brombeergebüsche auf potentiell natürlichen Quercion robori-petraea-Standorten in Nordwestdeutschland. Mitt. Flor-soz. Arbeitsgem. N.F. 19/20:343-351.

Weber HE (1977b) Die ehemahlige und jetzige Brombeerflora von Mennighüffen, Kreis Herford, Ausgangsgebiet der europäischen Rubus-Forschung durch K.E. Weihe (1779-1834). Ber. Naturwiss. Ver. Bielefeld 23:161-193.

Weber HE (1981a) Kritische Gattungen als Problem für die Syntaxonomie der Rhamno-Prunetea in Mitteleuropa. In: Dierschke H (ed), Syntaxonomie. Berichte der Internationalen Symposien der Internationalen Vereinigung für Vegetationskunde: 477-496. J. Cramer, Vaduz. 
Weber HE (1981b) Revision de Sektion Corylifolii (Gattung Rubus, Rosaceae) in Skandinavien und im Nördlichen Mitteleuropa. Verlag Paul Parey, Hamburg, Berlin.

Weber HE (1986a) Rote Liste der Brombeeren Westfalens mit grundsätzlichen Bemerkungen zur Bewertung apomiktischer Sippen beim Artenschutz. Abh. Westf. Museum Naturkunde 48:187-202.

Weber HE (1986b) Rubi Westfalici. Die Brombeeren Westfalens und des Raumes Osnabrück (Rubus L., Subgenus Rubus). Westfälisches Museum für Naturkunde, Münster.

Weber HE (1987) Typen ornithochorer Arealentwicklung, dargestellt an Beispielen der Gattung Rubus L. (Rosaceae) in Europa. Bot. Jahrb. Syst. 108:525-535.

Weber HE (1990) Übersicht über die Brombeergebüsche der Pteridio-Rubetalia (Franguletea) und Prunetalia (Rhamno-Prunetea) in Westdeutschland mit grundsätzlichen Bemerkungen zur Bedeutung der Vegetationsstruktur. Ber. Reinhold-Tüxen-Ges. 2:91-119.

Weber HE (1991) Zeigerwerte von Rubus-Arten In: Ellenberg H, Weber HE, Düll R, Wirth V, Werner W, Paulissen D (eds), Zeigerwerte von Pflanzen in Mitteleuropa. Scripta Geobotanica 18: 167-174. Verlag Erich Goltze KG, Göttingen.

Weber HE (1995) Rubus L. In: Conert HJ, Jäger EJ, Kadereit JW, Schultze-Motel W, Wagenitz G, Weber HE (eds), Gustav Hegi Illustrierte Flora von Mitteleuropa. Band IV. Teil 2A. Spermatophyta: Angiospermae: Dicotyledones 2(2): 284-595. Blackwell, Berlin.

Weber HE (1996) Former and modern taxonomic treatment of the apomictic Rubus complex. Fol. Geobot. Phytotax. 31:373.

Weber HE (1997) Hecken und Gebüsche in den Kulturlandschaften Europas - Pflanzensoziologische Dokumentation als Basis für Schutzmassnahmen. Ber. Reinhold-Tüxen-Ges. 9:75-106.

Weber HE (1998a) Franguletea (H1). Faulbaum-Gebüsche. Synopsis der Pflanzengesellschaften Deutschlands 4:3-86.

Weber HE (1998b) Outline of the vegetation of scrubs and hedges in the temperate and boreal zone of Europe. Itiner. Geobot. 11:85-120.

Weber HE (1999a) The present state of taxonomy and mapping of blackberries (Rubus) in Europe. Act. Bot. Fenn. 162:161-168.

Weber HE (1999b) Rhamno-Prunetea (H2A). Schlehen- und Traubenholunder-Gebüsche. Synopsis der Pflanzengesellschaften Deutschlands 5:3-108.

Weber HE (2002a) Entwicklung und Stand der Rubus-Forschung in Europa. Ber. Bayer. Bot. Ges. 72:177185.

Weber HE (2002b) Rubus wittigianus spec. nov., eine sich ausbreitende Brombeerart in Westfalen und bei Osnabrück. Osnabr. Naturwiss. Mitt. 28:153-158.

Weber HE (2003a) Eine neue Haselblattbrombeere in Westfalen und Niedersachsen. Osnabr. Naturwiss. Mitt. 29:83-90.

Weber HE (2003b) Gebüsche, Hecken, Krautsäume. Ulmer, Stuttgart.

Weeda EJ (1989) Een gewijzigde indeling van Nederland in floradistricten. Gorteria 15:119-126.

Weeda EJ, Ozinga WA, op Akkerhuis GJ (2006) Diversiteit hoog houden. Bouwstenen voor een geïntegreerd natuurbeheer. Alterra, Wageningen. 
Weeda EJ, Schaminée JHJ, Stortelder AHF (1999) Galio-Urticetea. In: Stortelder AHF, Schaminée JHJ, Hommel PWFM (eds), De vegetatie van Nederland. Deel 5. Plantengemeenschappen van ruigten, struwelen en bossen: 41-72. Opulus Press, Uppsala, Leiden.

Weeda EJ, Schaminée JHJ, Van Duuren L (2005) Atlas van Plantengemeenschappen in Nederland. Deel 4: Bossen, struwelen en ruigten. KNNV Uitgeverij, Utrecht.

Weihe A, Nees von Esenbeck CG (1822-1827) Rubi Germanici. Elberfeldae.

Werlemark G, Nybom H (2003) Pollen donor impact on progenies of pseudogamous blackberries (Rubus subgen. Rubus). Euphytica 133:71-80.

Wesche K, Partzsch M, Krebes S, Hensen I (2005) Gradients in dry grassland and heath vegetation on rock outcrops in eastern Germany - an analysis of a large phytosociological data set. Folia Geobot. 40:341356.

Western D (1992) The biodiversity crisis: A challenge for biology. Oikos 63:29-38.

Westhoff V, Schaminée JHJ, Stortelder AHF (1995) De analytische fase van het vegetatieonderzoek. In: Schaminée JHJ, Stortelder AHF, Westhoff V (eds), De vegetatie van Nederland. Deel 1. Inleiding tot de plantensociologie - grondslagen, methoden en toepassingen: 63-80. Opulus Press, Uppsala, Leiden.

Westhoff V, Van Der Maarel E (1978) The Braun-Blanquet approach. In: Whittaker RH (ed), Ordination and Classification of Communities: 287-373. Springer, The Hague.

Wiens JJ (2007) Species Delimitation: New Approaches for Discovering Diversity. Syst. Biol. 56:875-878.

Wiley EO (1978) The Evolutionary Species Concept Reconsidered. Syst. Biol. 27:17-26.

Wilkins JS (2003) How to be a chaste species pluralist-realist: the origins of species modes and the synapomorphic species concept. Biol. Philos. 18:621-638.

Wilkins JS (2006) The concept and causes of microbial species. Hist. Phil. Life Sci. 28:389-408.

Wilkins JS (2007) The dimensions, modes and definitions of species and speciation. Biol. Philos. 22:247266.

Wilkins JS (2009a) Species are not theoretical objects, or, On what there is in biology. Phil-Sci Archive, 23 pp., at http://philsci-archive.pitt.edu/id/eprint/4835.

Wilkins JS (2009b) Species. A history of the idea. University of California Press, Berkely, Los Angeles, London.

Wilkins JS (2010) What is a species? Essences and generation. Theory Biosci. 129:141-148.

Wilkins JS (2011) Phylosophically speaking, how many species concepts are there? Zootaxa 2765:58-60.

Willmot A (1980) The woody species of hedges with special reference to age in Church Broughton Parish, Derbyshire. The Journal of Ecology:269-285.

Wilson AM, Fuller RJ, Day C, Smith G (2005) Nightingales Luscinia megarhynchos in scrub habitats in the southern fens of East Anglia, England: associations with soil type and vegetation structure. Ibis $147: 498-511$.

Wilson EO (2010) The diversity of life. Harvard University Press, Cambridge.

Wirtgen PW (1854-61) Herbarium Ruborum rhenanorum ed. 1 \& ed. 2. (exsiccata collection).

Wisskirchen R, Haeupler H (1998) Die Farn- und Blütenpflanzen Deutschlands. Bd. 1. Standardliste der Farn- und Blütenpflanzen Deutschlands. Eugen Ulmer, Stuttgart. 
Wittig R (1976) Die Gebüsch- und Saumgesellschaften der Wallhecken in der Westfälischen Bucht. Abh. Westf. Mus. Naturk. 38:1-78.

Wittig R (1977) Rubus-Arten in Wallhecken als Zeigerpflanzen der potentiellen natürlichen Vegetation. Mitt. Flor-soz. Arbeitsgem. N.F. 19/20:353-355.

Wittig R, Burrichter E (1979) Die Verbreitung und pflanzensoziologische Stellung von Rubus-Arten in naturnahen Waldgesellschaften der Westfälischen Bucht und ihrer Randgebiete. Mitt. Flor-soz. Arbeitsgem. N.F. 21:151-165.

Wittzell H (1999) Chloroplast DNA variation and reticulate evolution in sexual and apomictic sections of dandelions. Mol. Ecol. 8:2023-2035.

Zahn KH (1921-1923) Compositae - Hieracium. In: Engler A (ed), Das Pflanzenreich. Regni vegetabilis conspectus: 1-1146. Verlag von Wilhelm Engelmann, Leipzig.

Zahn KH (1930-1935) Hieracium 2. In: Ascherson P, Graebner P, Graebner fil. P (eds), Synopsis der mitteleuropäischen Flora, zwölfter Band, zweite Abteilung: 1-790. Verlag von Gebrüder Borntraeger, Leipzig.

Zahn KH (1931) Hieracium 2. In: Ascherson P, Graebner P, Graebner fil. P (eds), Synopsis der mitteleuropäischen Flora, zwölfter Band, zweite Abteilung, Bogen 21-30: 1-150. Verlag von Gebrüder Borntraeger, Leipzig.

Zahn KH (1936-1938) Hieracium 3. In: Ascherson P, Graebner P, Graebner fil. P (eds), Synopsis der mitteleuropäischen Flora, zwölfter Band, dritte Abteilung: 1-707. Verlag von Gebrüder Borntraeger, Leipzig. 



\section{List of photos}

This list contains an explanation of the photo on the cover as well as of the photos opposite to the opening pages of the chapters. Photos R. Haveman and I. de Ronde.

Cover. The 'Maasheggen' area is famous for its length of preserved hedges. On the back cover Rubus praecox, which is considered characteristic for the Corno-Rubetum vestiti.

Chapter 1. Rubus mantle vegetation along a field road at the Mantingerbos, with amongst others Rubus glandithyrsos, $R$. gratus, $R$. flexuosus, and $R$. mucronulatus. The Mantingerbos is an ancient woodland remnant with many typical nemophilous species, like $R$. bellardii and $R$. erinulus.

Chapter 2. A selection of first years shoots (primocanes, or turio) of Dutch species of Rubus subgen. Rubus. From left to right, beginning at the upper row: Rubus gratus, $R$. rudis, $R$. campaniensis, $R$. armeniacus, $R$. sulcatus, $R$. dejonghii, $R$. foliosus, $R$. pugiunculosus, $R$. polyanthemus, $R$. phyllostachys, $R$. pedemontanus, $R$. vestitus, $R$. ulmifolius, $R$. coccinatus, $R$. phoenicacanthus, and $R$. picearum.

Chapter 3. Rubus 'Sion' is an undescribed species with only two known localities in Salland (Overijssel, the Netherlands). Herbarium exciccata like this serve as a reverence collection for further research, for instance for the purpose of comparison.

Chapter 4. A selection of leaves of Dutch species of Rubus subgen. Rubus. From left to right, beginning at the upper row: Rubus macrophyllus, $R$. gratus, $R$. thallassarctos, $R$. scissus, $R$. euryanthemus, $R$. grisiae, $R$. lindleianus, $R$. sulcatus, $R$. ubericus, $R$. rosaceus, $R$. leucandrus, $R$. plicatus, $R$. oreades, $R$. phyllostachys, $R$. affinis, $R$. bellardii, $R$. arrhenii, $R$. mucronulatus, $R$. adspersus, $R$. muenteri, $R$. erinulus, $R$. cardiophyllus, $R$. taxandriae, $R$. prei, and $R$. radula.

Chapter 5. Rubus glandithyrsos is a typical species of the NW-Continent flora, including the Netherlands and the nort-west German plain. Remarkable are the deep pink ('red') petals and the imbricate leaves with shallow dentation and recurved teeth.

Chapter 6. Ruriculous Pruno-Rubetum sprengelii in an old field border near Ede, Gelderse Vallei.

Chapter 7. Rubus campaniensis, one of the character species of the Rubetum taxandriae.

Chapter 8. Inflorescenses of Dutch Rubus species. From left to right, beginning at the upper row: Rubus rudis, $R$. ulmifolius, $R$. laevicaulis, $R$. phyllostachys, $R$. rosaceus, $R$. bellardii, $R$. rubrumcadaver, and $R$. geniculatus. Rubus rudis and $R$. rosaceus are very rare species in the Netherlands, $R$. bellardii is characteristic for ancient woodland remnants, whereas $R$. ulmifolius is almost exclusively found in ruricolous scrubs. 



\section{Summary}

A characteristic feature of the north-west European flora is the large proportion of apomicts: plants which reproduce generatively without preceding fertilisation of the egg-cell. The central subject of this thesis are brambles (Rubus subgenus Rubus) a largely apomictic group. Since fertilisation of the egg-cell is prevented, the seed contains only genetic material of the maternal parent, and is the F1-generation genetically identical to the mother plant. These genetically constant lineages mutually differ only minimally, but the differences are constant. In Central-Europe alone, specialists recognise at least 700 of such Rubus lineages as species.

In Europe, Rubus has its centre of diversity in the Atlantic and sub-Atlantic parts, viz. north-west Germany, the Benelux countries, and France. Some of these species have large distribution areas, but the majority of the Rubus species have a limited distribution. Taxa with a distribution area under $50 \mathrm{~km}$ are not regarded as taxonomical species, and usually not described. There is much controversy whether apomict lineages are good species. This might seem a theoretical issue, but it has serious bearings on phytogeographical, phytosociological, and biodiversity studies as well as nature conservation. Apomict bramble species represent a concealed diversity, because in most scientific studies and in nature conservation they are neglected completely.

The first questions in this thesis are whether the apomict brambles are species, and how many species can be distinguished in the Netherlands. Secondly, the major factors determining large and medium scale distribution patterns of brambles and local species assemblages of bramble scrubs are studied. Finally, the question of the nature conservation value of brambles and bramble scrubs is answered.

Chapter 2 is a literature review of species concepts and the species status of apomicts. After a historical description of the development of species concepts it is concluded that 1) there are no essential characters defining species, therefore the species category cannot be universally defined, and 2) species come in kinds because their evolutionary path and history can be fundamentally differing. Species are not defined, but discovered, they are phenomena to be explained from case to case. In the second halve of the 20 th century, the nature of species lead to a heated discussion, but at the end of the millennium, the notion of 'consilience' was introduced in the species debate: evidence from independent, unrelated sources can converge to the strong conclusion that a population really is a separate species. The species concepts described in literature all have their role in bringing in this evidence. Therefore, for an adequate evaluation of the species status of a population, a thorough knowledge and understanding of the biology of the genus concerned is required. Case studies of various apomict groups based on such an integrative taxonomy, confirm the species status of apomict brambles: they are 
genetically, morphologically and reproductively separated, have own distribution areas and clearly ecologically defined.

In chapter 3, it is argued that the so-called 'pragmatic species concept (in which species with too small distribution areas are not treated taxonomically) isn't an essential element of modern batology. It has been a necessary step though to make an accessible international list of Rubus species, cleaning up a chaotic number of names in literature. Within the group of brambles with small distribution areas four categories can be distinguished which should be separated to solve the involved taxonomical problems: 1) primary hybrids, 2) stabilised apomicts, 3) variation within species with wide distribution areas, and 4) unstabilised hybrid swarms in areas with brambles with retained sexuality. There is no fundamental difference between Rubus species with a regional or wider distribution area and the species in category 2 , and there are no sound scientific arguments to exclude this group from taxonomical treatments. It leads to misinterpretation of species numbers and obscures the clear view on the first steps of expansion of young species. The other categories $(1,3$, and 4$)$ don't form well distinguishable species.

Chapter 4 gives a complete species list of Dutch Rubus species, including details on distribution, rarity, and references to figures. In the Netherlands, 191 species belonging to Rubus subgen. Rubus are known. Of these species, 97 have a regional distribution (area diameter 50-500 km). Only 22 of the 191 species are common, and on a national scale, 142 species are rare or very rare, although these species can be abundant locally or regionally.

On the basis of a large-scale multivariate analysis of distribution areas of brambles in Denmark, Germany, the Netherland, Britain and Ireland, 3 bramble territories could be distinguished, each consisting of 4 florulas (regions with a distinctive Rubus flora; chapter 5). It is concluded that large water bodies are an effective barrier for the distribution of brambles on the basis of the relatively large differences between the bramble flora of the British Isles and the studied parts of the continent. The differences between the Rubus floras of the north-western and south-eastern continent are caused mainly by the evolutionary history of the genus: the western flora wears the stamp of Rubus ulmifolius, the eastern one the stamp of $R$. canescens. Also in the realisation of patterns on a regional scale, between the florulas, evolutionary history seems to be more important than ecological factors.

At landscape scale, the bramble species in bramble scrubs are not randomly distributed, causing a clustering of floristically similar bramble scrubs in the landscape (chapter 6). Rubus scrubs in landscapes with old elements are usually more species rich than scrubs in young landscapes; this can be contributed to the ecology and/or dispersion capacity 
of brambles. From this study it became clear that an important part of the variation in bramble scrubs was not described in formal vegetation classifications, and therefore a new scrub type was described for the Barony and Campine in the southern part of the Netherlands, the Rubetum taxandriae (chapter 7). This association is characterised by several species with a southern distribution area which are not growing in the northerly distributed Rubetum silvatici: $R$. taxandriae, $R$. campaniensis, $R$. baronicus, and $R$. insectifolius.

On the basis of this, a full treatment of Rubus is advocated in taxonomy as well as in other biological studies and nature conservation. This should result in the inclusion in standard floras, standard lists and red lists. The results were the reason for a syntaxonomical revision of the bramble scrubs in which the evolutionary background of the brambles is reflected better. Although the arguments for this revision are given in this thesis, the revision is published elsewhere. It led to the recognition of 10 bramble scrub types (associations), which are assigned to three alliances (Pruno-Rubion sprengelii, Athyrio-Rubion en Lonicero-Rubion) and two classes (Rhamno-Prunetea, Lonicero-Rubetea plicati). These associations are mainly found in old landscapes, but to the contrary, new chances for brambles are mainly found in the urban environment and in areas with changing management, like abandoned grasslands and grazed nature conservation areas. Bramble scrubs have a high nature conservation value and are important for the conservation of biodiversity, especially in agricultural landscapes and in old landscape elements. They are an important biotope for rare shrub species and endemic Rubus species. Additionally, scrubs rich in bramble species are important because they provide foraging and nesting habitats for numerous vertebrates and invertebrates. This is clear when the variation in flowering phenology and architecture and mophology of the various Rubus species is taken into account. The study of the relation between Rubus richness and fauna diversity has hardly begun though, and is a promising starting point for further research. 



\section{Samenvatting}

Een typisch fenomeen van de flora van Noord- en Noordwest-Europa is het grote aandeel apomicten: planten die zich voortplanten via zaad zonder dat bevruchting van de eicel heeft plaatsgevonden. Bramen (Rubus subgenus Rubus), het centrale thema van dit proefschrift, zijn een voorbeeld van een apomictische plantengroep. Doordat geen bevruchting plaatsvindt bevat het zaad van bramen - en daardoor ook de nieuwe planten die hieruit ontstaan - alleen het genetische materiaal van de moeder. Hierdoor ontstaan zuivere lijnen van genetisch gelijke planten die onderling sprekend op elkaar lijken en die miniem maar constant verschillen van andere zuivere lijnen. In Midden-Europa worden door specialisten ongeveer 700 van deze zuivere lijnen als soorten beschouwd.

De hoogste diversiteit in Europa bereikt het genus in de atlantische en subatlantische delen: Noordwest-Duitsland, de Benelux-landen en Frankrijk. Een deel van de soorten heeft een groot verspreidingsgebied, maar het belangrijkste deel kent slechts een regionale verspreiding. Soorten met een verspreidingsgebied kleiner dan $50 \mathrm{~km}$ worden in de moderne batologie (braamkunde) niet beschreven. Er bestaat veel discussie of apomicten wel als soorten moeten worden opgevat. Hoewel dit een academische discussie lijkt, heeft dit wel degelijk gevolgen voor verspreidings- en biodiversiteitsonderzoek, de plantensociologie en het natuurbeheer. In veel onderzoek en in het natuurbeheer worden apomictische bramensoorten genegeerd zodat er sprake is van versluierde diversiteit.

In deze dissertatie wordt allereerst ingegaan op de vraag of bramen als soorten op te vatten zijn en hoeveel bramensoorten er in Nederland voorkomen. In de tweede plaats wordt onderzocht wat de belangrijkste factoren zijn voor de totstandkoming van grootschalige verspreidingspatronen en welke factoren de soortensamenstelling van braamstruwelen bepalen. Tenslotte richt deze studie zich op de waarde van bramen en braamstruwelen voor het natuurbeheer.

Hoofdstuk 2 is een literatuurstudie naar het wezen van soorten en de soortstatus van apomicten. Een wetenschapshistorische beschrijving van de ontwikkeling van het soortconcept leidt tot twee conclusies, namelijk 1) dat de categorie soort niet te definiëren is aan de hand van essentiële kenmerken en 2) dat soorten in soorten en maten komen doordat hun evolutionaire weg en geschiedenis verschilt. Soorten worden niet gedefinieerd, maar ontdekt, het zijn fenomenen waarvan het bestaan telkens verklaard moet worden. In de laatste helft van de 20 e eeuw werd een polemische discussie gevoerd over het wezen van de categorie soort, maar tegen het einde van het millennium werd in het debat de notie van 'consilience' geïntroduceerd: evidentie uit verschillende onafhankelijke bronnen leidt tot de conclusie dat een populatie daadwerkelijk een zelfstandige soort is. Hier komen ook de verschillende soortconcepten in beeld: ze dragen alle een extra argument aan om een taxon als soort te beschouwen, maar 
hiervoor is een grondige kennis van de biologie van de betreffende groep noodzakelijk. Casestudies naar verschillende apomictische groepen die uitgaan van een dergelijke geïntegreerde taxonomie bevestigen de soortstatus van apomictische bramen: ze zijn genetisch, morfologisch en reproductief goed gescheiden, hebben eigen arealen en zijn ecologisch gedifferentieerd.

In hoofdstuk 3 wordt geargumenteerd dat het 'pragmatisch soortconcept' (waarin soorten met een onvoldoende groot areaal niet worden beschreven) geen essentieel onderdeel uitmaakt van de moderne batologie. De werkwijze is echter wel een noodzakelijke stap gebleken om orde te scheppen in een chaos van namen en een internationaal overzicht te maken van bramen. Bramen met kleine arealen zijn in te delen in vier categoriën: 1) primaire hybriden, 2) gestabiliseerde apomicten, 3) variatie in soorten met een groot areaal en 4) ongestabiliseerde hybridenzwermen in gebieden met veel seksuele bramen. Er is geen wetenschappelijk argument om de gestabiliseerde apomicten met een klein areaal (categorie 2) in de taxonomie anders te behandelen dan de soorten met een groot areaal en het negeren van deze soorten leidt tot een te lage inschatting van soortenaantallen en verhinderd het zicht op de eerste stappen van areaalopbouw van jonge soorten. Binnen de overige genoemde categoriën (1, 3 en 4) zijn geen soorten te onderscheiden.

In hoofdstuk 4 wordt een complete soortenlijst gegeven van Nederlandse bramen, inclusief verspreidingsgegevens, zeldzaamheidsaanduidingen en verwijzingen naar plaatwerken. In Nederland zijn 191 bramensoorten bekend, waarvan 97 een regionale verspreiding hebben (areaaldiameter van 50-500 km). Slechts 22 van de 191 soorten komen algemeen voor. Landelijk gezien zijn 142 soorten zeldzaam tot zeer zeldzaam, maar lokaal en regionaal kunnen deze soorten dominant zijn in het landschap.

Een grootschalige multivariate analyse van verspreidingsgegevens van bramen in Denemarken, Duitsland, Nederland, Groot-Brittannië en Ierland leidde tot de onderscheiding van drie bramenterritoria en 12 florulas (regio's met een eigen bramenflora; hoofdstuk 5). De bramenflora van de Britse eilanden verschilt relatief sterk van die van de onderzochte delen van het continent, wat tot de conclusie leidt dat grote wateroppervlakten een tamelijk effectieve verspreidingsbarriere vormen voor bramen. De verschillen tussen de bramenflora van het noordwestelijke en het zuidoostelijke onderzoeksgebied worden echter vooral bepaald door de evolutionaire geschiedenis van het genus, waarbij de bramenflora in het westen het stempel draagt van Rubus ulmifolius en die in het oosten van $R$. canescens. Ook op regionale schaal, tussen de florulas, lijkt evolutionaire geschiedenis van groter belang te zijn dan ecologische factoren bij de totstandkoming van patronen. 
Op landschapsschaal blijken de soorten in braamstruwelen niet willekeurig ruimtelijk verdeeld zijn, maar blijken braamstruweeltypen gebonden te zijn aan ruimtelijk begrensde delen van het landschap (hoofdstuk 6). In landschappen met veel oude landschapselementen zijn rijker ontwikkelde braamstruwelen te vinden dan in jonge ontginningslandschappen, wat te maken heeft met de ecologie en/of de verspreidingscapaciteit van de braamsoorten. Uit deze studie is ook duidelijk geworden dat niet alle variatie in braamstruweeltypen eerder opgenomen is in vegetatieoverzichten. In hoofdstuk 7 is daarom een nieuw struweeltype beschreven voor de Baronie en Kempen, het Rubetum taxandriae. Deze associatie wordt gekenmerkt door het optreden van een aantal zuidelijk soorten die in het noordelijke Rubetum silvatici ontbreken: $R$. taxandriae, $R$. campaniensis, $R$. baronicus en $R$. insectifolius.

Op basis van de gepresenteerde resultaten wordt gepleit voor een volwaardige behandeling van bramen in taxonomie, biologisch onderzoek en natuurbeheer en -beleid. Dit zou moeten resulteren in opname in flora's, standaardlijsten en beschouwingen voor de Rode Lijst. De resultaten geven bovendien aanleiding de syntaxonomie van braamstruwelen te herzien, en beter te funderen in de evolutionair-historische achtergrond van de bramenflora. Dit is uitgewerkt buiten het bestek van deze dissertatie, maar de argumenten hiervoor zijn gegeven in de algemene discussie van dit proefschrift. Dit leidt tot de beschrijving van 10 formele braamstruweeltypen (associaties) in ons land, verdeeld over drie verbonden (Pruno-Rubion sprengelii, Athyrio-Rubion en Lonicero-Rubion) en twee klassen (Rhamno-Prunetea, Lonicero-Rubetea plicati). Deze braamstruwelen zijn kenmerkend voor oude landschappen. Nieuwe kansen voor bramen lijken juist te liggen in het urbane gebied en in gebieden met veranderd beheer, zoals begraasde natuurgebieden.

Braamstruwelen zijn van groot belang voor de instandhouding van de biodiversiteit, met name in agrarische landschappen en in oude landschapselementen. Ze zijn een belangrijk biotoop voor zeldzame struweelsoorten en endemische braamsoorten. Bovendien is de instandhouding van soortenrijke struwelen met uiteenlopende braamsoorten van belang omdat ze dienen als voedselbron en habitat voor tal van gewervelde en ongewervelde diersoorten. Dit wordt duidelijk als de variatie in bijvoorbeeld bloeitijdstippen en architectuur en morfologie van de verschillende braamsoorten in ogenschouw wordt genomen. De studie hiervan is echter nog nauwelijks van de grond gekomen en vormt een goed beginpunt voor verder onderzoek. 



\section{Acknowledgements}

As King Salomon knew, there is a time for everything, and a season to every purpose under the heavens; a time to be born and a time to die, a time to plant and a time to uproot, a time to kill and a time to heal, a time to build and a time to tear down, a time to weep and a time to laugh, a time to mourn and a time to dance (Ecclesiastes 3: 1-4). This is the time to end a long journey, the time to reflect on what was gained and what was lost, a time to mourn a little on what has ended, but also a time to be grateful for what many regaled. I will keep the first things for myself and a small circle of intimate friends, but I want to express my gratitude here, in public.

First of all Joop Schaminée. Dear Joop, I want to thank you that you had enough faith in me to ask me for a promotion study. I feel there was no direct reason for it, at least I didn't expect it. Your enthusiasm and energy are far beyond the ordinary, and, although your drive is sometimes exhausting, you know how to bring projects to an end successfully. Thank you for your trust, and your energy, your thoughts and ideas, and the time you gave to bring me where we are now.

Rienk-Jan Bijlsma, when I asked you as supervisor for this journey, you immediately answered positively. Your deep knowledge of the subject of this study, as well as of a broad array of other ecological and historical subjects, have been very beneficial. Much of the quality and novelties in my dissertation wouldn't have been without you. Probably you hoped for a different kind of study: we have our differences in approach when it comes to ecology. Besides, I am kind of hard to supervise, I guess, and several of the papers in this dissertation were started without your direct interference. Thank you for your pragmatism, that kept me from too strange paths and fatalism, thank you for your ideas, insights, and cooperation, not only in this project.

Frans Borgonje, thanks to you I could set aside time for this study in my daily work. Thank you for this chance! I can't imagine how it would have been possible to end it successfully without this time. Granting this was not self-evident, because our employer, the Ministry of Defence in the beginning, and the Ministry of the Interior and Kingdom Relations, has no direct benefit from it. Thank you!

Piet Bakker, I wonder if I would have gotten 'into' brambles if I hadn't done an internship under your supervision, way back in 1989. You encouraged me to look at the brambles in the Mantingerbos! I know we differ in some Rhodological issues, but I owe you a lot, and I dedicate this thesis to you.

Thanks goes to my direct colleagues of Team Ecology: Iris de Ronde, Anja van der Berg, Marije van Ravensberg, Niels Gilissen, Arno Braam, as well as Femke Sietsema and 
Menno Hornman. There were times I was hardly present, and the workload on your shoulders increased because of my absence. Thank you Iris, Anja en Marije for the time we spent during the 'transect time', it was very, valuable, in many respects!

There are many who knowingly and unknowingly, willingly and probably unwillingly contributed to this work in one or another way. I want to thank the colleagues of Wageningen Evironmental Research and Wageningen University: Stephan Hennekens (where would we all be without you?), Eddy Weeda (is there something you don't know?), John Janssen, Anton Stortelder, Rik Huiskes, Nina Smits, Wim Ozinga, Pieter Slim (you really read everything!), Patrick Hommel en Jan den Ouden (remember that surprising evening in the Geulhemermolen, with Iris and Patrick). John Rodwell and Henk Reitsema, thank you for the linguistic improvements of several of my papers. Leni Duistermaat, Rene Smulders and Eddy Weeda commented my 'Freakish Patterns' paper, Bram van de Beek on the paper on the Weberian Reform: thanks a lot! Several ideas didn't reach it to this dissertation, but not because of lack of support by others. Cajo ter Braak and Karle Sýkora spent time to help me with some of these not-papers. It's always sad when an idea doesn't make it to the end, and in this case it is completely due to me.

John (Janssen), I feel some kind of two-minds-one-thought when we speak about vegetation and phytosociology, we often follow the same lines of reasoning. Thank you that you want to stand next to me at the defence of my thesis! Iris, we made a long part of this journey together. It started at Texel, when I asked you to think about the randomisation of bramble scrub relevés. In many practical and substantive matters over the years, I could rely on you. You helped me out when I was stuck in my own reasoning or didn't trust that it was able to finish this project with good result. In the end you will help me through the defence of my thesis. Thank you, I hope there will be many years following in exiting projects!

Lieve pap en mam, dank jullie voor alles wat jullie me gaven over al die lange jaren en nog steeds. Het is ook en vooral dankzij jullie dat ik ben wat ik ben. Ik ben daar erg dankbaar voor! De verwondering voor de natuur komt van thuis, is me met de paplepel ingegoten. Sterker nog, op mijn geboortekaartje schreven jullie een tekst uit Psalm 104: Hoe talrijk zijn uw werken, o Here, Gij hebt ze alle met wijsheid gemaakt. Die tekst is al die jaren werkelijkheid gebleven, als een profetie.

Dear Annemien. I want to thank you for the person you are. Passionate and down to earth, reliable and always there, one hearted, my home, my love. Thank you for the laugh and the tear, for our life together, for the good things to share and the evil things to bear. You believed in me all the time, even when I lost courage. 


\section{Curriculum Vitae}

Rense Haveman was born in Hoogeveen at December 19th 1967 and he grew up in Dedemsvaart. From 1980 he visited the Christelijke Scholengemeenschap Jan van Arkel in Hardenberg where he graduated at the VWO-Athenaeum in 1986. From 1986-1990 he did his BSc in Forest- and Naturemanagement at the HBCS in Velp. This is where his fascination for brambles and their complex taxonomy started through the encouragement of Piet Bakker (Vereniging Natuurmonumenten), who supervised an internship comprising the mapping of the vegetation of the Mantingerbos, a woodland-remnant rich in typical Drenthian bramble species. In 1993 he finished his MSc Land- and Watermanagement the Agricultural University in Wageningen with a phytosociologal and a philosophical thesis.

From 1993-1996, Rense worked for the Adviesgroep Vegetatiebeheer on the survey of vegetation in road verges, as well as an inventory of endangered weeds and weed vegetation in nature reserve agricultural fields. As a result of this work, he volunteered in the IBN-DLO project on the national vegetation classification, which led to the publication of the five volume work De vegetatie van Nederland. In this project, which ended in 1999, he was the first author of the vegetation classes of weed vegetation at arable fields (Stellarietea mediae), and two classes of scrub vegetation (Lonicero-Rubetea plicati and Rhamno-Prunetea). In 1997 Rense became involved in the survey of the vegetation at military ranges at the Adviesgroep Vegetatiebeheer and its successor, the IKC-Natuurbeheer. In 2000, this work was taken over by the Dutch Ministry of Defence (DGW\&T (Dienst Gebouwen, Werken en Terreinen), later the DVD (Dienst Vastgoed Defensie)). Recently, due to reorganisations, the inventory and monitoring of nature of military areas is accommodated by the Central Government Real Estate Agency, part of the Ministry of the Interior and Kingdom Relations, where Rense coordinates the work of six ecologists. From 2001-2010, Rense worked also for Alterra-WUR, mainly on phytosociological and conservation issues.

Rense's main interests comprise the taxonomy and ecology of critical plant groups (e.g. Rubus, Hieracium, Festuca), and the phytosociology of scrubs and other disregarded vegetation types. As chair of the KNBV section taxonomy he is chief editor of the prestigious Nova Flora Neerlandica, which aims at the publication of a 25 volume critical flora of the Netherlands.

For a complete list of publications see: https://www.researchgate.net/profile/Rense_ Haveman/contributions?ev=prf_act 
The research in this thesis was financially supported by the Central Government Real Estate Agency of the Ministry of the Interior and Kingdom Relations and the Nordic Journal of Botany (chapter 2).

Financial support from Wageningen University for printing this thesis is gratefully acknowledged.

$\sqrt{2}^{0}$

FSC

Lay-out \& Printed by: ProefschriftMaken 


\section{H}

-

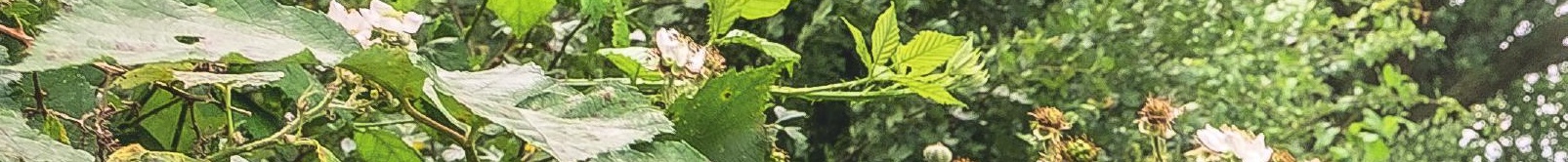

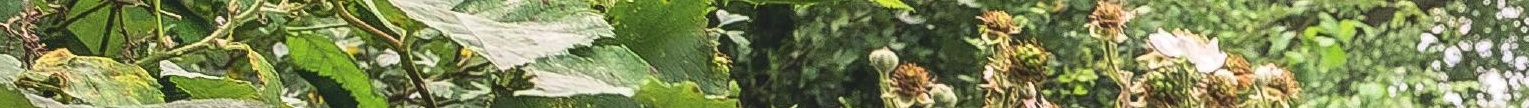

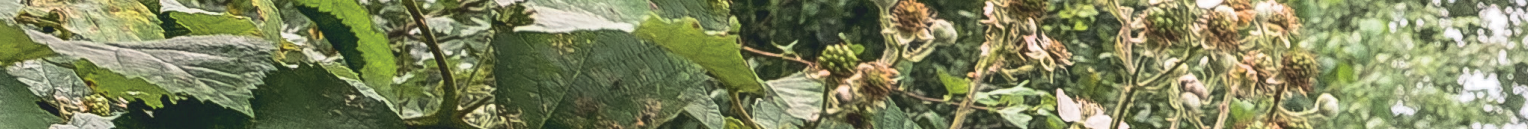

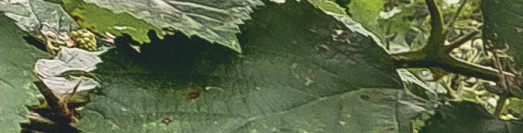

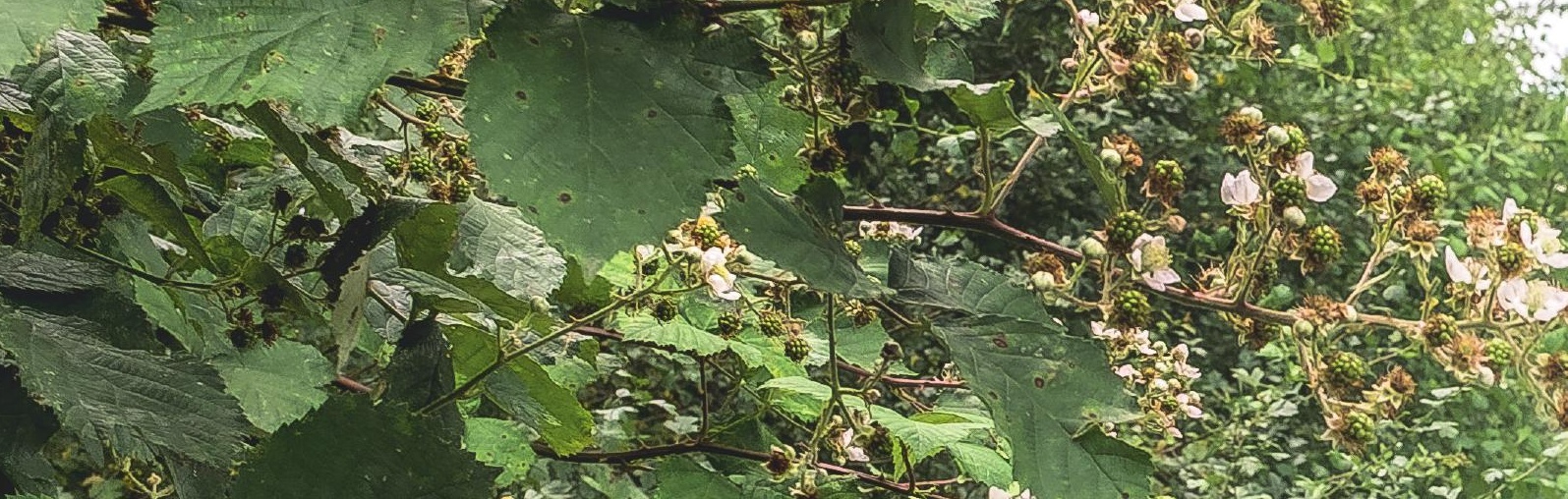

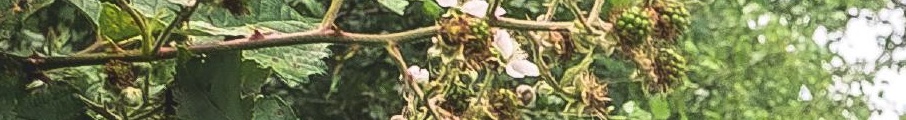

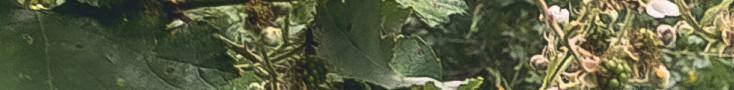

